\title{
Evaluation of a Dual Tank Indirect Solar-Assisted Heat Pump System for a High Performance House
}

\author{
by \\ Jenny Chu, B.Eng., Mechanical Engineering \\ Carleton University \\ A thesis submitted to the \\ Faculty of Graduate and Postdoctoral Affairs \\ in partial fulfillment of the requirements for the degree of
}

Master of Applied Science in Mechanical Engineering

Ottawa-Carleton Institute for Mechanical and Aerospace Engineering

Department of Mechanical and Aerospace Engineering

\author{
Carleton University \\ Ottawa, Ontario \\ April, 2014 \\ (C)Copyright \\ Jenny Chu, 2014
}




\section{Abstract}

This work focused on the design and evaluation of an integrated mechanical system, which incorporated a dual tank indirect solar-assisted heat pump, that offsets spaceheating, cooling, and domestic hot water loads for a high performance house. A model of the system was developed to investigate the effects of various parameters on the performance of the system. These parameters included the tank configurations, the solar collector size and orientation, and heat pump size and controls. In addition, an experimental study was conducted to investigate the relationship between the heat pump load side flow rate, the heat pump performance, and the thermal stratification in the storage tank. The experimental results indicated that the coefficient of performance of the heat pump reduced with lower flow rates. However, lower flow rates could result in higher temperature rises across the condenser and greater levels of the stratification which could improve the overall performance of the system by reducing the auxiliary energy consumption. Results from the modelling and experimental work were compared and the experimental results were used to improve the heat pump performance map that was used in the simulations. The simulation results showed that the system could achieve a free energy fraction of 0.506 (neglecting en-

ergy draws from circulation pumps and fans) for space-heating, cooling, and domestic hot water. This result suggests that the system does have the potential of reducing energy consumption in the residential sector in Canada. 


\section{Acknowledgments}

I would like thank my supervisor, Dr. Cynthia A. Cruickshank, for her continuous support, guidance, and encouragement over the past two years. It has been a great pleasure working with her. Her dedication to the research and to Team Ontario has truly been inspirational.

I would like to acknowledge Dr. Stephen J. Harrison, Wilkie Choi, Portia Murray, and Gary Johnson from the Queen's University Solar Calorimetry Lab. I have learned a lot from working with them and their patience and assistance were greatly appreciated. I would also like to express a special thank you to Team Ontario for believing in the research and being patient with the system design process. Working in a dedicated and multidisciplinary team and being able to showcase the research at an international competition was a truly phenomenal experience.

I would like to acknowledge the funding and support from Carleton University and the NSERC Smart Net-Zero Energy Buildings Strategic Research Network (SNEBRN). I would also like to thank my colleagues Christopher Baldwin, David

Ouellette, Jayson Bursill, Nina Dmytrenko, Daniel Bowie, and Brent Huchuk for their support and encouragement.

Finally, I would like to thank my family for their unconditional love, care, and support over the past two years. 


\section{Table of Contents}

$\begin{array}{lll}\text { Abstract } & \text { ii }\end{array}$

Acknowledgments

Table of Contents $\quad$ iv

List of Tables $\quad$ viii

List of Figures $\quad x$

Nomenclature xiv

1 Introduction 1

1.1 Motivation . . . . . . . . . . . . . . . . . . . 1

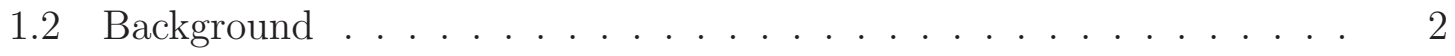

1.2.1 Solar Thermal Systems . . . . . . . . . . . . . . . . . 2

1.2.2 Vapour Compression Heat Pump Systems . . . . . . . . 5

1.2.3 Solar-Assisted Heat Pump Systems . . . . . . . . . . . 7

1.2.4 Solar Decathlon 2013: Team Ontario _. . . . . . . . . 9

1.3 Contribution of Research . . . . . . . . . . . . . . . . . 16

1.4 Organization of Research . . . . . . . . . . . . . . . . . . 17 
2 Literature Review $\quad 19$

2.1 Performance Metrics . . . . . . . . . . . . . . . . . 20

2.2 Comparative Studies . . . . . . . . . . . . . . . . . . . 22

2.3 Direct Solar-Assisted Heat Pump System Studies . . . . . . . . . . . 31

2.4 Indirect Solar-Assisted Heat Pump System Studies . . . . . . . . . 35

2.5 Literature Review Summary . . . . . . . . . . . . . . . . . . 38

3 Modelling Approach $\quad 40$

3.1 The TRNSYS Simulation Program . . . . . . . . . . . . . . . 40

3.2 Model of the Integrated Mechanical System _ . . . . . . . . . . . . . 41

3.2.1 Building Model . . . . . . . . . . . . . . . . 43

3.2.2 Delivery of Space-Heating, Cooling, and Domestic Hot Water . 44

3.2.3 System Controls . . . . . . . . . . . . . . . . . 46

3.2.4 Solar Collectors . . . . . . . . . . . . . . . . . 49

3.2.5 Thermal Storage . . . . . . . . . . . . . . 52

3.2.6 Heat Pump ................... 55

3.3 Sensitivity Studies . . . . . . . . . . . . . . . . 59

3.4 Closing Remarks . . . . . . . . . . . . . . . . 63

4 Experimental Approach $\quad 64$

4.1 Apparatus ............................ 65

4.2 Instrumentation . . . . . . . . . . . . . . . . . 67

4.3 Experimental Procedure . . . . . . . . . . . . . . . 69

4.4 Modelling of Experimental Approach . . . . . . . . . . . . . . 73

4.5 Closing Remarks . . . . . . . . . . . . . . . . . . . . . . . 74

5 Modelling and Experimental Results $\quad 75$ 
5.1 Modelling of the Integrated Mechanical System . . . . . . . . . . . 75

5.1.1 Base Model Results . . . . . . . . . . . . . . . . 76

5.1 .2 Sensitivity Studies _. . . . . . . . . . . . . . 79

5.1 .3 As-Built System Results . . . . . . . . . . . . . . . . . . . 84

5.1.4 Sensitivity Study of Heat Pump Load Side Flow Rate . . . . . 87

5.2 Experimental Results . . . . . . . . . . . . . . . . . . . 89

5.3 Modelling of the Experimental Set-up . . . . . . . . . . . . . . . . 95

5.4 Closing Remarks . . . . . . . . . . . . . . . . . . 100

6 Discussion of Results 101

6.1 Modelling Results of the Integrated Mechanical System . . . . . . . . 101

6.1.1 Sensitivity Study of Solar Collector Parameters . . . . . . . . 102

6.1.2 Sensitivity Study of Heat Pump Parameters . . . . . . . . . . 104

6.1.3 Sensitivity Study of Tank Parameters . . . . . . . . . . . . . 105

6.1.4 Recommended and As-Built Model . . . . . . . . . . . . . . . 109

6.1.5 Sensitivity Study of Heat Pump Load Side Flow Rate . . . . . 112

6.2 Experimental Results . . . . . . . . . . . . . . . . . . . . . . 112

6.2.1 Hot Tank Temperature Profiles . . . . . . . . . . . . . . . 113

6.2.2 Heat Pump Performance . . . . . . . . . . . . . . . . . . 115

6.3 Comparison of Experimental and Simulation Results . . . . . . . . 116

6.4 Annual Performance Simulation with Experimental Data . . . . . . . 120

6.5 Summary of Key Findings . . . . . . . . . . . . . . . . . . . . . . . . 121

7 Conclusions and Future Work $\quad 123$

7.1 Conclusions ........................... 123

7.2 Future Work . . . . . . . . . . . . . . . . . . . 127 
List of References

Appendix A TRNSYS Simulation Model

Appendix B Sensitivity Study of Simulation Parameters

B.1 Simulation Time-step . . . . . . . . . . . . . . . . . . . . . 139

B.2 Tank Nodes . . . . . . . . . . . . . . . . . . . . . 140

Appendix C Deck File for the Integrated Mechanical System Model 142

Appendix D Type 56 Multizone Building Setup File

Appendix E Additional Mathemathical References for TRNSYS Types

Used

E.1 Energy Recovery Ventilator . . . . . . . . . . . . . . 206

E.2 Heating and Cooling Coils . . . . . . . . . . . . . . . 208

E.3 Mixing Valve . . . . . . . . . . . . . . . . . . . . . . . . . 211

Appendix F Creating the Heat Pump Performance Map with MATLAB

Appendix G Heat Pump Performance Data for Type 927

Appendix H Instrumentation Calibration and Uncertainty Analysis 223

H.1 Flow Rate Uncertainty . . . . . . . . . . . . . . . . . . . . . 224

H.2 Thermocouple Uncertainty . . . . . . . . . . . . . . . . . . . 227

H.3 Error Propagation of Heat Pump Energy Transfer Rate . . . . . . . . 229

H.4 Error Propagation of Coefficient of Performance . . . . . . . . . . . . 231

H.5 Error Propagation of Accumulated Energy Transferred and Average Coefficient of Performance . . . . . . . . . . . . . . . . . . . 233 


\section{List of Tables}

1.1 Solar Decathlon contests . . . . . . . . . . . . . . . . . . 10

2.1 Summary of comparative studies (adapted from [22]) $\ldots \ldots \ldots$

2.2 Summary of direct systems: system set-up and performances (adapted from $[22]) \quad \ldots \ldots \ldots \ldots \ldots$

2.3 Summary of indirect systems: system set-up and performances (adapted from $[22]) \ldots \ldots \ldots \ldots \ldots \ldots$

3.1 Parameters for the glazed flat plate collectors . . . . . . . . 51

3.2 Parameters for the evacuated tube collectors . . . . . . . . . . 51

3.3 Parameters used in the base model and sensitivity study ranges . . . 62

4.1 Specifications for cylindrical storage tanks . . . . . . . . 67

4.2 Parameters for the experimental hot tank . . . . . . . . 73

5.1 Total loads from annual simulation of the base model from Chu et al. [17] 76

5.2 Parameters of the recommended system from Chu et al. [17] . . . . 85

5.3 Parameters of the as-built system $\ldots \ldots \ldots \ldots \ldots$

5.4 Final results of each experimental test $\ldots \ldots \ldots \ldots$

5.5 Comparison of experimental and simulated heat pump performances . 99

6.1 Total loads from annual simulations . . . . . . . . . . . . . . . 109

A.1 Key Types used in the TRNSYS model . . . . . . . . . . . . . 138 
G.1 Heat performance map created from MATLAB with experimental data and manufacturer's data . . . . . . . . . . . . . . . . . . 219

H.1 Propagated errors of the heat transfer rates and coefficient of performances . . . . . . . . . . . . . . . . . . . . . 231

H.2 Propagated errors of the accumulated energy transferred and average coefficient of performances . . . . . . . . . . . . . . . . . 234 


\section{List of Figures}

1.1 Residential energy use in Canada in $2009[1] \ldots \ldots \ldots \ldots$

1.2 Typical solar domestic hot water system with an external heat exchanger (adapted from [4]) . . . . . . . . . . . . . . 3

1.3 Differing levels of stratification within a tank from Cruickshank [3] . . 5

1.4 Schematic of an air-source heat pump water heater (adapted from [6]) 6

1.5 Schematic of a parallel solar-assisted heat pump system . . . . . . . 7

1.6 Schematic of a direct solar-assisted heat pump system (adapted from [6]) 8

1.7 Schematic of an indirect solar-assisted heat pump system (adapted from $[6]) \ldots \ldots \ldots \ldots$

1.8 South side of ECHO with exo-structure holding photovoltaic panels on top and solar collectors on the front (Photo credit: Jacob Morgan) . . 11

1.9 Schematic of the integrated mechanical system with the heating season operations highlighted $\ldots \ldots \ldots \ldots \ldots \ldots \ldots \ldots \ldots$

1.10 Schematic of the integrated mechanical system with the cooling season operations highlighted $\ldots \ldots \ldots \ldots \ldots \ldots$

1.11 ECHO's mechanical closet containing the designed SAHP (Photo credit: Carly Farmer) . . . . . . . . . . . . . . . . . . . 15

1.12 Research approach . . . . . . . . . . . . . . . . . 18 
2.1 Schematic of solar-assisted heat pump space-heating systems (adpated from $[23]) \ldots \ldots \ldots \ldots \ldots$

2.2 Schematic of dual source solar-assisted heat pump space-heating sys-

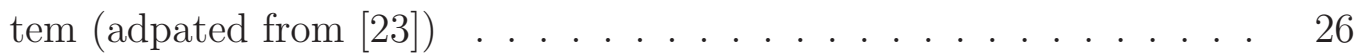

2.3 Schematic of solar-side solar-assisted heat pump (adpated from [30]) . 29

3.1 Graphical representation of the TRNSYS model from Chu et al. [17] . 42

3.2 Differential controller operation (adapted from [45]) . . . . . . . . . 47

3.3 Control logic for the integrated mechanical system . . . . . . . . . . . 49

3.4 Energy balance for node i in Type 60 (adapted from [43]) . . . . . . . 52

4.1 Experimental apparatus of dual tank indirect solar-assisted heat pump system .................................. 65

4.2 Solar simulator for the experimental apparatus . . . . . . . . . . . . 67

4.3 Schematic of experimental set-up and instrumentation locations . . . 69

4.4 Pressure gauges for heat pump refrigerant loop . . . . . . . . . . . . 69

4.5 Power curve for the circulation pumps [55] . . . . . . . . . . . . 71

4.6 TRNSYS model for experimental set-up . . . . . . . . . . . . . 73

5.1 Monthly solar energy gains from collectors, total energy loads (second column), and total electrical energy draws (third column) for the base model from Chu et al. [17] . . . . . . . . . . . . . . . . . . . . 77

5.2 Average indoor temperature simulated from the base model from $\mathrm{Chu}$ et al. $[17] \ldots \ldots \ldots \ldots 7 . \ldots \ldots$

5.3 Indoor relative humidity simulated from the base model from Chu et al. $[17] \ldots \ldots \ldots \ldots 7 . \ldots \ldots$

5.4 Sensitivity study of collector area, tank loss coefficient, tank sizes, and energy recovery ventilator effectiveness (adapted from [17]) . . . . . . 79

5.5 Sensitivity study of collector tilt angle . . . . . . . . . . . . . . . . 80 
5.6 Sensitivity study of heat pump control conditions (adapted from [17])

5.7 Sensitivity study of rated heat pump parameters (adapted from [17])

5.8 Sensitivity study of flat plate and evacuated tube collector array sizes (adapted from $[17]) \ldots \ldots \ldots \ldots \ldots \ldots$

5.9 Sensitivity study of the auxiliary heater height and inlet node heights within the hot tank (adapted from [17]) . . . . . . . . . . . 83

5.10 Hot tank configurations for various models . . . . . . . . . . . . . . . 87

5.11 Annual free energy fraction and average coefficient of performance as a function of heat pump load side flow rate . . . . . . . . . . . 88

5.12 Annual heat pump compressor energy usage and auxiliary energy usage as a function of heat pump load side flow rate . . . . . . . . .

5.13 Hot tank temperature profiles and heat pump load side temperatures with varying heat pump load side flow rates . . . . . . . . . . . . . 91

5.14 Instantaneous heat transfer rates and coefficient of performance . . . 92

5.15 Accumulated energy transferred to load and consumed by heat pump compressor and average coefficient of performance . . . . . . . .

5.16 Comparison of hot tank temperature profiles from simulation and experimental results . . . . . . . . . . . . . . . . . 96

5.17 Comparison of experimental data and simulation results . . . . . . 97

6.1 Approximated collector efficiencies . . . . . . . . . . . 103

6.2 Monthly solar energy gains from collectors, total energy loads (second column), and electrical energy draws (third column) for the recommended model . . . . . . . . . . . . . . . . . . . 110

6.3 Monthly solar energy gains from collectors, total energy loads (second column), and electrical energy draws (third column) for the as-built model ........................ 11 
6.4 Experimental and simulated heat pump load side inlet temperatures for $3 \mathrm{~L} / \mathrm{min}$ test . . . . . . . . . . . . . . . . . . . . . . 118

A.1 Graphical interface of the complete TRNSYS model of the integrated mechanical system with ECHO . . . . . . . . . . . . . 137

B.1 Sensitivity study of simulation time-step . . . . . . . . . . . . . 140

B.2 Sensitivity study of the number of nodes in the hot tank . . . . . . . 141

F.1 Heating capacity versus average load and source side temperatures from manufacturer's data . . . . . . . . . . . . . . . . . 216

F.2 Power draw versus average load and source side temperatures from manufacturer's data . . . . . . . . . . . . . . . . 216

F.3 Heating capacity versus average load and source side temperatures from experimental and manufacturer's data . . . . . . . . . . . . 217

F.4 Power draw versus average load and source side temperatures from experimental and manufacturer's data . . . . . . . . . . . . . . 217

F.5 Heating capacity versus average load and source side temperatures from performance map created from MATLAB . . . . . . . . . . . . . 218

F.6 Power draw versus average load and source side temperatures from performance map created from MATLAB . . . . . . . . . . . . . . 218

H.1 Recorded and gravimetric flow rates before and after calibration . . . 226

H.2 Recorded temperatures and platinum resistant thermometer temperatures before and after calibration . . . . . . . . . . . . . . 228

H.3 Energy transfer rate for the $3 \mathrm{~L} / \mathrm{min}$ test . . . . . . . . . . . . . . . 230

H.4 Coefficient of performance for the $3 \mathrm{~L} / \mathrm{min}$ test . . . . . . . . . . . . . 232

H.5 Accumulated energy transferred by the heat pump for the $3 \mathrm{~L} / \mathrm{min}$ test 233

H.6 Average coefficient of performance for the $3 \mathrm{~L} / \mathrm{min}$ test . . . . . . . . 234 


\section{Nomenclature}

a

$A_{\mathrm{c}}$

$A_{\text {coll }}$

$A_{\mathrm{i}, \mathrm{S}}$

$b_{\mathrm{o}}$

$b_{1}$

$C O P_{\text {average }}$

COP

$C_{\text {min }}$

$c_{\mathrm{p}}$

$c_{\mathrm{p}, \text { load }}$

$c_{\mathrm{p}, \text { source }}$

$c_{\mathrm{p} \text {,water }}$

$\epsilon_{\text {lat }}$

$\epsilon_{\text {sens }}$

$\eta$

$f_{\text {AirBypass }}$

FEF

$F_{\mathrm{R}}$

$h_{\text {air,CoilOut }}$

$h_{\text {air,in }}$
Short-wave absorptance of the solar collector absorber plate

Cross-sectional area of the storage tank fluid $\left(\mathrm{m}^{2}\right)$

Area of solar collector array $\left(\mathrm{m}^{2}\right)$

Surface area of the tank node $\mathrm{i}\left(\mathrm{m}^{2}\right)$

First order incident angle modifier

Second order incident angle modifier

Average coefficient of performance

Coefficient of performance

Minimum capacitance $\left(\dot{m} c_{\mathrm{p}}\right)$ of the two streams $(\mathrm{kJ} / \mathrm{h} \cdot \mathrm{K})$

Specific heat of a fluid $(\mathrm{kJ} / \mathrm{kg} \cdot \mathrm{K})$

Specific heat of the heat pump load side fluid $(\mathrm{kJ} / \mathrm{kg} \cdot \mathrm{K})$

Specific heat of the heat pump source side fluid $(\mathrm{kJ} / \mathrm{kg} \cdot \mathrm{K})$

Specific heat of water $(\mathrm{kJ} / \mathrm{kg} \cdot \mathrm{K})$

Latent effectiveness of the energy recovery ventilator

Sensible effectiveness of the energy recovery ventilator

Solar collector efficiency

Bypass fraction

Free energy fraction

Overall solar collector heat removal efficiency factor

Enthalpy of the air exiting the coils $(\mathrm{kJ} / \mathrm{kg})$

Enthalpy of the air entering the coils $(\mathrm{kJ} / \mathrm{kg})$ 


\begin{tabular}{|c|c|}
\hline$h_{\text {air,out }}$ & Enthalpy of the air exiting the coils $(\mathrm{kJ} / \mathrm{kg})$ \\
\hline$h_{\text {cond }}$ & Enthalpy of condensate $(\mathrm{kJ} / \mathrm{kg})$ \\
\hline$h_{\text {exhaust,in }}$ & Enthalpy of entering exhaust air $(\mathrm{kJ} / \mathrm{kg})$ \\
\hline$h_{\text {fresh,in }}$ & Enthalpy of entering fresh air $(\mathrm{kJ} / \mathrm{kg})$ \\
\hline exhaust,out & Enthalpy of exiting exhaust air $(\mathrm{kJ} / \mathrm{kg})$ \\
\hline$h_{\text {fresh,out }}$ & Enthalpy of exiting fresh air $(\mathrm{kJ} / \mathrm{kg})$ \\
\hline i & Tank node number \\
\hline v,exhaust,in & Enthalpy of water vapour of the entering exhaust air $(\mathrm{kJ} / \mathrm{kg})$ \\
\hline$h_{\mathrm{v}, \text { fresh,in }}$ & Enthalpy of water vapour of the entering fresh air $(\mathrm{kJ} / \mathrm{kg})$ \\
\hline$I A M$ & Incident angle modifier for solar collectors \\
\hline$I_{\mathrm{T}}$ & Global irradiance incident on the solar collector $\left(\mathrm{W} / \mathrm{m}^{2}\right)$ \\
\hline$k$ & Fluid conductivity $(\mathrm{W} / \mathrm{m} \cdot \mathrm{K})$ \\
\hline$\Delta k$ & $\begin{array}{l}\text { Additional conductivity term due to the interactions at the tank } \\
\text { wall and node surfaces }(\mathrm{W} / \mathrm{m} \cdot \mathrm{K})\end{array}$ \\
\hline$n_{\text {containter }}$ & Mass of the container $(\mathrm{kg})$ \\
\hline$m_{\text {final }}$ & Final mass measurement $(\mathrm{kg})$ \\
\hline$\dot{m}_{1}$ & Mass flow rate from one inlet to the node $(\mathrm{kg} / \mathrm{h})$ \\
\hline$\dot{n}_{2}$ & Mass flow rate from the second inlet to the node $(\mathrm{kg} / \mathrm{h})$ \\
\hline$\dot{m}_{\text {air }}$ & Mass flow rate of air $(\mathrm{kg} / \mathrm{h})$ \\
\hline$\dot{m}_{\text {cond }}$ & Mass flow rate of condensate $(\mathrm{kg} / \mathrm{h})$ \\
\hline$\dot{m}_{\mathrm{DHW}}$ & Mass flow rate of domestic hot water $(\mathrm{kg} / \mathrm{h})$ \\
\hline$n_{\text {exhaust }}$ & Mass flow rate of the exhaust air $(\mathrm{kg} / \mathrm{h})$ \\
\hline$\dot{m}_{\text {ExhaustToFresh }}$ & $\begin{array}{l}\text { Mass flow rate of moisture from the exhaust air stream to the } \\
\text { fresh air stream }(\mathrm{kg} / \mathrm{h})\end{array}$ \\
\hline$\dot{m}_{\text {fresh }}$ & Mass flow rate of the fresh air $(\mathrm{kg} / \mathrm{h})$ \\
\hline$\dot{m}_{\text {FreshToExhaust }}$ & $\begin{array}{l}\text { Mass flow rate of moisture from the fresh air stream to the ex- } \\
\text { haust air stream }(\mathrm{kg} / \mathrm{h})\end{array}$ \\
\hline$\dot{m}_{\mathrm{i}-1}$ & $\begin{array}{l}\text { Mass flow rate down from the tank node above to the node ex- } \\
\text { amined }(\mathrm{kg} / \mathrm{h})\end{array}$ \\
\hline & $\begin{array}{l}\text { Mass flow rate up from the tank node below to the node exam- } \\
\text { ined }(\mathrm{kg} / \mathrm{h})\end{array}$ \\
\hline
\end{tabular}




\begin{tabular}{|c|c|}
\hline$\dot{m}_{\min }$ & $\begin{array}{l}\text { Minimum of the two air stream flow rates of the energy recovery } \\
\text { ventilator }(\mathrm{kg} / \mathrm{h})\end{array}$ \\
\hline$\dot{m}_{\text {load }}$ & Load side mass flow rate of the heat pump $(\mathrm{kg} / \mathrm{h})$ \\
\hline$\dot{m}_{\text {source }}$ & Source side mass flow rate of the heat pump $(\mathrm{kg} / \mathrm{h})$ \\
\hline$\dot{m}_{\text {tank,DHW }}$ & $\begin{array}{l}\text { Mass flow rate of hot water from the hot tank to the DHW draw } \\
(\mathrm{kg} / \mathrm{hr})\end{array}$ \\
\hline$\dot{m}_{\text {tank }, \mathrm{L}}$ & Load side mass flow rate of the tank $(\mathrm{kg} / \mathrm{h})$ \\
\hline$\dot{m}_{\text {tank }, \mathrm{S}}$ & Source side mass flow rate of the tank $(\mathrm{kg} / \mathrm{h})$ \\
\hline$\dot{m}_{\text {transfer }}$ & $\begin{array}{l}\text { Moisture mass transfer between the two air streams of the energy } \\
\text { recovery ventilator }(\mathrm{kg} / \mathrm{h})\end{array}$ \\
\hline$\dot{m}_{\text {up }}$ & $\begin{array}{l}\text { Mass flow rate moving from one node of the tank to the node } \\
\text { above }(\mathrm{kg} / \mathrm{h})\end{array}$ \\
\hline$\dot{m}_{\text {down }}$ & $\begin{array}{l}\text { Mass flow rate moving from one node of the tank to the node } \\
\text { below }(\mathrm{kg} / \mathrm{h})\end{array}$ \\
\hline$M_{\mathrm{i}}$ & Mass of the node $(\mathrm{kg})$ \\
\hline$n$ & Number of data points measured \\
\hline$\omega_{\text {air,in }}$ & Absolute humidity ratio of entering air $\left(\mathrm{kg}_{\text {water }} / \mathrm{kg}_{\text {air }}\right)$ \\
\hline$\omega_{\text {air,CoilOut }}$ & Absolute humidity ratio of air exiting the coils $\left(\mathrm{kg}_{\text {water }} / \mathrm{kg}_{\text {air }}\right)$ \\
\hline$\omega_{\text {air,out }}$ & Absolute humidity ratio of exiting air $\left(\mathrm{kg}_{\text {water }} / \mathrm{kg}_{\text {air }}\right)$ \\
\hline$\omega_{\text {exhaust,in }}$ & Absolute humidity ratio of entering exhaust air $\left(\mathrm{kg}_{\text {water }} / \mathrm{kg}_{\text {air }}\right)$ \\
\hline$\omega_{\text {fresh,in }}$ & Absolute humidity ratio of entering fresh air $\left(\mathrm{kg}_{\text {water }} / \mathrm{kg}_{\text {air }}\right)$ \\
\hline$\omega_{\text {exhaust,out }}$ & Absolute humidity ratio of exiting exhaust air $\left(\mathrm{kg}_{\text {water }} / \mathrm{kg}_{\text {air }}\right)$ \\
\hline$\omega_{\text {fresh,out }}$ & Absolute humidity ratio of exiting fresh air $\left(\mathrm{kg}_{\text {water }} / \mathrm{kg}_{\text {air }}\right)$ \\
\hline$P_{\text {comp }}$ & Electrical energy draw for the heat pump compressor $(\mathrm{kJ})$ \\
\hline$P_{\text {pump }}$ & Electrical energy required for circulation pumps (kJ) \\
\hline$\dot{P}_{\text {circ }}$ & Electrical power draw of the circulation pumps $(\mathrm{kW})$ \\
\hline$\dot{P}_{\text {comp }}$ & Electrical power draw of the heat pump compressor $(\mathrm{kJ} / \mathrm{h})$ \\
\hline$\dot{P}_{\text {measured }}$ & Measured electrical power draw $(\mathrm{kW})$ \\
\hline$Q_{\text {air }}$ & Energy collected from air $(\mathrm{kJ})$ \\
\hline$Q_{\text {aux }}$ & Auxiliary energy input (kJ) \\
\hline$Q_{\text {coll }}$ & Useful collected solar energy $(\mathrm{kJ})$ \\
\hline
\end{tabular}


$Q_{\text {CoolingCoil }} \quad$ Energy transferred to the cooling coil from the air $(\mathrm{kJ})$

$Q_{\text {HeatingCoil }} \quad$ Energy transferred from the heating coil to the air $(\mathrm{kJ})$

$Q_{\text {load }}$

Energy transferred from the load side of the heat pump (kJ)

$Q_{\text {load, total }}$

Energy required to meet the space-heating, cooling and/or DHW loads $(\mathrm{kJ})$

$\dot{Q}_{\mathrm{aux}, \mathrm{i}}$

Auxiliary power input to node $\mathrm{i}(\mathrm{kJ} / \mathrm{h})$

$\dot{Q}_{\text {fluid }}$

Energy transfer from the fluid to the air stream $(\mathrm{kJ} / \mathrm{h})$

$\dot{Q}_{\text {latent }}$

$\dot{Q}_{\text {load }}$

Latent energy transferred in the energy recover ventilator $(\mathrm{kJ} / \mathrm{h})$

$\dot{Q}_{\text {source }}$

Energy transfer rate from the load side of the heat pump $(\mathrm{kJ} / \mathrm{h})$

Energy transfer rate from the source side of the heat pump $(\mathrm{kJ} / \mathrm{h})$

$\dot{Q}_{\text {sens }}$

Sensible energy transfer in the energy recovery ventilator $(\mathrm{kJ} / \mathrm{h})$

$\dot{Q}_{\text {tot }}$

Total energy transferred in the energy recover ventilator $(\mathrm{kJ} / \mathrm{h})$

$\rho_{\text {water }}$

Density of water $\left(\mathrm{kg} / \mathrm{m}^{3}\right)$

$S F$

Solar fraction

$S P F$

Seasonal performance factor

$t$

Time (min)

$T_{\mathrm{amb}}$

Outdoor ambient air temperature $\left({ }^{\circ} \mathrm{C}\right)$

$T_{\text {air,in }}$

Inlet air temperature $\left({ }^{\circ} \mathrm{C}\right)$

$T_{\text {coll,in }}$

Collector inlet fluid temperature $\left({ }^{\circ} \mathrm{C}\right)$

$T_{\text {env }}$

Temperature of the surrounding environment $\left({ }^{\circ} \mathrm{C}\right)$

$T_{\text {exhaust, in }}$

Temperature of the air entering the exhaust air side of the energy recovery ventilator $\left({ }^{\circ} \mathrm{C}\right)$

$T_{\text {fluid,in }}$

Temperature of fluid entering the coils $\left({ }^{\circ} \mathrm{C}\right)$

$T_{\text {fluid,CoilOut }}$

Temperature of fluid exiting the coils $\left({ }^{\circ} \mathrm{C}\right)$

$T_{\text {fluid,out }}$

Temperature of fluid exiting the coils accounting the bypassed fraction $\left({ }^{\circ} \mathrm{C}\right)$

$T_{\text {fresh,in }}$

Temperature of the air entering the fresh air side of the energy recovery ventilator $\left({ }^{\circ} \mathrm{C}\right)$

$T_{\mathrm{i}} \quad$ Temperature of tank node $\left({ }^{\circ} \mathrm{C}\right)$

$T_{\mathrm{i}+1} \quad$ Temperature of tank node below $\left({ }^{\circ} \mathrm{C}\right)$ 
$T_{\mathrm{i}-1}$

$T_{1, \text { in }}$

$T_{2, \text { in }}$

$T_{1, \text { out }}$

$T_{2, \text { out }}$

$T_{\mathrm{DHW}}$

$T_{\text {load,ave }}$

$T_{\text {load,in }}$

$T_{\text {load,out }}$

$T_{\text {mains }}$

$T_{\text {source,ave }}$

$T_{\text {source,in }}$

$T_{\text {source,out }}$

$T_{\text {tank }}$

$T_{\text {tank,L,in }}$

$T_{\text {tank,S,in }}$

$\tau$

$\Delta t$

$\theta$

$u_{\mathrm{COP}}$

$u_{C O P_{\text {average }}}$

$u_{Q_{\text {load }}}$

$u_{P_{\text {comp }}}$

$u_{\dot{P}_{\text {comp }}}$

$u_{\dot{Q}_{\text {load }}}$

$U$

$U_{\mathrm{L}}$
Temperature of tank node above $\left({ }^{\circ} \mathrm{C}\right)$

Temperature of inlet flow one $\left({ }^{\circ} \mathrm{C}\right)$

Temperature of inlet flow two $\left({ }^{\circ} \mathrm{C}\right)$

Temperature of outlet flow one $\left({ }^{\circ} \mathrm{C}\right)$

Temperature of outlet flow two $\left({ }^{\circ} \mathrm{C}\right)$

Domestic hot water delivery temperature $\left({ }^{\circ} \mathrm{C}\right)$

Heat pump average load side temperature $\left({ }^{\circ} \mathrm{C}\right)$

Heat pump load side entering temperature $\left({ }^{\circ} \mathrm{C}\right)$

Heat pump load side exiting temperature $\left({ }^{\circ} \mathrm{C}\right)$

Temperature of mains water $\left({ }^{\circ} \mathrm{C}\right)$

Heat pump source side average temperature $\left({ }^{\circ} \mathrm{C}\right)$

Heat pump source side entering temperature $\left({ }^{\circ} \mathrm{C}\right)$

Heat pump source side exiting temperature $\left({ }^{\circ} \mathrm{C}\right)$

Temperature of hot tank water to domestic hot water load $\left({ }^{\circ} \mathrm{C}\right)$

Tank load side inlet fluid temperature $\left({ }^{\circ} \mathrm{C}\right)$

Tank source side inlet fluid temperature $\left({ }^{\circ} \mathrm{C}\right)$

Short-wave transmittance of the collector cover

Time elapsed between each data point measurement (s)

Incident angle (rad)

Uncertainty of the coefficient of performance

Uncertainty of the average coefficient of performance

Uncertainty of the accumulated energy transferred $(\mathrm{kJ})$

Uncertainty of the accumulated heat pump energy consumption $(\mathrm{kJ})$

Uncertainty of the heat pump power consumption $(\mathrm{kW})$

Uncertainty of the heat pump heat transfer rate $(\mathrm{kW})$

Tank loss coefficient $\left(\mathrm{kJ} / \mathrm{h} \cdot \mathrm{m}^{2} \mathrm{~K}\right)$

Overall thermal loss coefficient per unit area of collector $\left(\mathrm{kJ} / \mathrm{h} \cdot \mathrm{m}^{2} \mathrm{~K}\right)$ 
$U_{\mathrm{L} / \mathrm{T}}$

$\dot{V}$

$\dot{V}_{\mathrm{GR}}$

$\Delta x$
Thermal loss coefficient dependency on the collector temperatures $\left(\mathrm{kJ} / \mathrm{h} \cdot \mathrm{m}^{2} \mathrm{~K}^{2}\right)$

Volumetric flow rate $(\mathrm{L} / \mathrm{min})$

Gravimetric flow rate $(\mathrm{L} / \mathrm{min})$

Distance between nodes in the storage tank $(\mathrm{m})$ 


\section{Chapter 1}

\section{Introduction}

\subsection{Motivation}

In Canada, residential building energy use accounts for approximately $17 \%$ of the total secondary energy consumption (or total energy consumed by an end-use) and roughly $81 \%$ of this energy is used for space-heating, cooling, and domestic hot water (DHW) requirements [1]. As shown in Figure 1.1, space-heating, cooling, and DHW loads account for $63 \%, 1 \%$, and $17 \%$ of secondary energy use, respectively. For enduse greenhouse gas (GHG) emissions, approximately the same percentages can be

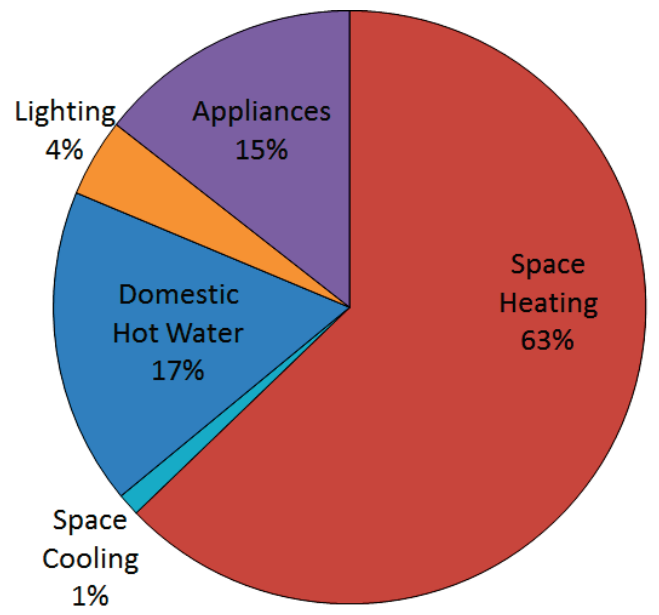

Figure 1.1: Residential energy use in Canada in 2009 [1] 
attributed to these demands. In Canada, space-heating, cooling, and DHW demands are typically met with electricity or natural gas. The use of solar thermal energy can reduce the use of conventional fossil fuels and the emission of GHGs. Worldwide, heat pumps are commonly used to meet residential space-heating, cooling, and/or DHW loads. Past studies have suggested that the combination of heat pump and solar thermal energy systems as a single solar-assisted heat pump (SAHP) system is a promising technology for offsetting these loads. In the European Market, packaged systems are offered for single-family houses [2].

\subsection{Background}

This chapter provides background information on solar thermal and heat pump systems, as well as the performance drawbacks of each technology when operating independently in cold climates. The key benefit of coupling solar thermal and heat pump technologies together is the performance improvement of each component that can result in an overall increase in the performance of the SAHP system as a whole. This chapter also outlines the different SAHP configurations and how these configurations can improve the heat pump and solar collector performances are discussed.

\subsubsection{Solar Thermal Systems}

Solar thermal systems are often used for space-heating or DHW requirements. Solar thermal energy can also be used to drive adsorption chillers, absorption chillers, and liquid desiccant dehumidification systems for space-cooling. The principle of solar thermal systems is the use of solar collectors to capture solar thermal radiation energy in the form of heat. The working fluid within the collectors absorbs the heat and transports it to an energy storage either through a heat exchanger (internal or external 
to the storage) or directly into the storage if the working fluid is water [3]. A thermal storage is required because space-heating and DHW requirements do not necessarily coincide with when the solar energy is available. In freezing climates such as Canada, solar DHW systems have one pump that circulates an antifreeze solution from the collectors to the source side of an external heat exchanger, as shown in Figure 1.2, and another pump circulates water from the storage tank to the load side of the heat exchanger [3]. An auxiliary heating system is also commonly used in a solar thermal system to make up for instances when solar thermal output is insufficient to meet either space-heating or DHW loads.

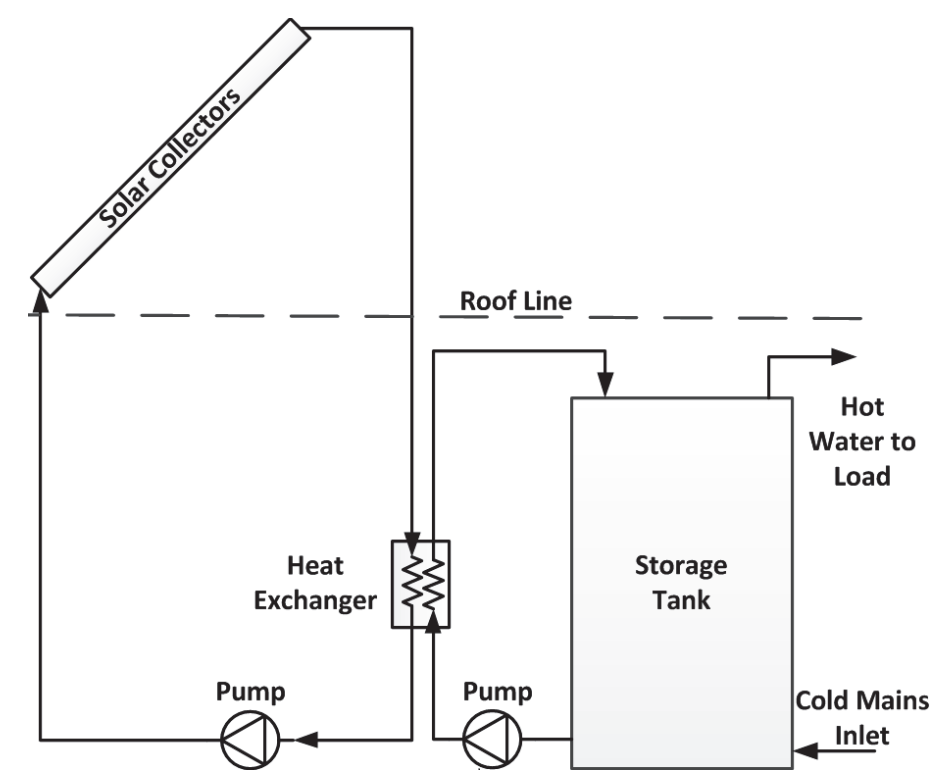

Figure 1.2: Typical solar domestic hot water system with an external heat exchanger (adapted from [4])

\section{Solar Collectors}

The three main types of collectors are unglazed flat plate collectors, glazed flat plate collectors, and evacuated tube collectors [5]. An unglazed flat plate collector contains an absorber (usually a dark coated metal plate) attached to a system of pipes carrying 
a working fluid. The absorber collects the thermal energy which is transferred to the working fluid. The reverse side of unglazed collectors is typically not insulated. Glazed flat plate collectors are similar to unglazed collectors, however, it contains a glass cover on the front side and insulation on the reverse side. The glass cover reduces convective and long-wave radiation losses, and transmits about $80-90 \%$ of the irradiance to the absorber as the remainder is absorbed or reflected by the glass [5]. Irradiance absorbed or reflected is known as optical loss. Evacuated tube collectors are glass cylinders containing absorber plates or coatings. The air is evacuated from the glass cylinder to minimize convective and conductive heat transfer from the absorber

to the ambient air. A collector array would consist of multiple tubes attached to a single header. The optical losses from the evacuated tubes are greater compared to glazed flat plate collectors due to their lower aperture to gross area ratio caused by the spaces between tubes. Glazed flat plate collectors and evacuated tube collectors are typically used for solar DHW applications due to their higher delivery temperatures and reduced heat loss. In Canada, the efficiency of collectors tends to decrease in the winter due to low ambient temperatures and greater heat losses [6].

\section{Thermal Storage and Stratification}

The most common thermal energy storage method for residential applications is the use of sensible storage in the form of hot water tanks. Other storage mediums include latent energy storage with phase change materials and thermochemical storage.

Hot water storage tanks should be sized for the expected loads of the system and these tanks could be designed for thermal stratification. Thermal stratification refers to the differing temperature levels from the bottom to the top of the tank. Stratification is driven by buoyancy forces that cause water of differing densities, and hence, temperatures, to move to different levels in the tank. Stratification creates a 
cold water zone and a hot water zone with a temperature gradient or thermocline zone in between. Thermal stratification can improve the performance of the system by providing hot water to the load and colder water to the collectors, promoting higher temperature differences across the collectors. Figure 1.3 shows three storage tanks with the same amount of stored energy but with differing levels of stratification. Figure 1.3(a) is the most stratified due to the small thermocline zone compared to Figure 1.3(b), which is the moderately stratified case with a larger thermocline zone. Figure 1.3(c) shows a fully mixed tanks with no thermal stratification [3].
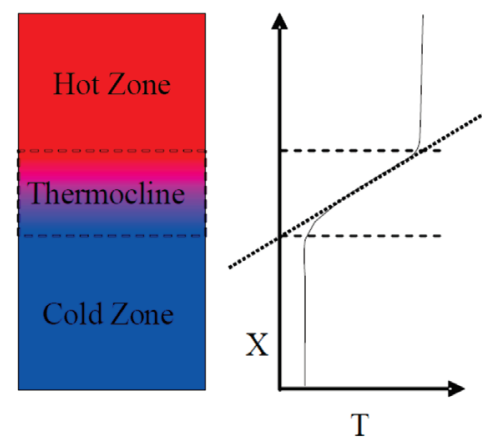

(a) Highly stratified

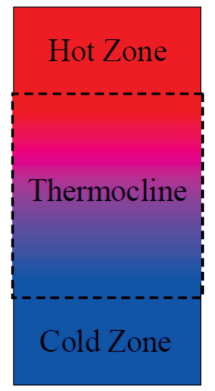

(b) Moderately stratified

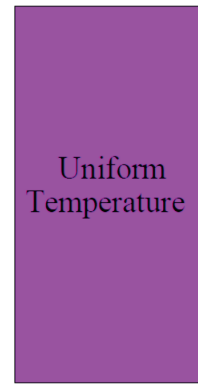

(c) Fully mixed

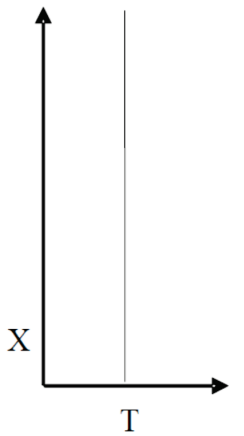

Figure 1.3: Differing levels of stratification within a tank from Cruickshank [3]

\subsubsection{Vapour Compression Heat Pump Systems}

The basic components of a heat pump are the compressor, condenser, expansion valve, and evaporator, and a refrigerant is used as a heat transfer fluid between the four components [7]. An air-source heat pump, as shown in Figure 1.4, can be used to charge a storage tank. Also shown in Figure 1.4 is a temperature versus entropy $(T-s)$ diagram for an ideal heat pump cycle. The refrigerant enters the evaporator (point 4) at a low pressure and temperature (the evaporating temperature). In the evaporator, the refrigerant absorbs the heat from the outside air and leaves the evaporator as a 


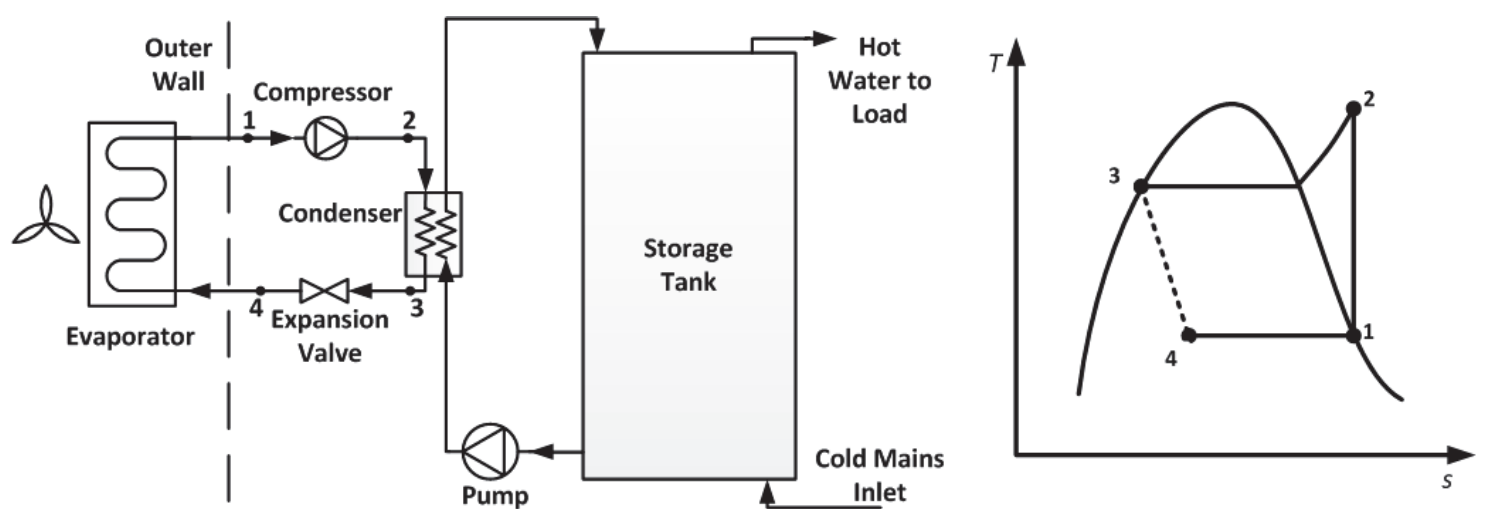

Figure 1.4: Schematic of an air-source heat pump water heater (adapted from [6])

vapour (process 4 to 1 ). The refrigerant then enters the compressor, which increases the pressure and temperature of the refrigerant (process 1 to 2). The refrigerant then flows through the condenser (process 2 to 3 ) where energy from the refrigerant is rejected to the storage tank water which flows through the load side of the condenser. The refrigerant exits the condenser at the condensing temperature. The pressure of the refrigerant is then reduced through the expansion valve (process 3 to 4 ) prior to re-entering the evaporator [7]. The coefficient of performance $(C O P)$ of a heat pump is the ratio between thermal energy delivered in the condenser to the work input required to drive the compressor [7].

Other common forms of heat pumps are air-to-air and liquid-to-liquid. Air-to-air heat pumps are commonly used for spacing-heating and cooling. For cooling, the heat pump cycle reverses and the evaporator and condenser exchange roles. Groundsource or geothermal heat pumps are an example of liquid-source heat pumps where the evaporator draws heat from fluid circulated through borehole heat exchangers. Like solar thermal collectors, the cold winters also negatively impact the performance of air-source heat pumps. As ambient air decreases in temperature, less energy is available to heat the refrigerant in the evaporator. As the refrigerant enters the compressor at a lower temperature, more energy would be required to drive the compressor 
to raise the temperature and pressure of the refrigerant for the heating requirements in the condenser. Therefore, the $C O P$ can be significantly reduced at low outdoor temperatures [8]. As a result, typical air-source heat pumps are not popular for water heating purposes in Canada [9]. For space-heating, cold climate air-source heat pumps are showing improved heating capacities at low temperature conditions [10].

\subsubsection{Solar-Assisted Heat Pump Systems}

The use of solar thermal and heat pump technology together has the potential of alleviating the aforementioned limitations each system experiences individually in the winter [6]. To charge a thermal energy storage, the solar thermal and heat pump components can be combined in parallel or series. Figure 1.5 shows a schematic of a parallel system where the red dotted lines are for the air-source heat pump operation and black lines are for the solar thermal charging operation. In the parallel configuration, when the amount of solar energy available from the collectors is insufficient

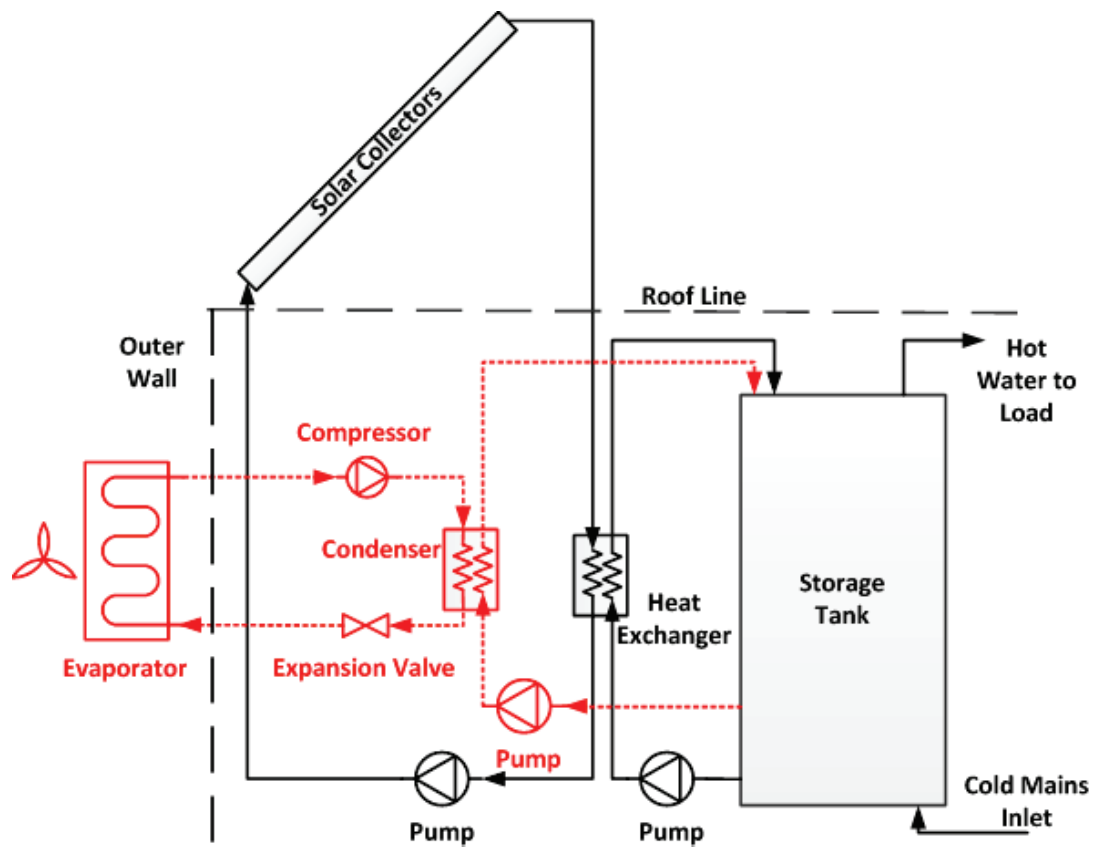

Figure 1.5: Schematic of a parallel solar-assisted heat pump system 
then the air-source heat pump would operate to charge the storage.

When combined in series, the collected solar energy would be used in the evaporator to heat the refrigerant. This would lead to an increase of source energy and a decrease of compressor energy which results in an improved $C O P$ even in the winter. Series systems can be assembled in a direct or indirect configuration. In a direct system, as shown in Figure 1.6, the collectors act as the evaporator and the working fluid in the collectors would be the refrigerant of the heat pump.

In an indirect system, a liquid-to-liquid heat pump can be implemented as a closed unit and energy is transferred from the collectors to the refrigerant loop in the heat pump via the evaporator heat exchanger. Figure 1.7 shows a schematic of an indirect system. This system can use an antifreeze solution in the collectors, which is required for cold weather [11]. When the evaporator removes energy from the collector working fluid, the temperature of the working fluid returning to the collectors is reduced. In the winter, this decreases the temperature difference between the collectors and the ambient air which leads to a decrease in heat loss and increase in collector efficiency.

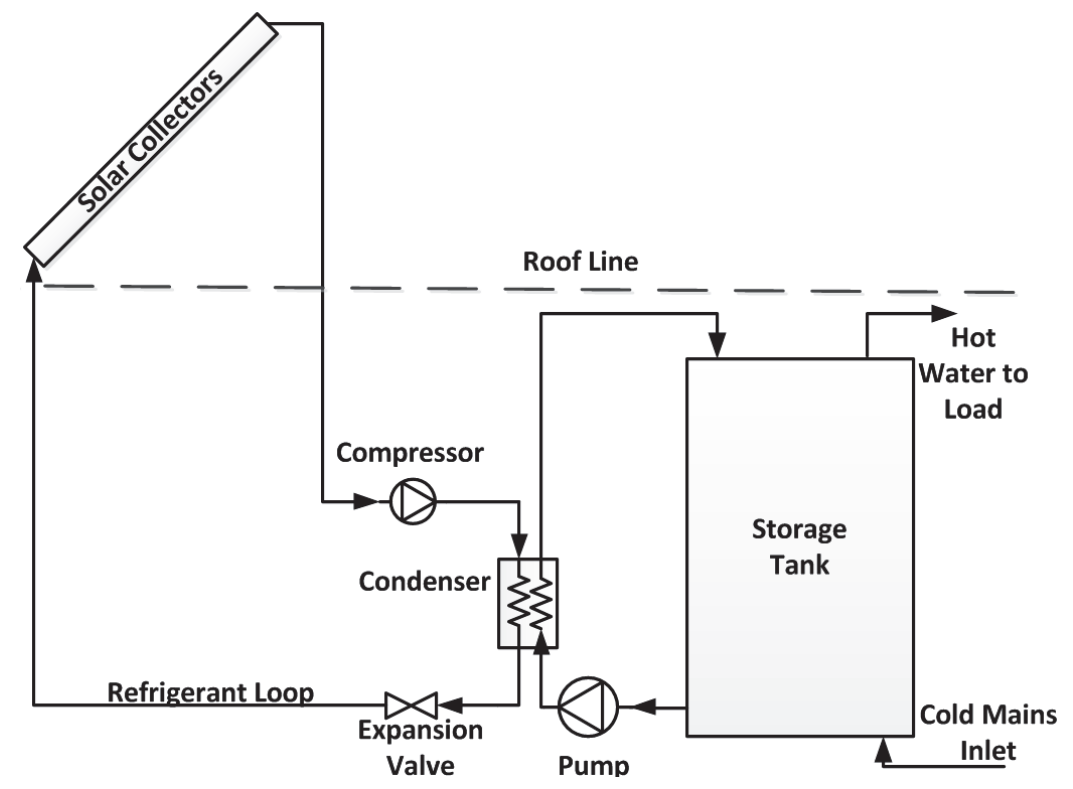

Figure 1.6: Schematic of a direct solar-assisted heat pump system (adapted from [6]) 


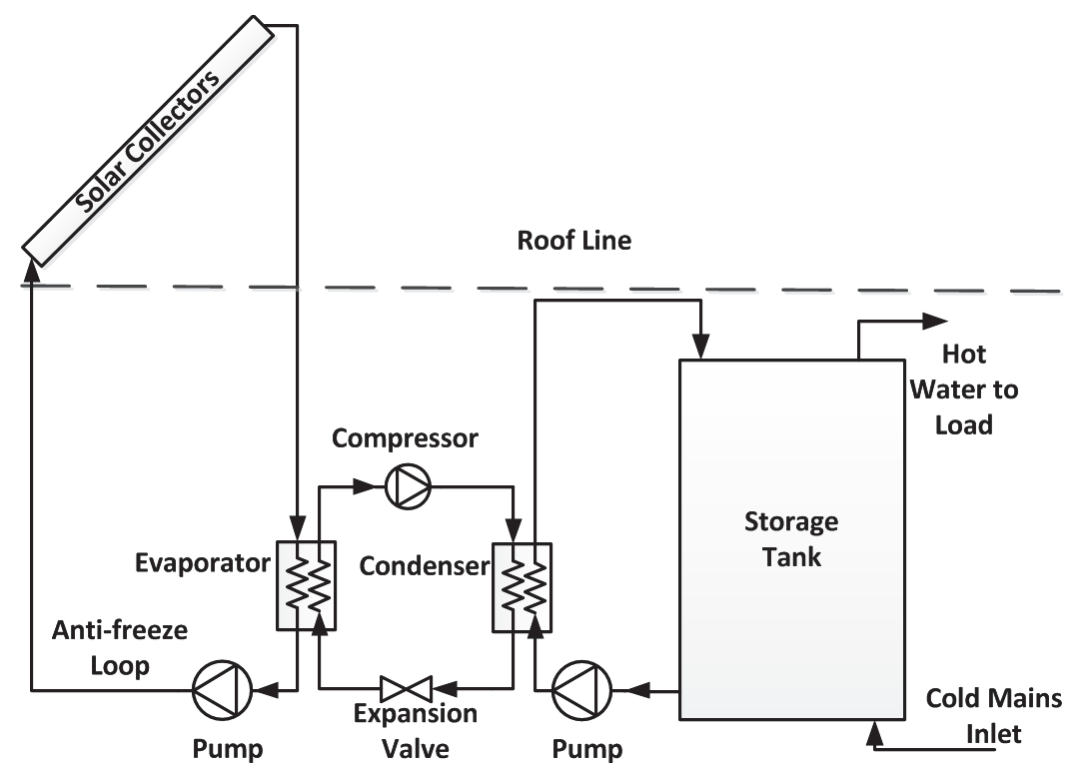

Figure 1.7: Schematic of an indirect solar-assisted heat pump system (adapted from [6])

In the shoulder seasons and the summer, the temperature of the collector fluid can be lower than the ambient temperature. As a result, the collectors can also absorb energy from the surroundings, which further increases the collector efficiency and increases the daily operation period of the collectors [11]. In this arrangement, the solar collectors also increase the amount of energy available for the source side of the heat pump which can improve its performance. Many other variations of SAHP also exist and some are discussed in literature review examples in Chapter 2. One variation of a series indirect SAHP system includes two storage tanks. This system was used in Team Ontario's competition entry to the Solar Decathlon 2013 Competition.

\subsubsection{Solar Decathlon 2013: Team Ontario}

The U.S. Department of Energy holds the Solar Decathlon Competition every two years to challenge 20 collegiate teams to "design, build, and operate solar-powered houses that are cost effective, energy efficient, and attractive" [12]. The competition 
has ten contests which are listed in Table 1.1. For the Engineering contest, a jury of engineers would evaluate the engineering designs of the house in terms of innovation, functionality, efficiency, and reliability. The Comfort Zone contest would award full points if the indoor temperature remains between $21.7^{\circ} \mathrm{C}$ and $24.4^{\circ} \mathrm{C}$ and the indoor relative humidity remains below $60 \%$ during measurement hours. During the competition, scheduled hot water draws would occur one to three times a day in the morning. For full points, each draw must have an average temperature of $43.3^{\circ} \mathrm{C}$ and at least $56.8 \mathrm{~L}$ of water must be drawn within 10 minutes. Full points are awarded for the Energy Balance contest if the net electrical energy balance is zero or less [13].

Table 1.1: Solar Decathlon contests

\begin{tabular}{|c|c|}
\hline Juried & Measured \\
\hline Architecture & Comfort Zone \\
Market Appeal & Hot Water \\
Engineering & Appliances \\
Communications & Home Entertainment \\
Affordability & Energy Balance \\
\hline
\end{tabular}

Team Ontario competed in the Solar Decathlon 2013 Competition which took place Irvine, California. Team Ontario is a collaboration of students and faculty from Queen's University in Kingston, Ontario, and Carleton University and Algonquin College in Ottawa, Ontario. Team Ontario designed a $89 \mathrm{~m}^{2}\left(960 \mathrm{ft}^{2}\right)$ detached, singlestory house for the Ottawa, Ontario climate. The house was named ECHO, as it was an ECological HOme built for the target audience of next generation home owners who are sometimes referred to as the "Echo Boomers" [14]. To achieve net-zero energy consumption for the Energy Balance contest, a photovoltaic array containing 30 monocrystalline panels was installed on ECHO for a peak production of $7.8 \mathrm{~kW}$. ECHO 
was built with vacuum insulation panels in the walls, floor, and ceiling to give a total $\mathrm{R}$-value of $9.4 \mathrm{~m}^{2} \mathrm{~K} / \mathrm{W}\left(53 \mathrm{~h} \cdot \mathrm{ft}^{2 \circ} \mathrm{F} / \mathrm{Btu}\right)[15]$. These panels were integrated into the building envelope to reduce the space-heating and cooling loads by minimizing heat transfer between the house and the outdoors. A predictive shading algorithm was also used to control external bottom-up roller blinds installed on the large, south-facing windows in order to control the solar gains and to reduce both space-heating and cooling loads [16]. The advanced building envelope and shading systems were designed to reduce loads that the integrated mechanical system must meet so that comfort zone can be more easily achieved with reduced energy consumption. Figure 1.8 shows the south side of the house with the exo-structure built to hold photovoltaic panels on the top and solar collectors on the front.

Team Ontario developed a preliminary computer building model to predict the energy performance. In addition, a model of the integrated mechanical system (IMS) was also created. The IMS included a SAHP as the primary system for supplying energy to meet the space-heating, cooling, and DHW loads. In the SAHP system investigated, two thermal energy storage tanks were used in order to offset spaceheating, cooling, and DHW loads with one single system [17]. Figures 1.9 and 1.10 are schematics of the system in heating and cooling operations, respectively.

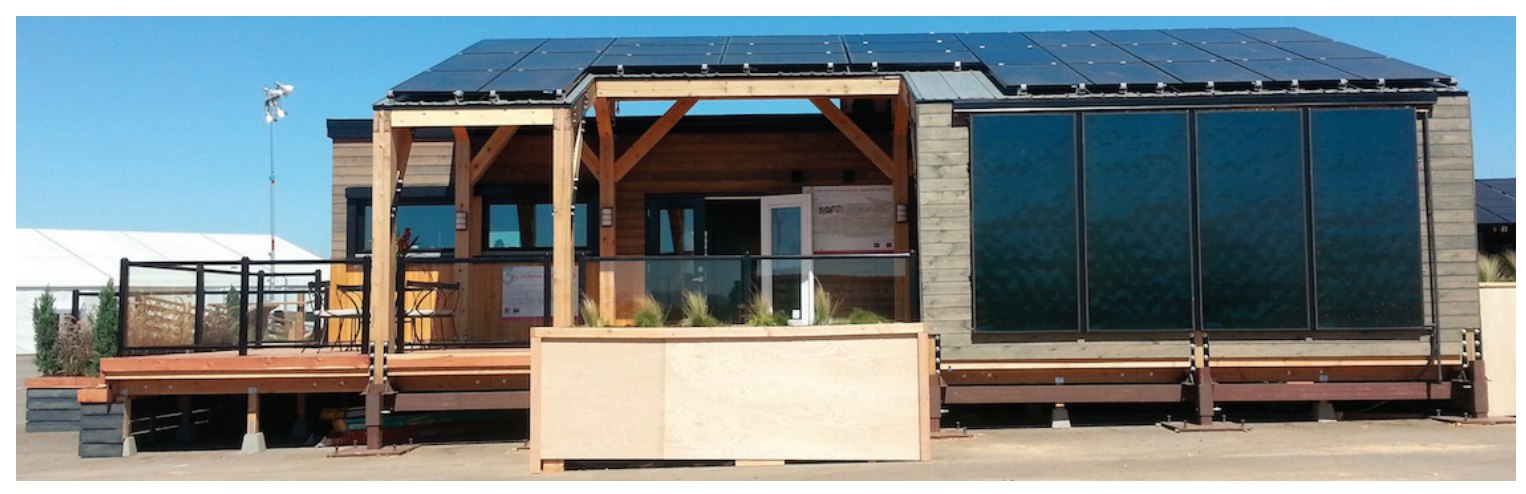

Figure 1.8: South side of ECHO with exo-structure holding photovoltaic panels on top and solar collectors on the front (Photo credit: Jacob Morgan) 


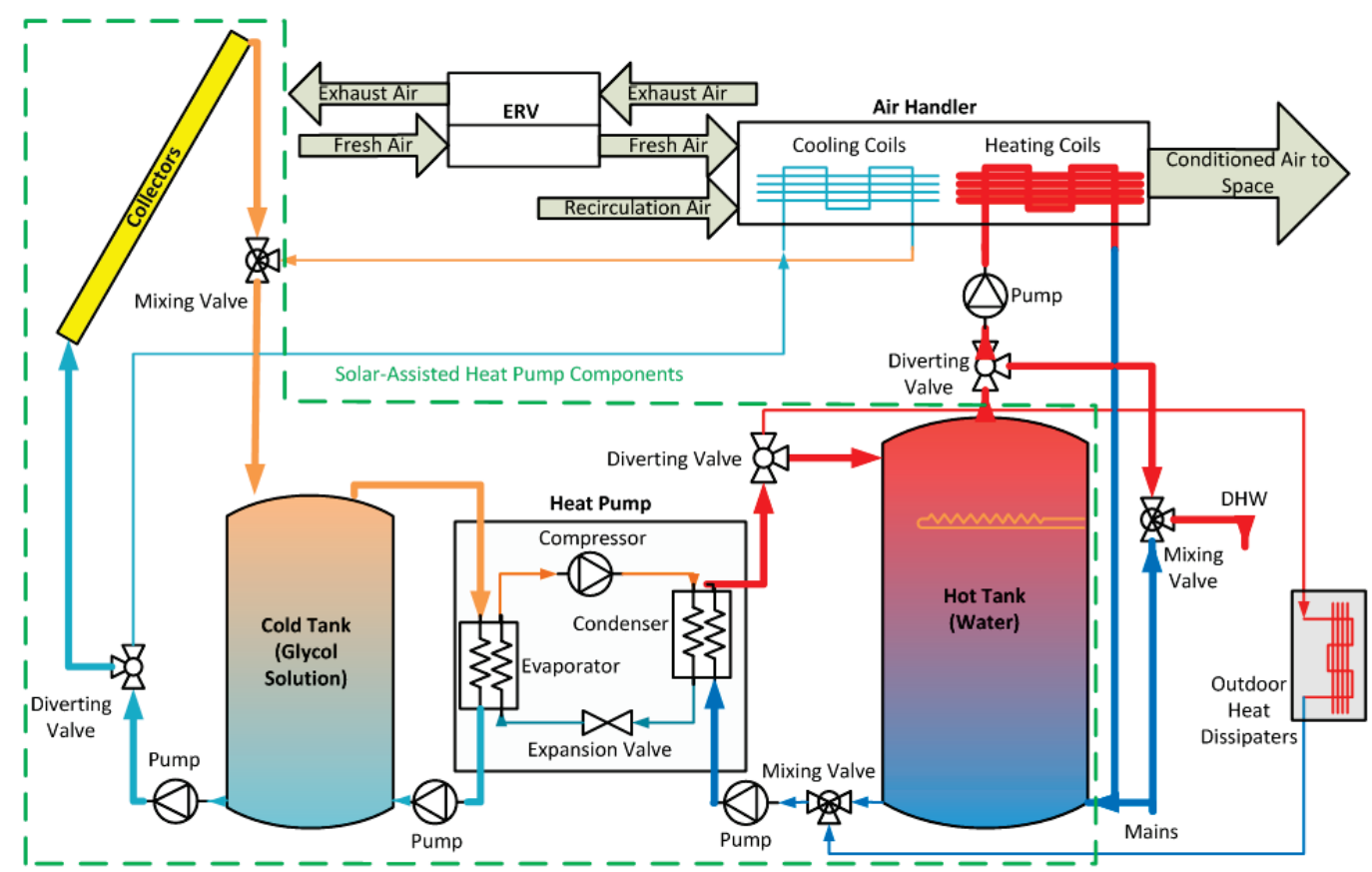

Figure 1.9: Schematic of the integrated mechanical system with the heating season operations highlighted

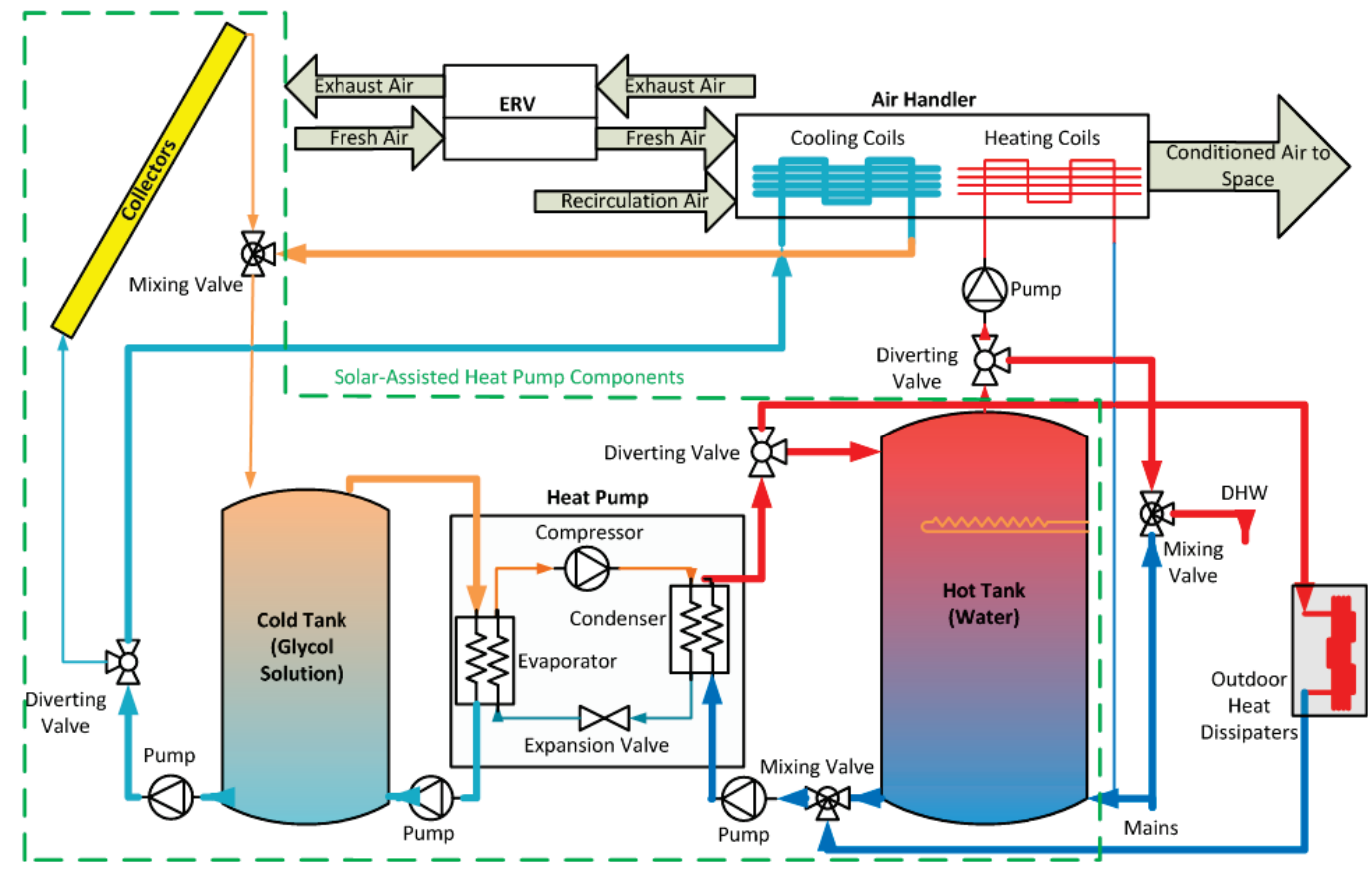

Figure 1.10: Schematic of the integrated mechanical system with the cooling season operations highlighted 
The IMS used a forced air distribution system with an air handling unit that heated, cooled, and dehumidified the supply air. During the Solar Decathlon Competition, the house must be brought to comfort zone conditions within 30 minutes of public exhibit periods during which no space conditioning occurs. Even though radiant systems have lower temperature requirements, a forced air distribution system was chosen due to the faster response time compared to a radiant system. As fresh air must be mechanically ventilated into the house for indoor air quality requirements, a ducting system would already be required and can be adapted to meet heating and cooling requirements as well. The forced air distribution system also dehumidifies the supply air. If a radiant system was used, a separate dehumidification system would be required to avoid condensate from forming on surfaces. An energy recovery ventilator (ERV), was used to recover energy from exhaust air to preheat incoming ventilation fresh air.

The main components of the SAHP system were the collectors, the two energy storage tanks, and the liquid-to-liquid heat pump. In the winter, the collectors were used to charge a cold tank containing a 50/50 glycol-water solution by volume. The glycol solution would be drawn from the top of the cold tank to the evaporator of the heat pump to provide source energy. A glycol solution was used because the collectors required an antifreeze solution as a working fluid since the IMS was designed to operate in a freezing climate. The use of the glycol solution instead of water in the cold tank also eliminated the need for an additional heat exchanger and the associated energy losses with it, and eliminated the need for an extra pump and the energy consumption associated with it. The glycol solution also allowed the heat pump to reduce the source side flow to temperatures below $0^{\circ} \mathrm{C}$ which helped extend the operation period of the heat pump. The heat pump transferred energy from the glycol solution to the hot tank through the condenser. The heated water from the 
condenser was returned to the top of the hot tank to maintain thermal stratification. Space-heating in the winter would be achieved by running hot water to the air handler as shown in Figure 1.9. When the hot tank is lacking energy from the heat pump, an internal auxiliary heater is located in the top half of the tank to maintain the temperature at the top of the hot tank at $55^{\circ} \mathrm{C}$ for DHW requirements [17].

In the summer, the glycol solution was used in the air handler for space-cooling and dehumidification as shown in Figure 1.10. Therefore, the solar collectors were not used in the summer since the cold tank must remain chilled. Energy recovered from space-cooling was transferred from the cold tank to the hot tank using the heat pump in order to meet DHW loads in the summer. When the hot tank is fully charged and the cold tank requires cooling, the heat pump will operate but the excess energy would be rejected with an outdoor heat dissipater. The glycol solution would flow through cooling coils within the air handler to provide dehumidification by reducing the temperature of the air to as low as $10^{\circ} \mathrm{C}$. After cooling, the air would be reheated in the heating coils to $16^{\circ} \mathrm{C}$, as requested by Team Ontario's mechanical systems group for the low velocity air distribution system [17].

The system also had space constraints where the system must fit within a $2.4 \mathrm{~m}$ (8 $\mathrm{ft}$ ) wide and $1.2 \mathrm{~m}(4 \mathrm{ft})$ deep mechanical closet. Figure 1.11 is a photo of the closet housing the IMS. The system was first built in a laboratory for the experimental analysis of this research and was then transferred and installed into ECHO for the competition.

The IMS was first inspired by a system designed by Morofsky and Campbell in 1991 for "The Advanced House" which was a Canadian project that demonstrated energy efficient products and systems [18]. The proposed system used heat from waste water and exhaust air to charge the cold storage. The expected energy performance of this IMS was not available. As ECHO was only one storey, drain water heat recovery 


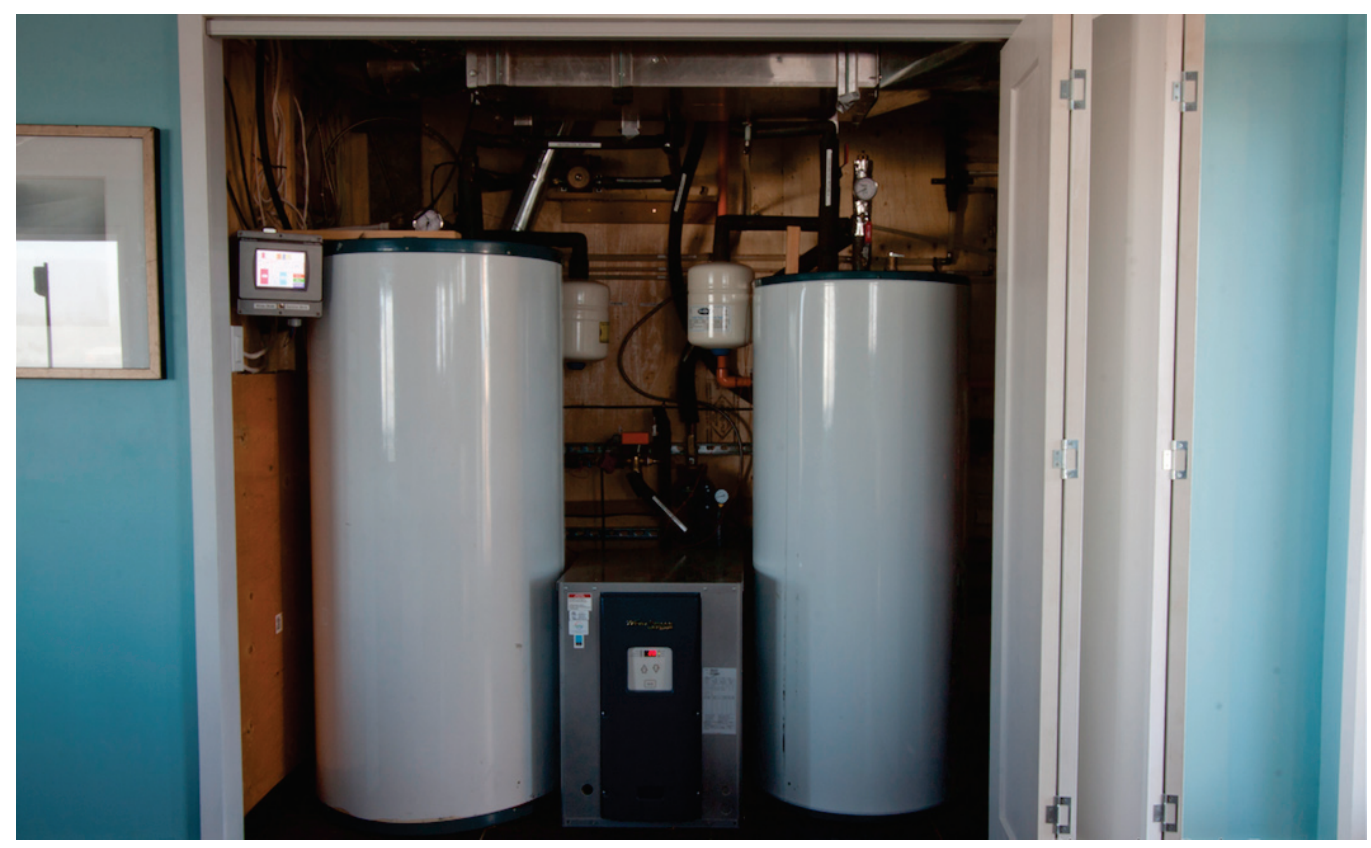

Figure 1.11: ECHO's mechanical closet containing the designed SAHP (Photo credit: Carly Farmer)

was difficult to implement with the IMS. Through the ERV of the IMS, the energy from the exhaust air was recovered to directly preheat incoming fresh air, therefore, solar collectors were added to the IMS to heat the cold storage.

The IMS was chosen for ECHO because the Solar Decathlon Competition did not allow the use of non-solar fuels. The competition also did not allow the use of a ground-source heat pump as ground penetration was only permitted for tie-downs [13]. The IMS has the capability of offsetting the combination of DHW, space-heating, and cooling requirements. Typical air-source heat pumps are not commonly used for space and water-heating in the cold climates due to reduced performances $[8,9]$. As previously mentioned, cold climate air-source heat pumps are showing improved heating capacities at low temperature conditions [10], however, the investigation of this technology was outside the scope of this research. 


\subsection{Contribution of Research}

The objective of this research was to design and evaluate the solar-assisted heat

pump (SAHP) system of the integrated mechanical system (IMS). Specifically, the study examined how the performance of the IMS was affected by the design of the solar collectors, the heat pump, and the storage tanks. The research contributed:

1. two journal papers regarding the following findings which were accepted for publication:

- a literature review of some of the past and current SAHP research; and

- sensitivity study results that revealed how the overall performance of the IMS was affected by various parameters of the system, such as tank size, collector size, and heat pump controls;

2. a computer model of the IMS system that was developed in TRNSYS (a simulation program that uses built-in subroutines to model the transient operation of a variety of energy components and systems [19]); and,

3. experimental analysis results that indicated the relationships between the heat pump load side flow rate, heat pump performance, and thermal stratification.

Following the experimental work of this study, the experimental set-up was transferred to ECHO and used for the Solar Decathlon 2013 Competition. The system also contributed to Team Ontario's achievement of first place in the Engineering contest and tied first place for the Hot Water contest. Throughout the competition, the system was able to maintain the indoor temperature and humidity within the comfort zone requirements for $93.3 \%$ of the time that measurements were taken.

Future work surrounding this project is summarized in Chapter 7. Quantifying the benefits of combining solar thermal collectors and a heat pump into a series 
SAHP for the IMS was not specifically examined in this study. In order to quantify the benefits, a more refined model of the IMS would need to be developed, and the simulated performance of the IMS should be compared to the performance of a system that uses the same solar thermal and heat pump components separately to meet the loads. An economic analysis was also not perform for system as the scope of the research focused on the performance of the system.

\subsection{Organization of Research}

The information presented in this thesis documents the research that was conducted over the span of two years. Over this period, two papers have been published in conference proceedings and have been accepted for journal publication. This thesis includes a compilation of results presented in these papers which are referenced throughout the document.

This thesis is divided into the following chapters:

Chapter 1: Introduction

Chapter 2: Literature Review

Chapter 3: Modelling Approach

Chapter 4: Experimental Approach

Chapter 5: Modelling and Experimental Results

Chapter 6: Discussion of Results

Chapter 7: Conclusions and Future Work

Appendices A through $\mathrm{H}$ present additional material that supports this research. A flowchart summarizing the approach of this study is shown in Figure 1.12. 


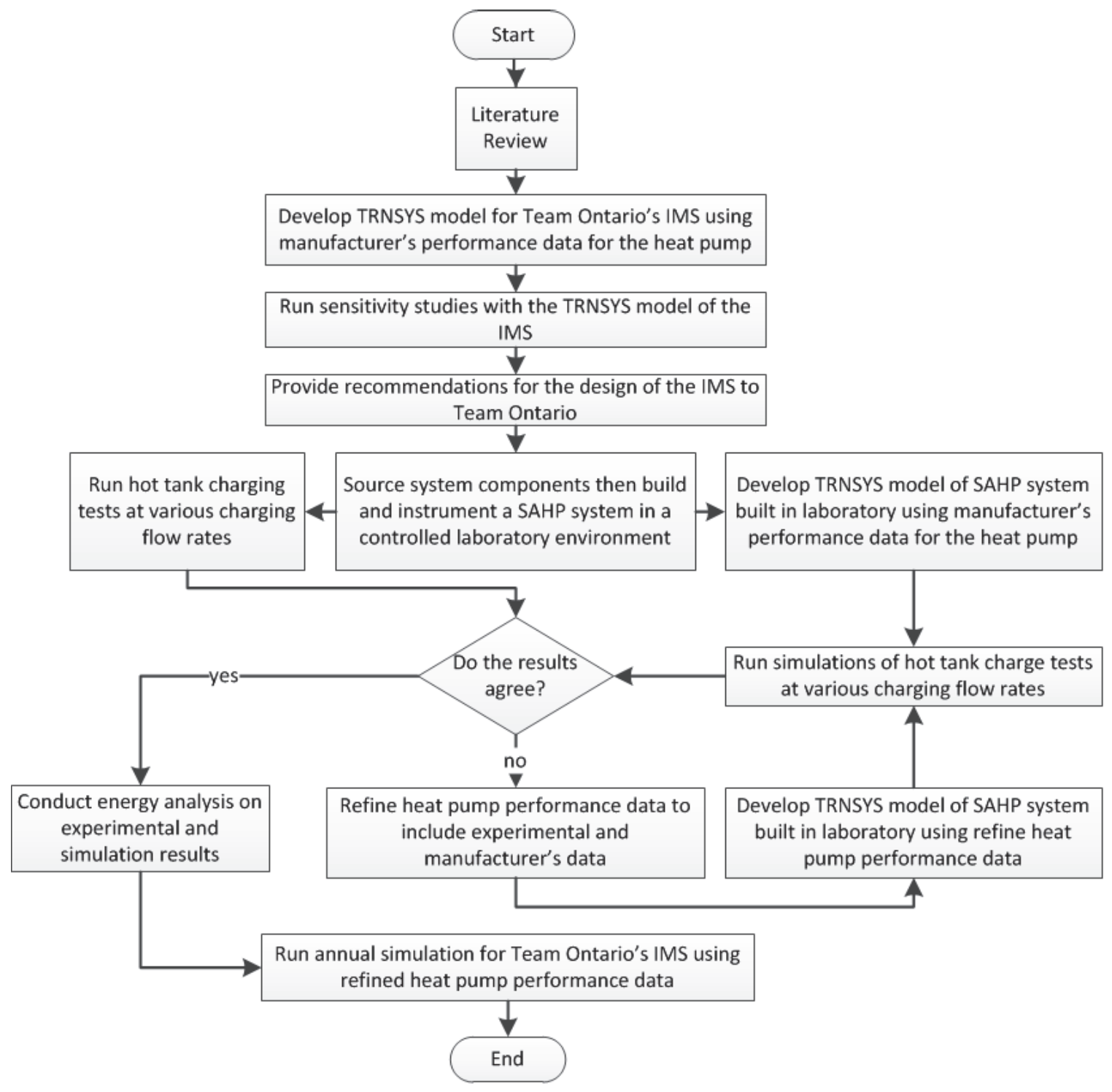

Figure 1.12: Research approach 


\section{Chapter 2}

\section{Literature Review}

The concept of solar-assisted heat pump (SAHP) systems can be dated back to the 1950s and extensive research on these systems began in the 1970s [6]. This chapter presents a review of past and current work on SAHP systems. Specifically, the key performance data from several studies are highlighted and different system configurations are compared in order to establish insight towards which system configurations are suitable for the Canadian residential sector.

Task 44 of the Solar Heating and Cooling (SHC) Programme of the International Energy Agency (IEA) aimed to optimize solar thermal and heat pump systems for single houses. This project was conducted in conjunction with the IEA Heat Pump Programme which referred to the task as Annex 38. The task, which operated between January 2010 to December 2013, focused on small-scale residential heating and hot water systems, available packaged systems, electrically driven heat pumps and advanced solutions [20]. In March of 2013, Task 44 released survey results from 135 market-available combined solar thermal heat pump systems that were available from 88 companies from 11 countries [21]. Although Canada was a participant of Task 44, the survey did not indicate that there were any market-available systems in Canada. About $13 \%$ of the systems surveyed were designed to only meet or offset DHW loads. 
Active or passive space-cooling capabilities were found in $58 \%$ of the systems. In terms of configurations, $61 \%$ of the systems were parallel only, $6 \%$ were series only, and $33 \%$ had a combination of parallel and series operation modes. Ground source heat pumps were incorporated in $34 \%$ of the systems. Of the surveyed systems, $47 \%$ used glazed flat plate collectors, $2 \%$ used evacuated tube collectors, and $36 \%$ of the systems could use either glazed flat plate or evacuated tube collectors. About $14 \%$ of the systems used either unglazed flat plate collectors, photovoltaic-thermal collectors, or others [21]. The task has also released a number of research publications since 2011 and these research studies are referred to throughout this chapter.

\subsection{Performance Metrics}

In literature, various performance metrics are used to characterize SAHP systems. The coefficient of performance, $C O P$, for the heat pump and the collector efficiency, $\eta$, indicate the performance of each component individually. Equations 2.1 and 2.2 are used to calculate these factors.

$$
C O P=\frac{\dot{Q}_{\text {load }}}{\dot{P}_{\text {comp }}}
$$

where $\dot{Q}_{\text {load }}$ is the heating rate of the heat pump to the load, in $\mathrm{kJ} / \mathrm{h}$, and $\dot{P}_{\text {comp }}$ is the electrical energy consumption rate required to run the compressor, in $\mathrm{kJ} / \mathrm{h}[7]$.

$$
\eta=\frac{\dot{Q}_{\text {coll }}}{A_{\text {coll }} \cdot I_{\mathrm{T}}}
$$

where $\dot{Q}_{\text {coll }}$ is the rate of energy collection, in $\mathrm{kJ} / \mathrm{h}, A_{\text {coll }}$ is the collector array area, in $\mathrm{m}^{2}$, and $I_{\mathrm{T}}$ is the global irradiance incident on the collector, in $\mathrm{W} / \mathrm{m}^{2}$ [5].

The collector performance can also characterized by the collector performance 
factor $(C P F)[6]$ which is the same as the collector efficiency (as calculated with Equation 2.2) but can have a value greater than 1. In the series systems, the $C P F$ can be greater than 1 since energy can also be collected from the outdoor ambient air.

Other metrics such as the solar fraction, the free energy fraction, and the seasonal performance factor are used to characterize the performance of an entire SAHP system. The solar fraction, $S F$, is the ratio of the total energy load, $Q_{\text {load, total }}$ in $\mathrm{kJ}$, met by useful solar energy collected by the collectors, $Q_{\text {coll }}$ in kJ [3]. The total energy load represents the energy requirements for space-heating, cooling and/or DHW.

$$
S F=\frac{Q_{\text {coll }}}{Q_{\text {load,total }}}
$$

The $S F$ does not account for the free energy that can be absorbed from ambient air. The free energy fraction, $F E F$, is the portion of the total loads that are met using all sources of free energy (solar energy and energy absorbed from ambient air) [6]. This fraction can be found from Equation 2.4.

$$
F E F=\frac{Q_{\text {coll }}+Q_{\text {air }}}{Q_{\text {load,total }}}=\frac{Q_{\text {load,total }}-Q_{\text {aux }}-P_{\text {comp }}-P_{\text {pump }}}{Q_{\text {load,total }}}
$$

where $Q_{\text {air }}$ is the energy collected from surrounding air, in $\mathrm{kJ}, Q_{\mathrm{aux}}$ is the auxiliary energy input, in kJ, and $P_{\text {pump }}$ is the energy required to operate any circulation pumps in the system, in kJ. Since the IMS also uses energy recovered from the cooling coils as a source of energy to charge the hot tank, the $F E F$ was used to characterize the performance of the system.

Some studies found in literature characterizes the performance of SAHP systems with the seasonal performance factor, $S P F$, which is the ratio of the total loads met by the system to the total electrical energy consumed [2]. Like the $F E F$, the $S P F$ 
is also suitable for describing the performance of an entire SAHP system.

$$
S P F=\frac{Q_{\text {load }, \text { total }}}{Q_{\text {aux }}+P_{\text {comp }}+P_{\text {pump }}}
$$

\subsection{Comparative Studies}

A comparative study examines SAHP system with differing configurations or components. The performances of these systems are compared using experiments or computer simulations to reveal which specific system has the potential of outperforming another specific system. Table 2.1 provides an overview of the system configurations and performances from the studies reviewed. For the system set-ups, only the characteristics found in the publications are listed. The following paragraphs also describe some key information regarding the studied systems.

Table 2.1: Summary of comparative studies (adapted from [22])

\begin{tabular}{|c|c|c|}
\hline Authors & SAHP Set-up & Performance \\
\hline $\begin{array}{l}\text { Freeman, } \\
\text { Mitchell, } \\
\text { and } \\
\text { Audit [23] }\end{array}$ & $\begin{array}{l}\text { Configurations: Liquid-based } \\
\text { parallel, series, and dual source } \\
\text { Heat Pump: } 3 \text { ton } \\
\text { Collector Type: Flat plate } \\
\text { Collector Area: } 0.075 \mathrm{~m}^{3} / \mathrm{m}^{2} \text { for the } \\
\text { ratio of storage size to collector area } \\
\text { Energy Storage: Water tank } \\
\text { Loads: DHW and space-heating (floor } \\
\text { area of } 120 \mathrm{~m}^{2} \text { ) } \\
\text { Climate: Madison, Wisconsin and } \\
\text { Albuquerque, New Mexico }\end{array}$ & $\begin{array}{l}\boldsymbol{F} \boldsymbol{E F} \text { : For collector areas between } 0 \\
\text { and } 60 \mathrm{~m}^{2}, 0.38 \text { to } 0.8 \text { in Madison and } \\
0.38 \text { to } 0.95 \text { in Albuquerque } \\
\boldsymbol{C O P} \text { of the Heat Pump: seasonal } \\
\text { average of } 2.0 \text { for parallel, } 2.53 \text { for } \\
\text { dual source and } 2.84 \text { for series } \\
\text { Collector Efficiency: about } 50 \% \text { for } \\
\text { series and dual source and } 30 \% \text { for } \\
\text { parallel in January ( } 10 \mathrm{~m}^{2} \text { collector } \\
\text { area) and annual efficiency of } 45 \% \text { for } \\
\text { series and dual source and } 35 \% \text { for } \\
\text { parallel ( } 10 \mathrm{~m}^{2} \text { collector area) }\end{array}$ \\
\hline
\end{tabular}




\begin{tabular}{|c|c|c|}
\hline Authors & SAHP Set-up & Performance \\
\hline $\begin{array}{l}\text { Chandra- } \\
\text { shekar, Le, } \\
\text { Sullivan, and } \\
\text { Hollands [24] }\end{array}$ & $\begin{array}{l}\text { Configurations: liquid-based } \\
\text { parallel, series, dual source and dual } \\
\text { storage and air-based parallel and dual } \\
\text { source configurations } \\
\text { Heat Pump: } 2,3 \text {, and } 3.5 \text { ton } \\
\text { Collector Type: Flat plate with } \\
\text { black painted absorber } \\
\text { Loads: DHW and space-heating (124 } \\
\mathrm{m}^{2} \text { single family residential dwelling } \\
\text { and a } 100 \mathrm{~m}^{2} \text { per unit, 10-unit } \\
\text { multiplex dwelling) } \\
\text { Climate: Vancouver, Edmonton, } \\
\text { Winnipeg, Toronto, Ottawa, Montreal, } \\
\text { and Fredericton }\end{array}$ & $\begin{array}{l}\text { The main performance criteria used } \\
\text { was the life cycle unit cost of energy } \\
\text { (LUC) which is the ratio of the total } \\
\text { cost (capital, maintenance, and energy } \\
\text { cost over the system) to the total } \\
\text { energy demand over the system life in } \\
\$ / \text { GJ. }\end{array}$ \\
\hline $\begin{array}{l}\text { Kaygusuz } \\
\text { and } \\
\text { Ayhan [25] }\end{array}$ & $\begin{array}{l}\text { Configurations: Same as those } \\
\text { examined by Freeman et al. [23] } \\
\text { Heat Pump: Hermetic driven with a } \\
1490 \mathrm{~W} \text { motor } \\
\text { Collector Type: Glazed flat plate } \\
\text { Collector Area: } 29.16 \mathrm{~m}^{2} \text { for } \\
\text { experimental and } 30 \mathrm{~m}^{2} \text { for simulation } \\
\text { Collector Orientation: Facing south } \\
\text { with a tilt of } 48^{\circ} \\
\text { Energy Storage: Phase change } \\
\text { material packings in a tank that has a } \\
\text { diameter of } 1.3 \mathrm{~m} \text { and a length of } \\
3.2 \mathrm{~m} \text { for experimental and } \\
\text { length/diameter ratio of } 2.46 \text { for } \\
\text { simulation } \\
\text { Loads: Space-heating } \\
\text { Climate: Trabzon, Turkey }\end{array}$ & $\begin{array}{l}\boldsymbol{F} \boldsymbol{E F}: 0.6,0.75 \text { and } 0.8 \text { for series, } \\
\text { parallel, and dual source systems, } \\
\text { respectively from simulations } \\
\boldsymbol{S P F}: 3.30,3.37 \text { and } 4.20 \text { for series, } \\
\text { parallel, and dual source systems, } \\
\text { respectively from simulations } \\
\boldsymbol{C O P} \text { of the Heat Pump: } 4.0,3.0 \\
\text { and } 3.5 \text { for series, parallel and dual } \\
\text { source systems, respectively from } \\
\text { simulations } \\
\text { Collector Efficiency: average } \\
\text { monthly values of } 0.56 \text { to } 0.64 \text { for } \\
\text { series and } 0.48 \text { to } 0.54 \text { for parallel from } \\
\text { experimental data. From simulations, } \\
\text { the average seasonal values for parallel } \\
\text { and series systems are } 50 \% \text { and } 60 \% \text {, } \\
\text { respectively. }\end{array}$ \\
\hline $\begin{array}{l}\text { Haller and } \\
\text { Frank [26] }\end{array}$ & $\begin{array}{l}\text { Configurations: Parallel, series and } \\
\text { dual source } \\
\text { Heat Pump: } 16 \mathrm{~kW} \\
\text { Collector Type: Covered and } \\
\text { uncovered flat plate } \\
\text { Collector Area: } 16 \mathrm{~m}^{2} \\
\text { Collector Orientation: Tilt of } 45^{\circ} \\
\text { Energy Storage: } 1000 \mathrm{~L} \\
\text { Loads: DHW and space-heating loads } \\
\text { from IEA-SHC Task } 32 \text { reference } \\
\text { system SFH } 100 \text { building } \\
\text { Climate: Zurich and Madrid }\end{array}$ & $\begin{array}{l}\text { The study focused on when it is } \\
\text { advantageous to switch from using } \\
\text { solar energy in a parallel configuration } \\
\text { to using the energy indirectly in a heat } \\
\text { pump. }\end{array}$ \\
\hline
\end{tabular}




\begin{tabular}{|c|c|c|}
\hline Authors & SAHP Set-up & Performance \\
\hline $\begin{array}{l}\text { Bertram, } \\
\text { Pärisch, and } \\
\text { Tepe [27] }\end{array}$ & $\begin{array}{l}\text { Configurations: } 3 \text { systems involving } \\
\text { flat plate collectors, borehole heat } \\
\text { exchanger (BHE) and a heat pump } \\
\text { Heat Pump: } 7.9 \mathrm{~kW} \\
\text { Collector Type: Flat plate } \\
\text { Energy Storage: } 150 \mathrm{~L} \text { without solar } \\
\text { and } 300 \mathrm{~L} \text { with solar } \\
\text { Loads: DHW and space-heating (floor } \\
\text { area of } 140 \mathrm{~m}^{2} \text { ) } \\
\text { Climate: Strasbourg, France }\end{array}$ & $\begin{array}{l}\boldsymbol{S P F} \text { (concept 1): about } 3.8 \text { to } 4.0 \\
\text { with BHE of } 110 \mathrm{~m} \text { and collector area } \\
\text { between } 5 \mathrm{~m}^{2} \text { and } 15 \mathrm{~m}^{2} \\
\boldsymbol{S P F}(\text { concept } 2): 4.95 \text { and } 5.21 \text { for } \\
5 \mathrm{~m}^{2} \text { and } 10 \mathrm{~m}^{2} \text { of collector area, } \\
\text { respectively and BHE of } 110 \mathrm{~m} \\
\boldsymbol{S P F} \text { (concept } 3 \text { ): about } 4.8 \text { with a } \\
5 \mathrm{~m}^{2} \text { collector area and } 110 \mathrm{~m} \text { BHE } \\
\boldsymbol{S F}: 65 \% \text { with } 5 \mathrm{~m}^{2} \text { of collectors (for } \\
\text { DHW) }\end{array}$ \\
\hline $\begin{array}{l}\text { Tamasaus- } \\
\text { kas, Poirer, } \\
\text { Zmeureanu, } \\
\text { and } \\
\text { Sunyé [28] }\end{array}$ & $\begin{array}{l}\text { Configurations: Indirect system } \\
\text { with an ice slurry in a tank } \\
\text { Collector Type: Flat plate } \\
\text { Collector Area: } 65.67 \mathrm{~m}^{2} \\
\text { Collector Orientation: Tilt of } \\
65.625^{\circ} \\
\text { Energy Storage: } 32.05 \mathrm{~m}^{3} \text { solar } \\
\text { thermal tank and } 1.5 \mathrm{~m}^{3} \text { warm water } \\
\text { tank } \\
\text { Loads: DHW and space-heating (floor } \\
\text { area of } 186 \mathrm{~m}^{2} \text { ) } \\
\text { Climate: Montreal, Quebec }\end{array}$ & $\begin{array}{l}\boldsymbol{S P F}: 8.22 \\
\boldsymbol{S F}: 0.88 \\
\boldsymbol{C O P} \text { of the Heat Pump: } 4.03 \text { with } \\
\text { the design evaporator inlet } \\
\text { temperature at } 0^{\circ} \mathrm{C} \text { and condenser } \\
\text { inlet temperature of } 20^{\circ} \mathrm{C} \\
\text { Collector Efficiency: } 0.43 \text { (seasonal) }\end{array}$ \\
\hline $\begin{array}{l}\text { Sterling and } \\
\text { Collins } \\
{[29,30]}\end{array}$ & $\begin{array}{l}\text { Configurations: Dual tank indirect } \\
\text { system and solar-side system } \\
\text { Collector Type: Flat plate } \\
\text { Collector Area: } 4 \mathrm{~m}^{2} \\
\text { Collector Orientation: Facing south } \\
\text { with a tilt of } 45^{\circ} \\
\text { Energy Storage: } 350 \mathrm{~L} \text { DHW tank } \\
\text { and } 500 \text { L float tank } \\
\text { Loads: DHW } \\
\text { Climate: Ottawa, Ontario }\end{array}$ & $\begin{array}{l}\boldsymbol{S F}: 0.67 \text { for the dual tank system and } \\
0.66 \text { for the solar-side system }\end{array}$ \\
\hline
\end{tabular}

A comparative study of SAHP systems for space-heating and DHW was undertaken by Freeman et al. [23]. For each of the three configurations investigated using TRNSYS, the collectors were used to charge a DHW tank through built-in internal heat exchanger contained within the tank. For the first configuration, parallel space-heating was used and therefore, hot water from the storage tank was used in a water-to-air heat exchanger (solar coil) to heat air. The air first passed the solar coil then passed the condenser of an air-source heat pump. This configuration is shown in 
Figure 2.1(a). In the series space-heating system, water from the tank was only used in the solar coil if the temperature of the tank was high enough. If the temperature of the tank was higher than the set minimum (usually just above freezing), but not high enough for space-heating directly, then a heat pump would source energy from the storage tank to heat air as shown in Figure 2.1(b). The third system, shown in Figure 2.2, used two evaporators allowing the heat pump to either source energy from the storage tank or from outdoor air. This is known as a dual source system. This set-up operated the same way as the series system but if the tank temperature was below the minimum temperature or the ambient temperature, the heat pump would draw energy from outdoor air. The results showed that the collector efficiency of the parallel system was significantly less than the efficiencies for the series and dual source systems. This difference can be attributed to the lower average storage temperatures for series and dual source systems. The results also showed that the series configuration displayed higher heat pump performance than the dual source because the minimum input temperature into the evaporator was $5^{\circ} \mathrm{C}$ for the series

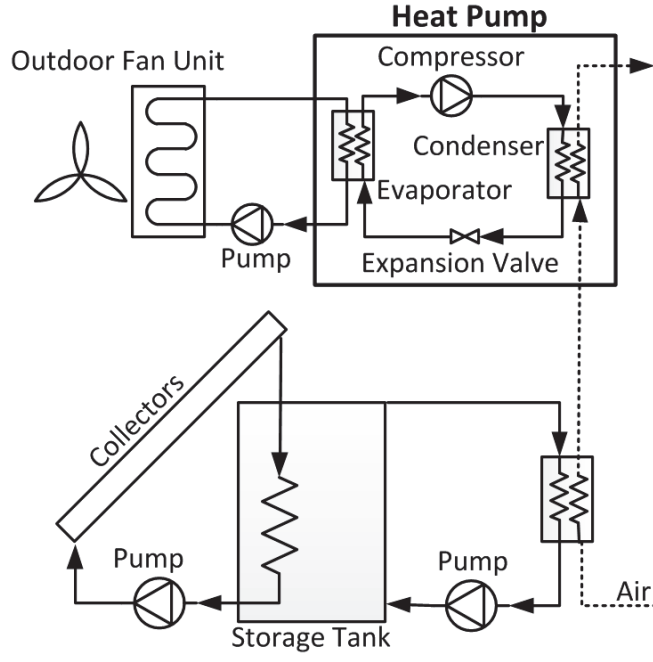

(a) Parallel

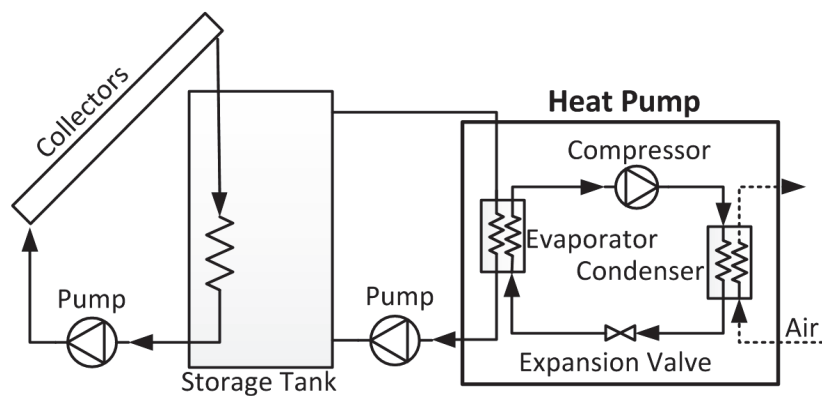

(b) Series

Figure 2.1: Schematic of solar-assisted heat pump space-heating systems (adpated from $[23])$ 


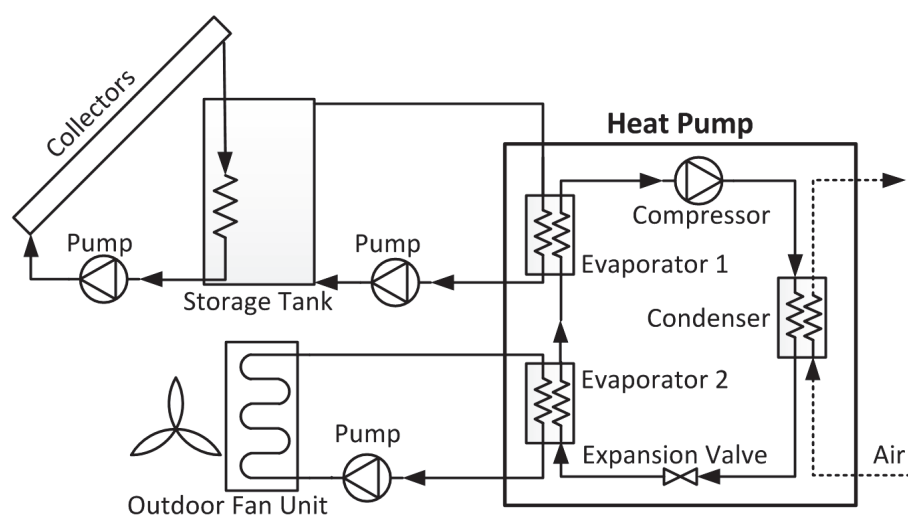

Figure 2.2: Schematic of dual source solar-assisted heat pump space-heating system (adpated from [23])

system. For the dual source system, the input temperature from the ambient air can be significantly lower than $5^{\circ} \mathrm{C}$. The parallel system had slightly higher FEFs than the series and dual source systems. Freeman et al. [23] noted that in the series and dual source systems, work input into the heat pump was required to deliver the collected solar energy to the space whereas for the parallel system, direct heating from the solar coil did not required additional heat pump work. The operation of the heat pump will always require energy input even with better $C O P$. With the parameters used in this study, it appeared to be more advantageous to use collected solar energy to directly offset loads to reduce heat pump operation [23].

Chandrashekar et al. [24] studied SAHP systems for space-heating and DHW requirements in Canadian cities. The software WATSUN was used to examine six different configurations which included liquid and air-based systems. The air-based systems had the option of directly using heated air from the collectors for spaceheating. Simulations for all systems were conducted for Vancouver and Winnipeg. Simulation results for a single family dwelling in Winnipeg indicated that liquidbased systems outperform air-based systems in terms of the life cycle unit cost of energy. Based on unit cost of energy, a liquid-based dual source system was the 
best configuration. This conclusion differs from the findings by Freeman et al. [23]. Chandrashekar et al. noted that the combination of higher collector efficiencies and $C O P$ of the heat pump of the dual source system outweighed the disadvantage of having to use the heat pump to deliver solar energy for space-heating. In Vancouver, however, the parallel system achieved better energy savings. Air-based and liquidbased dual source systems were chosen for further simulations for Edmonton, Toronto, Ottawa, Montreal and Fredricton but it was found that the system performances were insensitive to location [24].

Kaygusuz and Ayhan [25] presented findings from an experimental set-up that was assembled to investigate the performance of SAHP systems used for space-heating. The computer program, BASIC, was also used to conduct a comparative study of the experimental system. For the same reason indicated by Freeman et al. [23], it was found that the $C O P$ of the series system is higher than the dual source system [25].

As part of IEA SHC Programme Task 44, Haller and Frank [26] presented a mathematical relationship for determining whether using solar energy for the evaporator was more beneficial than using it directly to meet loads. The study examined a dual source system that can switch its operation between parallel and series. The system was modelled using TRNSYS and it was found that the use of solar energy for the evaporator is only advantageous if the $C O P$ of the heat pump increases by 1 while the collector efficiency simultaneously increases by $150 \%$ relative to the parallel configuration. Also, if the irradiation level is below a certain limit, indirect use of solar energy is more advantageous to the system's performance factor. The value of the limit depends on the heat pump and the collector characteristics. Simulation results suggested that in series, the use of uncovered collectors was more beneficial. It was concluded that the series operation improved performance by increasing the runtime of the collectors [26]. 
Also part of IEA SHC Programme Task 44, Bertram et al. [27] used TRNSYS to conduct a simulation study of three system concepts involving flat plate collectors, borehole heat exchangers (BHEs), and a heat pump. Energy from the BHEs was used for the evaporator of the heat pump. The heat pump supplied energy to the DHW tank and to the floor heating system. In the first concept, the collectors charged the BHEs which supply the energy to the heat pump. For the second concept, the heat pump still draws energy from the BHEs but the collectors are parallel to the heat pump to charge the DHW tank directly. For the third concept, which is a combination of the first two concepts, the collectors would charge the BHEs when the collector temperature is not high enough to charge the DHW tank. It was found that the performance of concept three was slightly lower than the performance of concept two. This was due to the lower amount of solar energy delivered to the storage. The results indicated that it is more beneficial to use solar energy directly rather than using it to charge BHEs [27].

Tamasauskas et al. [28] presented a model developed for an indirect SAHP using an ice slurry in a float tank. A float tank, like the cold tank of the IMS, is charged with collectors and serves as an energy source for the heat pump. The study compared this system with the same system that used a sensible storage instead. A heat pump extracted energy from the float tank and to heat a warm water tank. If the output temperatures from the collectors were high enough, then the collector fluid would bypass the ice tank and the heat pump to directly heat the warm water tank. The system was designed for radiant floor space-heating. A mathematical model of the ice tank was developed and implemented in TRNSYS and simulations were conducted for the heating season. Compared to the electric heater, the SAHP system with the sensible storage and the system with an ice tank storage reduced the energy consumption by $81 \%$ and $86 \%$, respectively [28]. 
Also using TRNSYS, Sterling and Collins [29] investigated the feasibility of a dual tank indirect SAHP system for DHW requirements. The system was compared to an electric DHW system and a traditional solar thermal system. The dual tank configuration used collectors to charge a float tank and energy from this tank was transferred to a DHW tank either through a heat exchanger or a heat pump. If the temperature of the float tank was above $55^{\circ} \mathrm{C}$ the DHW would be charged through the heat exchanger. In a thesis paper by Sterling [30], a solar-side indirect SAHP system was added to the comparison. This system, as shown in Figure 2.3, has the same configuration as the solar thermal system except a heat pump was added in parallel to the collectors. The evaporator removed energy from the stream of working fluid entering the collectors and the energy was transferred to the stream of fluid exiting the collectors. The heat pump used for the solar-side system had a lower capacity than the one used for the dual tank system. The dual tank system showed increased collector efficiencies, collector run times and tank losses. It was noted that the dual

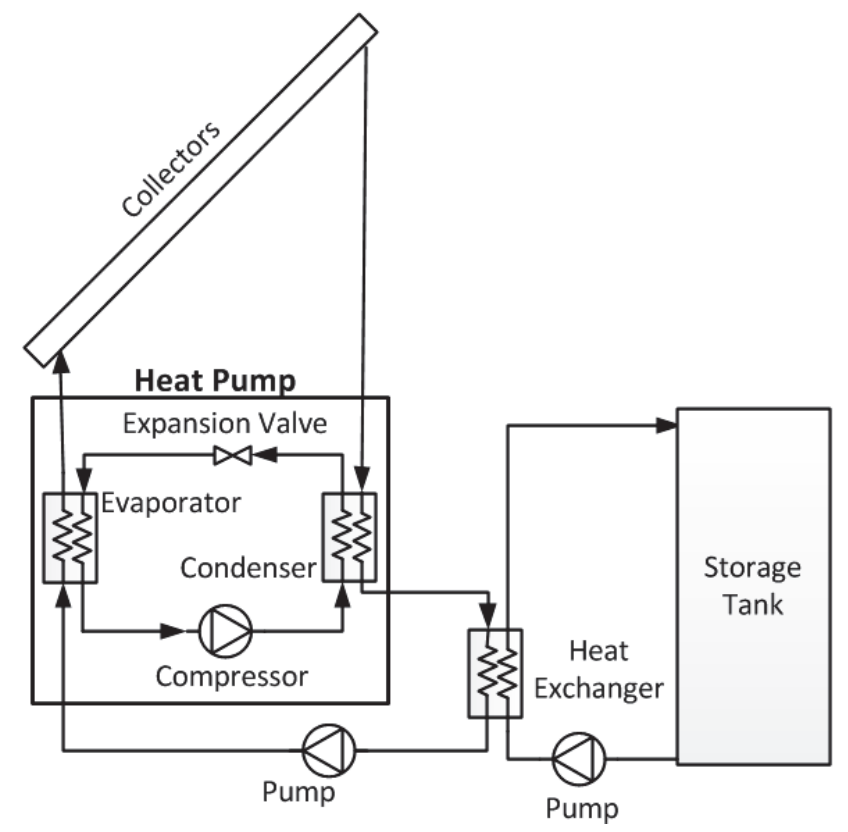

Figure 2.3: Schematic of solar-side solar-assisted heat pump (adpated from [30]) 
tank system had longer run times in the winter and the solar-side system had longer runtimes in the summer. Compared to the dual tank system, the solar-side system had lower tank losses and consumed less electrical energy. It was concluded that the SAHP systems were more energy efficient than the standard electric water heater and the standard solar thermal system [30].

From three comparative studies previously discussed, Freeman et al. concluded that the parallel configuration had the best FEF [23], Kaygusuz and Ayhan showed that the dual source system could achieve a better FEF than the parallel system [25] and Chandrashekar et al. noted that the parallel system achieved better energy savings in the milder Vancouver climate while the dual source system achieved better energy savings in the colder Winnipeg climate [24]. These studies suggest that the most suitable configuration for Canadian residential buildings or any other application depend on a combination of factors which may include occupant behaviour, building characteristics, operation parameters, system components and climate [22]. In these studies, the differences in these factors led to differing results and conclusions. Haller and Frank indicated that the series configuration is only advantageous if the COP of the heat pump increases by 1 while the collector efficiency simultaneously increases by $150 \%$ compared to the parallel configuration [26]. However, these performance criteria also depend on the factors listed above. Bertram et al. [27], Tamasauskas et al. [28], and Sterling and Collins [29] presented studies focusing on other nonconventional configurations or system parameters that can be implemented to improve performance. Tamasauskas et al. [28] concluded that the SAHP system outperformed the use of an electric heater and Sterling and Collins [29] noted that the SAHP systems studied were more energy efficient than a standard electric water heater and a standard solar thermal system. 


\subsection{Direct Solar-Assisted Heat Pump System}

\section{Studies}

Table 2.2 provides a summary of the system configurations and performances from some studies that focused on direct systems. Again, for SAHP set-up, only characteristics found in the referred publications are listed.

Table 2.2: Summary of direct systems: system set-up and performances (adapted from $[22])$

\begin{tabular}{|c|c|c|}
\hline Authors & SAHP Set-up & Performance \\
\hline $\begin{array}{l}\text { Huang and } \\
\text { Chyng [31] }\end{array}$ & $\begin{array}{l}\text { Heat Pump: Equipped with a } 150 \mathrm{~W} \\
\text { compressor } \\
\text { Collector Type: Unglazed } \\
\text { tube-in-sheet } \\
\text { Collector Area: } 1.44 \mathrm{~m}^{2} \\
\text { Energy Storage: } 120 \mathrm{~L} \\
\text { Loads: DHW }\end{array}$ & $\begin{array}{l}\text { COP of the Heat Pump: } 2.54 \\
\text { when solar radiation was at its highest } \\
\text { and the highest COP reached was } 3.83\end{array}$ \\
\hline $\begin{array}{l}\text { Guoying, } \\
\text { Xiaosong, } \\
\text { and } \\
\text { Shiming [33] }\end{array}$ & $\begin{array}{l}\text { Heat Pump: Rotary type with a } \\
\text { rated capacity of } 400 \mathrm{~W} \\
\text { Collector Type: Flat plate with } \\
\text { spiral-finned tubes } \\
\text { Collector Area: } 2.2 \mathrm{~m}^{2} \\
\text { Energy Storage: } 150 \mathrm{~L} \\
\text { Loads: DHW } \\
\text { Climate: Nanjing, China }\end{array}$ & $\begin{array}{l}\text { COP of the Heat Pump: } 4.32 \text { on } \\
\text { sunny days in the shoulder season, } \\
4.69 \text { on sunny, summer days, } 3.83 \text { on } \\
\text { sunny, winter days and } 3.3 \text { on } \\
\text { overcast, winter days }\end{array}$ \\
\hline $\begin{array}{l}\text { Hawlader, } \\
\text { Chou, and } \\
\text { Ullah [34] }\end{array}$ & $\begin{array}{l}\text { Heat Pump: Variable speed } \\
\text { compressor } \\
\text { Collector Type: Unglazed flat plate } \\
\text { Collector Area: } 3 \mathrm{~m}^{2} \text { for experiment } \\
\text { and various for simulation } \\
\text { Collector Orientation: Facing } \\
\text { south, tilt angle of } 10^{\circ} \text { for simulation } \\
\text { Energy Storage: } 250 \mathrm{~L} \text { for } \\
\text { experimental and various for } \\
\text { simulation } \\
\text { Loads: DHW } \\
\text { Climate: Singapore }\end{array}$ & $\begin{array}{l}\boldsymbol{S F}: 0.2 \text { to } 0.75 \text { (collector areas } \\
\text { ranging from } 3 \mathrm{~m}^{2} \text { to } 6 \mathrm{~m}^{2} \text { and storage } \\
\text { volume from } 75 \mathrm{~L} \text { to } 1650 \mathrm{~L} \text { ) } \\
\text { COP of the Heat Pump: } 4 \text { to } 9 \text { for } \\
\text { tank temperatures between } 30^{\circ} \mathrm{C} \text { and } \\
50^{\circ} \mathrm{C} \\
\text { Collector Efficiency: } 40 \% \text { to } 75 \% \\
\text { for tank temperatures between } 30^{\circ} \mathrm{C} \\
\text { and } 50^{\circ} \mathrm{C}\end{array}$ \\
\hline
\end{tabular}




\begin{tabular}{|c|c|c|}
\hline Authors & SAHP Set-up & Performance \\
\hline $\begin{array}{l}\text { Kuang and } \\
\text { Wang [35] }\end{array}$ & $\begin{array}{l}\text { Heat Pump: } 3 \text { HP rotary type } \\
\text { hermetic compressor } \\
\text { Collector Type: Unglazed flat plate } \\
\text { Collector Area: } 10.5 \mathrm{~m}^{2} \\
\text { Collector Orientation: Facing south } \\
\text { on tilted roof } \\
\text { Energy Storage: } 200 \mathrm{~L} \text { DHW tank } \\
\text { and } 1000 \mathrm{~L} \text { heat storage tank } \\
\text { Loads: DHW, space-heating, and } \\
\text { cooling } \\
\text { Climate: Shanghai, China }\end{array}$ & $\begin{array}{l}\text { SPF: } 2.1 \text { to } 3.5 \text { from an overcast day } \\
\text { to a sunny day in water heating mode } \\
\text { and } 2.1 \text { to } 2.7 \text { in space-heating mode } \\
\boldsymbol{C O P} \text { of the Heat Pump: } 2.6 \text { to } 3.3 \\
\text { for space-heating mode and } 2.9 \text { for } \\
\text { night-time operation in cooling mode }\end{array}$ \\
\hline $\begin{array}{l}\text { Chow, Pei, } \\
\text { Fong, Lin, } \\
\text { Chan, and } \\
\text { He }[36]\end{array}$ & $\begin{array}{l}\text { Heat Pump: } 1 \mathrm{~kW} \\
\text { Collector Area: } 12 \mathrm{~m}^{2} \\
\text { Collector Orientation: tilt } 25^{\circ} \\
\text { Energy Storage: } 2500 \mathrm{~L} \\
\text { Loads: DHW } \\
\text { Climate: Hong Kong }\end{array}$ & $\begin{array}{l}\boldsymbol{S P F}: \text { greater than } 10 \text { for maximum } \\
\text { instantaneous, } 7.50 \text { for July average, } \\
5.47 \text { for January average and } 6.46 \text { for } \\
\text { the annual average }\end{array}$ \\
\hline $\begin{array}{l}\text { Fernàndez- } \\
\text { Seara, } \\
\text { Piñeiro, } \\
\text { Albert } \\
\text { Dopazo, } \\
\text { Fernandes, } \\
\text { and } \\
\text { Sousa [37] }\end{array}$ & $\begin{array}{l}\text { Heat Pump: Rotary-type hermetic } \\
\text { compressor ( rated at 390-550 W) } \\
\text { Collector Area: } 1.6 \mathrm{~m}^{2} \\
\text { Energy Storage: } 300 \mathrm{~L} \\
\text { Loads: DHW }\end{array}$ & $\begin{array}{l}\boldsymbol{S P F}: 2.11 \text { with average ambient } \\
\text { temperature of } 7.8^{\circ} \mathrm{C} \text { and } 3.01 \text { with } \\
\text { temperature of } 21.9^{\circ} \mathrm{C} \\
\boldsymbol{C O P} \text { of the Heat Pump: } 2.44 \text { with } \\
\text { average ambient temperature of } 7.8^{\circ} \mathrm{C} \\
\text { and } 3.30 \text { with temperature of } 21.9^{\circ} \mathrm{C}\end{array}$ \\
\hline
\end{tabular}

Huang and Chyng [31] designed and tested a direct SAHP system containing a thermosyphon loop that was used to transfer heat from the condenser to a DHW storage tank. Tests showed that the $C O P$ of the heat pump initially increased with increasing solar radiation but eventually reached a saturation point. Huang and Lee [32] presented long-term test results of this system but with a $250 \mathrm{~W}$ compressor and $105 \mathrm{~L}$ storage tank. The electricity consumption per litre of hot water ranged from 0.01 to $0.03 \mathrm{kWh}$. The electricity consumption per litre increased on overcast days and when loads were decreased. A smaller load would cause the initial temperature in the tank to be higher which decreases the $C O P$ of the heat pump. The importance of properly sizing the system for the loads was emphasized [32]. 
Guoying et al. [33] developed a mathematical model of a SAHP water heating system. For each simulation conducted, the solar radiation and ambient temperature were set as constants depending on the season and weather. The initial temperature of the water tank was assumed to be equivalent to the ambient temperature. The simulations were conducted to determine the time and energy required to charge the tank to $55^{\circ} \mathrm{C}$. On sunny days in the shoulder season, about $1.45 \mathrm{kWh}$ of energy was consumed and 3.5 hours was required to charge the tank. Of the energy absorbed by the collectors, $9 \%$ was from the ambient air. To charge the tank on sunny, summer days, $0.75 \mathrm{kWh}$ of energy and 75 minutes was required and $21 \%$ of the energy absorbed by the collector was from ambient air. On sunny, winter days, the total energy consumption was $2.22 \mathrm{kWh}$, the time required was 7 hours and portion of energy absorbed from ambient air was 31\%. On overcast, winter days, 9 hours were required to charge the tank. About $85 \%$ of the energy collected was from the ambient air and $2.81 \mathrm{kWh}$ of energy was consumed [33].

Hawlader et al. [34] conducted an experimental study of a direct SAHP system for DHW. The tank was considered the condenser of the system as the refrigerant of the heat pump passes through an internal heat exchanger within the tank. In addition to the experimental set-up, a mathematical model was developed to investigate the influence of different parameters [34]. Findings of this study can be found in Table 2.2 .

Kuang and Wang [35] experimentally studied the performance of a multifunctional direct SAHP system which can be used for space-heating, cooling and DHW. In the water heating mode, the collectors served as the evaporators and, like the system studied by Hawlader, Chou and, Ullah [34], a DHW tank served as the condenser. For space-heating, collectors were used as the evaporator and heat was delivered to the space through a radiant floor. The system also had a forced-air heat 
exchanger to act as an evaporator when solar gain was insufficient. For cooling, the collectors were used as the condenser and rejected heat outside at night-time. A water-to-refrigerant plate heat exchanger was the evaporator and produced cooling water that would be used in a fan-coil unit for indoor cooling. The water used for space-heating and cooling was stored in a heat storage tank until required. In this study, the performance of the system for each mode was investigated individually. For water heating on a typical sunny day in spring, the temperature of the DHW tank reached $50^{\circ} \mathrm{C}$ in less than an hour and on overcast days, about two hours was required. The space-heating mode was tested for five days in February. The cooling mode was tested for two days. It was found that that the cold energy stored during the night-time was insufficient for the cooling load [35].

Chow et al. [36] presented modelling results for a SAHP system for DHW requirements in Hong Kong. Like Hawlader et al. [34] and Kuang and Wang [35], the condenser of this system was a water storage tank. For these annual simulations, no water was drawn from the tank during the daytime until outlet water reaches $50^{\circ} \mathrm{C}$. Water at ambient temperature was used to replace water drawn from the tank [36].

Fernández-Seara et al. [37] presented an experimental evaluation of a direct SAHP system during no solar radiation conditions. The system also used the storage tank as the condenser. The collectors were placed in a climate chamber where the average ambient temperature in the chamber was varied from $7^{\circ} \mathrm{C}$ to $22^{\circ} \mathrm{C}$ and the relative humidity was kept at $55 \%$. At the beginning of each test, the tank was filled with mains water. Each test continued until the water temperature reached $55^{\circ} \mathrm{C}$. It was found that as the ambient temperature increased, the time required for heating decreased and the $C O P$ of the heat pump and of the system increased [37].

The studies presented for direct systems show promising performances, however, these studies were conducted in Singapore, Taiwan, Shanghai, Nanjing, and Hong 
Kong and all these places experience milder climates than those typically experienced in Canada. There were no studies found for direct SAHP systems in a Canadian climate. In Canada, solar collectors require an antifreeze working fluid and a direct system requires the refrigerant of the heat pump to be the working fluid of the collector.

\subsection{Indirect Solar-Assisted Heat Pump System}

\section{Studies}

An overview of the system configurations and performances from several studies on indirect systems are presented in Table 2.3.

Table 2.3: Summary of indirect systems: system set-up and performances (adapted from $[22])$

\begin{tabular}{|c|c|c|}
\hline Authors & SAHP Set-up & Performance \\
\hline $\begin{array}{l}\text { Bridgeman } \\
{[11]}\end{array}$ & $\begin{array}{l}\text { Heat Pump: } 617 \mathrm{~W} \\
\text { Collector Type: } 3500 \mathrm{~W} \text { electric heater in } \\
\text { place of the collectors for experimental work } \\
\text { and various sizes of collectors were used for } \\
\text { simulations } \\
\text { Collector Orientation: Facing south, tilt } \\
\text { of } 10^{\circ} \text { to } 80^{\circ} \text { for simulations } \\
\text { Energy Storage: } 270 \mathrm{~L} \text { for experimental } \\
\text { work and various sizes for simulations } \\
\text { Loads: DHW } \\
\text { Climate: Toronto, Vancouver, Montreal, } \\
\text { Winnipeg and Halifax for simulations }\end{array}$ & $\begin{array}{l}\boldsymbol{F E F}: 0.546,0.556 \text { and } 0.521 \text { for } \\
\text { daily DHW draws of } 240 \mathrm{~L}, 300 \\
\mathrm{~L} \text { and } 350 \mathrm{~L} \text {, respectively and } \\
\text { storage tank of } 360 \mathrm{~L} \text { (from } \\
\text { simulations). Depending on } \\
\text { collector tilt the } F E F \text { ranged } \\
\text { from } 0.501 \text { to } 0.524 \text { in Toronto } \\
\text { (from simulations) } \\
\boldsymbol{C O P} \text { of Heat Pump: ranged } \\
\text { from } 2.3 \text { to } 3.3 \text { (from } \\
\text { experimental work) }\end{array}$ \\
\hline $\begin{array}{l}\text { Bakirchi and } \\
\text { Yuksel [38] }\end{array}$ & $\begin{array}{l}\text { Heat Pump: Compressor driven by a } 1491 \\
\text { W motor } \\
\text { Collector Area: twelve } 1.64 \mathrm{~m}^{2} \text { collectors } \\
\text { Collector Orientation: Facing south, tilt } \\
\text { angle of } 50^{\circ} \\
\text { Energy Storage: } 2000 \mathrm{~L} \\
\text { Loads: Space-heating (floor area of } 175 \mathrm{~m}^{2} \text { ) } \\
\text { Climate: Erzurum, Turkey }\end{array}$ & $\begin{array}{l}\boldsymbol{S P F}: 2.5 \text { to } 2.9 \text { (monthly } \\
\text { average) } \\
\boldsymbol{C O P} \text { of Heat Pump: } 3.3 \text { to } \\
3.8 \text { (monthly average) } \\
\text { Collector Efficiency: } 0.38 \text { to } \\
0.60 \text { (monthly average) }\end{array}$ \\
\hline
\end{tabular}




\begin{tabular}{|l|l|l|}
\hline \multicolumn{1}{|c|}{ Authors } & \multicolumn{1}{|c|}{ SAHP Set-up } & \multicolumn{1}{c|}{ Performance } \\
\hline $\begin{array}{l}\text { Wang, Liu, } \\
\text { Liang, Sun, } \\
\text { and } \\
\text { Chen [39] }\end{array}$ & $\begin{array}{l}\text { Heat Pump: Hermetic rotary compressor, } \\
\text { displacement volume of } 22.5 \mathrm{~cm}^{3} \\
\text { Energy Storage: } 150 \mathrm{~L} \\
\text { Loads: DHW, space-heating, and cooling }\end{array}$ & $\begin{array}{l}\text { COP: approaching 4 (heating } \\
\text { mode only) }\end{array}$ \\
\hline $\begin{array}{l}\text { Loose, } \\
\text { Drück, }\end{array}$ & $\begin{array}{l}\text { Configuration: Integrated system with } 75 \\
\text { Hanke, and } \\
\text { Thole [40] }\end{array}$ & $\begin{array}{l}\text { Heat Pump: } 5 \mathrm{~kW} \\
\text { Collector Area: } 11 \mathrm{~m}^{2} \\
\text { Energy Storage: } 750 \mathrm{~L}\end{array}$ \\
& $\begin{array}{l}\text { Loads: DHW and space-heating (floor area } \\
\left.\text { of } 140 \mathrm{~m}^{2}\right) \\
\text { Climate: Herford, Germany }\end{array}$ & \\
\hline
\end{tabular}

Bridgeman [11] conducted an in-laboratory, experimental investigation of an indirect SAHP system for DHW. The system used natural convection to drive the flow between the condenser and the storage tank. Stratification of the tank was achieved due to the low flow rates from the natural convection loop. During each test, it was found that the flow rate through the natural convection loop began at about 0.0125 $\mathrm{kg} / \mathrm{s}$ and dropped off to about $0.008 \mathrm{~kg} / \mathrm{s}$ at the end of the test. In addition to the experiments, a TRNSYS model of the system was created. Annual simulations were conducted for the climate in Toronto. The FEF was the highest with a 360 L tank. Annual simulations were also conducted for the cities of Vancouver, Montreal, Winnipeg and Halifax. The system performed approximately the same for all cities between the months March and October. Outside of these months, the system performed the best in Halifax, roughly the same in Montreal and Vancouver and the worst in Winnipeg. It was noted that Winnipeg tends to experience colder weather which would result in lower collector temperatures due to heat loss [11].

Bakirchi and Yuksel [38] conducted an experimental study of an indirect SAHP system for space-heating. The collectors of this system were used to directly charge a storage tank. The storage tank is connected to the evaporator to act as the heat 
source for the heat pump and heat was delivered to the space through a radiator [38].

Wang et al. [39] presented a novel, multi-functional system that can provide DHW, space-heating and cooling. For space-heating, the heat pump had two evaporators which drew energy from the ambient air and from a storage tank. The storage tank can either be charged with solar collectors or with the heat pump sourcing energy from outdoor ambient air. Water from this same storage tank was also used for DHW. For space cooling, a liquid-to-air evaporator heat exchanger cools the indoor air. The heat pump system then transfers the heat to the storage tank through a condenser heat exchanger. An experimental set-up was created and results for the heat pump water heating and solar-assisted space-heating modes were presented. Like Bridgeman's study [11], an electric heater was used to simulate solar input. For the solar-assisted space-heating mode, the compressor began to run after the water in the tank reached $35^{\circ} \mathrm{C}$ from the simulated solar input to provide space-heating. The experimental results suggest that the system could run with high efficiency and heat capacity in the winter if the solar radiation intensity was high [39].

As part of IEA SHC Programme Task 44, the results of completed and ongoing field tests for different combined solar and heat pump system concepts with different heat sources were presented by Loose et al. [40]. One system made use of collectors and a geothermal heat pump with a borehole heat exchanger. The system was used to provide DHW and space-heating to a new building with radiant floor heating. When sufficient solar energy was available, the collectors would charge the storage directly. When the collectors were running at lower temperatures that were not high enough to heat the storage, the low grade energy from the collectors would be used in the heat pump for space-heating. At instances when the storage tank reached its energy storage capacity and the heat pump was not in operation, the collectors would be used to charge the borehole heat exchanger. After the summer, the heat pump would 
source heat from the boreholes. This installation showed promising results after a three year monitoring period. The solar regeneration of the ground ensured that the heat pump could operate long term with a high SPF [40].

The studies of indirect systems presented mainly focused on the design and evaluation of the systems. Therefore, these studies did not compare the SAHP systems to more convention systems to determine the benefits of combining the solar thermal and heat pump technologies. Several of the studies presented for indirect systems as well as systems examined in the comparative studies were conducted for Canadian climates. However, none of the systems presented examined a dual tank indirect SAHP system that was designed to offset the combination of DHW, space-heating, and cooling loads for a residential house in the Canadian Climate.

\subsection{Literature Review Summary}

Since 2011, Task 44 of the SHC Programme within the IEA has released a number of studies that investigated solar thermal and heat pump systems for residential use. Extensive research of SAHP systems have also been conducted at various institutions worldwide. A broad range of system configurations and performances were presented. The comparative studies of parallel, series, and dual source systems suggest that the most suitable configuration for Canadian residential buildings depend on a combination of factors which may include occupant behaviour, building characteristics, operation parameters, system components, and climate [22]. Several of the studies

presented were conducted for Canadian climates [11,24,28-30] but all of these studies were for indirect series systems. The direct system was not considered for the design of the IMS for ECHO because of the need of an antifreeze solution for the working fluid of the solar collectors. The studies of direct systems were mainly conducted in 
climates that are milder than those experienced by most Canadian cities.

The studies of indirect systems for Canadian cities and the other cities presented showed promising results, however, from this review, it was found that different authors used various performance metrics and this inconsistency adds to the difficulty of comparing the studies of different systems. Task 44 of the IEA SHC Programme included Subtask B which focused on the assessment of the solar thermal and heat pump systems. This subtask aimed to reach a common definition regarding the performance metrics of these systems and establish how these systems should be assessed. At the time of publication of this thesis, the findings from Subtask B were not yet available. For the study of the IMS, the $F E F$ was the performance metric used in order capture the performance of not only the heat pump but the entire IMS.

Based on literature alone, the variety of configurations and parameters that exist made it challenging to compare the systems and establish an optimal configuration for a certain building or climate [22]. For the research presented in this thesis, simulation was used to design a system that was tailored for ECHO. Even though dual storage indirect systems were studied in the past by Tamasauskas et al. [28] and Sterling and Collins [29] for the Canadian climate, the research presented in this thesis uses the system for the combination of space-heating, cooling, and DHW requirements as opposed to just offsetting energy consumption for space-heating or DHW. 


\section{Chapter 3}

\section{Modelling Approach}

A model was developed to investigate the performance of the integrated mechanical system (IMS) for Team Ontario's Solar Decathlon 2013 Competition entry [17]. The model of the system was created in TRNSYS (TRaNsient SYstem Simulation) 17, which is a simulation program that uses built-in subroutines to model the transient operation of a variety of energy components and systems [19].

The model of the IMS was used to conduct a sensitivity study to examine how varying certain parameters, such as tank and collector sizes, can affect the annual performance. System design recommendations were provided to Team Ontario based

on the results [17]. This chapter will described the model developed and some of the equations used in the subroutines to model the key components of the system such as the collectors, the heat pump, and the tanks.

\subsection{The TRNSYS Simulation Program}

TRNSYS was selected because of its ability to model complex systems. TRNSYS allows the user to alter component parameters and customize system configurations. The TRNSYS model was set up using a graphical interface in which object "Types" 
are chosen from a library and linked to each other. A TRNSYS Type is a pre-defined mathematical subroutines that represent a physical component in the system. Each Type uses parameters, inputs, and outputs in the calculations. Parameters are set by the user and they do not change during the simulation. Inputs are variables which are defined by the outputs of other Types through links. The output variables are those calculated by a Type. The links between the Types are used to pass data, such as temperature and flow rate, from one Type to another. For each model developed, a "deck" file containing all the simulation components, component parameters, and initial conditions is created. The TRNSYS simulation engine reads the deck file and initiates the simulation in user-defined time-steps. For each time-step, the equations of all the components are solved iteratively until convergence is achieved. Results from each simulation are provided in an output file [19].

\subsection{Model of the Integrated Mechanical System}

The graphical representation of the TRNSYS model is shown in Figure 3.1. The data output and control components are hidden in Figure 3.1 to reduce congestion of Types and connections. Figure A.1 of Appendix A shows the complete graphical interface of the model and Table A.1 lists and describes the key Types that were used. Simulations were conducted at 3 minute time-steps. A study of the system performance as a function of simulation time-steps can be found in Appendix B. This study showed that the shorter the time-step, the more accurately the simulation would model the system in real-life operation as sudden fluctuations can be captured. The 3 minute time-step was chosen to reduce simulation time and the final results from simulating with 1 minute time-steps and 3 minute time-steps only differed by $0.02 \%$. Appendix C contains the simulation deck file for the IMS model. The simulations 


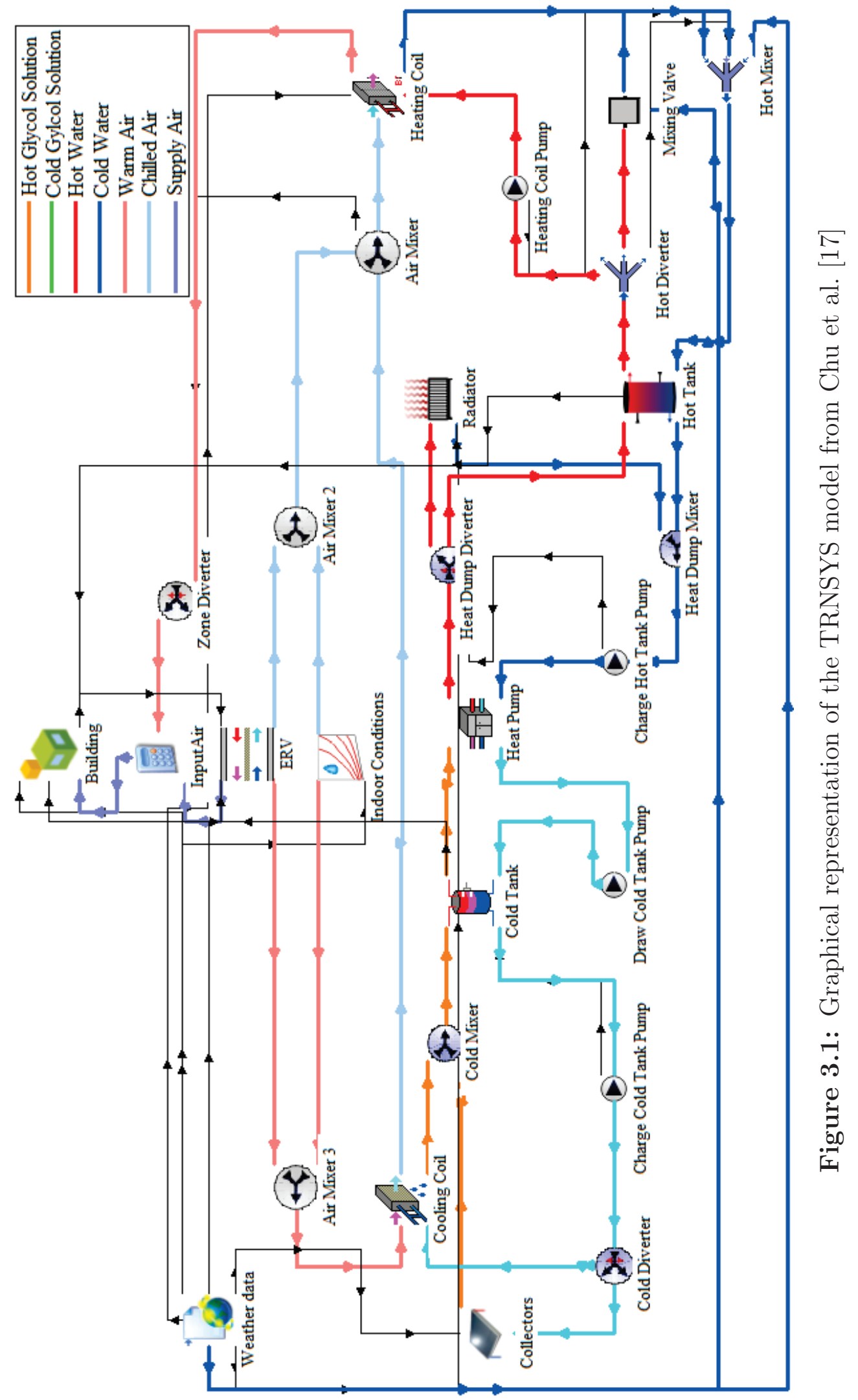


were conducted with a convergence tolerance of 0.05 .

The model was built to simulate the system operations as described in Chapter 1. The model was developed in many phases where additional components or complexities were added from one phase to the next. The simulation data from each phase was analysed to ensure that the energy balances surrounding the tanks were accurate. The first phase modelled DHW draws with the system that only included the collectors, tanks, and heat pump. In later phases, the building model developed by Team Ontario and the air distribution system was added to simulate space-heating and cooling. Interactions between the building conditions and SAHP operations were monitored to ensure appropriate connections were made. For these simulations, it was found that the hot tank over heats in the cooling season and heat dissipation was required in order to keep the heat pump running to chill the cold tank. Therefore, in the final model, a heat dissipater was also added to the design.

\subsubsection{Building Model}

TRNBuild [41], a TRNSYS plug-in, was used to create a multi-zone building (Type 56) to model ECHO. This building model, developed by Team Ontario members, included the preliminary building envelope design, predicted internal gains schedules, predicted occupant schedules, constant mechanical ventilation, and reactive shading. At the time the model was developed, the predictive shading algorithm was not yet completed. The weather data was from a Typical Meteorological Year 2 (TMY2) file for Ottawa, Ontario. The building model was also split into two zones (east and west) but heating and cooling of the zones occurred simultaneously. Appendix D contains the building set-up file used for Type 56 . 


\subsubsection{Delivery of Space-Heating, Cooling, and Domestic Hot Water}

The air handler in the system was modelled using a set of heating and cooling coils (Type 753 and Type 508, respectively) [17]. These Types in TRNSYS used a bypass model in which the user specifies the fraction of air that bypasses the coils. These fractions were set by default to be 0.1 meaning $10 \%$ of the flow is not affected by the coils. The component also bypasses a portion of the input liquid in order to maintain the user specified exit air temperature [42]. The cooling coils were also used for dehumidification. The air input into the heating and cooling coils was a mixture of fresh ventilation air and recirculated air from the space. Air was recirculated from the space at $0.125 \mathrm{~L} / \mathrm{s}(450 \mathrm{~kg} / \mathrm{h})$ in heating mode and $0.256 \mathrm{~L} / \mathrm{s}(920 \mathrm{~kg} / \mathrm{h})$ in cooling mode. These values were specified by Team Ontario's mechanical systems group. For the simulations of the IMS, the air supply to the house was split equally between the east and the west zones [17]. The mathematical relations used to model the heating and cooling coils can be found in Appendix E. Appendix E contains mathematical references for several components that are not part of the core SAHP system and not described in this chapter. Outdoor fresh air was constantly ventilated into the house at about $0.0278 \mathrm{~L} / \mathrm{s}(100 \mathrm{~kg} / \mathrm{h})$ which was also specified by Team Ontario. Energy was exchanged between the fresh air and exhaust through an ERV which was modelled with Type 667 [17]. Type 667 uses a "constant effectiveness - minimum capacitance" methodology [42] as described in Appendix E.

In the summer, the cooling coils had a set-point temperature of $10^{\circ} \mathrm{C}$ so that moisture in the air can condense on the coils. This air temperature was too low to use directly for Team Ontario's low velocity air distribution system and therefore, the air was reheated in the heating coils to $16^{\circ} \mathrm{C}$. The flow rate of the glycol solution 
in the cooling coils was set to $4.58 \mathrm{~L} / \mathrm{min}(275 \mathrm{~kg} / \mathrm{h})$ and the flow rate of water in the heating coils to reheat the air was set to $1.25 \mathrm{~L} / \mathrm{min}(75 \mathrm{~kg} / \mathrm{h})$. In the heating season, the set-point temperature of the air leaving the heating coils was $37^{\circ} \mathrm{C}$. Water would flow from the hot tank through the heating coils at $2 \mathrm{~L} / \mathrm{min}(120 \mathrm{~kg} / \mathrm{h})$ [17]. These flow rates through the coils were selected to approximately match the liquid capacitance value $\left(\dot{m} c_{\mathrm{p}}\right)$ with the air capacitance value. The flow rate through the heating coils to reheat cool air was set low so that the return temperature of the water would be low enough for the heat pump to operate. Although these flow rates do have an impact on the performance of the system, these parameters were kept constant and were not examined in the sensitivity studies due to the lack of information regarding the design of the air handling unit.

The heating and cooling in the building was controlled using Type 1502 and Type 1503 thermostats, respectively, which read the temperature of the west zone of the building. The thermostats were set to $23^{\circ} \mathrm{C}$ with dead-bands of $2.7^{\circ} \mathrm{C}$. These values were selected to reflect the Solar Decathlon Competition comfort zone requirements in which the indoor temperatures must be between $21.7^{\circ} \mathrm{C}$ and $24.4^{\circ} \mathrm{C}$ [13]. To conserve energy in the winter, a setback condition was in place to allow the temperature of the building to drop to $18^{\circ} \mathrm{C}$ at night and also during the day when occupants were expected to be away from the house. In the summer, a similar setforward was used so that the temperature can reach $26.4^{\circ} \mathrm{C}$ in the house during the day when there are no occupants [17]. Type 41, a load profile sequencer for a week [43], was used to input the temperature settings to the thermostats. Weekend and weekday temperature settings were set in Type 14, a time dependent forcing function [43], and used as an input to Type 41 [17]. Type 14 allows the user to input specific daily, weekly, or yearly schedules that constantly repeat throughout the simulations.

Type 14 was used also to input a CSA F379-M1982 standard [44] based water draw 
profile, with a total daily draw of $180 \mathrm{~L}$ based on the recommendation from Team Ontario for 2 occupants. Water from the hot tank mixed with mains water through a custom Type mixing valve to achieve the desired temperature of $45^{\circ} \mathrm{C}$ [17]. Appendix E summarizes the equations used for the mixing valve. If the number of occupants increases, then the daily DHW draw would increase. As occupants are also a source of internal gains, changing the number of occupants would affect space-heating and cooling loads and alter the overall performance of the IMS.

\subsubsection{System Controls}

The Type 14 forcing function was also used as a switch to change the system between summer operation and winter operation. Although heating and cooling modes are occupant controlled in ECHO, for the simulations, the summer operation was specified as between mid-April and mid-October. During the summer, flow from the cold tank is diverted, through a diverting valve, to the cooling coils (instead of the collectors) to absorb heat from the house. The set-up between the cold tank, cooling coils, solar collectors, and diverting valve is shown in Figure 1.9. The diverting valve was modelled with Type 11, a controlled flow diverter [43]. During the summer, the goal of the heat pump is to maintain low temperatures in the cold tank and if the hot tank is fully charged, the load side flow of the heat pump would be diverted from the hot tank to the outdoor heat dissipater. If the temperature input from the hot tank to the heat pump is greater than the heat pump maximum load side inlet cutoff temperature, then another Type 11 diverter would direct the load flow to the outdoor heat dissipaters. The outdoor heat dissipaters were modelled as a radiator, Type 1231 [42], with a designed capacity of $6.5 \mathrm{~kW}$. The control logic for the heat dissipation was implemented using a calculator component in TRNSYS [17].

In winter operation, the flow from the cold tank would be directed to the collectors 
instead of the cooling coils. The goal of the heat pump in the winter is to transfer the energy from the cold tank to the hot tank. When the hot tank is fully charged, the heat pump would not operate and the cold tank would be charged from the collectors. The outdoor heat dissipaters would not be used in the winter. A differential controller (Type 2b) [43] was used to control the circulation pump between the collectors and the cold tank [17]. Figure 3.2 illustrates how the differential controller operates. The controller compares the temperature of the liquid in the collectors with the temperature at the bottom of the cold tank. The upper and lower dead-band temperature difference of the controller was set to $5^{\circ} \mathrm{C}$ and $2^{\circ} \mathrm{C}$, respectively. This meant that if the temperature of the collectors was $5^{\circ} \mathrm{C}$ or more above the temperature at the bottom of the cold tank, then the pump would turn on. The pump continues to run until the collector temperature was $2^{\circ} \mathrm{C}$ higher than the temperature at the bottom of the cold tank. Charging of the cold tank only occurs in the heating season and the flow rate of the glycol solution through the collectors was set to $2.5 \mathrm{~L} / \mathrm{min}(150 \mathrm{~kg} / \mathrm{h})$. During the cooling season, glycol from the cold tank would run through the cooling coils. The glycol absorbs energy from the air and is returned to the cold tank where the recovered energy is transferred through the heat pump to the hot tank to meet DHW loads. The energy recovered from the cooling coils is used to charge the cold tank and the solar collectors do not need to operate in the summer [17].

All circulation pumps were modelled with Type 3. The mass flow rate from these

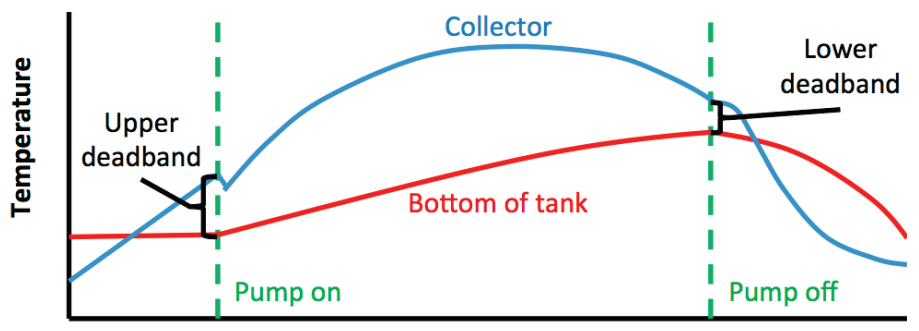

Time of day

Figure 3.2: Differential controller operation (adapted from [45]) 
pumps can be controlled through a variable signal between 0 and 1 . The control signal is then multiplied to the user defined maximum flow capacity [43].

The heat pump was controlled by a customized Type 296 developed by Elliot [6]. This controller monitors the temperature at the top of the cold tank and the temperature at the bottom of the hot tank. If the temperature at the top of the cold tank was above the source side minimum inlet cut-off temperature and the temperature at the bottom of the hot tank was below the load side maximum inlet cut-off temperature then the following operations occurred:

- The compressor of the heat pump turned on;

- Glycol from the top of the cold tank was pumped through the evaporator of the heat pump at $6.67 \mathrm{~L} / \mathrm{min}(400 \mathrm{~kg} / \mathrm{h})$ and returned to the bottom of the cold tank; and

- Water from the bottom of the hot tank was pumped through the condenser of the heat pump at $2.92 \mathrm{~L} / \mathrm{min}(175 \mathrm{~kg} / \mathrm{h})$ and returned to the hot tank [17].

The heat pump source and load side flow rates were held constant throughout the sensitivity studies. The source side flow rate of $6.67 \mathrm{~L} / \mathrm{min}(400 \mathrm{~kg} / \mathrm{h})$ was chosen so that the temperature drop across the evaporator of a small $5.3 \mathrm{~kW}$ (1.5 ton) heat pump would be high enough to quickly chill the bottom of the cold tank for spacecooling in the summer. The load side flow rate of $2.92 \mathrm{~L} / \mathrm{min}(175 \mathrm{~kg} / \mathrm{h})$ was also chosen to ensure that the temperature rise across the condenser would be high enough to quickly heat the top of the hot tank for space-heating and DHW loads in the winter and to maintain thermal stratification in the hot tank.

The flow chart in Figure 3.3 outlines the control logic of the IMS and was used to develop the control algorithm. The IMS built in ECHO was controlled with a 
programmable logic controller and the control algorithm was coded with ladder logic with the help from members of Team Ontario.

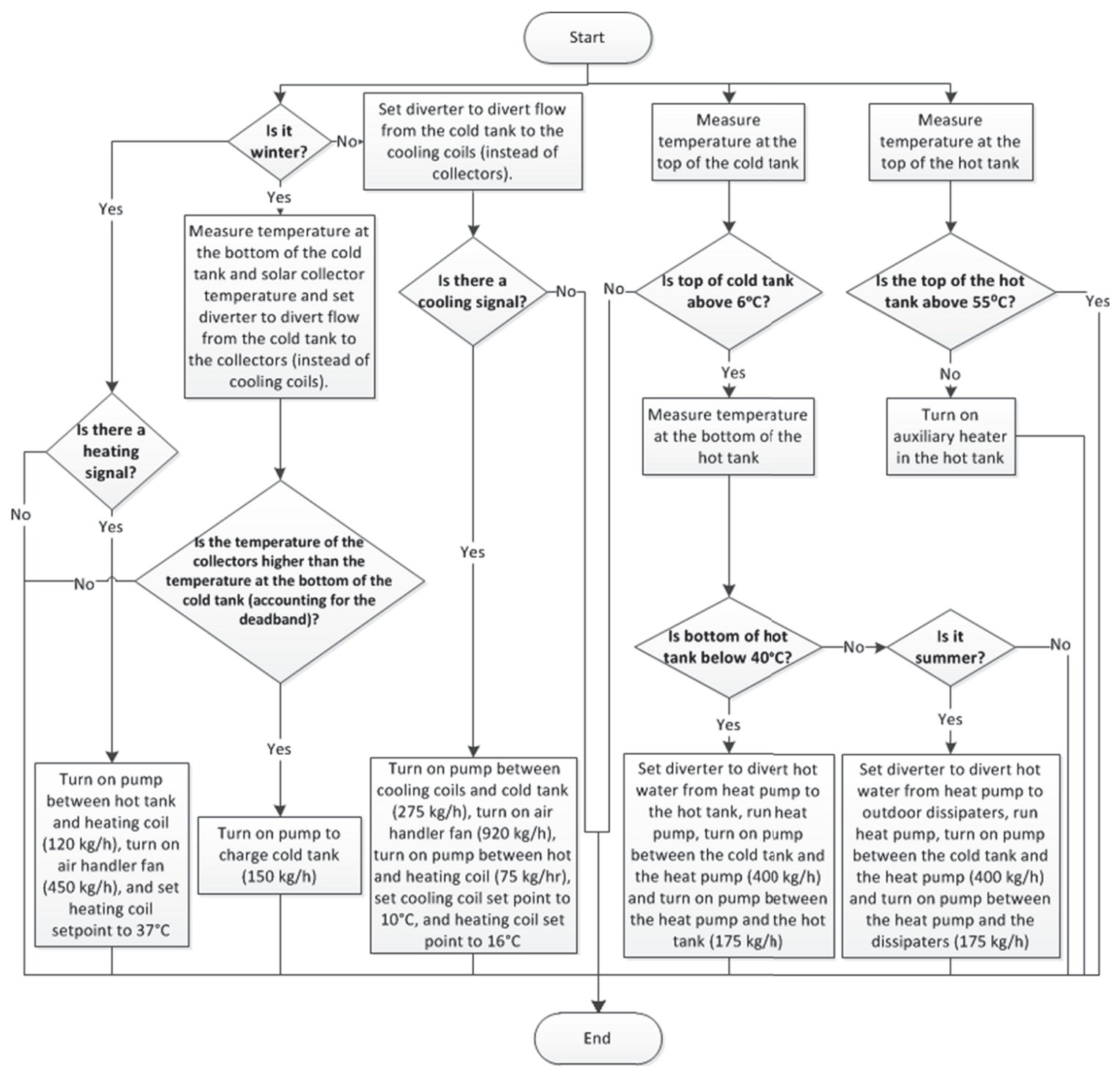

Figure 3.3: Control logic for the integrated mechanical system

\subsubsection{Solar Collectors}

The glazed flat plate collectors for the system were modelled with Type 1 [17]. This model uses the Hottel-Whillier-Bliss efficiency equation. As shown in Equation 3.1, 
the efficiency, $\eta$, is a function of the collector inlet fluid temperature, $T_{\text {coll,in }}$ in ${ }^{\circ} \mathrm{C}$, the outdoor ambient air temperature, $T_{\mathrm{amb}}$ in ${ }^{\circ} \mathrm{C}$, the global irradiance incident on the solar collector, $I_{\mathrm{T}}$ in $\mathrm{kJ} / \mathrm{h} \cdot \mathrm{m}^{2}$, the intercept (maximum) of the collector efficiency, $F_{\mathrm{R}}(\tau \alpha)_{\mathrm{n}}$, the efficiency slope, $F_{\mathrm{R}} U_{\mathrm{L}}$ in $\mathrm{kJ} / \mathrm{h} \cdot \mathrm{m}^{2} \cdot \mathrm{K}$, and the efficiency curvature, $F_{\mathrm{R}} U_{\mathrm{L} / \mathrm{T}}$ in $\mathrm{kJ} / \mathrm{h} \cdot \mathrm{m}^{2} \cdot \mathrm{K}^{2}[43]$.

$$
\eta=F_{\mathrm{R}}(\tau \alpha)_{\mathrm{n}}-F_{\mathrm{R}} U_{\mathrm{L}} \frac{T_{\text {coll,in }}-T_{\mathrm{amb}}}{I_{\mathrm{T}}}-F_{\mathrm{R}} U_{\mathrm{L} / \mathrm{T}} \frac{\left(T_{\text {coll,in }}-T_{\mathrm{amb}}\right)^{2}}{I_{\mathrm{T}}}
$$

where $F_{\mathrm{R}}$ is the overall heat removal efficiency factor, $\tau$ is the short-wave transmittance of the cover, $\alpha$ is the short-wave absorptance of the absorber plate, $U_{\mathrm{L}}$ is the overall thermal loss coefficient per unit area, in $\mathrm{kJ} / \mathrm{h} \cdot \mathrm{m}^{2} \cdot \mathrm{K}$, and $U_{\mathrm{L} / \mathrm{T}}$ is the thermal loss coefficient dependency on the inlet fluid temperature and the outdoor ambient air temperature, in $\mathrm{kJ} / \mathrm{h} \cdot \mathrm{m}^{2} \cdot \mathrm{K}$. The subscript $\mathrm{n}$ represents the variable at normal incidence.

The collector's efficiency equation is based on a collector performing with normal incidence. To correct for the non-normal solar radiation, the intercept efficiency is multiplied by an incident angle modifier, $I A M$, which is calculated according to Equation $3.2[43]$ :

$$
I A M=1-b_{\mathrm{o}}\left(\frac{1}{\cos \theta}-1\right)-b_{1}\left(\frac{1}{\cos \theta}-1\right)^{2}
$$

where $b_{\mathrm{o}}$ and $b_{1}$ are the first and second order incident angle modifiers, respectively, and $\theta$ is the incident angle.

Knowing the efficiency and the global irradiance incident on the collectors, the rate of useful energy collection can be determine using Equation 2.2. The collectors in the model used parameters as specified in Table 3.1. The parameters were obtained from the TRNSYS model developed by Elliot [6] who examined glazed flat plate 
collectors from the same manufacturer that sponsored Team Ontario. Glazed flat plate collectors were chosen because of their enhanced performance in the winter due their increased insulation and lower heat loss compared to unglazed collectors [6].

Table 3.1: Parameters for the glazed flat plate collectors

\begin{tabular}{|c|c|}
\hline Parameter & Value \\
\hline Tested flow rate & $251 \mathrm{~kg} / \mathrm{m}^{2} \mathrm{~h}$ \\
Intercept efficiency & 0.729 \\
Efficiency slope & $4.76 \mathrm{~W} / \mathrm{m}^{2} \mathrm{~K}$ \\
Efficiency curvature & $0.009 \mathrm{~W} / \mathrm{m}^{2} \mathrm{~K}^{2}$ \\
1st-order IAM & 0.110 \\
2nd-order IAM & 0.051 \\
\hline
\end{tabular}

Evacuated tube collectors were also considered in the sensitivity studies. These collectors were modelled with Type 71 [19] and the parameters indicated in Table 3.2 which were obtained from the Solar Rating and Certification Corporation [46] . Type 71 has the same code as Type 1 but reads and interpolates an external data file containing a list of IAMs at various combinations of transverse and longitudinal angles [43]. An IAM data file was also created based on the information found from the Solar Rating and Certification Corporation [46].

Table 3.2: Parameters for the evacuated tube collectors

\begin{tabular}{|c|c|}
\hline Parameter & Value \\
\hline Tested flow rate & $62.6 \mathrm{~kg} / \mathrm{m}^{2} \mathrm{~h}$ \\
Intercept efficiency & 0.601 \\
Efficiency slope & $1.170 \mathrm{~W} / \mathrm{m}^{2} \mathrm{~K}$ \\
Efficiency curvature & $0.00735 \mathrm{~W} / \mathrm{m}^{2} \mathrm{~K}^{2}$ \\
\hline
\end{tabular}




\subsubsection{Thermal Storage}

The cold tank of the system was modelled with Type 60 using 50 nodes [17]. The number of nodes refers to the number of sections the tank is divided into from the bottom to the top of the tank. Each section is equal in volume and fully mixed [43]. The return inlet for the collectors and cooling coil was located at the top of the tank (node 1) while the outlet to the collectors and cooling coil was at the bottom of the tank (node 50). No internal auxiliary heating was used for the cold tank. Figure 3.4 shows the energy balance for the $\mathrm{i}^{\text {th }}$ node of the cold tank with two inlet and outlet flows, $\dot{m}_{1}$ and $\dot{m}_{2}$ in $\mathrm{kg} / \mathrm{h}$. Figure 3.4 also includes the flows moving between nodes, $\dot{m}_{\text {up }}$ and $\dot{m}_{\text {down }}$ in $\mathrm{kg} / \mathrm{h}$. In Figure $3.4, k$ is the fluid conductivity, in $\mathrm{W} / \mathrm{m} \cdot \mathrm{K}$, $\Delta k$ is an additional conductivity term due to the interactions at the wall and node surfaces, in $\mathrm{W} / \mathrm{m} \cdot \mathrm{K}, A_{\mathrm{c}}$ is the cross-sectional area of the tank fluid, in $\mathrm{m}^{2}, \Delta x$ is the distance between nodes, in $\mathrm{m}, U$ is the tank loss coefficient, in $\mathrm{kJ} / \mathrm{h} \cdot \mathrm{m}^{2} \cdot \mathrm{K}$ and $A_{\mathrm{i}, \mathrm{S}}$ is the surface area of the node, in $\mathrm{m}^{2}$. The model uses a verified 1-D finite volume approach in the vertical direction of the tank [47].

For stratification, at the end of each time-step, any temperature inversions that exist are eliminated by total mixing of the appropriate adjacent nodes. Temperature inversion occurs when the temperature of one node is higher than the temperature of the node above it. For Type 60, instead of using the time-steps specified in TRNSYS

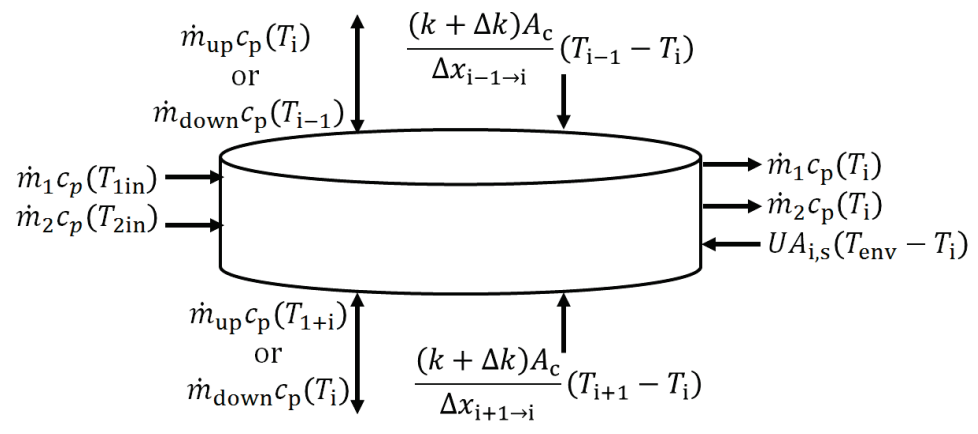

Figure 3.4: Energy balance for node i in Type 60 (adapted from [43]) 
to calculate the temperature at each node, the component uses its own internal timestep to improve accuracy [43].

The hot tank was initially modelled with Type 4 since using Type 60 resulted in convergence issues. There exists some minor differences between the two Types. Type 4 does not take into account thermal conductivity of the fluid and the tank wall and the temperature of each node is calculated at the end of each time-step [43]. Despite these drawbacks, the study proceeded to use Type 4 since the main focus was to examine the sensitivity of the overall system performance to various parameters of the system. The hot tank supplied hot water for space-heating and DHW from the top of the tank (node 1). With only two inlets and two outlets allowable for Type 4, the inlets for the heating coil return and mains water were placed at the same position. Later simulations used Type 534 for the hot tank as it allowed for multiple inlets and outlets at various locations [48]. These simulation were run with the inlet for the heating coil return and mains water were placed at different positions. This model also mixes any nodes where temperature inversions occur [49]. In both Type 4 and Type 534, the inlet fluid into a node is completely mixed with the node water before this fluid is moved to the next node [43,49]. For Type 4, the basic governing differential equation for the $\mathrm{i}^{\text {th }}$ node is as follows [43].

$$
\begin{aligned}
& M_{\mathrm{i}} c_{\mathrm{p}} \frac{d T_{\mathrm{i}}}{d t}=\alpha_{\mathrm{i}} \dot{m}_{\mathrm{tank}, \mathrm{S}} c_{\mathrm{p}}\left(T_{\mathrm{tank}, \mathrm{S}, \mathrm{in}}-T_{\mathrm{i}}\right)+\beta_{i} \dot{m}_{\mathrm{tank}, \mathrm{L}} c_{\mathrm{p}}\left(T_{\text {tank }, \mathrm{L}, \mathrm{in}}-T_{\mathrm{i}}\right) \\
& +\gamma_{\mathrm{i}} \dot{m}_{\mathrm{i}-1} c_{\mathrm{p}}\left(T_{\mathrm{i}-1}-T_{\mathrm{i}}\right)+\delta_{\mathrm{i}} \dot{m}_{\mathrm{i}+1} c_{\mathrm{p}}\left(T_{\mathrm{i}+1}-T_{\mathrm{i}}\right) \\
& +\epsilon \dot{Q}_{\mathrm{aux}, \mathrm{i}}-U A_{\mathrm{i}, \mathrm{S}}\left(T_{i}-T_{\mathrm{env}}\right)
\end{aligned}
$$

where

$\alpha_{\mathrm{i}}=1$, if the flow from the heat source enters node, 0 otherwise

$\beta_{\mathrm{i}}=1$, if the flow from the mains enters node, 0 otherwise

$\gamma_{\mathrm{i}}=1$, if the net flow enters the node from the node above, 0 if no net flow

$\gamma_{\mathrm{i}}=-1$, if the net flow enters the node from the node below, 0 if no net flow 
$\delta_{i}=1$, if the net flow enters the node from the node above, 0 if no net flow $\delta_{\mathrm{i}}=-1$, if the net flow enters the node from the node below, 0 if no net flow $\epsilon=1$, if auxiliary is on in node, 0 otherwise

For Equation 3.3, $M_{\mathrm{i}}$ is the mass of the node, in $\mathrm{kg}, \dot{m}_{\mathrm{tank}, \mathrm{S}}$ and $\dot{m}_{\mathrm{tank}, \mathrm{L}}$ are the mass flow rates of the energy source side and load side of the tank, in $\mathrm{kg} / \mathrm{h}$, respectively, $\dot{m}_{\mathrm{i}-1}$ and $\dot{m}_{\mathrm{i}+1}$ are the mass flow rates from the node above and below, in $\mathrm{kg} / \mathrm{h}$, respectively, $T_{\text {tank,S,in }}$ and $T_{\text {tank,L,in }}$ are the inlet temperatures of the source and load fluids, in ${ }^{\circ} \mathrm{C}$, respectively, $T_{\mathrm{i}}, T_{\mathrm{i}+1}$ and $T_{\mathrm{i}-1}$ are the temperatures of the node, the node below, and the node above, in ${ }^{\circ} \mathrm{C}$, respectively, $c_{\mathrm{p}}$ is the specific heat of the fluid, in $\mathrm{kJ} / \mathrm{kg} \cdot \mathrm{K}, \dot{Q}_{\text {aux }, \mathrm{i}}$ is the auxiliary power input to the node, $\mathrm{kJ} / \mathrm{h}, U$ is the tank loss coefficient, in $\mathrm{kJ} / \mathrm{h} \cdot \mathrm{m}^{2} \cdot \mathrm{K}, A_{\mathrm{i}, \mathrm{S}}$ is the surface area of the node, in $\mathrm{m}^{2}$, and $T_{\text {env }}$ is the temperature of the surrounding environment, in ${ }^{\circ} \mathrm{C}$. Equation 3.3 is solved analytically for each time-step in TRNSYS. Type 534 uses a similar energy balance equation as Type 4 but with several differences. For Type 534, the specific heat of water is calculated for each time-step based on the temperature of the node while for Type 4, the specific heat is a user-input constant value. Type 534 also allows a different method of calculating mixing. This model can calculate the elapsed time into a time-step at which temperature inversions would occur. It would then start mixing the nodes and solving the energy balance equation before the end of the time-step until the temperature inversions are eliminated. This would improve the accuracy of the energy balance of the tank. Like Type 60, Type 534 also allows users to account for conduction in the storage tank wall [49].

In addition to fixed inlets, Type 534 offers a fractional inlet mode to more accurately reflect an entering cold water jet where the water entering the tank is distributed among different nodes [48]. This option was used when modelling the experimental set-up with higher heat pump load side flow rates. 
For this study, the hot tank was modelled with 30 nodes [17]. A sensitivity study for the number of nodes in Type 534 was conducted. Findings of this study can be found in Appendix B. In the simulations of the IMS, the maximum number of nodes allowed was 50. If more nodes were used then the total number of derivatives in the entire simulation would exceed the number of derivatives allowed. In order to accurately model stratification, it was found that a large number of nodes are required. For the model of the IMS, 30 nodes were used in the hot tank. Although using 50 nodes would yield more accurate results, the difference of the temperature at the top of the tank was found to only differed by about $0.1^{\circ} \mathrm{C}$ between the 50 -node and 30-node simulations conducted in the sensitivity study found in Appendix B.

For this model, node 1 is located at the top of the tank and node 30 is located at the bottom of the tank. The DHW and heating coil supply was set to node 1 and the heat pump supply was set to node 30 for the sensitivity studies.

\subsubsection{Heat Pump}

The TRNSYS simulation model used Type 927 to model a single-stage liquid-toliquid heat pump [17]. Type 927 relies on reading a file containing the normalized performance maps of the heat pump. These files provide the normalized capacity and power draw of the heat pump at specific load and source side flow rates and inlet temperatures. The normalized values are the ratio of the actual heating capacities and power draws at a specific operating condition to the rated heating capacity and power draw of the heat pump. The rated values are input parameters for Type 927. Type 927 uses the data file and interpolates for the normalized heating capacity and power draw at a given operating condition and multiplies these values with the rated values to get the actual heating capacity and power draw for each time-step [50]. For Type 927, the COP is calculated with Equation 2.1. The rate of energy absorbed 
from the source fluid, $\dot{Q}_{\text {source }}$ in $\mathrm{kJ} / \mathrm{h}$, is calculated with Equation 3.4.

$$
\dot{Q}_{\text {source }}=\dot{Q}_{\text {load }}-\dot{P}_{\text {comp }}
$$

The exiting temperatures at the source, $T_{\text {source, out }}$, and load side, $T_{\text {load, out }}$ in ${ }^{\circ} \mathrm{C}$, are calculated with the following equations.

$$
\begin{gathered}
T_{\text {source, out }}=T_{\text {source, in }}-\frac{\dot{Q}_{\text {source }}}{\dot{m}_{\text {source }} c_{\mathrm{p}, \text { source }}} \\
T_{\text {load, out }}=T_{\text {load,in }}+\frac{\dot{Q}_{\text {load }}}{\dot{m}_{\text {load }} c_{\mathrm{p}, \text { load }}}
\end{gathered}
$$

where $T_{\text {source, in }}$ and $T_{\text {load, in }}$ are the heat pump source and load side inlet temperatures, in ${ }^{\circ} \mathrm{C}$, respectively, $\dot{m}_{\text {source }}$ and $\dot{m}_{\text {load }}$ are the source and load side mass flow rates, in $\mathrm{kg} / \mathrm{h}$, respectively, and $c_{\mathrm{p}}$, source and $c_{\mathrm{p}}$, load are the heat capacities of the source and load side fluid, in $\mathrm{kJ} / \mathrm{kg} \cdot \mathrm{K}$, respectively.

Catalogue performance data for a small $5.3 \mathrm{~kW}$ (1.5 ton) commercially available ground-source heat pump was obtained from the manufacturer and used for the simulations. The data only indicated the performance of the heat pump with water as the working fluid on the source and load side. The use of a glycol solution on the source side would affect the performance of the heat pump [51]; however, for this sensitivity study, the heat pump data for water-to-water operation was still used even though the simulated system used a glycol solution on the source side. The performance of the heat pump would be affected by the use of a glycol solution due to its different specific heat capacity from water. As indicated in the heat pump catalogue [51], the use of an antifreeze solution for the source side fluid would reduce the heating capacity and power draw by a factor that is dependent on the inlet flow rates and temperatures. For example, for a certain heat pump model operating at the rated 
flow rates, if the entering source temperature was $32.2^{\circ} \mathrm{C}$ and entering load temperature was $10^{\circ} \mathrm{C}$, then the corrected heating capacity for using a glycol solution instead of water on the source side of the heat pump would be the heating capacity indicated in the catalogue data multiplied by 0.922 [51]. These performance reduction factors were only provided for certain operation points and were not provided for the full range of operation points within the catalogue data. Since the inlet flow rates and temperatures are expected to be consistent whether a glycol solution or water was used on the source side, the heating capacity and power draws are expected to be reduce by a consistent factor when simulating glycol-to-water operation with waterto-water operation data instead. Therefore, it was assumed for the sensitivity studies that simulating glycol-to-water operation with water-to-water operation data would have little effect on the trends representing how the performance of the overall system changed with various parameters, such as collector and tank sizes.

The manufacturer's performance data [51] provided the heating capacity and power draw for operating points at:

- Source and load side flow rates of $3 \mathrm{gpm}(681 \mathrm{~kg} / \mathrm{h}), 4 \mathrm{gpm}(908 \mathrm{~kg} / \mathrm{h})$, and 5 $\operatorname{gpm}(1140 \mathrm{~kg} / \mathrm{h})$

- Inlet source side temperatures of $25^{\circ} \mathrm{F}\left(-3.89^{\circ} \mathrm{C}\right), 30^{\circ} \mathrm{F}\left(-1.11^{\circ} \mathrm{C}\right), 50^{\circ} \mathrm{F}\left(10^{\circ} \mathrm{C}\right)$, $70^{\circ} \mathrm{F}\left(21.1^{\circ} \mathrm{C}\right)$, and $90^{\circ} \mathrm{F}\left(32.2^{\circ} \mathrm{C}\right)$; and

- Inlet load side temperatures of $60^{\circ} \mathrm{F}\left(15.6^{\circ} \mathrm{C}\right), 80^{\circ} \mathrm{F}\left(26.7^{\circ} \mathrm{C}\right), 100^{\circ} \mathrm{F}\left(37.8^{\circ} \mathrm{C}\right)$, and $120^{\circ} \mathrm{F}\left(48.9^{\circ} \mathrm{C}\right)$.

For the system studied, the load side flow rate influences the stratification of the hot tank; therefore, performance data for load side flow rates lower than those provided by the manufacturer were required for the simulations. Using MATLAB and the manufacturer's performance data, a data file was created for Type 927 with 
load and source side flow rates as low as $2.92 \mathrm{~L} / \mathrm{min}(175 \mathrm{~kg} / \mathrm{h})$ and $6.67 \mathrm{~L} / \mathrm{min}$ $(400 \mathrm{~kg} / \mathrm{h})$, respectively. For a heat pump, the heating capacity and power draw can be estimated from condensing and evaporating temperatures of the refrigerant. The method used to create the data file in MATLAB assumed that the performance at each operating point can be characterized by the average source and load side temperatures which are related to the condensing and evaporating temperatures of the refrigerant, respectively. From the manufacturer's data, two three-dimensional scatter plots were created for the heating capacity and power draws as a function of the average source and load side temperatures. These plots can be found Figures F.1 and F.2 in Appendix F. The following iterative procedure was used to estimate the heating capacity and power draws at the specified source and load side flow rates and inlet temperatures for the data file:

1. A heating capacity and power draw was estimated.

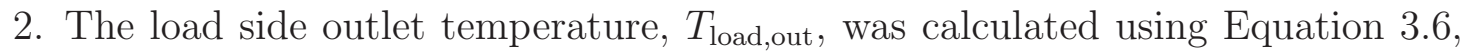
the estimated heating capacity, the specified load side inlet temperature and the specified flow rate.

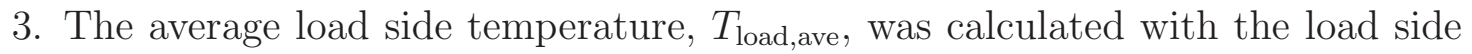
outlet temperature and the specified load side inlet temperature.

$$
T_{\text {load,ave }}=\frac{T_{\text {load,out }}+T_{\text {load,in }}}{2}
$$

4. The cooling capacity (difference between the heating capacity and power draw), specified source side inlet temperature and source side flow rate were used to calculate the outlet source side temperature using Equation 3.5.

5. With the calculated source side outlet temperature and the specified source side 
inlet temperature, calculate the average source side temperature, $T_{\text {source,ave }}$.

$$
T_{\text {source,ave }}=\frac{T_{\text {source,out }}+T_{\text {source,in }}}{2}
$$

6. With the average source and load side temperatures, the three-dimensional plots created with the manufacturer's data were interpolated for a heating capacity and power draw.

7. If the differences between the interpolated values and the estimated values were less than 0.01 then the interpolated values were used as the heating capacity and power draw for the specified source and load side flow rates and inlet temperatures. If the differences between the interpolated values and the estimated values were greater than 0.01 then the process was repeated and the interpolated values would be used as the next estimated values.

The MATLAB code can be found in Appendix F. Appendix G gives an example of the data (not normalized) required by Type 927 to function. For the heat pump data from the manufacturer, the rated heating capacity was set to $5 \mathrm{~kW}$ and rated power draw was set to $1.5 \mathrm{~kW}$. These values approximately reflect the heat pump's operation with 5 gpm (about $19 \mathrm{~L} / \mathrm{min}$ ) load and source side flow rates, $50^{\circ} \mathrm{F}\left(10^{\circ} \mathrm{C}\right)$ source side input, and $104^{\circ} \mathrm{F}\left(40^{\circ} \mathrm{C}\right)$ load side input temperatures [51]. The rated heating capacity and power draw was altered in the sensitivity to investigate how the size of the heat pump can potentially affect the overall performance of the IMS.

\subsection{Sensitivity Studies}

The main purpose of the TRNSYS model was to investigate how various parameters of the system can affect the overall annual free energy fraction $(F E F)$ of the system. As 
mentioned in Chapter 2, the FEF was the performance metric used since it describes the performance of the entire IMS. It was assumed that the trends found through the sensitivity study would remain consistent despite the assumptions made in the model that may affect the magnitude of the results. The $F E F$ was calculated with the following equations from Chu et al. [17].

$$
F E F=\frac{Q_{\text {load,total }}-Q_{\text {aux }}-P_{\text {comp }}}{Q_{\text {load,total }}}
$$

where

$$
Q_{\text {load,total }}=Q_{\text {HeatingCoil }}+Q_{\text {CoolingCoil }}+Q_{\text {DHW }}
$$

For Equation 3.10, $Q_{\text {HeatingCoil }}$ and $Q_{\text {CoolingCoil }}$ are the energies transferred in the heating and cooling coils, in kJ, respectively. The energy consumption of the circulation pumps and fans were not considered in this analysis. The power draws of these components depend on the actual components used, which were unknown at the time of the studies. The circulation pumps used in the experimental analysis can draw up to $20 \mathrm{~W}$ when operated in its "minimum mode" as described in the next chapter. The electrical draw from the fans will also depend on the pressure losses across the coils and resistance of the ducting system. Losses from the electrical loads of the system (from the pumps, the fans, and the compressor) were also neglected since these losses also depend on the actual components used. Heat losses from the DHW draws to the space were also neglected in the model as it was assumed that all hot water flows down the drain and exits the house immediately after draw. In addition to the IMS design, the $F E F$ of the system also depend on the space-heating and cooling loads. These loads can be affected by many factors such as the building envelope, appliances, lighting, passive solar gains, and the number of occupants. These factors were kept consistent throughout each simulation and the effects of these factors on 
the performance of the IMS were not investigated within the scope of this study.

In the winter the $F E F$ would be equivalent to the solar fraction as the only free energy in the winter was from solar energy. In the cooling season, the free energy was mainly collected from energy recovered from space-cooling to meet DHW loads.

Table 3.3 lists the parameters investigated, the values used in the base model as a baseline measurement, and the range of values used in the sensitivity study. For each sensitivity study, a parameter was varied through a range of values while all other parameters are kept at the base model values. This approach was taken to investigate the impact of each parameter on the performance of the system and to formulate preliminary design recommendations early enough so that the system can be built, tested, and commissioned in ECHO for the competition. This approach does have limitations as the effect of a certain parameter may depend on the value of another parameter. Overall, the trends found are relative to the base model values used.

The sensitivity studies focused on the core components of the SAHP system. The ERV was added to the study as it directly affected the heating and cooling loads that the SAHP system must be designed to meet. The heat pump rated $C O P$ (the ratio of the rated heating capacity to rated power) was altered through a range of $\pm 50 \%$ of the base model by changing the rated power draw of the heat pump. For each simulation, the temperature in the house was examined to ensure it remained within set temperatures of the house. The overall annual FEF for the base model using Type 4 as the hot tank was 0.571 while it was 0.549 using Type 534 as the hot tank. This variation is due to the difference between the two Types as previously indicated. Type 4 was used for all the sensitivity studies except for the study where the heating coil return inlet to the hot tank was separated from the mains inlet. In this study, the mains water inlet remained at node 30. Type 534 allowed three sets of the inlets 
and outlets for the tank. The difference in annual FEFs obtained from the two tank models was not further examined as the focus of this study was to determine how changing various parameters of the system can affect the overall performance of the IMS. In each sensitivity study, the percent variation of the annual $F E F$ from the base model of each respective case was reported.

The heat pump load side flow rate was set to $2.92 \mathrm{~L} / \mathrm{min}(175 \mathrm{~kg} / \mathrm{h})$ in the base model to promote thermal stratification, however, the heat pump supplier for Team

Table 3.3: Parameters used in the base model and sensitivity study ranges

\begin{tabular}{|c|c|c|}
\hline Parameter & $\begin{array}{l}\text { Base } \\
\text { Model } \\
\text { Value }\end{array}$ & Sensitivity Study Range \\
\hline Collector area (glazed flat plate) & $12 \mathrm{~m}^{2}$ & 2.4 to $18 \mathrm{~m}^{2}$ (-80 to $+50 \%$ of base model $)$ \\
\hline Collector tilt angle & $90^{\circ}$ & 15 to $90^{\circ}(-83$ to $0 \%$ of base model $)$ \\
\hline Cold storage tank size & $270 \mathrm{~L}$ & 180 to $540 \mathrm{~L}(-33$ to $+102 \%$ of base model $)$ \\
\hline Hot storage tank size & $450 \mathrm{~L}$ & 180 to $800 \mathrm{~L}(-60$ to $+78 \%$ of base model $)$ \\
\hline Tank loss coefficient & $\begin{array}{c}4.132 \\
\mathrm{~kJ} / \mathrm{h} \cdot \mathrm{m}^{2} \mathrm{~K}\end{array}$ & $\begin{array}{c}2.066 \text { to } 6.198 \mathrm{~kJ} / \mathrm{h} \cdot \mathrm{m}^{2} \mathrm{~K}(-50 \text { to }+50 \% \text { of base } \\
\text { model })\end{array}$ \\
\hline $\begin{array}{l}\text { Heat pump source side min. } \\
\text { inlet cut-off temp. }\end{array}$ & $6^{\circ} \mathrm{C}$ & 6 to $15^{\circ} \mathrm{C}$ \\
\hline $\begin{array}{l}\text { Heat pump load side max. inlet } \\
\text { cut-off temp. }\end{array}$ & $40^{\circ} \mathrm{C}$ & 30 to $40^{\circ} \mathrm{C}$ \\
\hline Heat pump rated power & $1.5 \mathrm{~kW}$ & $\begin{array}{c}1 \text { to } 3 \mathrm{~kW} \text { (rated heating capacity remained } \\
\text { constant, } C O P \text { ranged } 1.67 \text { to } 5 \text { or }-30 \text { to } \\
+50 \% \text { of base model) }\end{array}$ \\
\hline $\begin{array}{l}\text { Heat pump rated heating } \\
\text { capacity }\end{array}$ & $5 \mathrm{~kW}$ & $\begin{array}{c}2.5 \text { to } 7.5 \mathrm{~kW} \text { ( }-50 \text { to }+50 \% \text { of base model } \\
\text { while keeping rated } C O P \text { constant by } \\
\text { changing the rated power to the corresponding } \\
\text { values from } 0.75 \text { to } 2.25 \mathrm{~kW} \text { ) }\end{array}$ \\
\hline $\begin{array}{l}\text { Hot tank auxiliary heater } \\
\text { position }\end{array}$ & node 5 & node 1 to 11 \\
\hline Hot tank heat pump return inlet & node 5 & node 1 to 11 \\
\hline $\begin{array}{l}\text { Hot tank mains water supply } \\
\text { and heating coil return inlet }\end{array}$ & node 25 & node 21 to node 30 \\
\hline ERV sensible effectiveness & 0.75 & 0.5 to $0.9(-33$ to $+20 \%$ of base model $)$ \\
\hline ERV latent effectiveness & 0.5 & 0.3 to 0.7 ( -40 to $+40 \%$ of base model $)$ \\
\hline
\end{tabular}


Ontario expressed concerns regarding the heat pump performance at such low flow rates. As a result, later sensitivity studies were also conducted on the heat pump load side flow rate using the "as-built" model as summarized in Chapter 5. The results from this investigation were further examined in the experimental analysis which will be described in the next chapter.

\subsection{Closing Remarks}

This chapter summarized the IMS model developed in TRNSYS, the equations that were used in the subroutines of the key components, and the sensitivity studies approach. The TRNSYS program was used because of its ability to model complex customized energy systems. The building model was developed by Team Ontario and was not modified or investigated in this study. Parameters of the space-heating and cooling distribution system were also specified by Team Ontario and not altered in this study in order for the system to integrate with ECHO. The parameters investigated in the sensitivity studies mainly surround the design of the SAHP components (solar collectors, tanks, and heat pump). These components were modelled with Types that are available in the TRNSYS component library. The heat pump was not modelled with first principles and required performance map data that was created based on catalogue data. As described in the next chapter, later simulations used experimental data to create a new performance map for the heat pump model.

The following chapter will describe the experimental analysis of this study. Chapter 5 summarizes the results of sensitivity studies and a discussion of the results can be found in Chapter 6. Chapter 5 also includes details of a recommended system that was designed based on the simulation results and also the details of the as-built system that was assembled and commissioned in ECHO. 


\section{Chapter 4}

\section{Experimental Approach}

This chapter summarizes the experimental approach of this study which examines the relationship between the heat pump load side flow rate, the heat pump performance, and the level of stratification that can be achieved in the hot tank. From the simulation studies summarized in Chapter 5, it was found that the lower the load side flow rate, the higher the FEF but the lower the annual COP of the heat pump. Lower flow rates allow for greater stratification in the hot tank and reduce the need for auxiliary heating. An experimental set-up of the SAHP system was constructed in the Solar Calorimetry Lab at Queen's University in Kingston, Ontario. The experimental apparatus, instrumentation, and procedure are described in this chapter. Tests were performed with constant solar temperature input, heat pump source side flow rate, and initial tank temperatures. The heat pump load side flow rate varied with each test. The losses through piping and the tanks were not analysed in this study. The experimental analysis was further modelled using TRNSYS in order to validate and improve the heat pump model in TRNSYS. 


\subsection{Apparatus}

The main components of the apparatus were the two water storage tanks, a $5.3 \mathrm{~kW}$ (1.5 ton) liquid-to-liquid heat pump, and a solar simulator providing the required heat input. Figure 4.1 shows a photo of the apparatus with the hot tank on the left, the cold tank on the right, and the heat pump in the middle.

The heat pump performance data that was used to create the performance map for Type 927 in the TRNSYS model was from the same heat pump unit used in this experimental set-up. The heat pump used R-410a as a refrigerant, a scroll compressor, and large coaxial heat exchangers. The heat pump had a built-in high pressure fault switch which turns the heat pump off when the pressure of refrigerant reaches 4,137 $\mathrm{kPa}(600 \mathrm{psi})$ which is approximately the critical pressure of refrigerant $\mathrm{R}-410 \mathrm{a}$. The

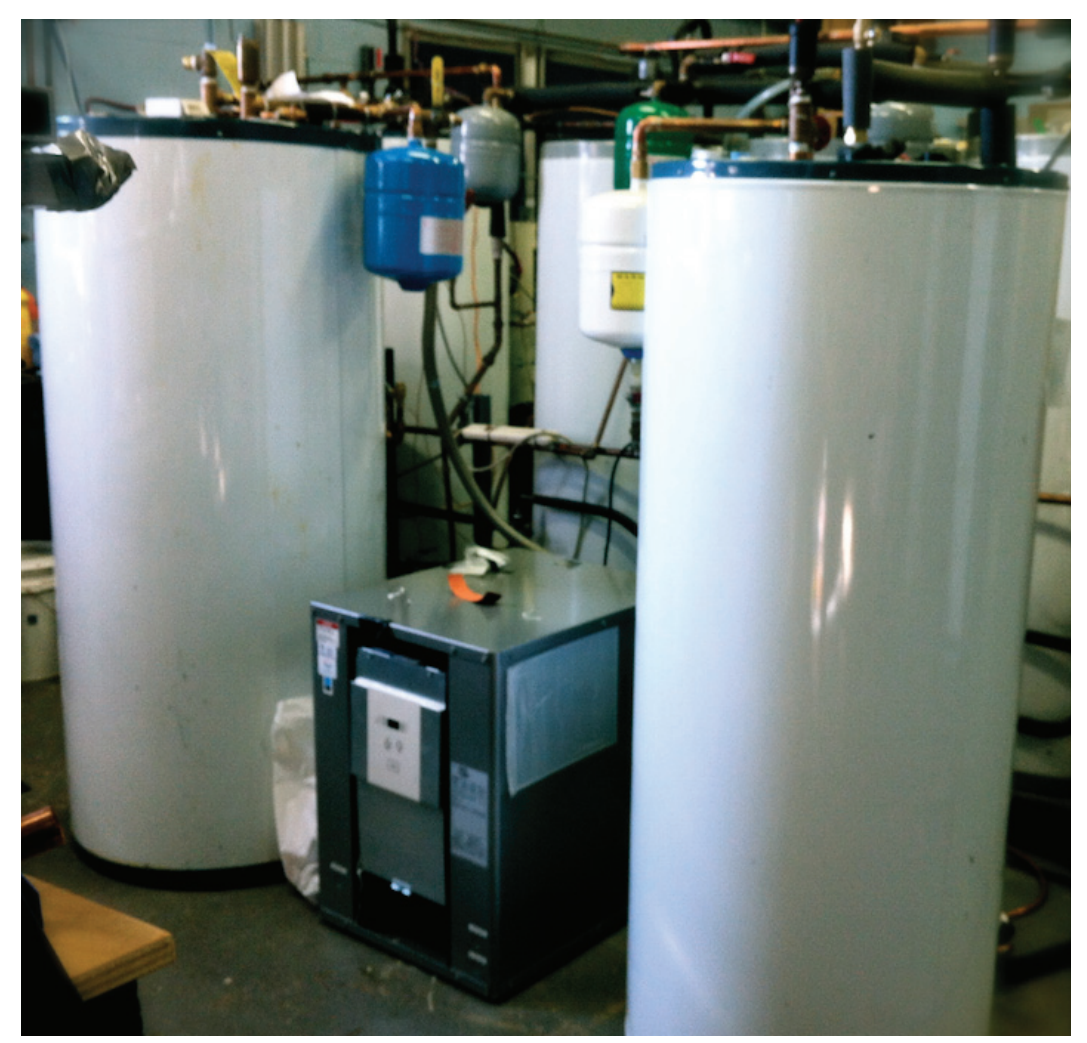

Figure 4.1: Experimental apparatus of dual tank indirect solar-assisted heat pump system 
heat pump also had a freeze detection fault switch which would turn the heat pump off if the water in the evaporator began to freeze [51]. The two circulation pumps for the load and source side flows were wired to the heat pump so that both pumps would turn on with the compressor. Balancing valves were placed both in the load and source side flows in order to control the flow rates of each loop.

Water from the top of the cold tank was pumped to the source side of the heat pump and was returned to the bottom of the tank. For this apparatus, water was used in the cold tank as opposed to a glycol solution. This helped the comparison of simulation and experimental results as the heat pump operation was simulated with water-to-water operation data. Also, for the Solar Decathlon Competition, Team Ontario used water in the cold tank oppose to a glycol solution to avoid the complication associated with using a large volume of glycol on the competition site. The use of water on the source side of the heat pump for the experimental study would mimic the heat pump operation during the competition.

The auxiliary heaters in the tanks were disabled in this study. Water from the bottom of the hot tank was supplied to the load side of the heat pump. In the system built for ECHO, the return from the heat pump was located at the side port of the hot tank which was slightly below the auxiliary heater. The side port was about two-thirds the tank height from the floor. Since the experimental study focused on the stratification, the return inlet from the heat pump was placed at the top of the tank as hot water draws and the auxiliary heating was not implemented. Some basic specifications of the storage tanks from the manufacturer [52] are listed in Table 4.1.

The solar input to the cold tank was simulated with two, $3 \mathrm{~kW}$ electric heaters that maintained a constant temperature charge. Water was drawn from the bottom of the cold tank, heated through the solar simulator and returned to the top of the tank. The solar simulator set-up is shown in Figure 4.2. 
Table 4.1: Specifications for cylindrical storage tanks

\begin{tabular}{|c|c|c|}
\hline Parameter & Hot Tank Value & Cold Tank Value \\
\hline Tank volume & $0.454 \mathrm{~m}^{3}$ & $0.303 \mathrm{~m}^{3}$ \\
Tank height & $1.575 \mathrm{~m}$ & $1.492 \mathrm{~m}$ \\
Tank outer diameter & $0.718 \mathrm{~m}$ & $0.622 \mathrm{~m}$ \\
Tank loss coefficient & $1.224 \mathrm{~kJ} / \mathrm{h} \cdot \mathrm{m}^{2} \mathrm{~K}$ & $1.181 \mathrm{~kJ} / \mathrm{h} \cdot \mathrm{m}^{2} \mathrm{~K}$ \\
\hline
\end{tabular}

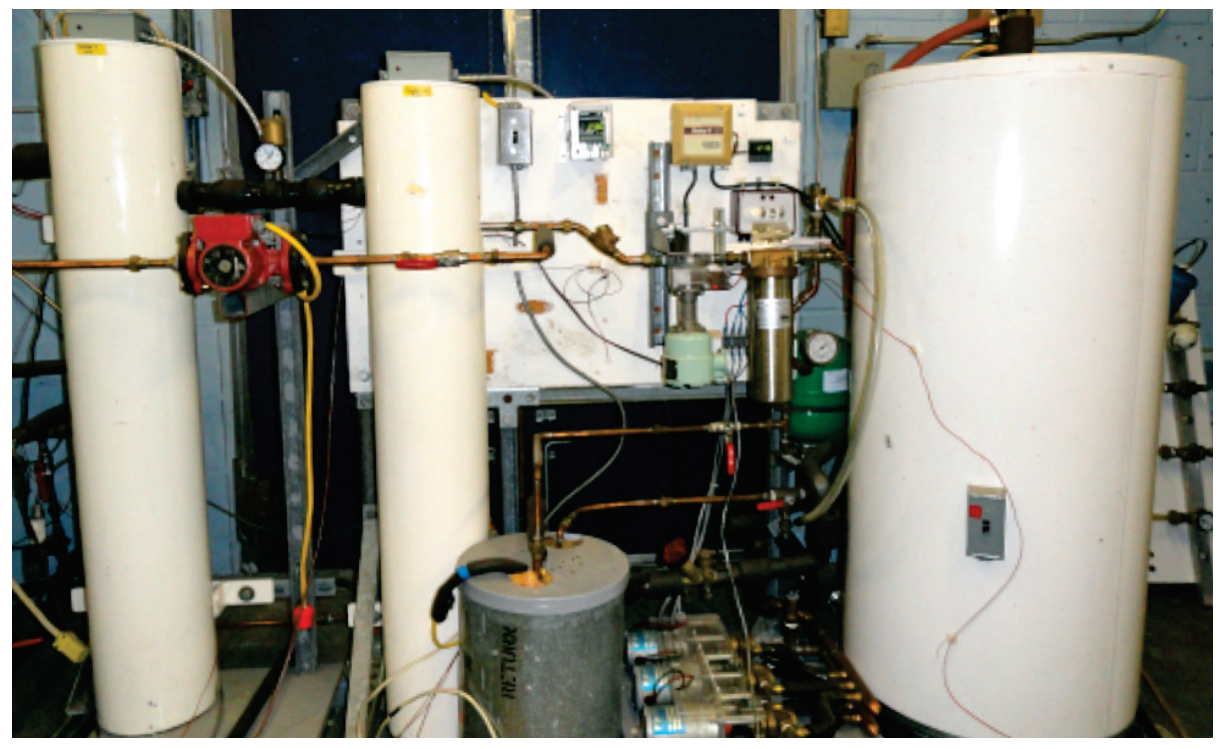

Figure 4.2: Solar simulator for the experimental apparatus

\subsection{Instrumentation}

To examine thermal stratification in the hot tank, a temperature probe with nine Type "T" thermocouples was inserted into the hot tank to record the temperature profile at $15 \mathrm{~cm}$ intervals from the top of the tank. The total distance from the top thermocouple on the probe to the bottom was about $1.2 \mathrm{~m}$. Since the height of the tank was about $1.575 \mathrm{~m}$, the probe did not measure the temperatures at the bottom of the tank.

Thermocouples were also placed at the load and source side inlets and outlets of the heat pump and at the solar simulator inlet on the cold tank. The four thermocouples 
used to measure the heat pump temperatures were calibrated with a temperature bath and a platinum resistance thermometer. Details of the calibration process can be found in Appendix H. Following the calibration process, the uncertainty of the thermocouples was determined to be $\pm 0.10^{\circ} \mathrm{C}$.

A magnetic flow meter was placed in the load side flow. In a magnetic flow meter, a magnetic induction field is generated with magnetic coils and fluid flow through the field creates a voltage. The voltage is measured by the flow meter and used to calculate a corresponding flow rate [53]. The volumetric flow rate measurements were calibrated against gravimetric flow rate measurements as also described in Appendix H. The final uncertainty of the flow rate readings was determined to be $\pm 0.045 \mathrm{~L} / \mathrm{min}$.

A power meter was connected to the heat pump to record the power draw from the heat pump. Because the two circulation pumps on the load and source flows were wired to the heat pump, the power meter readings included the power used for the circulation pumps in addition to power consumed by the compressor. The uncertainty of the power meter was $\pm(0.2 \%$ of reading $+0.07 \%$ of range $)[54]$.

A schematic of the experimental set-up and the instrumentation locations is shown in Figure 4.3. All the data from the instrumentation shown in Figure 4.3 were recorded at 1.5-minute time intervals with a computer based data acquisition system and a custom National Instruments LabVIEW program, which displayed the temperatures, the load side flow rate and the power consumption in real-time. Refrigerant pressure gauges, shown in Figure 4.4, were also placed on the suction side and discharge side ports of the refrigerant loop within the heat pump. Readings from these pressure gauges were not recorded with the computer based data acquisition system, instead, they were taken in approximately ten minute intervals. These readings helped ensure that the refrigerant pressure did not reach the critical to set off the high pressure fault switch and to ensure the heat pump did not get damaged. 


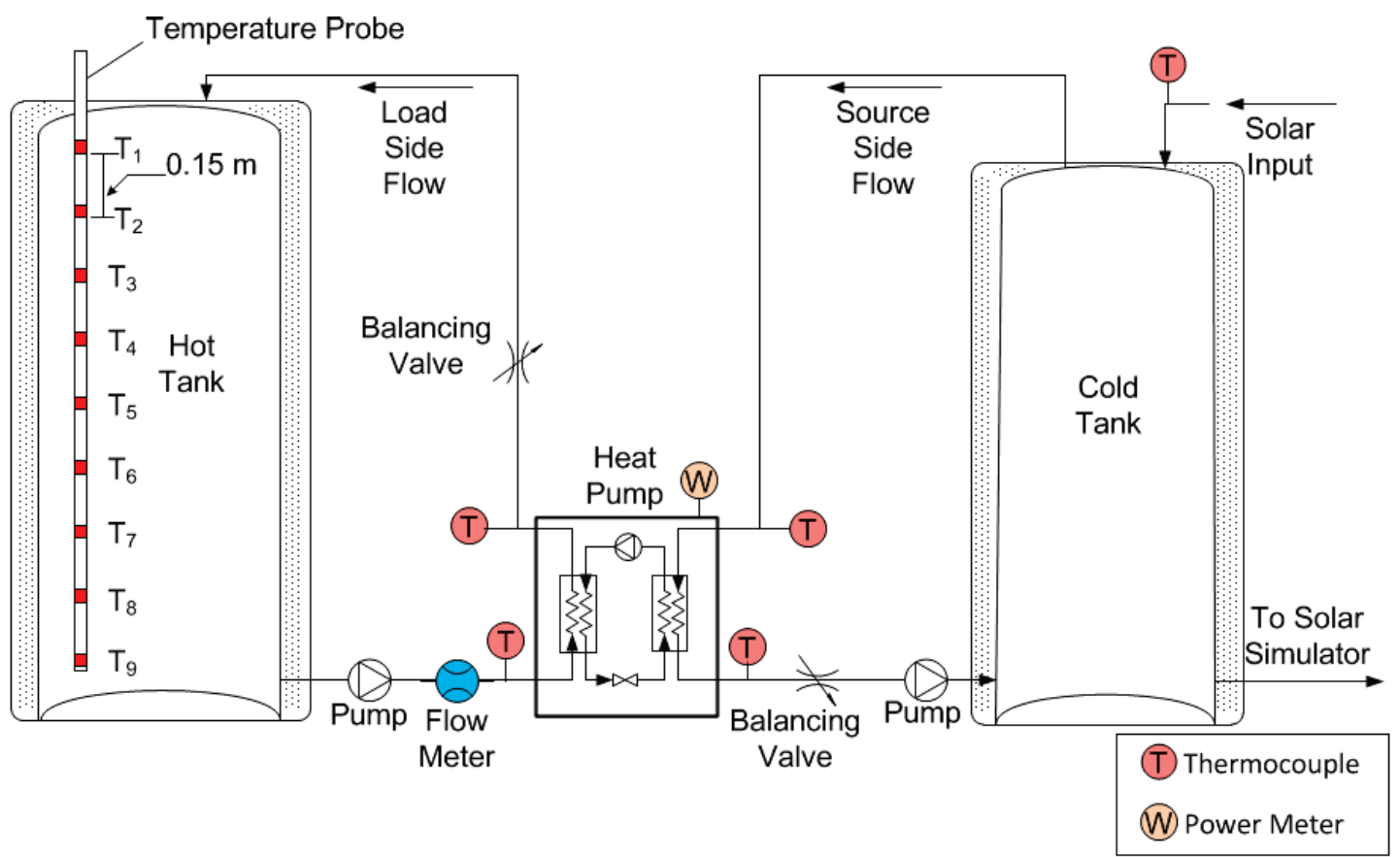

Figure 4.3: Schematic of experimental set-up and instrumentation locations

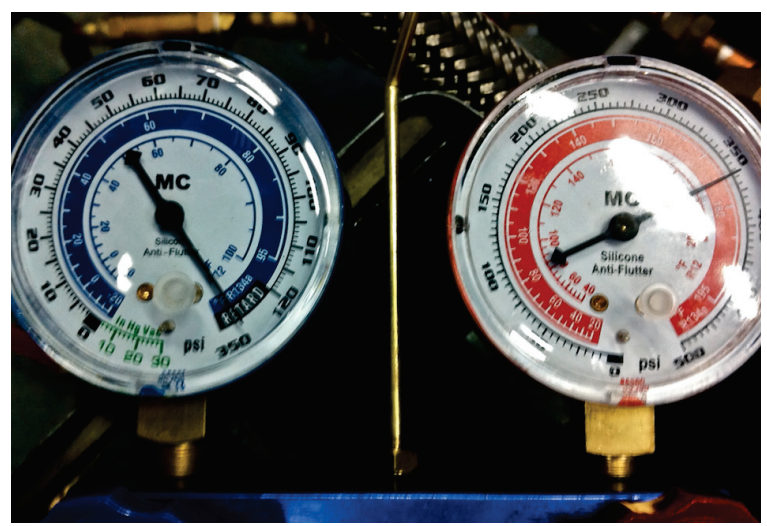

Figure 4.4: Pressure gauges for heat pump refrigerant loop

\subsection{Experimental Procedure}

For the initial conditions of each test, the temperatures of both tanks were maintained at $20^{\circ} \mathrm{C}$ from top to bottom. The source side volumetric flow rate was kept at approximately $10 \mathrm{~L} / \mathrm{min}$ for each test. To ensure the heat pump had a sufficient amount of energy to source from, a constant temperature input of about $20^{\circ} \mathrm{C}$ was 
supplied to the top of the cold tank by the solar simulator at $5 \mathrm{~L} / \mathrm{min}$. Separate tests were conducted with load side volumetric flow rates of $2 \mathrm{~L} / \mathrm{min}, 3 \mathrm{~L} / \mathrm{min}, 4 \mathrm{~L} / \mathrm{min}, 6$ $\mathrm{L} / \mathrm{min}, 8 \mathrm{~L} / \mathrm{min}$, and $10 \mathrm{~L} / \mathrm{min}$. Each test was terminated when the pressure of the refrigerant reached approximately 3,447 (500 psi) to protect the heat pump.

The instantaneous heat transfer rate was calculated with the following equation:

$$
\dot{Q}_{\text {load }}=\dot{m}_{\text {load }} c_{\text {p,water }}\left(T_{\text {load }, \text { out }}-T_{\text {load,in }}\right)
$$

where

$$
\dot{m}_{\text {load }}=\dot{V} \rho_{\text {water }}
$$

The density of water, $\rho_{\text {water }}$ in $\mathrm{kg} / \mathrm{m}^{3}$, and the heat capacity of water, $c_{\mathrm{p} \text {, water }}$ in $\mathrm{kJ} / \mathrm{kg} \cdot \mathrm{K}$, were approximated with the average load side temperature which ranged from $25^{\circ} \mathrm{C}$ to $40^{\circ} \mathrm{C}$. As a result, the density and heat capacity at $32.5^{\circ} \mathrm{C}$ was used in the calculations and a conservative range of $\pm 10^{\circ} \mathrm{C}$ was used to determine the corresponding uncertainty values. The maximum uncertainty for each test run ranged from $\pm 1.45 \%$ to $\pm 2.1 \%$ of the heat transfer rates calculated. Appendix H summarizes the propagation of errors calculations.

The $C O P$ was calculated according to Equation 2.1, using the previously determined heating capacity and compressor power consumption. Since the measured power consumption of the compressor also included the power consumed by the load and source side circulation pumps, it was necessary to deduct each of these contributions from the total power consumption. Each pump's power consumption was approximated using the known flow rate and the power curve for the pumps shown in Figure 4.5. The pumps can operate is six different modes which are represented by each line in Figure 4.5. For the experimental analysis, the circulation pumps were set on "minimum mode". Since the magnitude of the measured powers are about a 


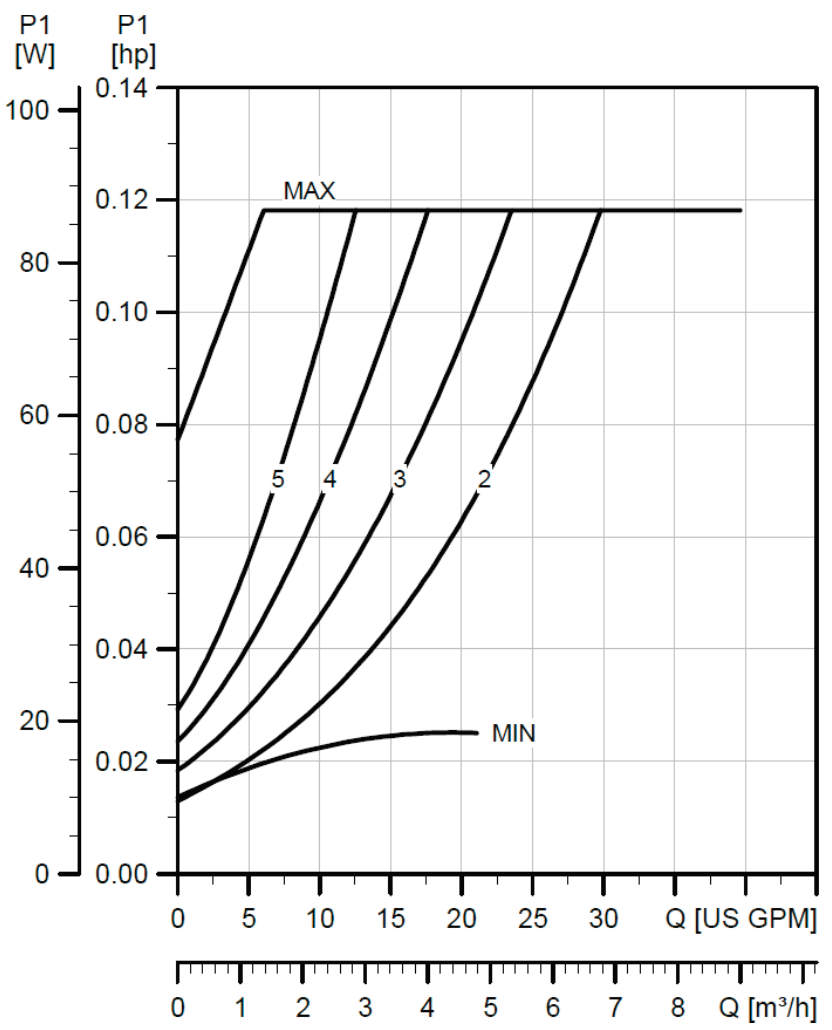

Figure 4.5: Power curve for the circulation pumps [55]

factor of 100 larger than the estimated circulation pump powers, the source side mass flow rate, $\dot{m}_{\text {source }}$ in $\mathrm{L} / \mathrm{min}$, was approximated with Equation 4.3 using the measured powers, in $\mathrm{kW}$.

$$
\dot{m}_{\text {source }}=\frac{\dot{Q}-\dot{P}_{\text {measured }}}{c_{\mathrm{p}, \text { water }}\left(T_{\text {source } \text { in }}-T_{\text {source }, \text { out }}\right)}
$$

The estimated power draws from the circulation pumps were subtracted from the measured power to determine the power draw of the heat pump compressor alone. A conservative uncertainty of $\pm 5 \mathrm{~W}$ was applied to the estimated circulation pump power draws due to the reading errors of Figure 4.5 and the approximation of the source side flow rate. Accounting for the uncertainty of the power meter, the overall maximum uncertainty of the determined power draw of the heat pump for each test 
ranged from $\pm 0.424 \%$ to $\pm 0.557 \%$ as indicated in Appendix H. Also summarized in Appendix $\mathrm{H}$, the maximum $C O P$ uncertainty for each test ranged from $\pm 1.49 \%$ to $\pm 2.20 \%$ of the calculated $C O P$.

The accumulated amount of energy transferred by heat pump, $Q_{\text {load }}$ in kJ, was found with the following equation.

$$
Q_{\text {load }}=\sum_{\mathrm{i}=1}^{n} \dot{Q}_{\text {load }, \mathrm{i}} \Delta t
$$

where $n$ is the total number of the data points measured, $\dot{Q}_{\text {load }}$ is the instantaneous heat transfer rate, in $\mathrm{kW}$, and $\Delta t$ is time elapsed between each data point, in minutes. Similarly, the accumulated amount of energy consumed by the heat pump, $P_{\text {comp }}$ in kJ, was found with Equation 4.5.

$$
P_{\text {comp }}=\sum_{\mathrm{i}=1}^{n} \dot{P}_{\text {comp }, \mathrm{i}} \Delta t
$$

The average $C O P$ was defined as the ratio of the accumulated energy transferred to the accumulated energy consumed.

$$
C O P_{\text {average }}=\frac{Q_{\text {load }}}{P_{\text {comp }}}
$$

The uncertainties for the accumulated amount of energy transferred and consumed by the heat pump as well as for the average $C O P$ for each test can be found in Table H.2 (Appendix H). The uncertainties of the accumulated energy transferred, the accumulated energy consumed, and the average COP ranged from $\pm 1.63 \%$ to $\pm 2.30 \%, \pm 0.447 \%$ to $\pm 0.576 \%$, and \pm 1.72 to $\pm 2.35 \%$, respectively. 


\subsection{Modelling of Experimental Approach}

A TRNSYS model was developed to simulate the experimental set-up. As shown in Figure 4.6, the model consists of the heat pump and the hot tank. The experimental results were compared to the modelling results for the $3 \mathrm{~L} / \mathrm{min}, 6 \mathrm{~L} / \mathrm{min}$, and 10 $\mathrm{L} / \mathrm{min}$ tests. Instead of modelling a cold tank being charged with the solar simulator and supplying water to the source side of the heat pump, the measured source side inlet temperatures were written into a text file and directly read by Type 9 in TRNSYS for the simulations. This eliminated any errors that may be introduced by the cold tank model when the primary focus was to examine the relationship between the heat pump load side flow rate, the heat pump performance and the hot tank stratification. To be consistent with the model for the IMS, Type 534 was used for the hot tank. The tank parameters were set based on the specifications of the tank used in the experimental set-up. Table 4.2 summarizes the key hot tank parameters obtained from the manufacturer [52]. For these simulations, the hot tank was modelled with 50 nodes in order to more accurately capture thermal stratification.

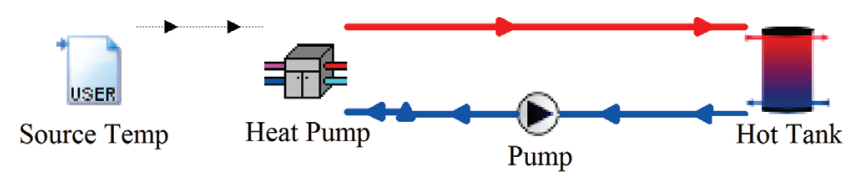

Figure 4.6: TRNSYS model for experimental set-up

Table 4.2: Parameters for the experimental hot tank

\begin{tabular}{|c|c|}
\hline Parameter & Value \\
\hline Tank volume & $0.454 \mathrm{~m}^{3}$ \\
Tank height & $1.575 \mathrm{~m}$ \\
Tank loss coefficient & $1.224 \mathrm{~kJ} / \mathrm{h} \cdot \mathrm{m}^{2} \mathrm{~K}$ \\
Height of heat pump return inlet & $1.575 \mathrm{~m}$ \\
Height of heat pump supply outlet & $0 \mathrm{~m}$ \\
\hline
\end{tabular}


The heat pump was first modelled with the same performance map created from data obtained from the manufacturer. Further simulations were conducted with an updated performance map that was also created with the same procedure as indicated in Chapter 3, however, for the updated performance map, a combination of experimental and manufacturer's data were used. For the average source and load side temperatures outside the range of the experimental data, the data from the manufacturer was used. Figures F.3 and F.4 in Appendix F show the scatter plots used as input data for creating the updated performance map. Figures F.5 and F.6 show the heating capacity and power draw as a function of the average source and load side temperatures for the updated performance map data. Appendix G also contains a sample of the data that was used in the simulation of the heat pump.

\subsection{Closing Remarks}

This chapter focused on the experimental approach of this study. The experimental apparatus, instrumentation, and procedure were outlined and Appendix H contains an uncertainty analysis conducted for the experimental results. These results are summarized in Chapter 5 and discussed in Chapter 6. After the data was gathered, the apparatus was dissembled and transferred to ECHO. Therefore, further analysis with the same equipment must be conducted in the house. 


\section{Chapter 5}

\section{Modelling and Experimental Results}

Results from the TRNSYS simulations and the experimental tests were recorded and analysed. This chapter summarizes the results of these investigations. Sensitivity studies were performed in simulation to help size components for Team Ontario's integrated mechanical system (IMS). Experimental data was analysed to examine the relationship between the heat pump performance and the stratification in the hot tank. Further simulations of the experimental set-up were also conducted to compare modelling and experimental results. A detailed discussion of the results and analysis can be found in Chapter 6.

\subsection{Modelling of the Integrated Mechanical System}

Annual simulations were conducted with the TRNSYS model and the free energy fraction $(F E F)$ of the system was found from each simulation. The sensitivity studies examined how the annual FEF changed with various parameters of the system. 


\subsubsection{Base Model Results}

A base model was created to investigate the sensitivity of varying certain parameters of the system. The parameters that were examined and the corresponding values used in the base model are indicated in Table 3.3 on page 62 . Table 5.1 indicates the total energy used in one year for domestic hot water (DHW), the total energy transferred through the heating and cooling coils, the total energy used for auxiliary heating, and the total energy used for the heat pump compressor. As mentioned in Chapter 3, the overall annual FEF for the base model, using Type 4 for the hot tank, was 0.571 , and the annual FEF for using Type 534 was 0.549 [17]. Between the two base models, the auxiliary energy consumption showed the largest difference. This was expected as the auxiliary energy consumption depends on the hot tank temperatures and the two models simulated node mixing differently. Type 534 also accounts for conduction in the walls which causes destratification. The differences between the two hot tank models are also outlined in Chapter 3.

For the sensitivity studies of each parameter indicated in Table 3.3, the annual

Table 5.1: Total loads from annual simulation of the base model from Chu et al. [17]

\begin{tabular}{|c|c|c|}
\hline Energy & $\begin{array}{l}\text { Base Model with } \\
\text { Type } 4 \text { Hot Tank }\end{array}$ & $\begin{array}{c}\text { Base Model with } \\
\text { Type } 534 \text { Hot Tank }\end{array}$ \\
\hline DHW & 9.81 GJ & 9.81 GJ \\
\hline Heating coil (Space-heating) & 11.9 GJ & $12.0 \mathrm{GJ}$ \\
\hline Heating coil (Cool air reheat) & 7.19 GJ & 7.24 GJ \\
\hline $\begin{array}{l}\text { Cooling coil (Cooling and } \\
\text { dehumidification) }\end{array}$ & 19.6 GJ & 19.6 GJ \\
\hline Auxiliary & 5.68 GJ & $6.76 \mathrm{GJ}$ \\
\hline Heat pump compressor & 15.1 GJ & $15.2 \mathrm{GJ}$ \\
\hline
\end{tabular}


DHW, heating coil, and cooling coil loads (as indicated in Table 5.1) remained consistent for each simulation with the exception of the studies for the energy recovery ventilator (ERV) effectivenesses and tank loss coefficient. Figure 5.1 shows the breakdown of the loads by month for the base model using Type 4 for the hot tank. The results suggest that the auxiliary energy consumption was higher in the winter months. This was due to the combination of space-heating and DHW loads. In the winter months, the $F E F$ is equivalent to the solar fraction as the only source of free energy was from the collectors. Based on the values shown in Figure 5.1, the average FEF from November to February was 0.424. Energy consumption from the heat pump compressor was higher in the summer months as the heat pump was set to keep the cold tank at low temperatures even if heat must be dissipated to the outdoors. The operation of the heat pump in the summer provided space-cooling and DHW loads. The source of free energy in the summer was the recovered energy from space-cooling that was used to heat water for DHW requirements. For the base model, the average FEF between the months of June and August was 0.563. In months of March, April, September, and October the average FEF was about 0.702. As shown in Figures

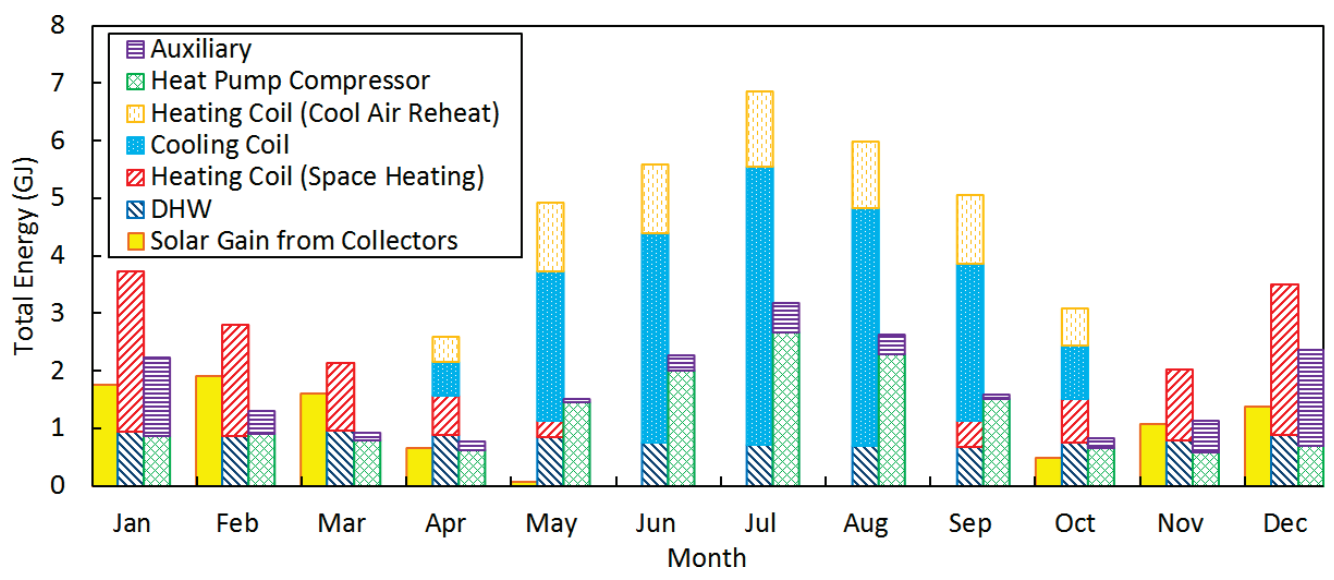

Figure 5.1: Monthly solar energy gains from collectors, total energy loads (second column), and total electrical energy draws (third column) for the base model from Chu et al. [17] 
5.2 and 5.3, the average indoor temperature and relative humidity were maintained within the set-points indicated in Chapter 3 for approximately $99 \%$ of the time over a year. It was found that indoor conditions did reach uncomfortably dry relative humidity values in the winter. As the Solar Decathlon Competition did not specify a minimum indoor relative humidity requirement, humidification was not included within the scope of the SAHP design.

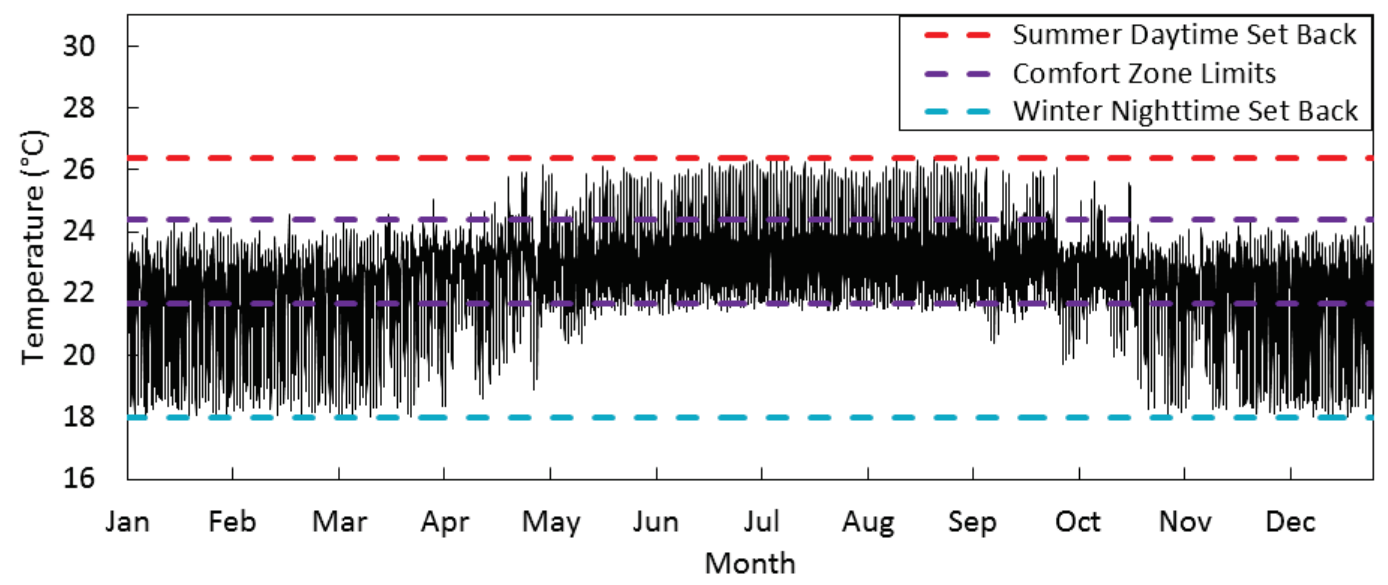

Figure 5.2: Average indoor temperature simulated from the base model from Chu et al. [17]

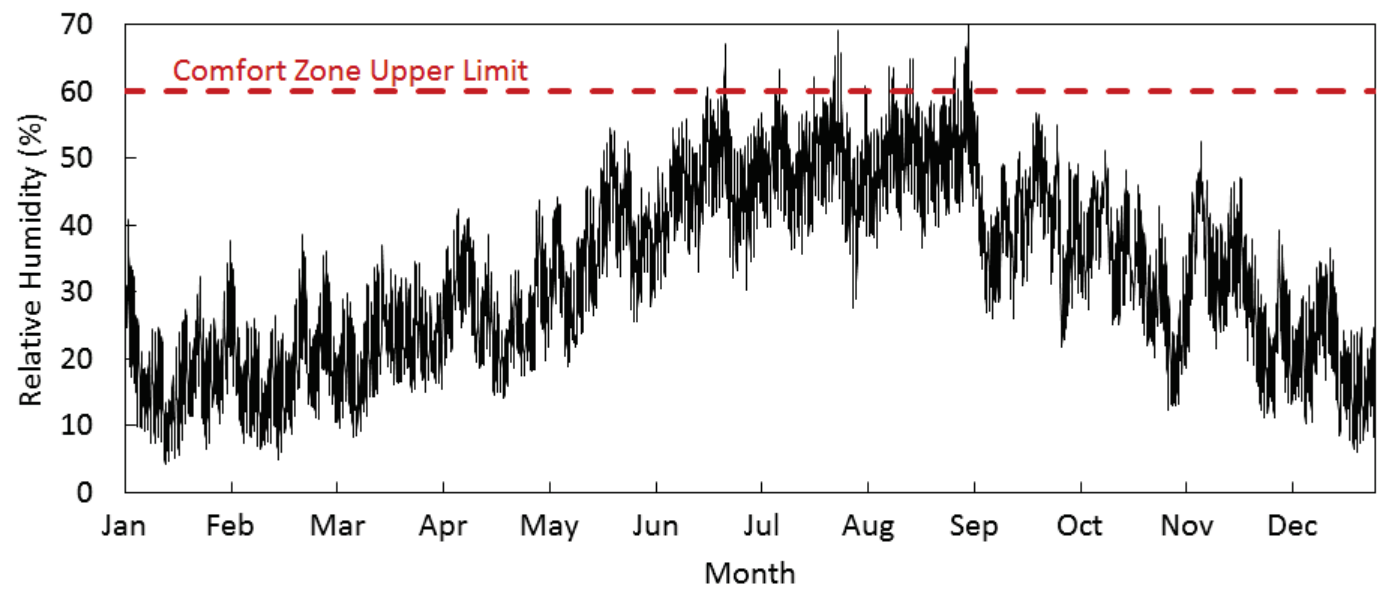

Figure 5.3: Indoor relative humidity simulated from the base model from Chu et al. [17] 


\subsubsection{Sensitivity Studies}

Each parameter indicated in Table 3.3 was varied to determine the performance sensitivity of these parameters. As mentioned in Chapter 3, all of the sensitivity studies were conducted with Type 4 for the hot tank except in the case where Type 534 was used for the study when the heating coil return inlet to the tank was separated from the mains water inlet. Sensitivity study results are presented in this chapter and discussed in Chapter 6.

The results of the sensitivity studies for the collector area, tank loss coefficient, cold tank size, hot tank size, and ERV sensible and latent effectiveness are shown in Figure 5.4. Figure 5.4 shows the percent variation of the FEF relative to the FEF achieved in the base model. For the base model FEF of 0.571 , a positive five percent variation represents a $F E F$ of 0.600 . Of these parameters shown in Figure 5.4, the collector area had one of the largest effects on the performance of the system. Reducing the area of the collectors by $50 \%$ and $80 \%$ would reduce the annual

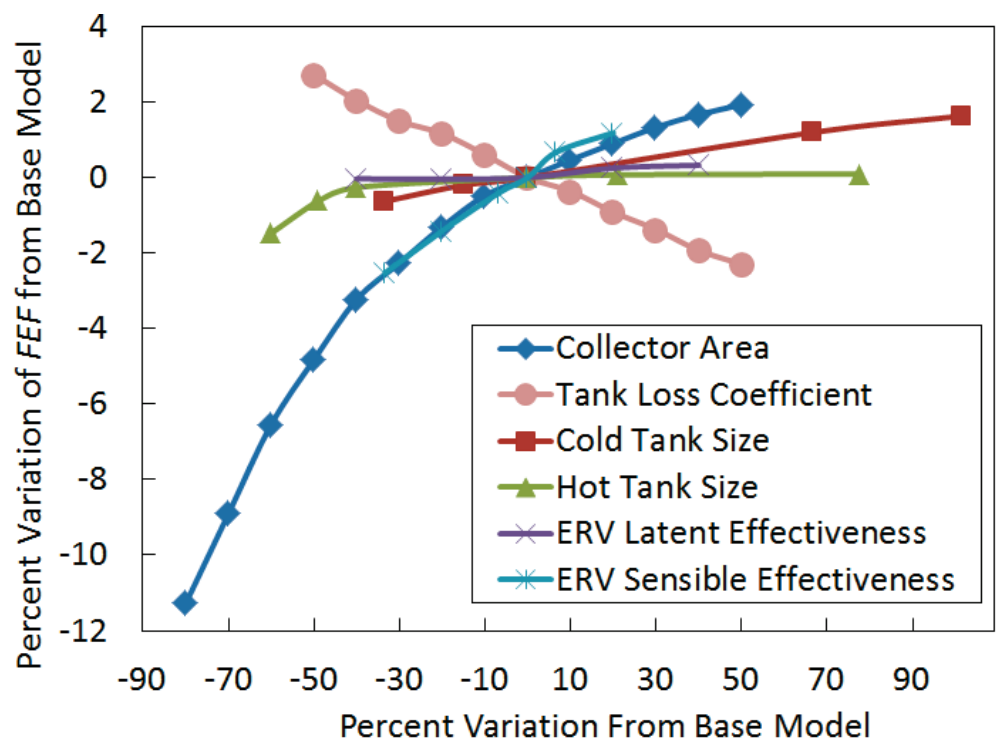

Figure 5.4: Sensitivity study of collector area, tank loss coefficient, tank sizes, and energy recovery ventilator effectiveness (adapted from [17]) 
FEF by about $5.0 \%$ and $11 \%$, respectively. For the ERV parameters, increasing the sensible effectiveness by $20 \%$ to 0.90 would increase the annual $F E F$ by $1.2 \%$. The latent effectiveness showed little effect on the overall performance of the system since increasing the value by $40 \%$ only resulted in an annual FEF increase of $0.3 \%$. The sensitivity studies also showed that decreasing tank loss coefficient by $50 \%$ increased the annual FEF by $2.7 \%$. The simulations also showed that by reducing the hot tank size by $60 \%$, the annual FEF dropped by $1.5 \%$ and increasing the cold tank size by almost $100 \%$ increased the annual FEF by $1.6 \%$ [17].

In addition to the collector area, the collector tilt angle was also examined in the sensitivity studies and the results are shown in Figure 5.5. The optimal angle for the collectors was about $75^{\circ}$, however, the improvement from $90^{\circ}$ was only $0.85 \%$.

The conditions for the heat pump source side minimum inlet cut-off temperature and load side maximum inlet cut-off temperature were also investigated and Figure 5.6 shows the annual FEF achieved for varying these heat pump control conditions. The performance map used to model the heat pump limited the range of values

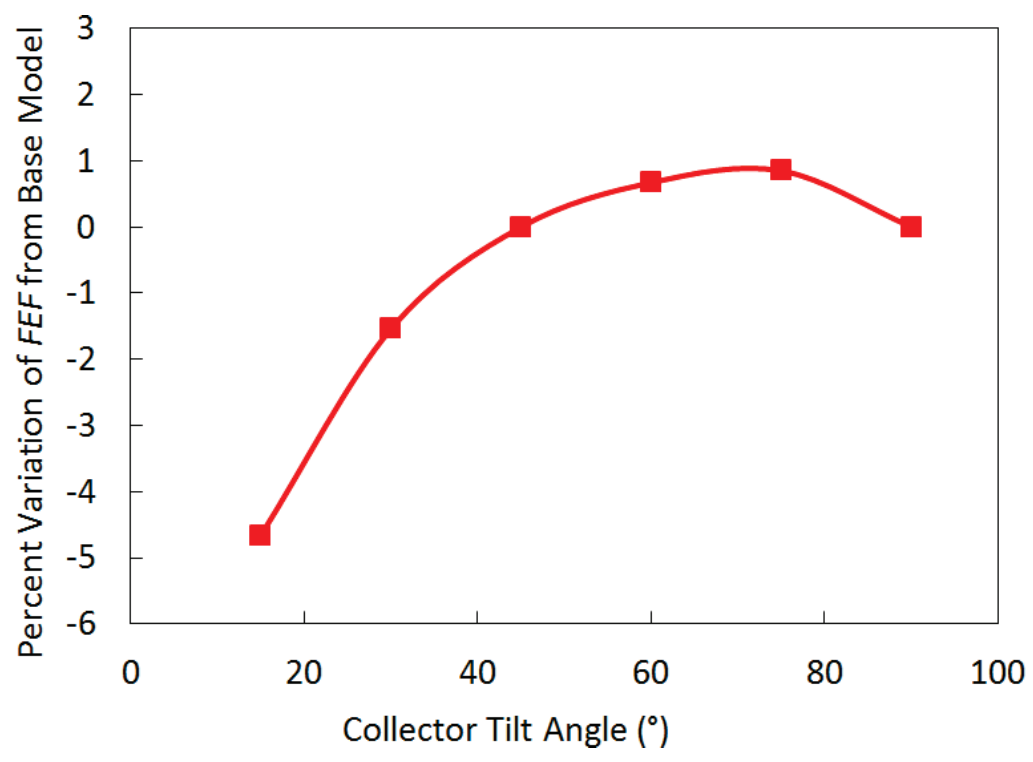

Figure 5.5: Sensitivity study of collector tilt angle 


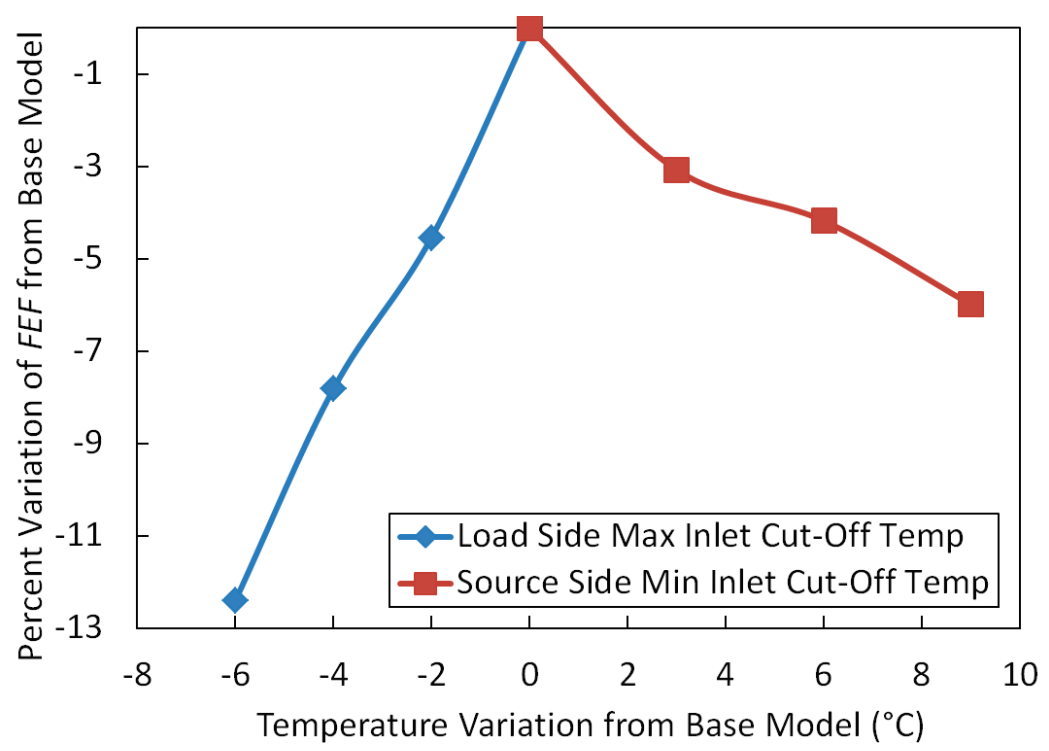

Figure 5.6: Sensitivity study of heat pump control conditions (adapted from [17])

that can be used for the sensitivity study. The results indicate that the annual FEF decreased with increasing minimum source side inlet cut-off temperature and decreasing maximum load side inlet cut-off temperature. If the load side maximum inlet cut-off temperature was decreased by $6^{\circ} \mathrm{C}$, the annual $F E F$ would decrease by 13\%. Also, if the minimum source side inlet cut-off temperature was increased by $9^{\circ} \mathrm{C}$, the annual FEF would decrease by $6.0 \%$ [17].

A sensitivity study was also performed to study the effect of the rated heating capacity and rated $C O P$ of the heat pump. The rated heating capacity was altered with the rated power in order to maintain the same $C O P$ as the base model while the rated $C O P$ was altered by changing the rated power draw and maintaining the base model rated heating capacity. The results of study can be found in Figure 5.7. The $\mathrm{y}$-axis range of Figure 5.7 is much larger compared to other graphs in this section. With a consistent rated $C O P$, the optimal heating capacity was found at about 6 $\mathrm{kW}$. Increasing the heating capacity beyond $6 \mathrm{~kW}$ resulted in a decrease of annual $F E F$. By varying the rated COP from $-30 \%$ to $+50 \%$, the percent variation of the 


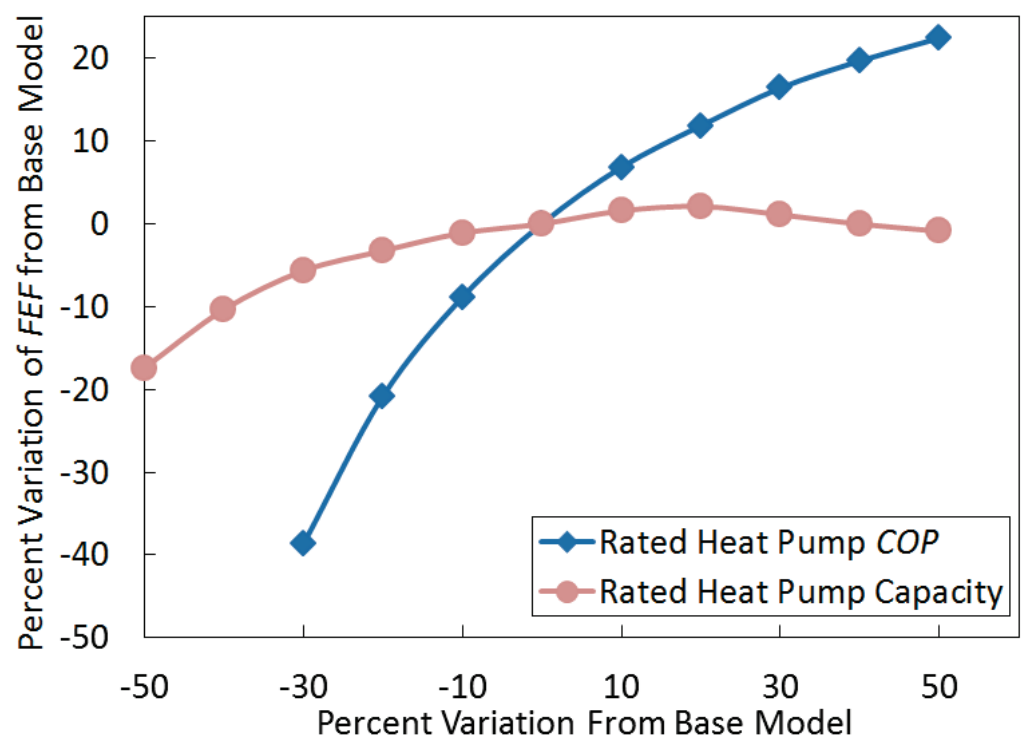

Figure 5.7: Sensitivity study of rated heat pump parameters (adapted from [17])

annual FEF from the base model changed from $-39 \%$ to $+22 \%$. This parameter had the largest effect on the overall performance of the system, compared to any other parameters examined [17]. Unfortunately, these rated values are dependent on the design of the heat pump and cannot be easily controlled.

Glazed flat plate collectors were used in the base model but for comparison, simulations were also conducted using evacuated tube collectors. The results shown in Figure 5.8 indicate that evacuated tubes did not perform as well as glazed flat plate collectors. With the same collector area, the annual FEFs for the glazed flat plate collectors were 0.0163 higher than the annual FEFs found for the evacuated tubes $[17]$.

Figure 5.9 shows how varying the location of the auxiliary heater and the location of water inlets in the hot tank changed the annual $F E F$ achieved. It was found that the annual performance improved as the auxiliary heater moves up in the tank. In fact, placing the auxiliary heater at the top of the tank (node 1) would increase the annual $F E F$ by about $4 \%$. On the other hand, as the hot water return inlet from the 


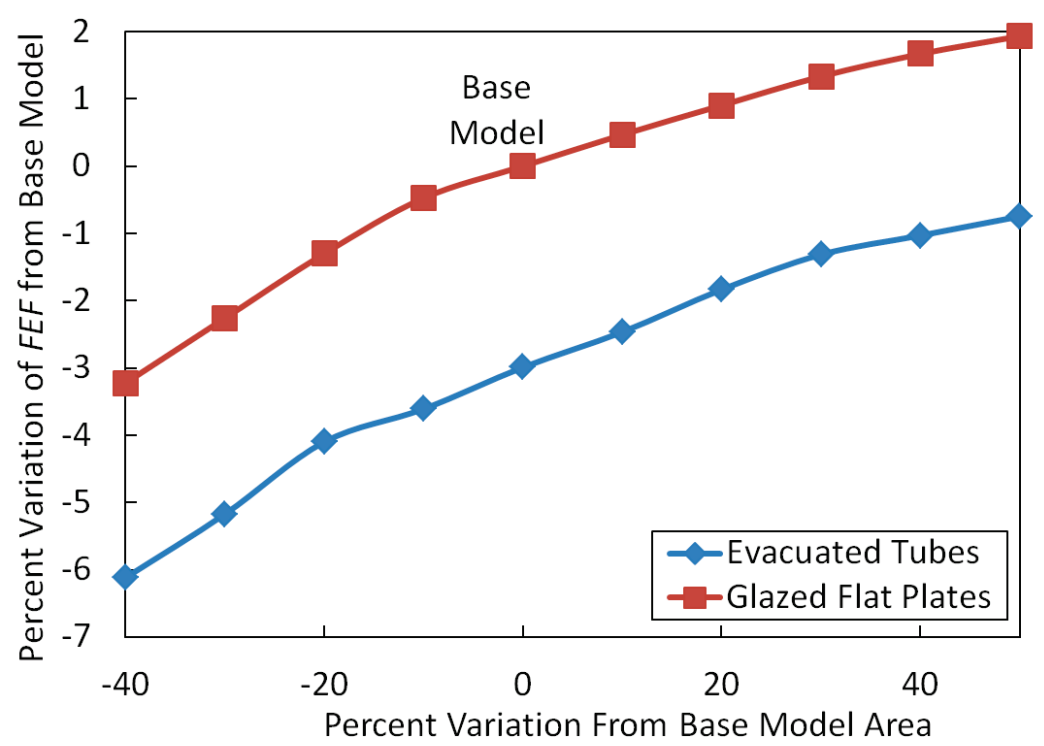

Figure 5.8: Sensitivity study of flat plate and evacuated tube collector array sizes (adapted from [17])

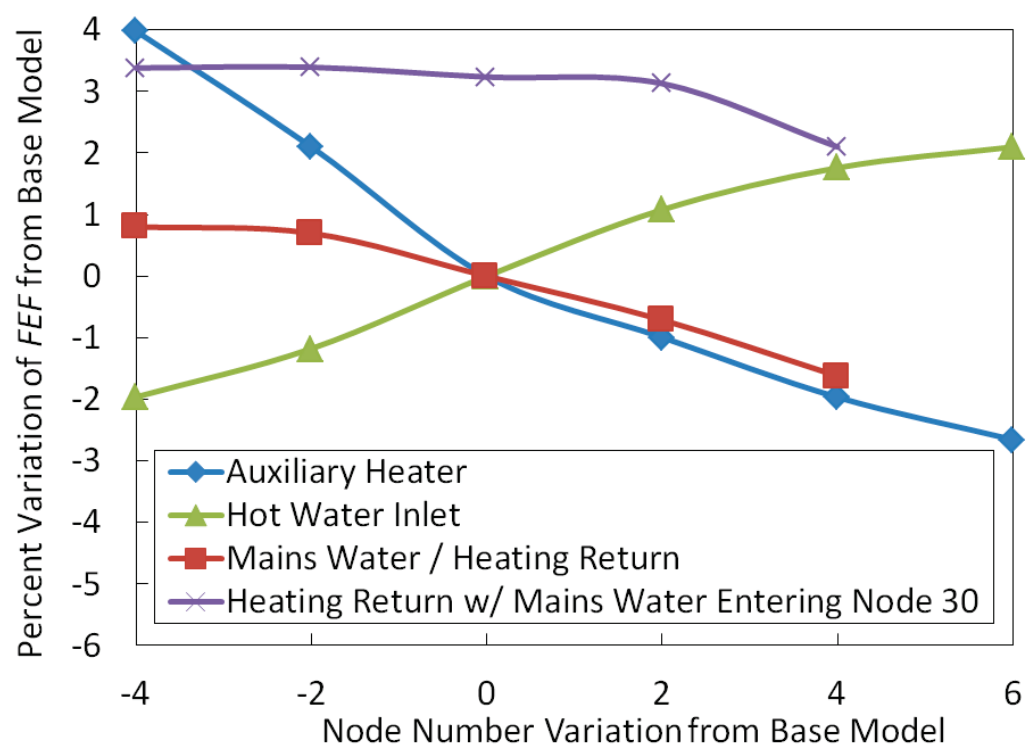

Figure 5.9: Sensitivity study of the auxiliary heater height and inlet node heights within the hot tank (adapted from [17])

heat pump moves up in the tank, the performance of the system decreases. When the hot water inlet is lowered to node 11, the annual FEF increased by about $2 \%$. When the mains water and heating coil return inlets were forced to be in the same location, it was found that as this single inlet moves down in the tank the annual 
FEF decreases; however, it was found that separating the heating coil return inlet from the mains water inlet improved the annual FEF by as much as $3.3 \%$ [17].

Examining the results of the parametric studies, a system with the parameters indicated in Table 5.2 was recommended to help source the components for the IMS. The parameters chosen were based on the results of the sensitivity study and the design constraints from Team Ontario, so that the IMS can be well integrated with ECHO. As indicated in Table 5.2, the collector size, tilt angle and tank sizes were not set as the most optimal performance values due to implementation complexity, size constraints or cost considerations by Team Ontario. For the recommended system, the mains water supply to the hot tank was set to the bottom of the tank. By simulating the system with the parameters indicated in Table 5.2 and using Type 534 for the hot tank, the recommended system achieved an annual $F E F$ of 0.583 [17].

\subsubsection{As-Built System Results}

Team Ontario used the recommended parameters to source the components for the IMS. Due to the final space available in the house and the specific characteristics of components that are available commercially, the system built did not match the recommended system exactly. The system built for the house is the same as the system that was tested in the experimental analysis of this study. Table 5.3 summarizes some of the parameters of the "as-built" system. Using the parameters of the as-built system for the house as input to the TRNSYS model, the system achieved a annual FEF of 0.611 .

Figure 5.10 shows the hot tank configurations for each of the models. Between the recommended and as-built model, the auxiliary heater was located lower in the tank. Therefore, the auxiliary heater in the as-built system must maintain the set-point temperature for a greater volume of water. 
Table 5.2: Parameters of the recommended system from Chu et al. [17]

\begin{tabular}{|c|c|c|}
\hline Parameter & Value & Note/Justification \\
\hline Collector area & $6 \mathrm{~m}^{2}$ & $\begin{array}{l}\text { Reducing the area by } 50 \% \text { would only reduce the annual } \\
F E F \text { by about } 5 \% \text {. This would significantly reduce the cost } \\
\text { of the system and reduce the area of collectors that must be } \\
\text { architecturally integrated with the house. }\end{array}$ \\
\hline Collector tilt angle & $90^{\circ}$ & $\begin{array}{l}\text { Setting the angle from } 90^{\circ} \text { to } 75^{\circ} \text { would only increase the } \\
\text { annual } F E F \text { by } 0.85 \% \text {. A } 90^{\circ} \text { angle reduces mounting } \\
\text { complexities as collectors can be mounted flush with a } \\
\text { vertical surface. This was also more architecturally appealing. }\end{array}$ \\
\hline $\begin{array}{l}\text { Hot storage tank } \\
\text { size }\end{array}$ & $450 \mathrm{~L}$ & $\begin{array}{l}\text { Even though reducing the volume from } 450 \mathrm{~L} \text { to } 270 \mathrm{~L} \text { will } \\
\text { only reduce the annual FEF by } 0.1 \% \text {, a larger tank was } \\
\text { chosen to ensure enough hot water is present at all times. }\end{array}$ \\
\hline $\begin{array}{l}\text { Cold storage tank } \\
\text { size }\end{array}$ & $270 \mathrm{~L}$ & $\begin{array}{l}\text { The study suggests that the a larger tank would yield better } \\
\text { performance; however, a smaller volume would limit the } \\
\text { amount of costly glycol required. Also, since the hot tank is } \\
\text { already } 450 \mathrm{~L} \text {, a } 450 \mathrm{~L} \text { or larger cold tank would be too large } \\
\text { for the mechanical room and would significantly reduce the } \\
\text { working space available. }\end{array}$ \\
\hline $\begin{array}{l}\text { Tank loss } \\
\text { coefficient }\end{array}$ & $\begin{array}{c}4.132 \\
\mathrm{~kJ} / \mathrm{h} \cdot \mathrm{m}^{2} \mathrm{~K}\end{array}$ & $\begin{array}{l}\text { This value was not changed as it depends on the tank that } \\
\text { will be used. Extra insulation can be added to tank to } \\
\text { improve performance. }\end{array}$ \\
\hline $\begin{array}{l}\text { Heat pump source } \\
\text { side min. inlet } \\
\text { cut-off temp. }\end{array}$ & $6^{\circ} \mathrm{C}$ & $\begin{array}{l}\text { This was limited by the heat pump performance map in the } \\
\text { simulations. The lower this value the better the performance } \\
\text { of the IMS. }\end{array}$ \\
\hline $\begin{array}{l}\text { Heat pump load } \\
\text { side max. inlet } \\
\text { cut-off temp. }\end{array}$ & $40^{\circ} \mathrm{C}$ & $\begin{array}{l}\text { This was limited by the heat pump performance map in the } \\
\text { simulations. The higher this value the better the performance } \\
\text { of the IMS but if the value is too high, the hot tank may be } \\
\text { heated to a temperature higher than needed. }\end{array}$ \\
\hline $\begin{array}{l}\text { Heat pump rated } \\
\text { heating capacity }\end{array}$ & $6 \mathrm{~kW}$ & $\begin{array}{l}\text { The optimal performance was determined at this value } \\
\text { assuming a constant rated } C O P \text { of } 3.3 \text {. }\end{array}$ \\
\hline $\begin{array}{l}\text { Heat pump rated } \\
\text { power }\end{array}$ & $1.8 \mathrm{~kW}$ & $\begin{array}{l}\text { The rated } C O P \text { was assumed to be } 3.3 \text { since the } C O P \\
\text { depends highly on the heat pump. }\end{array}$ \\
\hline $\begin{array}{l}\text { Hot tank auxiliary } \\
\text { heater position }\end{array}$ & node 5 & $\begin{array}{l}\text { Node } 5 \text { was chosen so that a sufficient volume of } 55^{\circ} \mathrm{C} \text { water } \\
\text { is available for DHW and space-heating at all times. }\end{array}$ \\
\hline $\begin{array}{l}\text { Hot tank heat } \\
\text { pump return inlet }\end{array}$ & node 10 & $\begin{array}{l}\text { Studies showed that having the hot water inlet below the } \\
\text { auxiliary heater could improve performance. }\end{array}$ \\
\hline $\begin{array}{l}\text { Hot tank heating } \\
\text { coil return inlet }\end{array}$ & node 21 & $\begin{array}{l}\text { This was the optimal height found since the return water } \\
\text { from the heating coil is higher in temperature than the mains } \\
\text { water which will enter node } 30 \text { at the bottom of the tank. }\end{array}$ \\
\hline $\begin{array}{l}\text { ERV sensible } \\
\text { effectiveness }\end{array}$ & 0.9 & $\begin{array}{l}\text { The higher the sensible effectiveness, the better the } \\
\text { performance. }\end{array}$ \\
\hline $\begin{array}{l}\text { ERV latent } \\
\text { effectiveness }\end{array}$ & 0.5 & This value had little effect on the overall performance. \\
\hline
\end{tabular}


Table 5.3: Parameters of the as-built system

\begin{tabular}{|c|c|c|}
\hline Parameter & Value & Note/Justification \\
\hline Collector area & $12 \mathrm{~m}^{2}$ & $\begin{array}{l}\text { The exterior of the house was architecturally designed for } \\
12 \mathrm{~m}^{2} \text { of collectors. Using a smaller area would negatively } \\
\text { affect the visual appeal of the house. }\end{array}$ \\
\hline Collector tilt angle & $90^{\circ}$ & See Table 5.2 \\
\hline $\begin{array}{l}\text { Cold storage tank } \\
\text { size }\end{array}$ & $303 \mathrm{~L}$ & $\begin{array}{l}\text { See Table } 5.2 \text {. This specific size was available from a } \\
\text { Team Ontario sponsor. }\end{array}$ \\
\hline $\begin{array}{l}\text { Hot storage tank } \\
\text { size }\end{array}$ & $454 \mathrm{~L}$ & $\begin{array}{l}\text { See Table } 5.2 \text {. This specific size was available from a } \\
\text { Team Ontario sponsor. }\end{array}$ \\
\hline $\begin{array}{l}\text { Cold tank loss } \\
\text { coefficient }\end{array}$ & $\begin{array}{c}1.181 \\
\mathrm{~kJ} / \mathrm{h} \cdot \mathrm{m}^{2} \mathrm{~K}\end{array}$ & This value was indicated in the cold tank specifications. \\
\hline $\begin{array}{l}\text { Hot tank loss } \\
\text { coefficient }\end{array}$ & $\begin{array}{c}1.224 \\
\mathrm{~kJ} / \mathrm{h} \cdot \mathrm{m}^{2} \mathrm{~K}\end{array}$ & This value was indicated in the hot tank specifications. \\
\hline $\begin{array}{l}\text { Heat pump source } \\
\text { side min. inlet } \\
\text { cut-off temp. }\end{array}$ & $6^{\circ} \mathrm{C}$ & See Table 5.2. \\
\hline $\begin{array}{l}\text { Heat pump load } \\
\text { side max. inlet } \\
\text { cut-off temp. }\end{array}$ & $40^{\circ} \mathrm{C}$ & See Table 5.2. \\
\hline $\begin{array}{l}\text { Heat pump rated } \\
\text { heating capacity }\end{array}$ & $5 \mathrm{~kW}$ & $\begin{array}{l}\text { Although smaller than the recommended value (and } \\
\text { equivalent to the base model value), this unit was available } \\
\text { from a Team Ontario sponsor. From the sensitivity study } \\
\text { shown in Figure } 5.7 \text {, increasing the base model value to } \\
6 \mathrm{~kW} \text { ( }+20 \% \text { of the base model) only increased the annual } \\
F E F \text { by } 2.1 \% \text { of the base model annual } F E F \text {. }\end{array}$ \\
\hline $\begin{array}{l}\text { Heat pump rated } \\
\text { power }\end{array}$ & $1.5 \mathrm{~kW}$ & See Table 5.2 and above note. \\
\hline $\begin{array}{l}\text { Hot tank rated } \\
\text { auxiliary heater } \\
\text { position }\end{array}$ & node 9 & $\begin{array}{l}\text { This was constrained by the specification of the hot tank. } \\
\text { The auxiliary heater was located above the hot tank hot } \\
\text { side inlet. }\end{array}$ \\
\hline $\begin{array}{l}\text { Hot tank heat } \\
\text { pump return inlet }\end{array}$ & node 12 & $\begin{array}{l}\text { A side-port was present in the hot tank which was right } \\
\text { below the auxiliary heater. }\end{array}$ \\
\hline $\begin{array}{l}\text { Hot tank heating } \\
\text { coil return inlet }\end{array}$ & node 21 & $\begin{array}{l}\text { A dip tube was used to bring the heating coil return to } \\
\text { this node in the tank. }\end{array}$ \\
\hline $\begin{array}{l}\text { ERV sensible } \\
\text { effectiveness }\end{array}$ & 0.7 & $\begin{array}{l}\text { Approximate value from the specifications of the ERV } \\
\text { obtained for Team Ontario [56]. }\end{array}$ \\
\hline $\begin{array}{l}\text { ERV latent } \\
\text { effectiveness }\end{array}$ & 0.6 & $\begin{array}{l}\text { Approximate value from the specifications of the ERV } \\
\text { obtained for Team Ontario [56]. }\end{array}$ \\
\hline
\end{tabular}




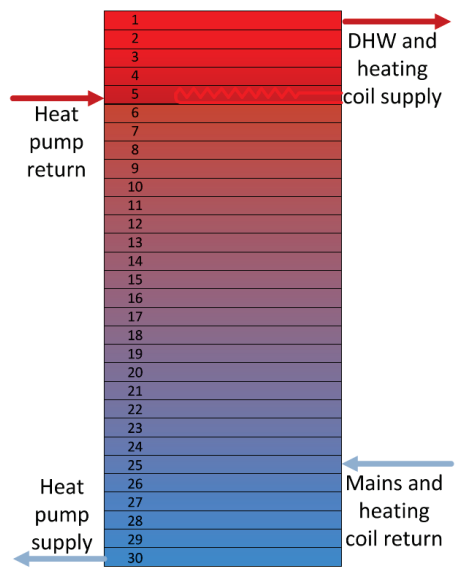

(a) Base model

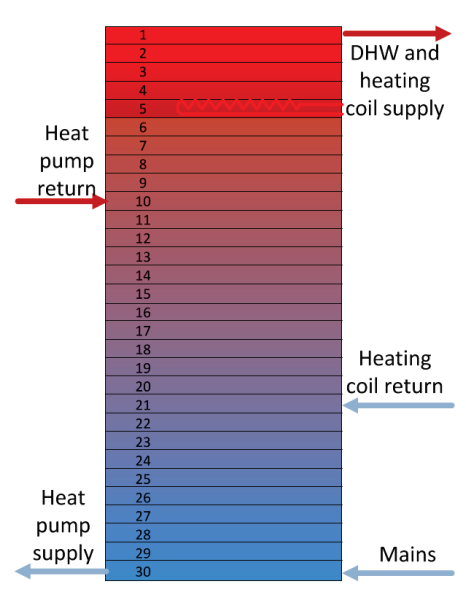

(b) Recommended model

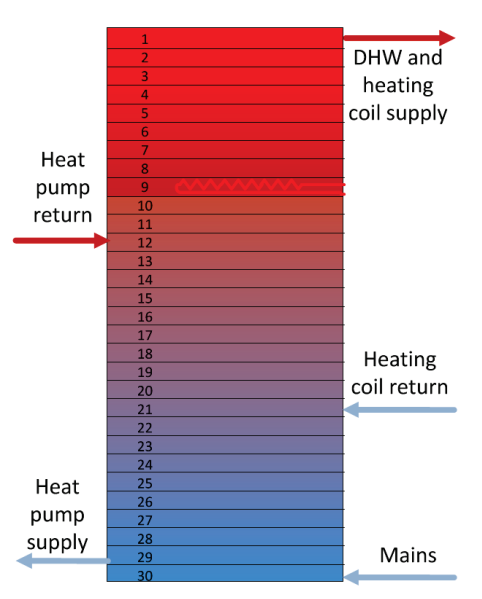

(c) As-built model

Figure 5.10: Hot tank configurations for various models

For the as-built model simulations, only the parameters indicated in Table 5.3 were updated. All other parameters of the IMS remained the same as those indicated in Chapter 3 in order to focus on how the overall performance changes with the parameters listed in Table 5.3. When the IMS was built and commissioned in the house, many parameters outside of those listed in Table 5.3 were changed, however, these changes were not examined in this study.

\subsubsection{Sensitivity Study of Heat Pump Load Side Flow Rate}

When obtaining the heat pump for Team Ontario, the supplier expressed concerns regarding the low flow rates required on the load side of the heat pump. The simulations conducted for the sensitivity studies used a load side flow rate of $2.92 \mathrm{~L} / \mathrm{min}$ $(175 \mathrm{~kg} / \mathrm{h})$. The original catalogue performance data from the manufacturer did not include information for operational conditions with load side flows rates as low as 2.92 $\mathrm{L} / \mathrm{min}(175 \mathrm{~kg} / \mathrm{h})$. A sensitivity study of the load side flow rate was conducted using the model with the parameters of the as-built system and the results of the study are presented in Figures 5.11 and 5.12. It was found that as the flow rate decreased, 
the annual FEF increased even though the annual average COP of the heat pump decreased. Increasing the flow rate to $9.58 \mathrm{~L} / \mathrm{min}(575 \mathrm{~kg} / \mathrm{h})$ can decrease the annual FEF by $19 \%$. As shown in Figure 5.12, as the flow rate increased, the annual energy usage for the heat pump compressor decreased but the amount of energy used in the auxiliary heater increased.

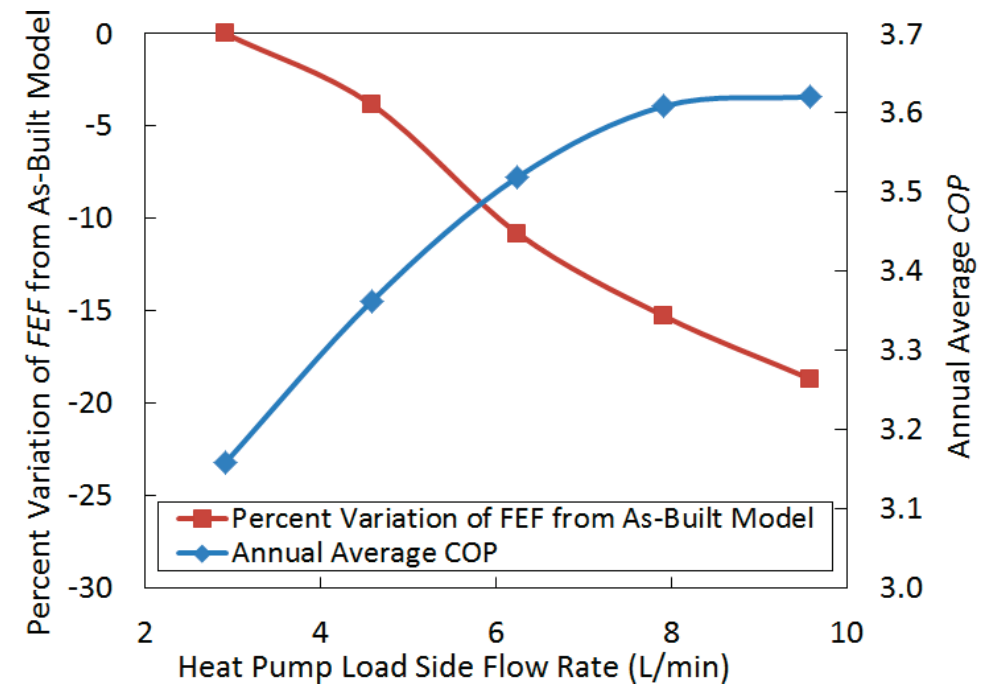

Figure 5.11: Annual free energy fraction and average coefficient of performance as a function of heat pump load side flow rate

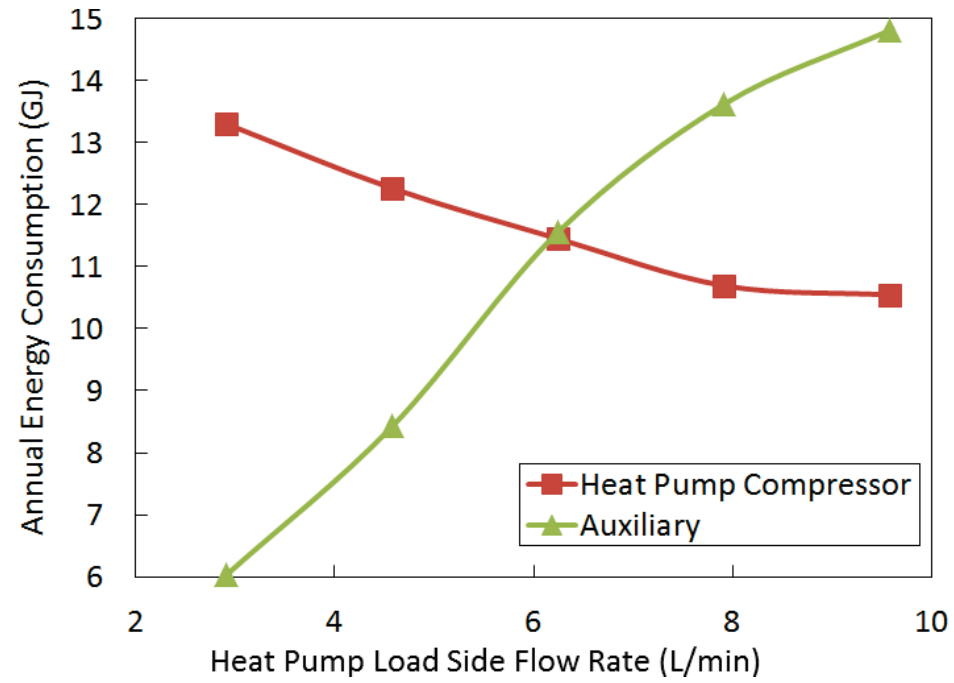

Figure 5.12: Annual heat pump compressor energy usage and auxiliary energy usage as a function of heat pump load side flow rate 


\section{$5.2 \quad$ Experimental Results}

As described in Chapter 4, all operational parameters and initial conditions were held constant while the load side flow rate of the heat pump was varied between each test. Tests were performed with load side flow rates at $2 \mathrm{~L} / \mathrm{min}, 3 \mathrm{~L} / \mathrm{min}, 4$ $\mathrm{L} / \mathrm{min}, 6 \mathrm{~L} / \mathrm{min}, 8 \mathrm{~L} / \mathrm{min}$, and $10 \mathrm{~L} / \mathrm{min}$. These tests were conducted to investigate how the load side flow rate influences the stratification in the hot tank and the heat pump performance. Each test was concluded when the refrigerant pressure reached 500 psi. Therefore, the duration of each test varied. The pressure of the refrigerant depends on the condensing temperature that the heat pump must achieve to meet the load. High condensing temperatures are required when the load is large due to lower flow rates or when the load side inlet temperature is too high. Table 5.4 summarizes the overall final results of each test. Only tests at $2 \mathrm{~L} / \mathrm{min}, 3 \mathrm{~L} / \mathrm{min}$, and $4 \mathrm{~L} / \mathrm{min}$ achieved temperatures over $50^{\circ} \mathrm{C}$ at the top of the tank by the end of the tests. All other tests reached temperatures close to $50^{\circ} \mathrm{C}$, with the lowest achieved temperature of $48.6^{\circ} \mathrm{C}$ for the $6 \mathrm{~L} / \mathrm{min}$ test. The overall results for heat transfer, power draw, and $C O P$ for each test cannot be directly compared due to the differing test durations.

Figure 5.13 shows the change in the temperature of the hot tank profile where each solid line represents the temperature measurements of the each temperature

Table 5.4: Final results of each experimental test

\begin{tabular}{|c|c|c|c|c|c|c|}
\hline Load Side Flow Rate (L/min) & $\mathbf{2}$ & $\mathbf{3}$ & $\mathbf{4}$ & $\mathbf{6}$ & $\mathbf{8}$ & $\mathbf{1 0}$ \\
\hline Test Duration (h) & 2.77 & 2.34 & 1.88 & 2.15 & 2.42 & 2.5 \\
Temperature at the Top of the Hot Tank $\left({ }^{\circ} \mathrm{C}\right)$ & 61.3 & 53.3 & 52.9 & 48.7 & 49.6 & 49.1 \\
Average Heat Transfer Rate (kW) & 5.79 & 5.95 & 5.59 & 5.66 & 5.47 & 5.38 \\
Average Heat Pump Power Draw (kW) & 1.94 & 1.63 & 1.46 & 1.40 & 1.42 & 1.43 \\
Total Energy Transferred (MJ) & 58.1 & 50.6 & 38.5 & 44.4 & 48.1 & 48.8 \\
Total Heat Pump Energy Draw (MJ) & 19.5 & 13.9 & 10.0 & 10.9 & 12.5 & 13.0 \\
Average COP & 2.98 & 3.64 & 3.84 & 4.06 & 3.86 & 3.76 \\
\hline
\end{tabular}


probe thermocouple as labelled in Figure 4.3. The change in heat pump load side inlet temperature ("Heat Pump Load In") and outlet temperature ("Heat Pump Load Out") over time are also indicated in Figure 5.13. The results show that stratification in the hot tank can be achieved with low flow rates less than $8 \mathrm{~L} / \mathrm{min}$. For the 2 $\mathrm{L} / \mathrm{min}$ and $3 \mathrm{~L} / \mathrm{min}$ tests, the tank reached temperatures over $50^{\circ} \mathrm{C}$ as required for DHW requirements after the entire volume of the hot tank passed through the heat pump once. At $2 \mathrm{~L} / \mathrm{min}$, the temperature change from the heat pump load side inlet to the outlet was about $40^{\circ} \mathrm{C}$ while for $3 \mathrm{~L} / \mathrm{min}$, the change was about $30^{\circ} \mathrm{C}$. For these tests, the volume of the tank only passed through the heat pump once. At the moderate flow rates of $4 \mathrm{~L} / \mathrm{min}$ and $6 \mathrm{~L} / \mathrm{min}$, the temperature change from the heat pump as shown in Figures 5.13(c) and 5.13(d) was approximately $20^{\circ} \mathrm{C}$ and $13^{\circ} \mathrm{C}$, respectively. For the $4 \mathrm{~L} / \mathrm{min}$ test, the entire volume of the tank passed through the heat pump once and the for the $6 \mathrm{~L} / \mathrm{min}$ test, two passes were achieved. Temperatures in the top portion of the tank only approached $50^{\circ} \mathrm{C}$ for the $8 \mathrm{~L} / \mathrm{min}$ test and the $10 \mathrm{~L} / \mathrm{min}$ test towards the end of the tests. As indicated in Figures 5.13(e) and 5.13(f), low levels of stratification were achieved in the $8 \mathrm{~L} / \mathrm{min}$ test and almost no stratification was observed in the $10 \mathrm{~L} / \mathrm{min}$ test. The volume of the tank was able to pass through the heat pump several times but with lower temperature increases. The average temperature changes through the heat pump were about $10^{\circ} \mathrm{C}$ and $8^{\circ} \mathrm{C}$ for the $8 \mathrm{~L} / \mathrm{min}$ and $10 \mathrm{~L} / \mathrm{min}$ tests, respectively.

Figure 5.14 shows the heat pump heat transfer rate, power draw and instantaneous $C O P$ for each test while Figure 5.15 shows the accumulated energy transferred to the load, the accumulated energy draw by the compressor and the average $C O P$ over the duration of the test. The results indicate that, with inlet temperatures of approximately $20^{\circ} \mathrm{C}$, the $C O P$ increased with increasing heat pump load side flow rate, however, as the inlet temperature increased, the $C O P$ decreased. As indicated 


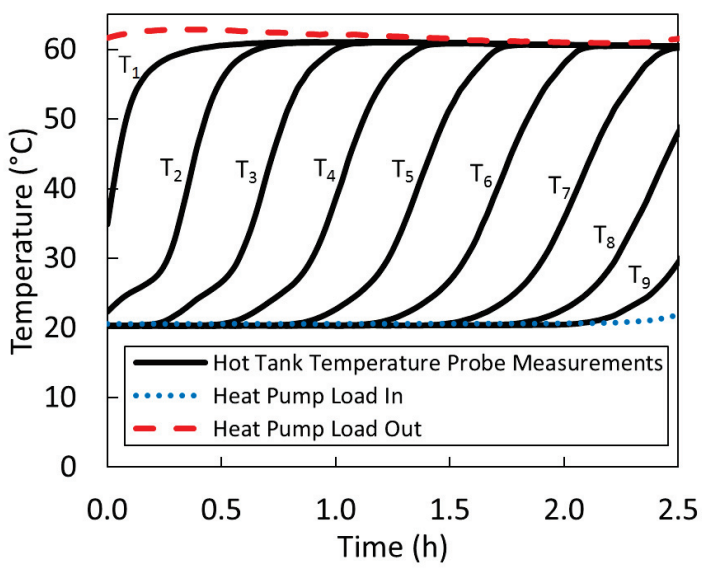

(a) $2 \mathrm{~L} / \mathrm{min}$

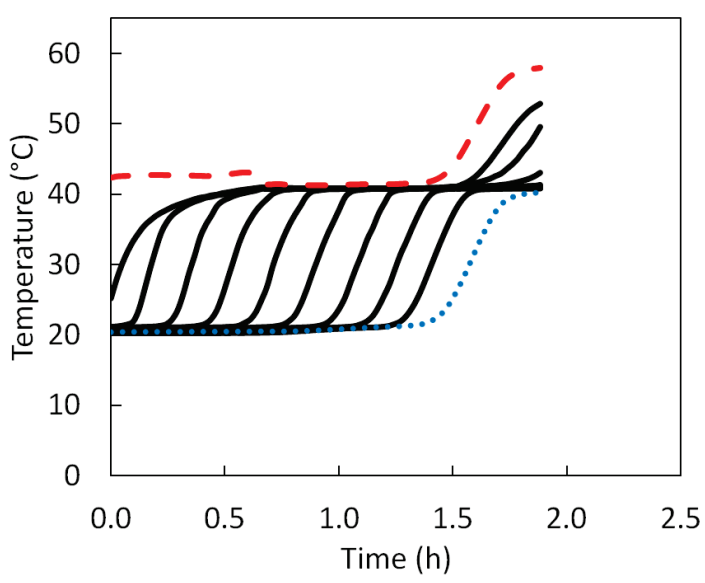

(c) $4 \mathrm{~L} / \mathrm{min}$

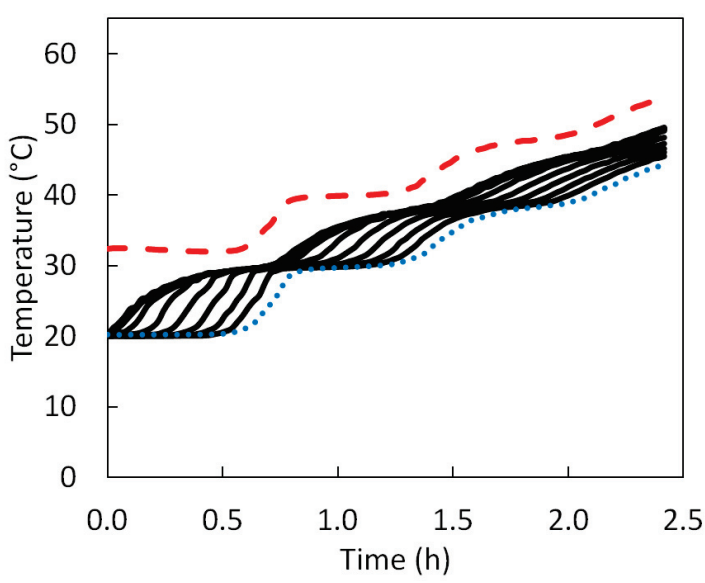

(e) $8 \mathrm{~L} / \mathrm{min}$

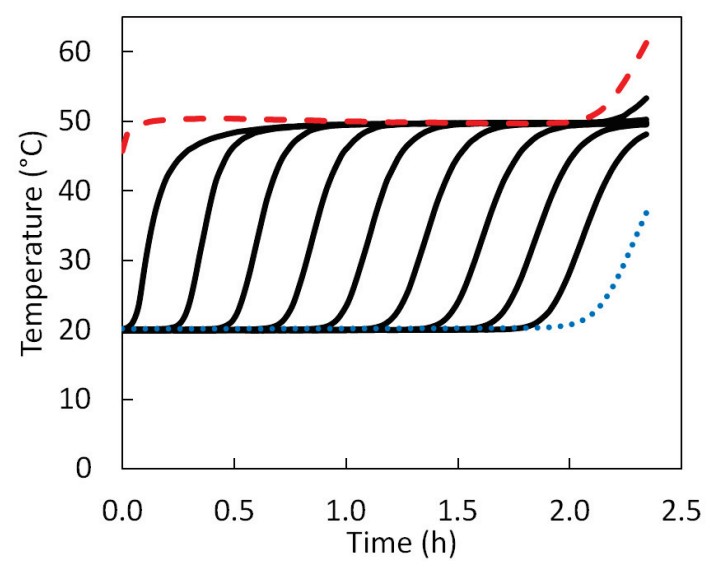

(b) $3 \mathrm{~L} / \mathrm{min}$

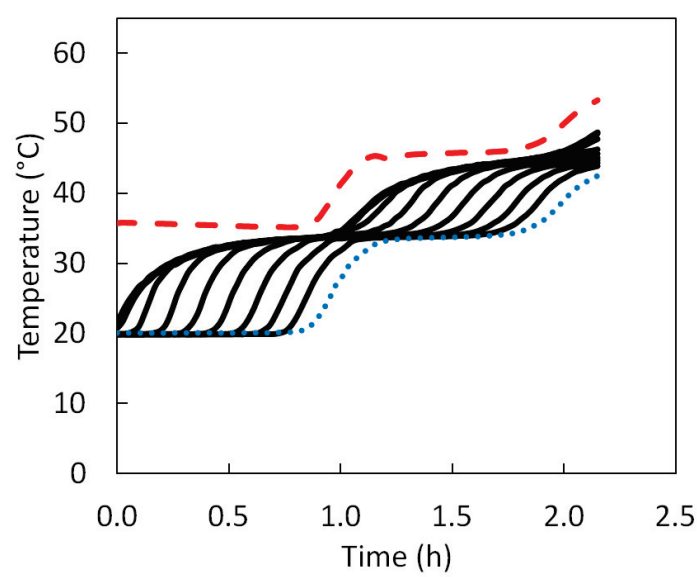

(d) $6 \mathrm{~L} / \mathrm{min}$

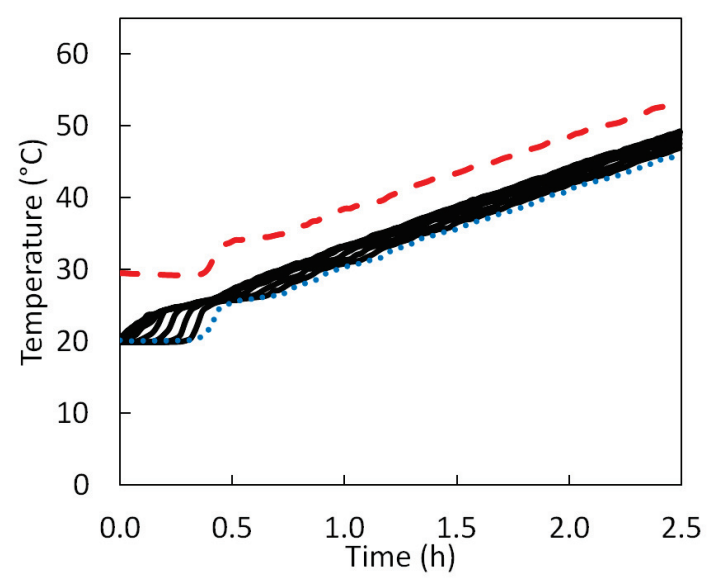

(f) $10 \mathrm{~L} / \mathrm{min}$

Figure 5.13: Hot tank temperature profiles and heat pump load side temperatures with varying heat pump load side flow rates 


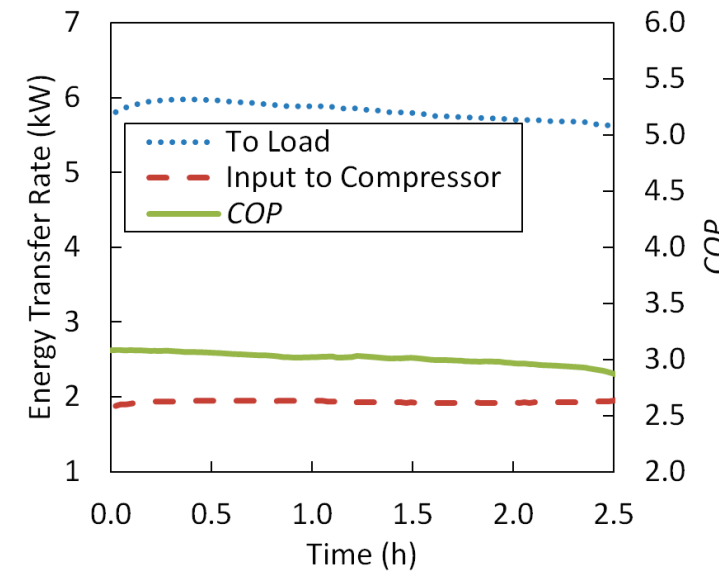

(a) $2 \mathrm{~L} / \mathrm{min}$

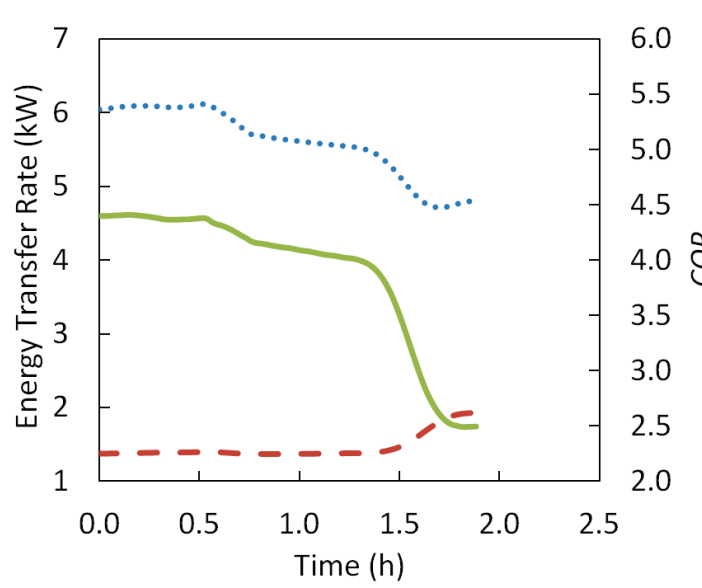

(c) $4 \mathrm{~L} / \mathrm{min}$

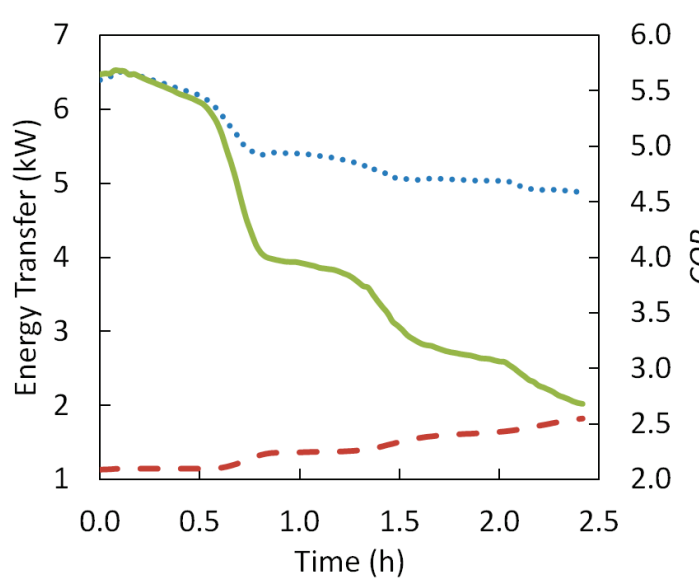

(e) $8 \mathrm{~L} / \mathrm{min}$

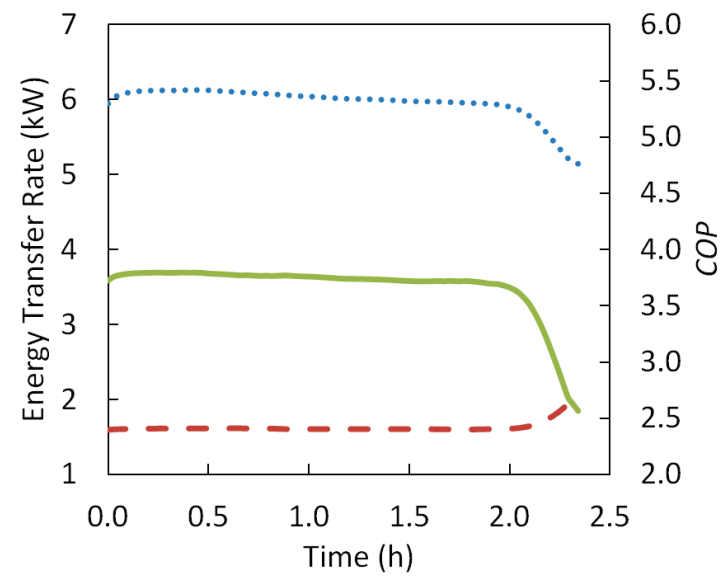

(b) $3 \mathrm{~L} / \mathrm{min}$

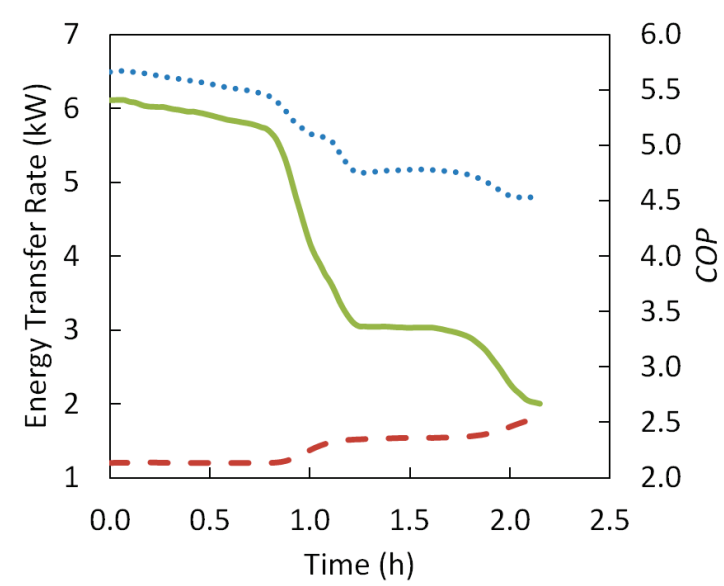

(d) $6 \mathrm{~L} / \mathrm{min}$

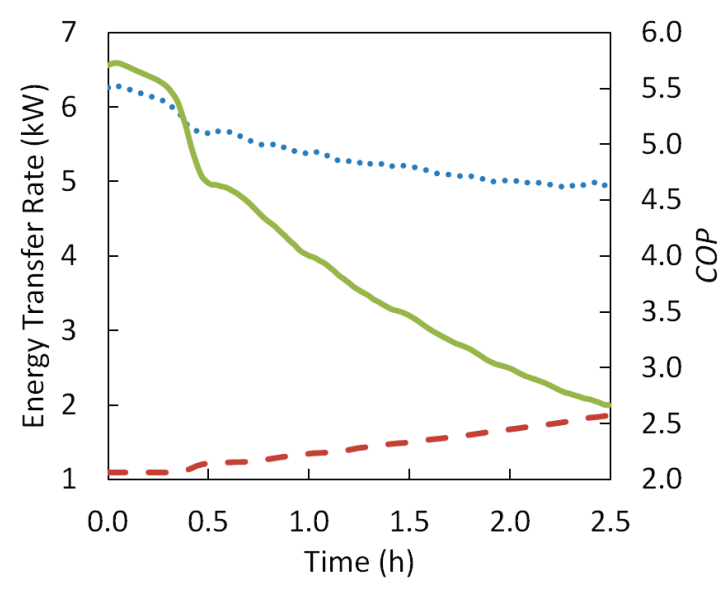

(f) $10 \mathrm{~L} / \mathrm{min}$

Figure 5.14: Instantaneous heat transfer rates and coefficient of performance 


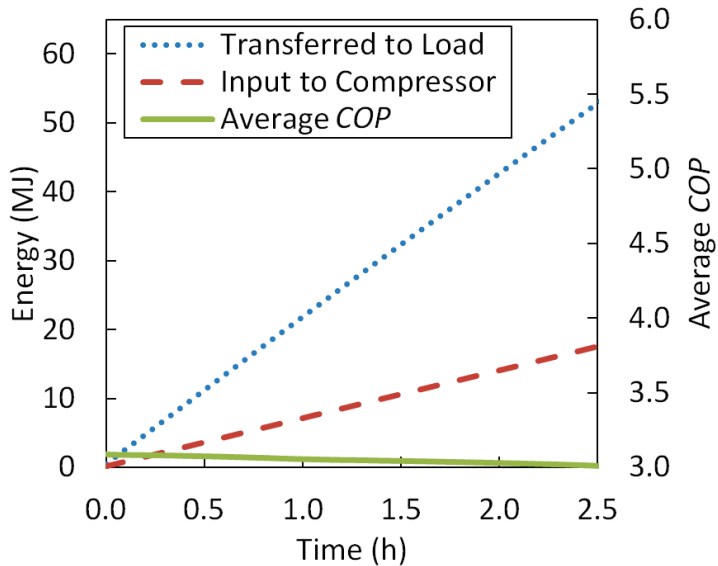

(a) $2 \mathrm{~L} / \mathrm{min}$

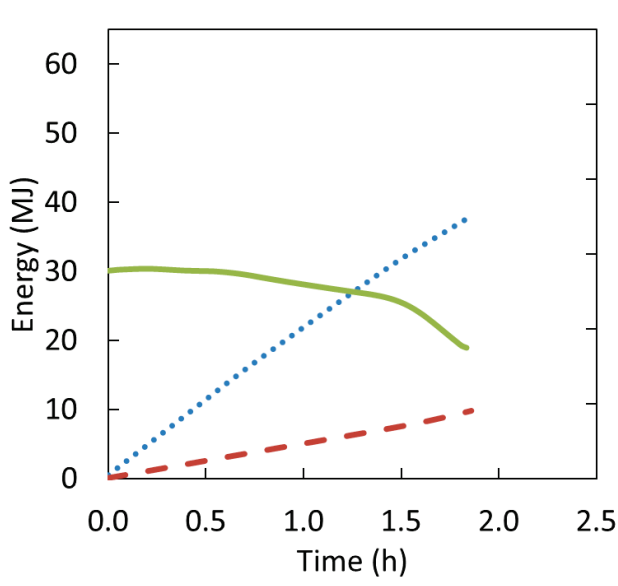

(c) $4 \mathrm{~L} / \mathrm{min}$

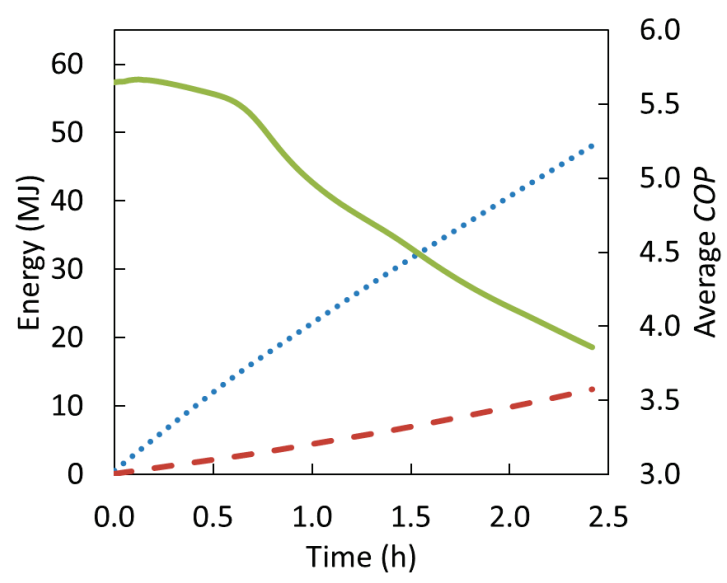

(e) $8 \mathrm{~L} / \mathrm{min}$

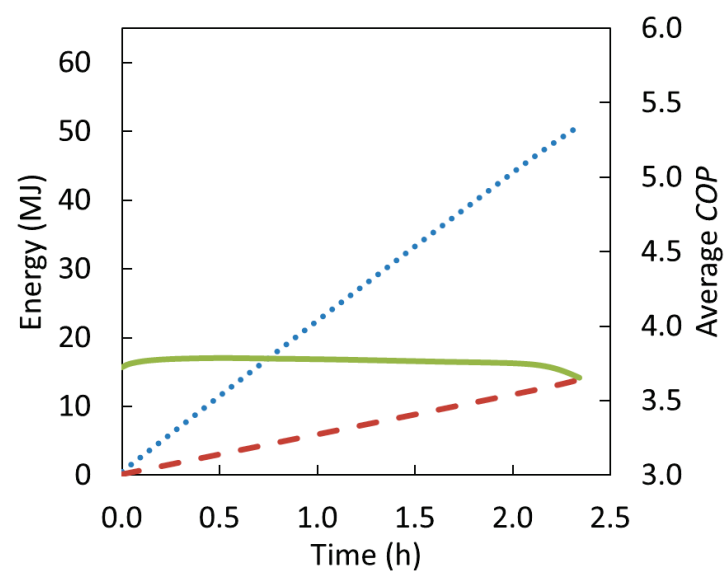

(b) $3 \mathrm{~L} / \mathrm{min}$

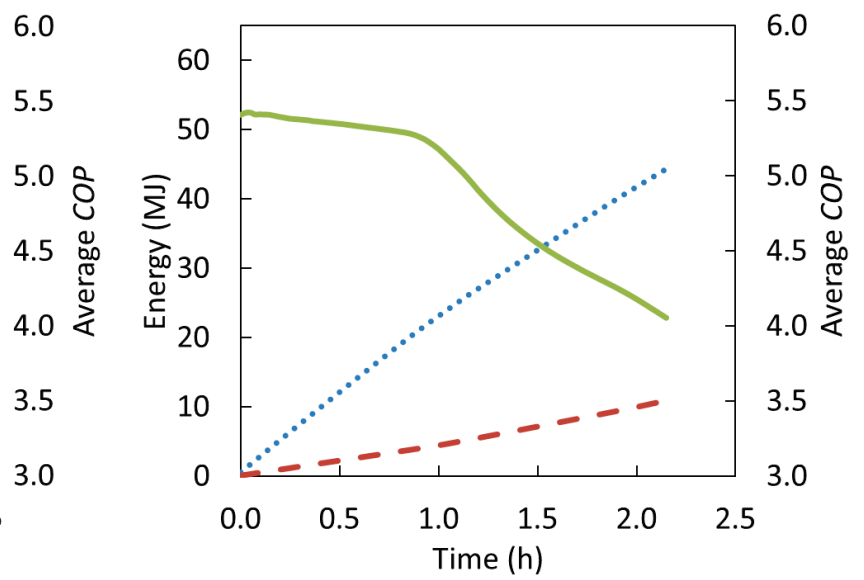

(d) $6 \mathrm{~L} / \mathrm{min}$

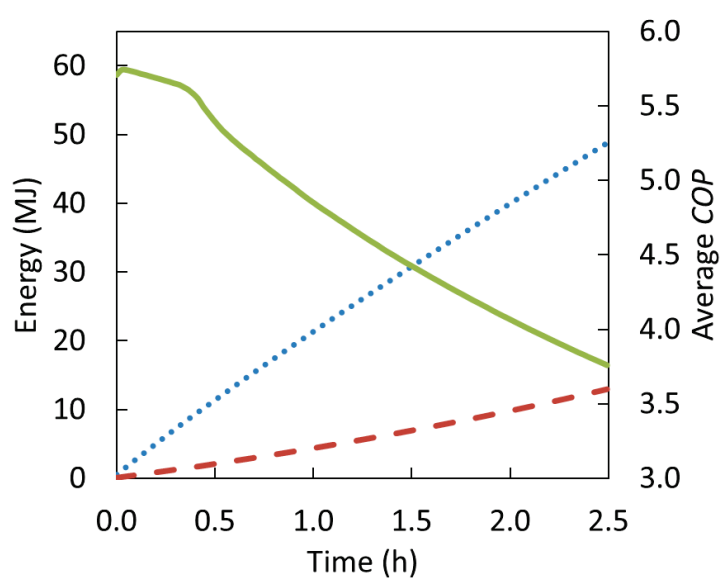

(f) $10 \mathrm{~L} / \mathrm{min}$

Figure 5.15: Accumulated energy transferred to load and consumed by heat pump compressor and average coefficient of performance 
in Table 5.4 and depicted in Figure 5.14, the range for the average heat transfer rate for each test was small, ranging from $5.38 \mathrm{~kW}$ from the $10 \mathrm{~L} / \mathrm{min}$ test to $5.95 \mathrm{~kW}$ from the $3 \mathrm{~L} / \mathrm{min}$ test. The average power draw ranged from $1.40 \mathrm{~kW}$ to $1.94 \mathrm{~kW}$ between all the tests. The results show that, with the same inlet temperature of about $20^{\circ} \mathrm{C}$, the compressor power draw was greater with lower flow rates, however, as the inlet temperature increased, the power draw also increased and the heat transfer rate decreased.

For each test, both tanks started at about $20^{\circ} \mathrm{C}$ from the bottom to the top of the tank. Throughout each test, water was drawn from the bottom of the cold tank and heated to approximately $20^{\circ} \mathrm{C}$ by the solar simulator and returned back to the top of the cold tank. For all of the tests, the rate at which energy was removed from the cold tank by the heat pump was greater than the rate at which the tank was charged. The flow between the cold tank and the heat pump was set to approximately $10.3 \mathrm{~L} / \mathrm{min}$. It was found that the source side inlet temperature gradually reduced throughout each test to final temperatures of about $11^{\circ} \mathrm{C}$ to $13^{\circ} \mathrm{C}$ depending on the test. The effects of the decreasing source side inlet temperature was evident as shown in Figures 5.13 and 5.14 for the $2 \mathrm{~L} / \mathrm{min}, 3 \mathrm{~L} / \mathrm{min}, 4 \mathrm{~L} / \mathrm{min}$, and $6 \mathrm{~L} / \mathrm{min}$ tests when the load side inlet temperature was a consistent $20^{\circ} \mathrm{C}$ but the heat transfer rate decreased very gradually over time. Since this study focused on the relationship between the heat pump performance and the thermal stratification in the hot tank, the relationships between the solar collector charging process, cold tank temperature profile and heat pump performance were not further examined. 


\subsection{Modelling of the Experimental Set-up}

The experimental set-up was modelled for the $3 \mathrm{~L} / \mathrm{min}, 6 \mathrm{~L} / \mathrm{min}$, and $10 \mathrm{~L} / \mathrm{min}$ tests. Figure 5.16 shows the modelled tank temperature profile with the temperatures of the nodes that are in the same position as the thermocouples of the temperature probe in the experimental set-up. For comparison, the temperature profiles obtained from the experimental results are also shown in Figure 5.16. The modelled hot tank profiles were from simulations using the performance map created with the combination of experimental and manufacturer's data. The modelled temperatures in the hot tank showed less stratification than the experimental results. The change in temperature of each node was more gradual than the change in temperature measured from each thermocouple in the hot tank.

Figure 5.17 shows the comparison of experimental results ("Exp."), simulation results using manufacturer's heat pump data ("Sim. w/ Manu. Data"), and simulation results using experimental and manufacturer's data ("Sim. w/ Exp. Data"). On the left half of Figure 5.17 are the results for the heat transfer rate to the load side of the heat pump and the compressor power draw and on the right half are the results for the $C O P$.

For the $3 \mathrm{~L} / \mathrm{min}$ test, the simulation using just the manufacturer's data underestimates the power draw compared to experimental data. As a result, the $C O P$ from the simulation using the manufacturer's data was higher than the experimental values. Using the performance map created from experimental and manufacturer's data significantly improved the simulation results to match the experimental results. For these simulations, the heat transfer rate and compressor power draw were only slightly lower than the experimental results and the resulting $C O P$ was slightly higher than the experimental results. 


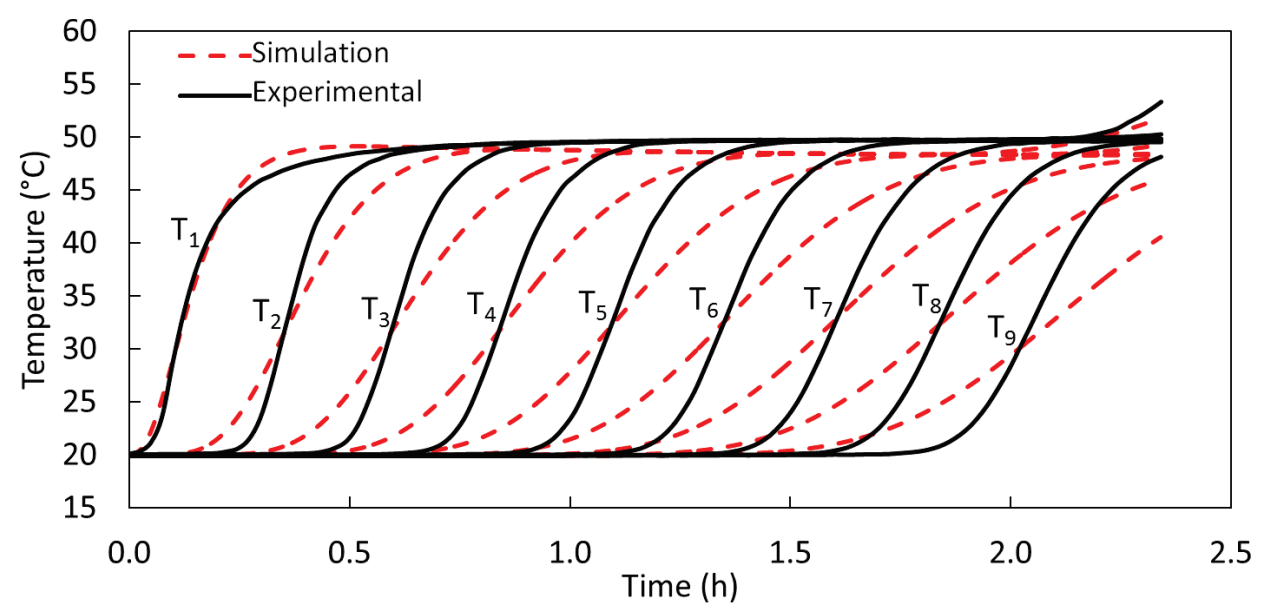

(a) Hot tank temperature profile for $3 \mathrm{~L} / \mathrm{min}$

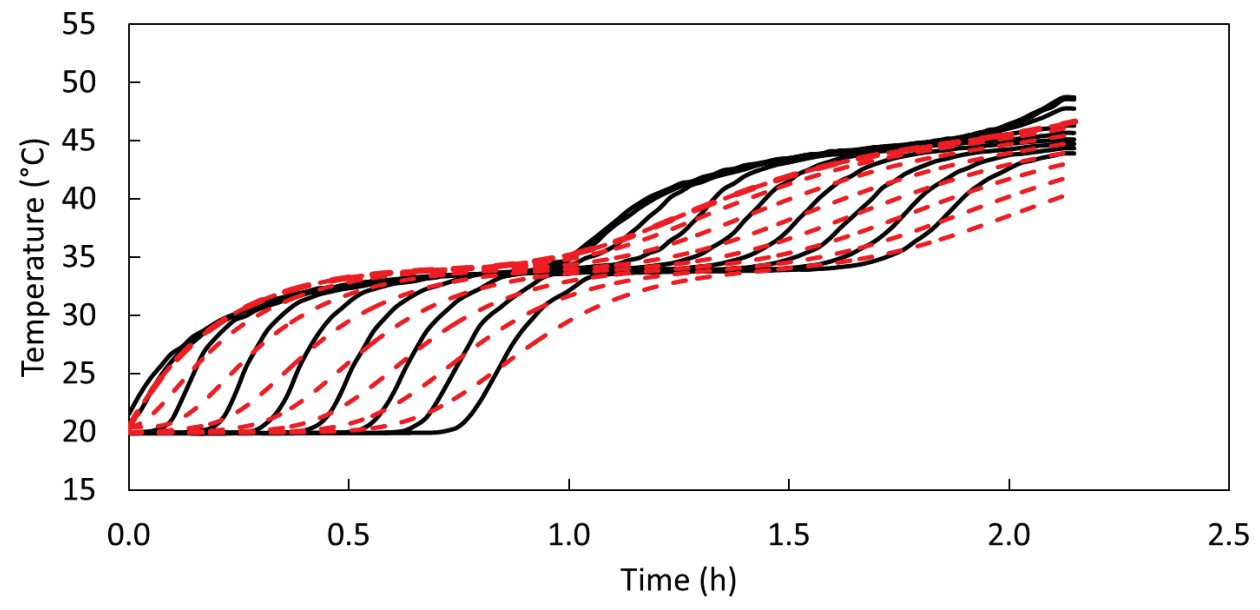

(b) Hot tank temperature profile for $6 \mathrm{~L} / \mathrm{min}$

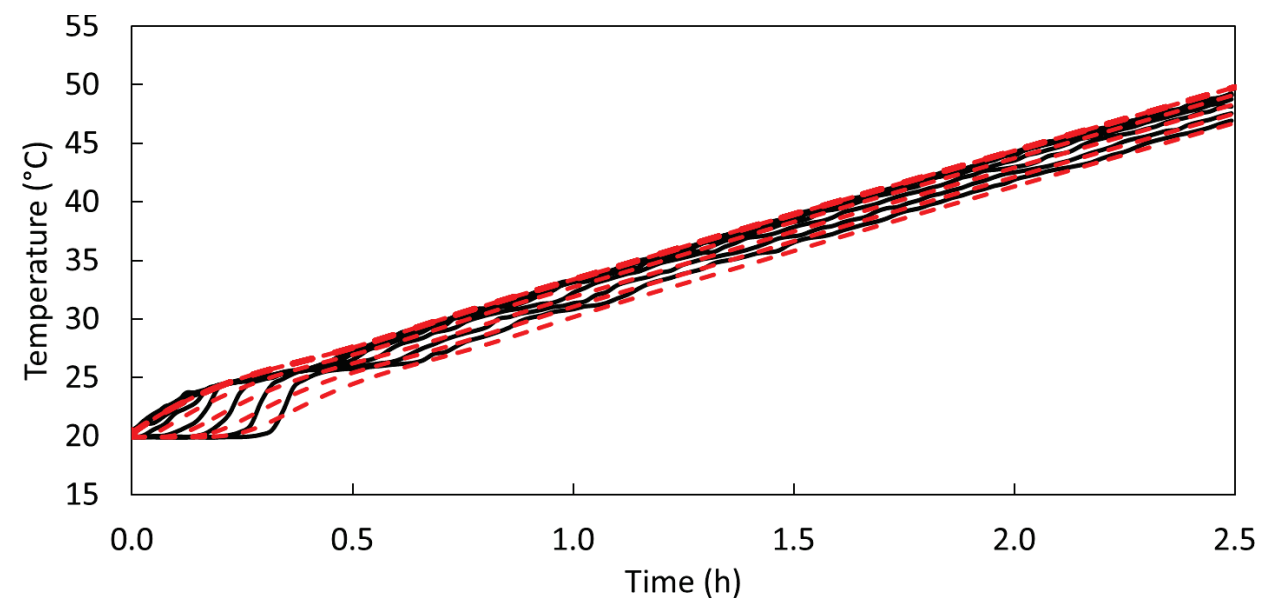

(c) Hot tank temperature profile for $10 \mathrm{~L} / \mathrm{min}$

Figure 5.16: Comparison of hot tank temperature profiles from simulation and experimental results 


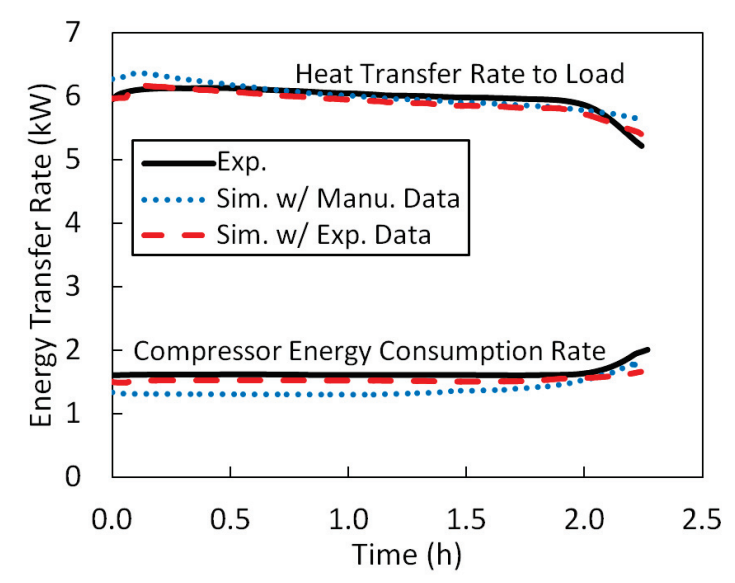

(a) Energy transfer rates for $3 \mathrm{~L} / \mathrm{min}$

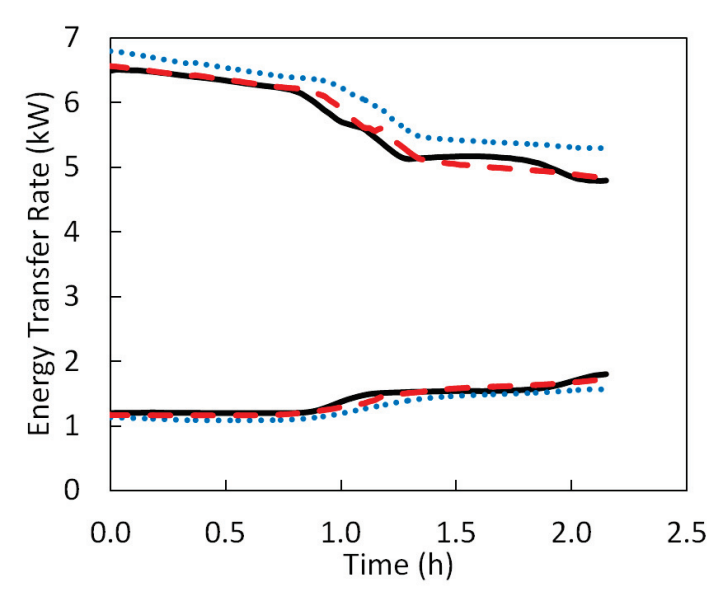

(c) Energy transfer rates for $6 \mathrm{~L} / \mathrm{min}$

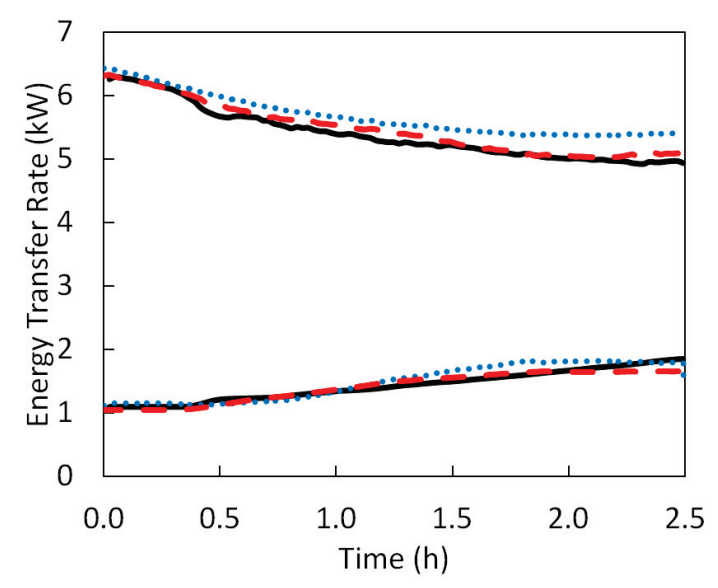

(e) Energy transfer rates for $10 \mathrm{~L} / \mathrm{min}$

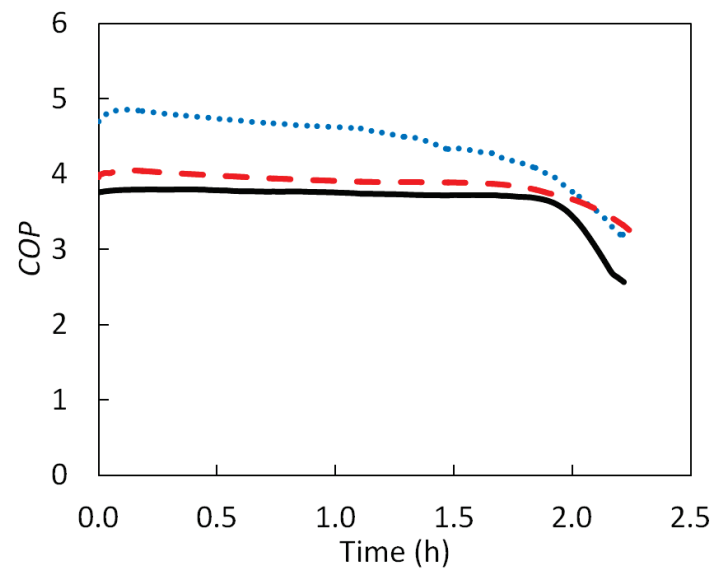

(b) COPs for $3 \mathrm{~L} / \mathrm{min}$

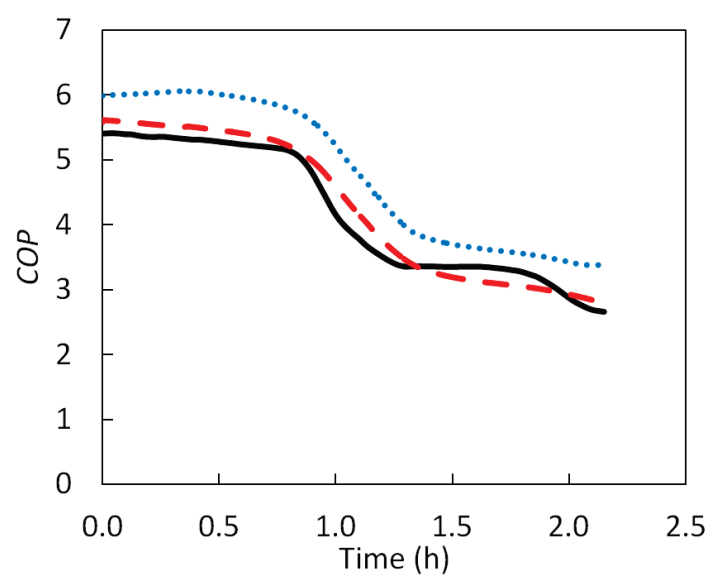

(d) COPs for $6 \mathrm{~L} / \mathrm{min}$

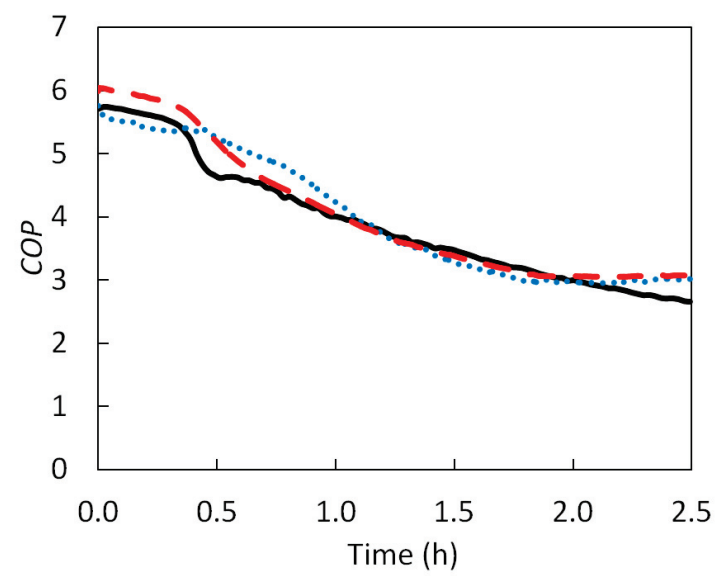

(f) COPs for $10 \mathrm{~L} / \mathrm{min}$

Figure 5.17: Comparison of experimental data and simulation results 
The simulation results using just the manufacturer's data for the $6 \mathrm{~L} / \mathrm{min}$ test overestimates the heat transfer rate and slightly underestimates the compressor power draw as compared to the experimental results. As a result, the simulation overestimated the $C O P$ for the $6 \mathrm{~L} / \mathrm{min}$ test. Using the experimental and manufacturer's data improved the simulation results when compared to the experimental results.

For the $10 \mathrm{~L} / \mathrm{min}$ test, the difference between the simulation and experimental results only differed slightly. Table 5.5 summarizes the comparison results between simulation and experimental data. Specifically indicated in Table 5.5 are the percent difference between the final simulation results and the experimental results. Also indicated in the last column of the table is the percent improvement to the experimental results by simulating with experimental and manufacturer's data as opposed to simulating with just manufacturer's data.

For the $3 \mathrm{~L} / \mathrm{min}$ test, the simulation with manufacturer's data indicated that the heat pump transferred $0.198 \%$ more energy to the load while the simulation with experimental data transferred $1.78 \%$ less energy to the load as compared to the experimental results. Both simulations underestimated the energy draw from the compressor. The energy draw result from the simulation using experimental data was $7.19 \%$ less than the experimental result but was a $9.35 \%$ improvement compared to result obtained from simulating with just the manufacturer's data. Overall, the result for the $C O P$ improved by $13.8 \%$ from simulating without experimental data to simulating with experimental data. The $C O P$ found through simulating with experimental data was 3.85 which was $5.84 \%$ greater than the experimental result of 3.64. The $6 \mathrm{~L} / \mathrm{min}$ test showed a similar improvement of $C O P$ of $13.0 \%$. The simulated $C O P$ using experimental data was 4.12 which is only $1.52 \%$ greater than the experimental value. All the final values for the $6 \mathrm{~L} / \mathrm{min}$ test were improved from incorporating the experimental data in the performance map of the heat pump. For 


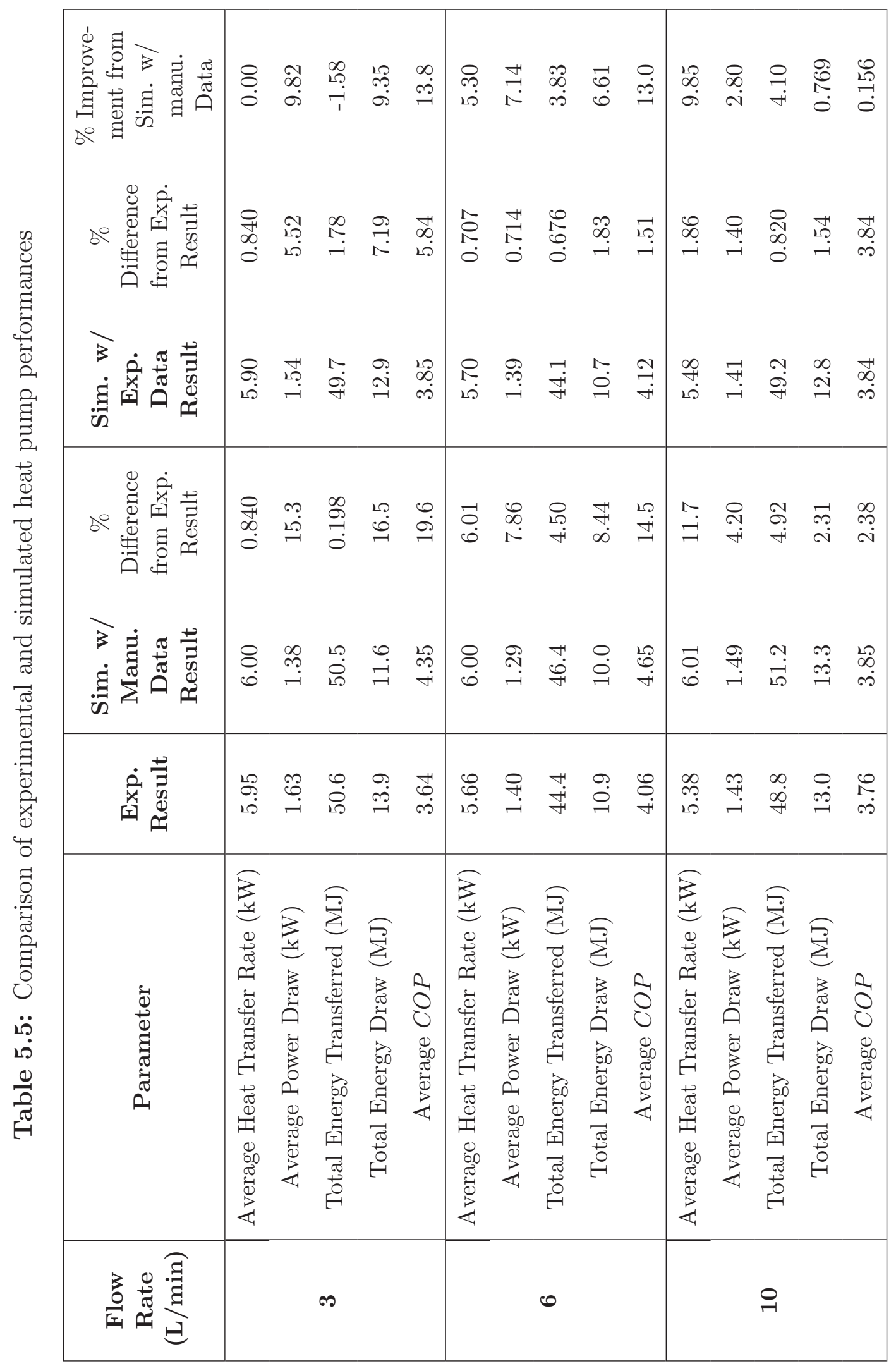


the $10 \mathrm{~L} / \mathrm{min}$ test, all final values were also improved, however, from simulating with just manufacturer's data, most of the results only differed from the experimental results by less than $5 \%$, with the exception of the average heat transfer rate.

\subsection{Closing Remarks}

This chapter summarized the simulation and experimental results of this study. Based on the sensitivity studies conducted, a set of system parameters were recommended to Team Ontario. Since market available parts were sourced, the parameters of the system as-built for ECHO did not match the recommended parameters. The simulation results suggest that a system with the as-built parameters can achieve an annual FEF of 0.611 . The trends found from the sensitivity studies are discussed in Chapter 6. The experimental results indicated that higher heat pump load side flow rates can improve the $C O P$ of the heat pump but destroy stratification in the hot tank. The implications of these findings are also discussed in Chapter 6. When simulating the experimental set-up, it was found that using experimental data for the performance map of the heat pump model significantly improved the results especially for the lower flow rate. Chapter 6 also contains a discussion of the discrepancies between simulation and experimental data. 


\section{Chapter 6}

\section{Discussion of Results}

Chapter 5 presented the simulation and experimental results of this study. Sensitivity studies were conducted for solar collector, heat pump, and thermal storage tank parameters. A study specifically examining the effect of the heat pump load side flow rate was also conducted. Results for an experimental study investigating the relationship between the heat pump load side flow rate, the heat pump performance and the stratification in the hot tank was also presented. The experimental set-up was simulated in TRNSYS and the results were compared with the experimental data. The experimental data was further used to refine the model in order to reduce the difference between the simulation and experimental results. Results of all these studies will be discussed in this chapter.

\subsection{Modelling Results of the Integrated Mechanical System}

A model of the IMS designed for ECHO was developed and used for sensitivity studies. System parameters were recommended for the IMS based on sensitivity results and components were obtained to form the as-built system. 


\subsubsection{Sensitivity Study of Solar Collector Parameters}

The results shown in Figure 5.4 on page 79 demonstrated that the annual FEF increased as collector array area increased. This is due to the increased amount of free solar energy being collected by the solar collectors. However, since the collectors are only used in the heating season, the overall effect of the collector array size was not significant to the annual FEF. In this study, the size of the cold tank limited the amount of solar energy that can be collected. As the collector area began to increase from $12 \mathrm{~m}^{2}$, the increase in annual FEF began to diminish as shown in Figure 5.4. If the cold tank of the base model was larger, then the impact of increasing collector area may be greater [17]. Since the collectors were only used in the heating season, the optimal tilt angle was found at about $75^{\circ}$ as the sun is lower in the sky in the winter in Ottawa, Ontario. However, decreasing the angle from $90^{\circ}$ to $75^{\circ}$ only increase the annual FEF by $0.85 \%$ [17].

The simulation results shown in Figure 5.8 on page 83 indicate that higher annual $F E F$ s can be achieved using the specific flat plate collectors investigated compared to the specific evacuated tube collectors investigated [17]. The modelling parameters of these collectors are summarized in Tables 3.1 and 3.2 on page 51. The intercept efficiency of the flat plate collectors (0.729) was higher than the intercept efficiency of the evacuated tube collectors used (0.601). As indicated in Equation 3.1 on page 50, the efficiency of the collector highly depend on the temperature difference between the inlet collector fluid and the outdoor ambient air temperature. Figure 6.1 shows the approximated efficiencies of the collectors based on Equation 3.1, and the parameters indicated in Tables 3.1 and 3.2. For the development of Figure 6.1, the effects of the incident angle modifiers were neglected and the total solar irradiance was assumed to be $350 \mathrm{~W} / \mathrm{m}^{2}$, which was the average value between November and February for Ottawa according to the TMY2 weather file used for the simulations. For the 


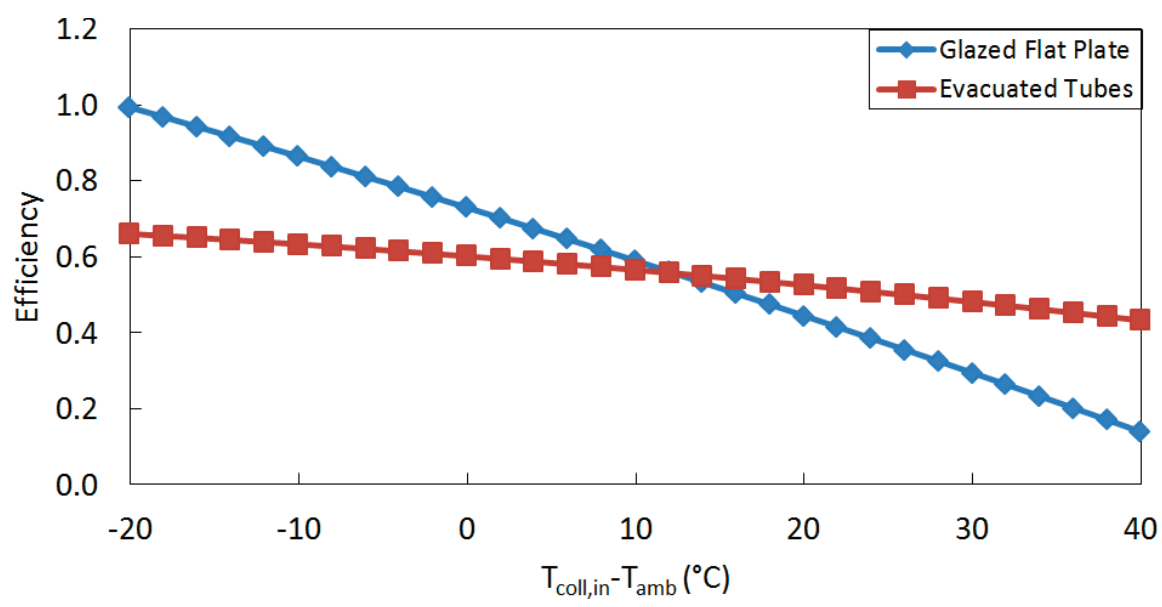

Figure 6.1: Approximated collector efficiencies

evacuated tubes, the optical losses, which are the irradiance absorbed and reflected by the glass, would be greater compared to glazed flat plate collectors, however, the evacuated tubes minimize the convective and radiative heat losses from the absorber. As indicated in Figure 6.1, the evacuated tube collectors would outperform the glazed flat plate collectors when the collector inlet temperature is about $12^{\circ} \mathrm{C}$ greater than the outdoor ambient temperature or when the heat loss to the environment is expected to increase. This is typically the case for a standard solar DHW system where the collector inlet temperature tends to be higher. For the SAHP system studied, the temperature of the working fluid at the inlet of the collectors was lowered by the heat pump and the temperature difference between the collector inlet and the ambient temperature in the winter was reduced. With this lower temperature difference, the flat plate collectors would operate more efficiently as the advantage of less irradiance being absorbed or reflect by the cover outweighs the potential heat losses to the environment.

Figure 5.6 on page 81 also indicates that the annual FEF would be reduced by increasing the heat pump source side minimum cut-off temperature which results in an overall increase in temperature of the cold tank. Increasing the temperature of the 
cold tank would increase the temperature of the working fluid entering the collectors and reduce the efficiency of the flat plate collectors. Although not investigated in this study, evacuated tubes collectors may outperform flat plate collectors if the cold tank temperature was increased by increasing the heat pump minimum source side cut-off temperature. Another advantage to using flat plate collectors is the potential for the lower temperature working fluid to absorb energy from the surrounding air while the evacuated tubes will inhibit this process [17]. This advantage was not specifically quantified in this study, however, any free energy gained by the collectors from the surrounding air would contribute to the FEF.

\subsubsection{Sensitivity Study of Heat Pump Parameters}

The results indicated in Figure 5.7 on page 82 suggest that the rated $C O P$ of the heat pump has the largest influence on the performance of the system. This is expected as a higher rated $C O P$ leads to less electrical input required for the heat pump to provide thermal energy to the hot tank [17], however, as the rated $C O P$ of the heat pump increased from 0 to $50 \%$ of the base model, the annual FEF increased but with diminishing returns. With a higher rated $C O P$ and the same rated heating capacity, less electrical energy was consumed by the compressor and more energy was sourced from the cold tank. Because of the heat pump source side minimum inlet cut-off temperature, there was a limit to the amount of energy available from cold tank. As more energy was sourced from the cold tank (with a higher rated $C O P$ ), the heat pump source side inlet temperature dropped faster which reduced the operating time of the heat pump. This in turn affected the overall performance of the system as the auxiliary heater consumed more energy when the heat pump operating period was shortened. As a result, with increasing rated $C O P$, the annual $F E F$ still increased due to the reduced heat pump energy consumption, but at a decreasing rate due to 
the increased auxiliary energy consumption.

When varying the rated heating capacity of the heat pump, the annual FEF peaked at $6 \mathrm{~kW}$. Increasing the rated heating capacity beyond $6 \mathrm{~kW}$ decreased the overall performance of the system. As the rated $C O P$ was maintained in this study, the increased heating capacity also increased power draw to the compressor. This shows the importance of properly sizing the components in the system as an oversized heat pump would negatively impact the performance of the overall system [17].

The results in Figure 5.6 on page 81 emphasises the importance of the control strategy of the heat pump. The annual FEF increased as the minimum source side inlet cut-off temperature decreased and the maximum load side inlet cut-off temperature increased. The decrease of the minimum source side inlet cut-off temperature and the increase of the maximum load side inlet cut-off temperature can extend the operating period of the heat pump. Since the heat pump has a higher $C O P$ than the auxiliary heater, it is more beneficial for the hot tank to receive thermal energy from the heat pump than the auxiliary heater. Therefore, extending the operating period of the heat pump can reduce the overall energy consumption of the IMS, however, for the recommended system, these cut-off conditions are limited by the data file that was used for the heat pump Type [17]. For the actual heat pump used in the system, these limits are dictated by heat pump specifications such as the safety limits of the refrigerant pressure.

\subsubsection{Sensitivity Study of Tank Parameters}

Figure 5.4 on page 79 suggests that a larger cold tank can improve system performance. Increasing the cold tank size increased the annual FEF since more energy can be stored in the cold tank during the winter and this increased the operation time of the collectors. Increasing the size of the hot tank from the base model, however, 
resulted in almost no change in the overall performance of the system. When the size of the hot tank was decreased, the performance decreased as less energy was sourced from the cold tank. In the winter, this led to more energy being stored in the cold tank which limited the solar energy collection. When the hot tank is larger, the temperature variation from the top to the bottom of the tank is greater due to the increase in tank height. Lower temperatures near the bottom of the tank would allow the heat pump to operate more often to heat the hot tank, which would reduce the auxiliary energy required. The impact of increasing the hot tank size greater than the base model was small due to the limit in energy that can be sourced from the cold tank. If the cold tank and collector area was increased to $450 \mathrm{~L}$ and $18 \mathrm{~m}^{2}$, respectively, then increasing the hot tank size may decrease the overall performance of the system as indicated in Chu et. al [17]. With more source energy, the heat pump energy consumption increased and auxiliary energy decreased with larger hot tank sizes. However, it was found that the increase in heat pump energy consumption was greater than the reduction of auxiliary energy consumption. Despite the $C O P$ of the heat pump, increasing the tank size will increase the volume of water that the heat pump must maintain at high temperatures. With the base model and as-built model hot tank configurations, about $83 \%$ and $60 \%$ of the volume of water, respectively, was at or below the heat pump water return inlet. For the results shown in Figure 5.4, the heating of the hot tank was limited by the source energy available and therefore, the increase in heat pump energy consumption was not as high as the case with a larger cold tank and collector area [17].

It was found that as the tank loss coefficient decreased, the annual FEF increased. Decreasing tank loss coefficient corresponds to an increasing level of insulation on the tanks. With more insulation, less heat is lost to the indoor environment from the hot 
tank, which reduces the space-cooling loads in the summer but increases the spaceheating loads in the winter. In the winter, when the energy losses from the hot tank are reduced and not contributing to space-heating, the extra energy retained in the hot tank is still used later on for DHW and space-heating when need. If the insulation level was reduced, then more heat would be lost from the hot tank, which increases the cooling loads in the summer and potentially increases the auxiliary energy required to make up for the lost energy.

The sensitivity study of the hot tank configuration showed an increase in performance as the location of the mains water and heating coil return inlet is placed higher in the tank. The performance of the system will increase with a higher level of stratification in the tank. Water drawn to the load is extracted from the top of the hot tank and the auxiliary heater is also placed in the top portion of the tank. A mixed tank would result in a lower temperature near the auxiliary heater resulting in more auxiliary energy input to heat to the top half of the tank. To promote thermal stratification, the mains water inlet is usually located closer to the bottom of the tank because the temperature of mains water is normally colder than any node in the tank. However, in the case of the system studied, the return water from the heating coil also entered the same inlet as mains water for the base model. Because the water from the heating coil is higher in temperature than mains water, returning it to the bottom of the tank may destroy the level of stratification that can be achieved and reduce the performance of the system. As a result, the model using Type 534 for the hot tank was used. It was evident from Figure 5.9 on page 83 that splitting the heating return inlet from the mains water inlet can increase the annual FEF by $3.3 \%$ compared to having both inlets at the same location (node 25). This is a more significant performance increase than having both inlets at the same location and increasing the height location of the inlet as shown in Figure 5.9 [17]. 
For the analysis shown in Figure 5.9, the heat pump return inlet was kept at node 5 while the auxiliary heater was moved from the node 1 to node 11 . When the auxiliary heater is moved to a location that is higher in the tank, the volume of water that the auxiliary heater must maintain at the set-point is reduced. This led to the reduction of auxiliary energy consumption but if the heating capacity of the auxiliary heater is not high enough, it may not be able to meet set-point temperatures if the draw volumes are larger than the volume of the heated water surrounding and above the auxiliary heater. When the auxiliary heater is positioned below the heat pump return inlet it would operate more often to heat the tank simultaneously with the heat pump as the energy supplied by the heat pump concentrates into the nodes above the hot water inlet before spreading to the rest of the tank. When the auxiliary heater is above the hot water inlet, the energy from the heat pump will be detected by the auxiliary heater sensor earlier, which reduces the operational time of the auxiliary heater. Therefore, not only is the location of the auxiliary heater important to the overall performance but the location of the auxiliary heater relative to the heat pump return inlet also affects the performance of the system [17].

Each parameter was examined independently for the sensitivity studies in order to develop the preliminary recommendations for building the IMS for Team Ontario. However, the effect of some of the parameters on the system performance is dependent on other parameters such as the relationship between the cold and hot tank sizes or the relationship between the collector area and cold tank volume. Further detailed studies should also examine the effect of the ratios between certain parameters in order to refine Team Ontario's IMS. 


\subsubsection{Recommended and As-Built Model}

According to the TRNSYS simulation results, the recommended system was predicted to achieve an annual FEF of 0.583 . This is $6.2 \%$ greater than the base model performance with the Type 534 tank component [17]. The as-built system can achieve an annual FEF of 0.611 , which is a $4.8 \%$ increase from the recommended model. Table 6.1 summarizes the annual loads from the various models.

Table 6.1: Total loads from annual simulations

\begin{tabular}{|c|c|c|c|}
\hline Load & $\begin{array}{c}\text { Base Model with } \\
\text { Type } \mathbf{4}\end{array}$ & $\begin{array}{c}\text { Recommended } \\
\text { Model }\end{array}$ & $\begin{array}{c}\text { As-Built } \\
\text { Model }\end{array}$ \\
\hline DHW & 9.81 GJ & 9.81 GJ & 9.81 GJ \\
Heating Coil (Space-heating) & 11.9 GJ & 10.8 GJ & 13.6 GJ \\
Heating Coil (Cool Air & 7.19 GJ & 8.91 GJ & 7.36 GJ \\
Reheat) & 19.6 GJ & 21.7 GJ & 18.9 GJ \\
Cooling Coil & 5.68 GJ & 5.85 GJ & 6.04 GJ \\
Auxiliary & 15.1 GJ & 15.4 GJ & 13.3 GJ \\
\hline
\end{tabular}

For the recommended model, the heating coil load decreased and the cooling coil load increased due to the improved ERV sensible effectiveness. With a higher effectiveness, more energy is recovered from the exhaust air. In the summer, energy recovery may not always be advantageous because during evening hours, when the outdoor temperature is lower than the indoor temperature, then the ERV will actually be heating the fresh air with the exhaust air. During these hours, cooling loads and fresh air requirements would be more efficiently met with free cooling through natural ventilation. Unfortunately, due to the complexity and lack of control for natural ventilation, it was not considered in these models. For the as-built model, the heating coil load increased and the cooling coil load decreased as a result of the decreased ERV sensible effectiveness. The improved tank loss coefficient of the asbuilt model also affected the heating coil loads as less heat was lost to the space from 
the tank, more space-heating was required through the heating coil. In the summer, the cooling load would also be reduced as less heat was again lost from the hot tank to the space.

Figure 6.2 shows the monthly loads for the recommended model. From November to February, the average FEF was 0.378 and from June to August, the average FEF was about 0.620. During the shoulder season months of March, April, September, and October the average FEF was approximately 0.707 . Compared to the base model loads shown in Figure 5.1 on page 77, the auxiliary energy consumption was significantly reduced in the summer months due to the improved hot tank configuration. The auxiliary energy consumption has increased in winter months because of the reduction in solar collector area which has reduced the source energy available for the heat pump. As a result, the heat pump operated less, causing an increase in auxiliary heater operation. The heat pump energy consumption also increased in the summer months. The new hot tank configuration increases the stratification level of the hot tank and increases the operation period of the heat pump as the temperature of the bottom of the hot tank is reduced. For the recommended model, the operation

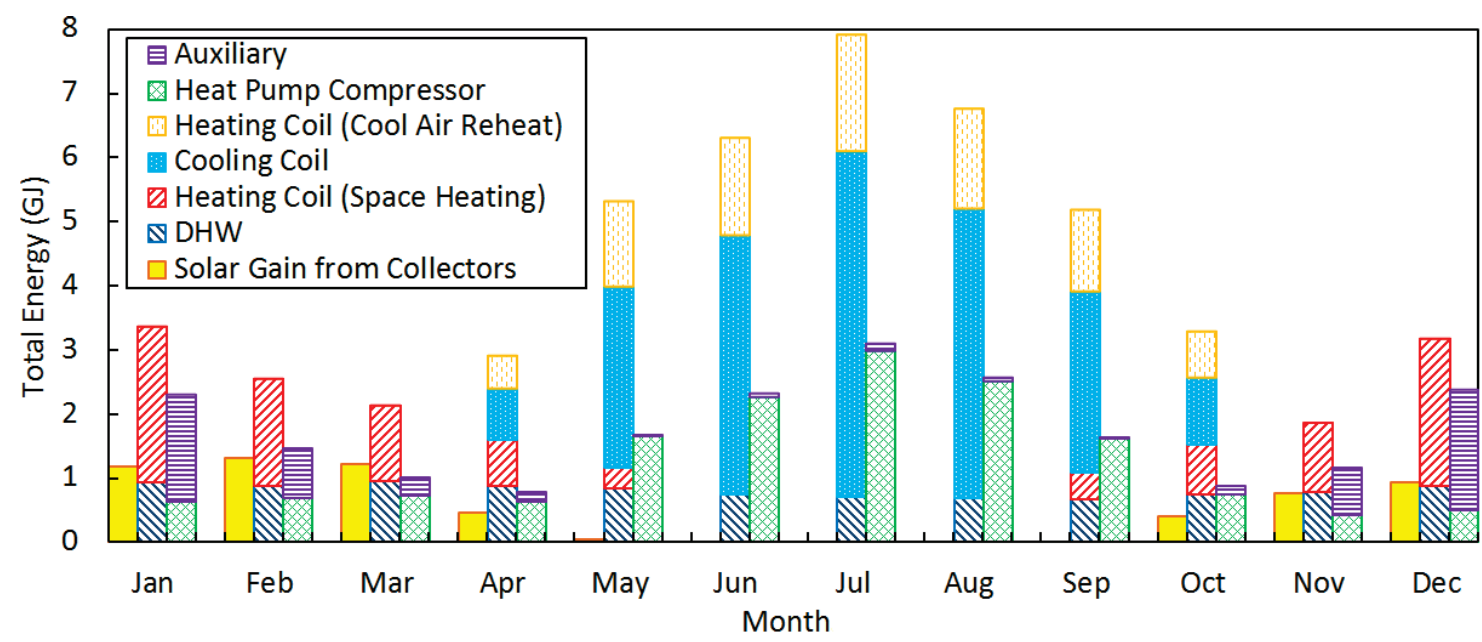

Figure 6.2: Monthly solar energy gains from collectors, total energy loads (second column), and electrical energy draws (third column) for the recommended model 
period of the heat pump was increased, while the auxiliary energy consumption was decreased in the summer. This increased the overall performance of the system as the heat pump operated at an average $C O P$ of 3.1 while an ideal auxiliary heater would produce one kilowatt of heating per kilowatt of electrical power consumption or, in other words, achieve a $C O P$ of 1 .

Figure 6.3 shows the monthly distribution of the loads for the as-built model. The average $F E F$ s in the winter, summer, and shoulder season months were roughly 0.491, 0.624, and 0.726, respectively. The increased solar collector area and cold tank volume from the recommended model increased the useful energy collection from the collectors and the amount of the source energy available for the heat pump to operate. Therefore, in the winter months heat pump operation increased while the auxiliary heater operation decreased. Unfortunately, in the summer months, the auxiliary energy consumption increased as the auxiliary heater moved to a lower location in tank as shown in Figure 5.10 on page 87. As a result, the volume of water that the auxiliary heater must maintain at the set-point temperature increased. The heat pump operation in the summer also decreased as it was primarily responsible for

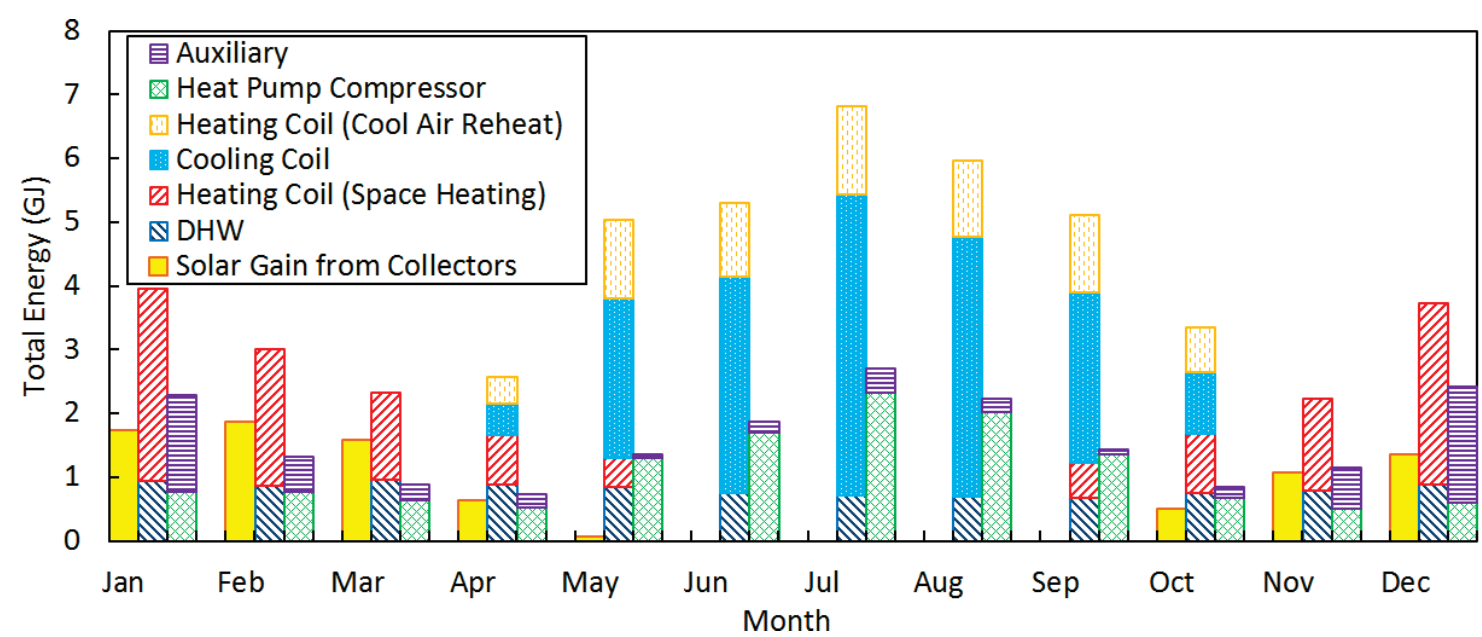

Figure 6.3: Monthly solar energy gains from collectors, total energy loads (second column), and electrical energy draws (third column) for the as-built model 
heating the volume of water under the auxiliary heater which was reduced in the as-built model.

\subsubsection{Sensitivity Study of Heat Pump Load Side Flow Rate}

A lower load side flow rate would increase the temperature rise required in the condenser of the heat pump. As a result, the compressor would consume more power to further increase the pressure and temperature of the refrigerant since the refrigerant temperature must be high enough to achieve the higher temperature change required in the condenser with low flow rates [6]. The sensitivity study of the load side flow rate shown in Figure 5.12 on page 88 suggests that as the flow rate increased, the annual energy requirement for the compressor decreased but the energy requirement for the auxiliary heater increased. This is due to the decreasing level of stratification that is achieved in the hot tank with higher flow rates. As the auxiliary heater is in the upper portion of the tank, it would operate less frequently when the upper portion of the tank is at a higher temperature, which can be achieved with stratification. The loss of stratification with high load side flow rates resulted in more auxiliary energy usage than what was saved through improved heat pump performance. Overall, as shown in Figure 5.11 on page 88, the annual FEF of the IMS increased with decreasing load side flow rate even though the average annual $C O P$ of heat pump increased.

\subsection{Experimental Results}

Experimental results as well as results from the simulations of the experimental set-up were presented in Chapter 5. The following paragraphs discuss these results as well as how the simulation results compared to the experiments. 


\subsubsection{Hot Tank Temperature Profiles}

Even though the final average temperature of each test was similar as shown in Figure 5.13 on page 91 , the point in time at which the top of the tank reached above $50^{\circ} \mathrm{C}$ differed. For the experimental set-up, the top of the tank is the inlet node for the heated water returning from the heat pump. For the system built for ECHO, this inlet node was at a side port which was $0.98 \mathrm{~m}$ from the ground. The side port is right below the auxiliary heater in the hot tank. In the annual simulations, the auxiliary heater was set to keep the top portion of the tank at $55^{\circ} \mathrm{C}$. If the temperatures at the top of the hot tank can reach above $50^{\circ} \mathrm{C}$ earlier in the experimental test, then that would suggest that the auxiliary heater's operation time would be reduced for the IMS built for ECHO.

At $2 \mathrm{~L} / \mathrm{min}$ or $3 \mathrm{~L} / \mathrm{min}$ flow rates, a high degree of stratification was achieved, as shown in Figures 5.13(a) and 5.13(b), due to the lower kinetic energy of the flow. At these low flow rates, higher temperatures above $50^{\circ} \mathrm{C}$ can be achieved with the heat pump when the load side inlet temperature was at about $20^{\circ} \mathrm{C}$. However, for these tests, the entire volume of the tank only passed through the heat pump once because the inlet temperature after the first pass was too high for the heat pump to continue to operate. For these flow rates, the top of the hot tank exceeded $50^{\circ} \mathrm{C}$ earlier in the test compared to faster flow rates and a high degree of stratification was maintained in the tank throughout the tests. If the low flow rates were used in the system built for the house, the auxiliary heater would operate less as the heat pump can heat the top of the tank to temperatures above $50^{\circ} \mathrm{C}$ earlier with lower load side inlet temperatures.

At $4 \mathrm{~L} / \mathrm{min}$, after the first pass, the heat pump had to be shut down as the load side inlet temperature reached about $40^{\circ} \mathrm{C}$ and the pressure of the refrigerant became too high (above $500 \mathrm{psi}$ ) with this combination of flow rate and inlet temperature. At 
$6 \mathrm{~L} / \mathrm{min}$, a second pass of the tank volume was achieved as the change in temperature on the load side of the heat pump was lower compared to the $4 \mathrm{~L} / \mathrm{min}$ test. After the first pass of the tank volume for the $6 \mathrm{~L} / \mathrm{min}$ test, the tank reached approximately $33^{\circ} \mathrm{C}$. The second pass not only had a lower input temperature compared to the $4 \mathrm{~L} / \mathrm{min}$ test but the change in temperature needed to be achieved by the heat pump was also smaller with a higher flow rate. This allowed the completion of the second pass without the pressure of the refrigerant reaching 500 psi. A third pass of the volume was not achieved. If moderate flow rates of $4 \mathrm{~L} / \mathrm{min}$ or $6 \mathrm{~L} / \mathrm{min}$ were used in the system built for the house, stratification can still be achieved but the auxiliary heater in the system would need to heat the water for a longer period of time since the heat pump was not able to meet the temperatures of about $50^{\circ} \mathrm{C}$ when the load side input temperature was about $20^{\circ} \mathrm{C}$. Temperatures only reached above $50^{\circ} \mathrm{C}$ in the second pass of the tank volume when the load side inlet temperature was higher.

At high flow rates of $8 \mathrm{~L} / \mathrm{min}$ or $10 \mathrm{~L} / \mathrm{min}$, the top of the tank only reached close to $50^{\circ} \mathrm{C}$ towards the end of the tests when the load side inlet temperatures reached much higher temperatures. This suggests that if high flow rates were used in the system built for the house, the auxiliary heater would need to consume much more energy to maintain the top of the tank at higher temperatures as the heat pump was not meeting the temperature requirements at lower load side inlet temperatures. For the $10 \mathrm{~L} / \mathrm{min}$ test, the average temperature increase of the water through the heat pump was low, at about $8^{\circ} \mathrm{C}$. Also, the high flow rates would de-stratify the tank which may further reduce the temperature near the top of the tank where hot water is drawn for the loads.

Overall, lower flow rates allowed the heat pump to increase the temperature of the water to above $50^{\circ} \mathrm{C}$ as required for DHW when load side inlet temperatures are about $20^{\circ} \mathrm{C}$ and allows stratification of the hot tank so that warmer water remains near the 
top of the tank. These experimental findings are consistent with the sensitivity study for the load side flow rate. As the flow rate increases, the amount of energy required for the auxiliary heater increases. The minimum flow rate that can be use for a heat pump will depend on the limitations of the equipment.

\subsubsection{Heat Pump Performance}

From the results shown in Figure 5.14 on page 92, with consistent load side inlet temperatures, the power draw of the compressor decreased and $C O P$ increased with increasing flow rate. As previously mentioned, at low flow rates, the temperature increase across the condenser is greater as indicated in Figure 5.13 on page 91. To achieve the greater increase in temperature, the refrigerant must be compressed to a higher pressure and temperature. This increases the power draw of the compressor and decreases the heat pump COP at lower flow rates. The tests also showed that at a set load side flow rate, the compressor power draw increases and the $C O P$ decreases with increasing load side inlet temperatures. The condensing temperature of the refrigerant must be higher than the load side inlet temperature. Therefore, with high load side inlet temperatures, the compressor must again work harder to increase the temperature of the refrigerant so that it meets the load and is higher than the load side inlet temperature.

As shown in Figure 5.15 on page 93, the average COP for the $10 \mathrm{~L} / \mathrm{min}$ test began much higher compared to the $2 \mathrm{~L} / \mathrm{min}$ or $3 \mathrm{~L} / \mathrm{min}$ test but it decreased over the entire course of the test. At this high flow rate, the volume of the tank was able to pass through the condenser several times while achieving lower temperature rises compared to the lower flow rates. Also, stratification was not achieved at the high flow rates due to the higher kinetic energy introduced by the higher speed flow. Therefore, the entire mixed hot tank temperature and the load side inlet temperature 
continuously increased throughout the test causing the $C O P$ to continuously decrease. As summarized in Table 5.4 on page 89, the final average COP from the $10 \mathrm{~L} / \mathrm{min}$ test was 3.76 which was only 0.12 higher than the average $C O P$ from the $3 \mathrm{~L} / \mathrm{min}$ test even though the average $C O P$ of the $10 \mathrm{~L} /$ min test was above 5 for the first 52 minutes of the test. For the $3 \mathrm{~L} /$ min test, the average $C O P$ remained at a consistent 3.77 until the final 20 minutes of the test when the load side inlet temperature began to increase from $20^{\circ} \mathrm{C}$. The $3 \mathrm{~L} / \mathrm{min}$ test ended when the load side inlet temperature reached $37^{\circ} \mathrm{C}$ which caused the pressure in the heat pump to rise above 500 psi.

Based on the experimental results, the $3 \mathrm{~L} / \mathrm{min}$ flow rate was used for the IMS. Even though the $2 \mathrm{~L} / \mathrm{min}$ test showed greater stratification and higher temperatures, the test was stopped when the load side inlet temperature reached only $28^{\circ} \mathrm{C}$ as the pressure of the refrigerant reached 500 psi. Using a $2 \mathrm{~L} / \mathrm{min}$ flow means that the maximum load side inlet cut-off temperature would have to be limited to $28^{\circ} \mathrm{C}$. As shown in the sensitivity study in Figure 5.6 on page 81, this would significantly reduce the annual FEF as it would limit the operational period of the heat pump. Also, if the level of stratification in the hot tank stratification was lower due to draws for space-heating or DHW, and the temperature of the bottom of the tank was higher than $28^{\circ} \mathrm{C}$, then the heat pump cannot operate if the flow rate was set to $2 \mathrm{~L} / \mathrm{min}$.

\subsection{Comparison of Experimental and Simulation Results}

The original simulation results that used just the manufacturer's data for the heat pump overestimated the $C O P$ compared to the experimental results as shown in Figure 5.17 on page 97 . Since the actual manufacturer's data did not indicate performances of the heat pump at flow rates as low as $3 \mathrm{~L} / \mathrm{min}$, the manufacturer's data was 
extrapolated as described in Chapter 3 by assuming that the performance of the heat pump can be characterized by the average source and load side temperatures. This extrapolation introduced errors between the simulation and the experimental results. As the flow rate increased from $3 \mathrm{~L} / \mathrm{min}$ to $6 \mathrm{~L} / \mathrm{min}$ and $10 \mathrm{~L} / \mathrm{min}$, the difference between the simulation and experimental results decreased. The minimum flow rate reported by the manufacturer's data was $11.4 \mathrm{~L} / \mathrm{min}$. Therefore, the simulations suggest that as the flow rate increases and approaches the range of flow rates provided by the manufacturer, the more accurate the simulation results will be compared to the experimental results.

The experimental data was used to create an improved performance map usable by Type 927 in the TRNSYS model. Because the operating range from the experimental data was narrow, manufacturer's data was used for points outside the range of average source and load side temperatures found in the experimental results. The data used to create the performance maps can be found in Figures F.3 and F.4 of Appendix F. Since the average temperatures used to characterize the heat pump performance are from the lower flow rate operations of the experimental data, the difference between the simulation results and the experimental data was significantly reduced especially for the $3 \mathrm{~L} / \mathrm{min}$ test when experimental data was used for the performance map.

The differences between the experimental and simulation data may be due to several factors. Even though experimental data was used, the performance map was created by interpolating between the experimental data when the average source or load side temperatures were within the range of the experimental data. When the average temperatures were outside the range of the experimental data, the heating capacities and power draws were found through interpolating between experimental data and manufacturer's data or just between manufacturer's data. This interpolation introduces errors in the performance map created for the simulation. Furthermore, 
the performance map was again interpolated in TRNSYS by Type 927 to obtain the heating capacity and power draw at specific source and load side inlet temperatures and flow rates that may not coincide perfectly with the points indicated on the performance map. This second interpolation process can again introduce errors.

The load side inlet temperature of the heat pump introduced further differences. Figure 6.4 shows the simulated heat pump load side inlet temperatures compared to the experimental temperatures. For each test, the initial tank temperature profile measured at the beginning was used to set the initial temperature conditions of each node in the hot tank of the simulation. Since the temperature probe did not measure the temperature at the very bottom of the tank, it was assumed that the temperature measured at the bottom most node on the temperature probe was the temperature at the bottom of the tank in the simulation. In the simulations, the temperature of the last node was also the temperature passed to the heat pump as the load side inlet temperature. This may introduce another discrepancy as for the experimental set-up, energy can be lost or gained in the pipes between the tank and the heat pump. This was not accounted for in the simulations. As shown in Figure 5.16, the change

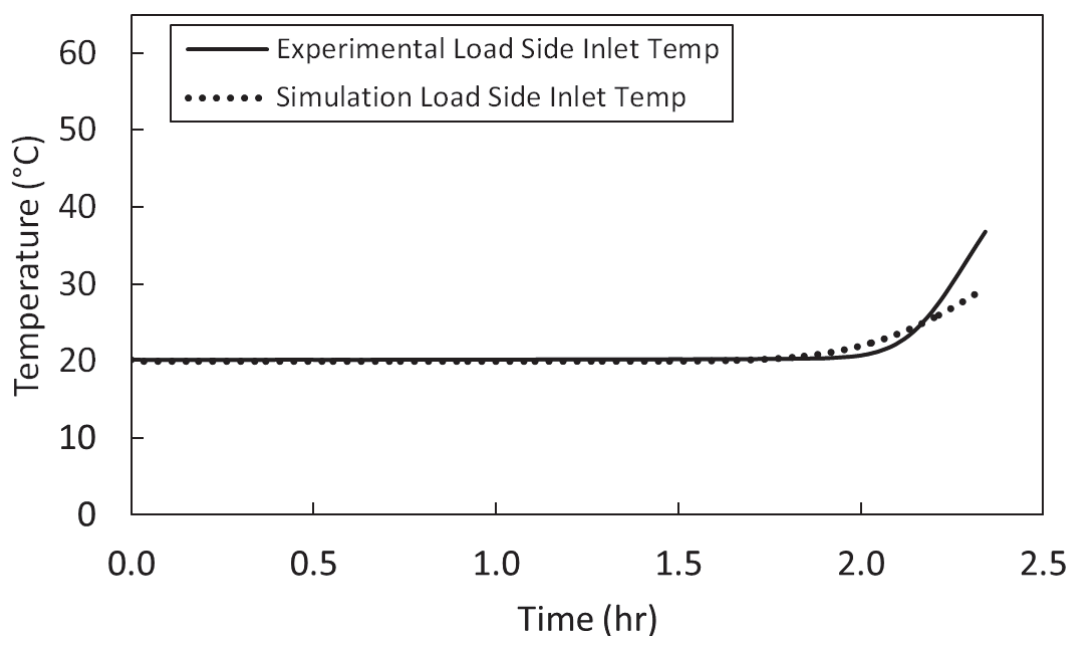

Figure 6.4: Experimental and simulated heat pump load side inlet temperatures for $3 \mathrm{~L} / \mathrm{min}$ test 
in temperature of each node of the hot tank in the simulations was more gradual than the measured temperatures by each thermocouple on the temperature probe in the hot tank. This relationship between the modelled results and experimental results was also seen by Cruickshank [3] and Dickinson [57] during their investigation of multi-tank storage systems. In simulation, each node is modelled as uniform in temperature. Therefore, each node is considered mixed within itself. In actuality, the tank has infinite number of nodes. As shown in Appendix B, as number of nodes reduces in simulation, the more de-stratified the tank becomes. Therefore, the simulation using 50 nodes appears to be less stratified than the experimental results. The thermocouples in the tank measured the temperature of the small volume that was in contact with the probe, while in simulation the temperature of each node represented the mixed temperature of the node that is $1 / 50$ of the volume of the tank. Towards the end of the tests, the differing levels of stratification in the hot tank caused the difference in heat pump load side inlet temperature as shown in Figure 6.4. This will also cause differences between the experimental and simulation heat transfer rates. As shown in Figure 5.17(a) on page 97, towards the end of the test when the load side inlet temperature began to deviate from approximately $20^{\circ} \mathrm{C}$, the heating capacity and power draw also changed. For the simulation results, the changes were more gradual than the experimental results which corresponds to the different temperature profiles between the simulation and experimental cases.

As suggested by Figure 6.4, with a flow rate of $3 \mathrm{~L} / \mathrm{min}$, if the maximum load side inlet cut-off temperature was set to $37^{\circ} \mathrm{C}$ (maximum reached in the test before the pressure of the refrigerant reached too high) then the simulation test may be able to run longer than the experimental test. Simulation tests were not conducted longer than the experimental tests due to the lack of information on the source side of the heat pump past the end point of experimental test period. Since the load 
side inlet temperature of the simulations reached the maximum temperature later, the operation period of the heat pump would be extended in simulation compared to the actual or experimental operation. This may cause further discrepancies between the simulation results and how the system will actually perform in ECHO. Further experimental tests are required to validate and improve the simulation model.

\subsection{Annual Performance Simulation with Experimental Data}

An annual simulation of the IMS in ECHO was conducted with the as-built system and the improved performance map using experimental data. For this simulation, the maximum load side cut-off temperature was set to $37^{\circ} \mathrm{C}$ to correspond the experimental results which indicated at this temperature, the pressure of the refrigerant in the heat pump would reach above 500 psi if the load side inlet flow rate was set to 3 $\mathrm{L} / \mathrm{min}$. For the results obtained prior to using experimental data, the load side flow rate was also set to approximately $3 \mathrm{~L} / \mathrm{min}$ (it was previously set to $175 \mathrm{~kg} / \mathrm{h}$ which is $2.92 \mathrm{~L} / \mathrm{min})$. As expected, for the simulation using the experimental data, the annual FEF reduced to 0.506 due to increased auxiliary and heat pump compressor energy consumption. Again, when using the performance map created with just the manufacturer's data, the $C O P$ of the heat pump was overestimated. As shown in Figure 5.6 on page 81, as the maximum load side inlet cut-off temperature reduces, the annual $F E F$ of the system decreases. Of all the parameters examined in the sensitivity study the maximum load side inlet cut-off temperature had one of the largest effects on the overall performance of the system. From Figure 5.6, if the maximum load side inlet cut-off temperature was reduced by $3^{\circ} \mathrm{C}$ from $40^{\circ} \mathrm{C}$, the predicted reduction in annual FEF was $6.2 \%$. 
These simulation results do suggest that the IMS will still help save electrical energy consumption. If the DHW and heating coil loads were met using an ideal auxiliary heater (where $C O P=1$ ) and the cooling coil load was met using an airto-air heat pump with a cooling $C O P$ of 4 , then this more conventional system may consume approximately $30 \%$ more electrical energy than the IMS.

\subsection{Summary of Key Findings}

The heat pump reduced the working fluid temperature entering the collectors which also reduced the heat loss from the collectors. For the IMS studied, it was found that the glazed flat plate collectors would outperform the evacuated tube collectors as the main advantage of the evacuated tube collectors was reducing heat loss which was already accomplished with the incorporation of the heat pump. This was one of the key advantages of combining heat pump and solar thermal technologies in the IMS. If the temperature of the cold tank increased, the efficiency of the collectors would reduce. The rated $C O P$ had the largest effect on the performance of the system, however, with increased rated $C O P$, more source energy is required. For the SAHP configuration studied, the solar energy helped boost the amount of energy available for the heat pump which allowed it to transfer more energy to the load while consuming less electrical energy. If solar energy input does not increase with increasing rated $C O P$ of the heat pump, then the amount of the energy available in the cold tank would be depleted earlier. As a result, the heat pump operation period would reduce and the auxiliary energy consumption would increase. The heat pump must also be properly sized for the expected loads as larger heat pumps with greater heating capacities would consume more electrical energy to operate.

Stratification of the hot tank was an important factor affecting the performance 
of the system. The relative locations of the heat pump hot water inlet and auxiliary heater of the hot tank affected the auxiliary energy requirements and $F E F$ of the system. The heat pump load side flow rate had a large effect on the performance of the system. It was found that decreasing the flow to increase the temperature rise across the heat pump and the stratification in the hot tank was more beneficial than increasing the flow rate to improve the $C O P$ of the heat pump. Increased temperature rise across the heat pump and stratification in the hot tank would decrease the amount of auxiliary energy required to maintain the top portion of the tank at the set-point temperature.

Simulation and experimental results were compared for the experimental set-up. It was found that the simulation model needed refinement and incorporating the experimental data in the simulations have improved simulation results when compared to the experimental data. An improved heat pump performance map was developed and used in the IMS model. It was found that the IMS may achieve a $F E F$ of 0.506 when the heat pump maximum load side inlet cut-off temperature was set to $37^{\circ} \mathrm{C}$ (limit found through the experimental analysis for the $3 \mathrm{~L} /$ min test). 


\section{Chapter 7}

\section{Conclusions and Future Work}

\subsection{Conclusions}

A TRNSYS model was developed for the integrated mechanical system (IMS) designed for Team Ontario's high performance house which competed in the Solar Decathlon 2013 Competition in Irvine, California. The model was used to conduct a sensitivity study of the system parameters in to order properly size components of the system to efficiently meet the space-heating, cooling, and domestic hot water (DHW) loads. The main performance metric used to characterize the system was the free energy fraction $(F E F)$. Since the solar collectors were only used in the heating season, the overall impact of the solar collector area and tilt on the annual performance of the system was small. Varying these parameters over a wide range only changed the annual FEF by approximately 5\%. Based on the sensitivity studies, the tank sizes had very little effect on the performance. The variation of the annual $F E F$ was less than $2 \%$ when the tank sizes varied over the range set for the sensitivity studies. It was found that as the cold tank size increased, the annual FEF improved. With the base model parameters, the $F E F$ increased with increasing hot tank size until a point

where the cold tank size limited the performance. It was also found that improving 
the level of insulation of storage tanks by $50 \%$ can increase the annual FEF by $2.7 \%$. The heat pump characteristics had a large impact on the overall performance. For the heat pump control, as the load side maximum inlet cut-off temperature increased and the source side minimum inlet cut-off temperature decreased the operation period of the heat pump increased. As the heat pump may operate at an average annual $C O P$ of about 3, less electrical energy would be consumed to heat the hot tank with the heat pump as compared to using the auxiliary heater which has an ideal $C O P$ of 1. Reducing the load side maximum inlet cut-off temperature by $3^{\circ} \mathrm{C}$ or increasing the source side minimum inlet cut-off temperature by $3^{\circ} \mathrm{C}$ reduced the overall annual FEF by about $6 \%$ and $3 \%$, respectively. The results of the sensitivity studies also suggested that, assuming a consistent rated $C O P$, the annual FEF of the system would decrease as the rated heating capacities increased above $6 \mathrm{~kW}$. The studies also indicate that the rated $C O P$ of heat pump had the greatest effect on the performance of the system. With a higher rated $C O P$, less electrical energy consumption was required for the same amount of heat transferred.

Based on the sensitivity studies and the needs of Team Ontario, a model was created with a set of recommended parameters. The recommend system achieved a $6.2 \%$ improvement of the annual FEF compared to the base model. Physical components of the system were sourced for ECHO based on the recommendations. As market available components were sourced, the parameters for the system built varied from the recommended parameters. A simulation of a model reflecting the as-built system was conducted and the annual FEF was found to be about $4.8 \%$ greater than the annual FEF of the recommended model. With the as-built model, an additional sensitivity study was conducted for the heat pump load side flow rate. The study showed that as the flow rate increased, the annual FEF decreased despite the increased annual average $C O P$ of the heat pump that was found with increased 
flow rates.

An experimental investigation was conducted to study the impact of the heat pump load side flow rate on the heat pump performance and the thermal stratification in the hot tank. The components used in the experimental set-up were those used in ECHO. It was found that with lower flow rates, the heat pump can output higher temperatures with the trade-off of a lower $C O P$. The lower flow rates also promote stratification of the hot tank which allowed the high temperature water returning from the heat pump to remain near the top of the tank reducing the need for auxiliary energy if the heater was activated. At higher flow rates such as $10 \mathrm{~L} / \mathrm{min}$, higher $C O P$ s can be achieved when the load side inlet temperature remains low (near $20^{\circ} \mathrm{C}$ ). However at higher flow rates, almost no stratification was achieved. As a result, the mixed hot tank continuously increased in temperature. As the load side inlet temperature increased, the $C O P$ decreased. This minimized the advantage of operating at higher flow rates to reduce compressor energy consumption. Also, since the hot tank was mixed, the auxiliary heater, if activated, would need to work harder as the temperature at the top of the tank does not reach over $50^{\circ} \mathrm{C}$ until the load side inlet temperature reaches above $40^{\circ} \mathrm{C}$. Like the modelling results, the experimental findings suggest that with higher flow rates the auxiliary energy consumption would increase. In simulation, as the flow rate increases, the auxiliary energy consumption increased at a higher rate than the decrease in heat pump compressor energy consumption. For the system designed for ECHO, the flow rate was set to approximately $3 \mathrm{~L} / \mathrm{min}$.

The experimental set-up of the heat pump and the hot tank was modelled in TRNSYS using the performance map created with the manufacturer's data. The experimental results were compared to the simulation results, and it was found that by using the performance map created with the manufacturer's data, the $C O P$ was 
overestimated at lower flow rates. Another performance map was created using the experimental data and the manufacturer's data. Using this performance map improved the simulation results when compared to the experimental results. For the $3 \mathrm{~L} / \mathrm{min}$ test, the simulated average heat transfer rate, average power draw, total energy transferred, total energy consumption and average COP differed from the experimental data by $0.840 \%, 5.52 \%, 1.78 \%, 7.19 \%$, and $5.84 \%$ respectively. An annual simulation of the as-built model was conducted with the updated performance map and the updated heat pump maximum load side inlet cut-off temperature of $37^{\circ} \mathrm{C}$. The resulting annual $F E F$ was 0.506 which was a $17 \%$ performance reduction compared to the as-built model simulation without experimental data.

Overall, the results suggest that the use of the integrated mechanical system with the dual tank indirect solar-assisted heat pump does have the potential of reducing energy consumption required for DHW, space-heating, and cooling by about 30\% as compared to a system that uses auxiliary heating for DHW and space-heating and a heat pump for space-cooling. The findings of these studies were used for Team Ontario's Solar Decathlon 2013 Competition entry. For the competition, Team Ontario received full points for the Energy Balance and Hot Water contests and the house stayed within comfort zone for $93.3 \%$ of the competition. The design of the integrated mechanical system also contributed to Team Ontario's first place achievement in the Engineering Contest. This study also filled the gap in literature as an investigation was performed for a dual tank indirect solar-assisted heat pump system used in a Canadian climate to offset space-heating, cooling and domestic hot water loads. 


\subsection{Future Work}

As mentioned in Chapter 6, the sensitivity studies examined each parameter independently to develop the preliminary recommendations for Team Ontario. Since the effect of some parameters is dependent on other parameters, such as the relationship between the cold and hot tank sizes or the relationship between the solar collector area and cold tank size, future studies should examine the effect of the ratios between certain parameters and use findings from these studies to refine the IMS. The implementation of genetic algorithms may also be used to further optimize the performance of the system.

The simulations conducted indicated that the ECHO required humidification in the winter. Further research should be conducted to investigate humidification options for ECHO. Following the experimental study, the test set-up was moved into ECHO's mechanical closet where it was commissioned with the rest of the integrated mechanical system to provide space-heating, cooling, and DHW during the competition. When ECHO is recommissioned in Ottawa, Ontario, the system should be re-instrumented with:

- a thermocouple probe in the hot and cold tanks

- thermocouples on:

- the heat pump inlets and outlets;

- the heating and cooling coil supplies and returns;

- the heat dissipater supply and return; and

- the inlet and outlets of the solar collectors;

- power meters to measure power draws from:

- the heat pump;

- the circulation pumps;

- the air handler fan; and 
- the auxiliary heater;

- flow meters on:

- heat pump source and load side loops;

- cooling and heating coil supply loops; and

- heat dissipater loop; and

- an anemometer on the air handler.

Data from these instruments can be used to help validate and improve the TRNSYS model of the IMS. The experimental data can also be used to optimize control settings of the system.

The TRNSYS model used heat pump performance data for water-to-water operation. The IMS should be recommissioned with a glycol solution in the cold tank in order to create a new performance map that represents the glycol solution-to-water operation. For the calculation of the FEF, the energy consumption of the circulation pumps and fans were not accounted for. Therefore, by instrumenting these components with power meters, these energy draws can be accounted for when characterizing the performance of the system. By instrumenting the cold tank with a temperature probe, possible stratification in the cold tank can be investigated.

When running the heat pump load side flow rate at $3 \mathrm{~L} / \mathrm{min}$, the maximum inlet cut-off temperature was set to $37^{\circ} \mathrm{C}$ based on the experimental results. When the inlet temperature increases above $37^{\circ} \mathrm{C}$, the high pressure may activate the high pressure fault switch of the heat pump. This pressure limitation is due to the refrigerant R410a used. Different heat pumps using different refrigerants, such as R-134a, should be investigated in order to increase the load side maximum inlet cut-off temperature and extend the operation period of the heat pump in the integrated mechanical system.

Quantifying the benefits of combining solar thermal collectors and a heat pump into a series SAHP system for the integrated mechanical system was not specifically 
examined in this study. When a more refined model of the system is developed, the benefits of combining solar thermal and heat pump technologies in the integrated mechanical system can be quantified by comparing the simulated performance of the IMS with the performance of a system that uses the same solar thermal and heat pump components separately to meet the loads.

The system should also be studied for use in more common residential houses in Canada. This investigation should also include an economic analysis as the long term cost of the system and the potential cost savings will dictate the feasibility of implementing the system in residential houses in Canada. 


\section{List of References}

[1] NRCan, "Energy Use Data Handbook, 1990 to 2009," Office of Energy Efficiency, Natural Resources Canada, Ottawa, ON, Canada, Technical Report M141-11/2009E-PDF, 2012.

[2] W. Sparber, K. Vajen, S. Herkel, J. Ruschenburg, A. Thür, R. Fedrizzi, and M. D'Antoni, "Overview in Solar Thermal Plus Heat Pump Systems and Review of Monitoring Results," IEA-SHC Task 44, 2011.

[3] C. A. Cruickshank, "Evaluation of a Stratified Multi-Tank Thermal Storage for Solar Heating Applications," Ph.D. dissertation, Queen's University, Kingston, ON, Canada, June 2009.

[4] C. A. Cruickshank, S. J. Harrison, "Investigation of Reverse Thermosyphoning in an Indirect SDHW System." ASME Journal of Solar Energy, June 2009.

[5] J. A. Duffie, and W. A. Beckman, Solar Engineering of Thermal Processes, 3rd ed. Hoboken, NJ: John Wiley and Sons, Inc., 2006.

[6] B. D. Elliot, "Evaluation of An Indirect Solar Assisted Heat Pump Water Heater in the Canadian Climate," Master's thesis, Queen's University, Kingston, ON, Canada, December 2011.

[7] M. J. Moran and H. N. Shapiro, Fundamentals of Engineering Thermodynamics, 5th ed. USA: John Wiley \& Sons, Inc., 2004.

[8] V. Stevens, C. Craven, and R. Garber-Slaght, "Air Source Heat Pump in Southeast Alaska: A review of the literature, a market assessment, and preliminary modeling on residential air source heat pumps in Southeast Alaska," Cold Climate Housing Research Center, 2013.

[9] C. Aguilar, D. J. White, and D. L. Ryan, "Domestic Water Heating and Water Heater Energy Consumption in Canada," Canadian Building Energy End-Use 
Data and Analysis Centre, Technical Report CBEEDAC 2005RP-02, April 2005.

[10] M. Kegel, R. Sunye and J. Tamasauskas, "Life Cycle Cost Comparison and Optimisation of Different Heat Pump Systems in the Canadian Climate," in Proceedings of eSim 2012: The Canadian Conference on Building Simulation, Halifax, NS, May 2012.

[11] A. G. Bridgeman, "Experimental Analysis of an Indirect Solar Assisted Heat Pump for Domestic Hot Water Heating," Master's thesis, Queen's University, Kingston, ON, Canada, October 2010.

[12] "U.S. Department of Energy, Solar Decathlon," http://www.solardecathlon.gov/ Accessed January 24, 2014.

[13] "Solar Decathlon Rules," U. S. Department of Energy, August 1, 2013.

[14] "ECHO by Team Ontario, Queen's University, Carleton University, and Algonquin College," http://www.solardecathlon.gov/m/team_ontario.html Accessed January 24, 2014.

[15] M. Schiedel, C. Baldwin and C. A. Cruickshank, "In-Situ Experimental Validation of THERM Finite Element Analysis for a High R-Value Wall Using Vacuum Insulation Panels," in Proceedings of the ASME 2013 rth International Conference on Energy Sustainability, Minneapolis, MN, USA, July 2013.

[16] B. Huchuk, W. O'Brien, and C. A. Cruickshank, "Preliminary results of model predictive control of shading systems (WIP)," in Proceedings of the Symposium on Simulation for Architecture \& Urban Design, Society for Computer Simulation International, 2013.

[17] J. Chu, W. Choi, C. A. Cruickshank, and S. J. Harrison. "Modelling of an Indirect Solar-Assisted Heat Pump System for a High Performance Residential House," in Proceedings of ASME 2013 7th International Conference on Energy Sustainability, Minneapolis, MN, USA, July 2013.

[18] E. Morofsky and F. Campbell, "Integrated Mechanical Systems and Demand Side Management in The Advanced House", in Proceedings of the International Energy Agency Conference on Advanced Technologies for Electric Demand-Side Management, Sorrento, April 1991. 
[19] S. A. Klein et al., "TRNSYS 17 - a TRaNsient SYstem Simulation program Volume 1: Getting Started," Solar Energy Laboratory - University of Wisconsin-Madison, Madison, WI, 2012.

[20] "International Energy Agency: Solar Heating \& Cooling Program Task 44, 2013, Project (Task) Description," http://task44.iea-shc.org/description, Accessed January 24, 2014.

[21] J. Ruschenburg and S. Herkel, "A Review of Market-Available Solar Thermal Heat Pump Systems," International Energy Agency: Solar Heating \& Cooling Program, Task 44, subtask A, March 2013.

[22] J. Chu and C. A. Cruickshank, "Solar-Assisted Heat Pump Systems: A Review of Existing Studies and Their Applicability to the Canadian Residential Sector," in Proceedings of ASME 2013 7th International Conference on Energy Sustainability, Minneapolis, MN, USA, July 2013.

[23] T. L. Freeman, J. W. Mitchell, and T. E. Audit, "Performance of Combined Solar-Heat Pump Systems," Solar Energy Vol. 22., pp. 125-135, 1978.

[24] M. Chandrashekar, N. T. Le, H. F. Sullivan, and K. G. T. Hollands, "A Comparative Study of Solar Assisted Heat Pump Systems for Canadian Locations," Solar Energy Vol. 28, No. 3, pp. 217-226, 1982.

[25] K. Kaygusuz and T. Ayhan, "Experimental and theoretical investigation of combined solar heat pump system for residential heating," Energy Conversion \& Management 40, pp. 1377-1396, 1999.

[26] M. Y. Haller and E. Frank, 2011, "On The Potential of Using Heat From Solar Thermal Collectors for Heat Pumps Evaporators," in Proceeding of ISES Solar World Congress 2011, Kassel, Germany, September 2011.

[27] E. Bertram, P. Pärisch and R. Tepe, "Impact of solar heat pump system concepts on seasonal performance - Simulation studies," IEA-SHC Task 44, 2012 .

[28] J. Tamasauskas, M. Poirer, R. Zmeureanu, and R. Sunyé, "Modeling and optimization of a solar assisted heat pump using ice slurry as a latent storage material," Solar Energy 86, pp. 3316-3325, 2012.

[29] S. J. Sterling and M. R. Collins, "Feasibility of an indirect heat pump assisted solar domestic hot water system," Applied Energy 93, pp. 11-17, 2012. 
[30] S. J. Sterling, "Feasibility Analysis of Two Indirect Heat Pump Assisted Solar Domestic Hot Water Systems," Master's thesis, University of Waterloo, Waterloo, ON, Canada, 2011.

[31] B. J. Huang and J. P. Chyng, "Integral-Type Solar-Assisted Heat Pump Water Heater," Renewable Energy 16, pp. 731-734, 1999.

[32] B. J. Huang and C. P. Lee, "Long-term performance of solar-assisted heat pump water heater," Renewable Energy 29, pp. 633-639, 2003.

[33] X. Guoying, Z. Xiaosong, and D. Shiming, "A simulation study on the operating performance of a solar-air source heat pump water heater," Applied Thermal Engineering 26, pp. 1257-1265, 2006.

[34] M. N. A. Hawlader, S. K. Chou, and M. Z. Ullah, "The performance of a solar assisted heat pump water heating system," Applied Thermal Engineering 21, pp. 1049-1065, 2001.

[35] Y. H. Kuang and R. Z. Wang, "Performance of a multi-functional direct-expansion solar assisted heat pump system," Solar Energy 80, pp. 795-803, 2005.

[36] T. T. Chow., G. Pei, K. F. Fong, Z. Lin, A. L. S. Chan, and M. He, "Modeling and application of direct-expansion solar-assisted heat pump for water heating in subtropical Hong Kong," Applied Energy 87, pp. 643-649, 2010.

[37] J. Fernández-Seara, C. Piũeiro, J. Alberto Dopazo, F. Fernandes, and P. X.B. Sousa, "Experimental analysis of a direct expansion solar assisted heat pump with integral storage tank for domestic water heating under zero solar radiation conditions," Energy Conversion and Management 59, pp. 1-8, 2012.

[38] K. Bakirci and B. Yuksel, "Experimental thermal performance of a solar source heat-pump system for residential heating in cold climate region," Applied Energy Engineering 31, pp. 1508-1518, 2011.

[39] Q. Wang, Y. Liu, G. Liang, J. Li, S. Sun, and G. Chen, "Development and experimental validation of a novel indirect-expansion solar-assisted multifunctional heat pump," Energy and Building 43, pp. 300-304, 2011.

[40] A. Loose, H. Drück, N. Hanke, and F. Thole, "Field test for performance monitoring of combined solar thermal and heat pump systems," IEA-SHC Task 44, 2011. 
[41] "TRNSYS 17 - a TRaNsient SYstem Simulation program - Volume 5: Multizone Building modeling with Type56 and TRNBuild," Solar Energy Laboratory - University of Wisconsin-Madison, Madison, WI, 2012.

[42] "TESSLibs 17: HVAC Library Mathematical Reference," Volume 10, Thermal Energy System Specialists, Madison, Wisconsin, 2012.

[43] S. A. Klein et al., "TRNSYS 17 - a TRaNsient SYstem Simulation program Volume 4: Mathematical Reference," Solar Energy Laboratory - University of Wisconsin-Madison, Madison, WI, 2010.

[44] Canadian Standards Association, "Solar Domestic Hot Water Systems Liquid-to-Liquid Heat Transfer," Rexdale, Ontario, Canada, 1982.

[45] The German Solar Energy Society, Planning and Installing Solar Thermal Systems: A Guide for Installers, Architects, and Engineers, 2nd ed., London: Earthscan, 2005.

[46] "Certified Solar Collector, Certification \# 2009049A," Solar Rating \& Certification Corportation, Cocoa, FL, 2014.

[47] I. Dinçer, and M. A. Rosen, Thermal Energy Storage - Systems and Applications, New York, NY: John Wiley and Sons, Inc., 2002.

[48] Y. Allard, M. Kummert, M. Bernier, and A. Mareau, "Intermodel Comparison and Experimental Validation of Electrical Water Heater Models in TRNSYS," in Proceedings of Building Simulation 2011: 12th Conference of International Building Performance Simulation Association, Sydney, 2011.

[49] "TESSLibs 17: Storage Library Mathematical Reference," Volume 10, Thermal Energy System Specialists, Madison, Wisconsin, 2012.

[50] "TESSLibs 17: Geothermal Heat Pump Library Mathematical Reference," Volume 10, Thermal Energy System Specialists, Madison, Wisconsin, 2012.

[51] "Envision Geothermal Hydronic Heat Pump 1.5 to 6 tons: Specification Catalogue," WaterFurnace International, Inc., Fort Wayne, IN, 2009.

[52] "Residential Solar Electric Solaraide Water Heaters \& Storage Tanks," Rheem Water Heating, Montgomery, AL, 2011. 
[53] Instrumentation Testing Association, Flowmeters for System Applications Designer Checklist: Flow Meter Designer Checklist, Instrumentation Testing Association, 1999.

[54] "Power \& RMS Measuring Instruments," http://www.elexbrno.cz/dldfile.php?id =1325, Accessed January 24, 2014.

[55] "Grundfos Product Guide: MAGNA, UPE Series 2000 circulator pumps, 50/60 Hz," Grundfos Pumps Corp., Olathe, KS, 2007.

[56] "Venmar AVS ERV EKO 1.5 Part no. 43911," Venmar Ventilation Inc., Drummondville, QC, Canada, 2013.

[57] R. M. Dickinson, "Analysis and Development of Draw Strategies for Multi-Tank Thermal Storage System for Solar Heating Applications," Master's thesis, Carleton University, Ottawa, ON, Canada, Dec. 2012.

[58] R. S. Figliola, D. E. Beasley, Theory and Design for Mechanical Measurements, 4th ed., Hoboken, NJ: Wiley, 2006.

[59] "Certificate of Calibration, Certificate no. GCS 10525," Guildline Instruments Limited, Smith Falls, ON, Canada, 2007.

[60] "Temperature Measurements," Supplement to American Society of Mechanical Engineers PTC 19.3, 1974. 


\section{Appendix A}

\section{TRNSYS Simulation Model}

Figure 3.1 on page 42 illustrates a graphical interface of the TRNSYS model with all the controls and output components removed. Figure A.1 shows the complete graphical interface of the TRNSYS model including all components.

Table A.1 summarizes all the Types that were used for the key components of the model. 


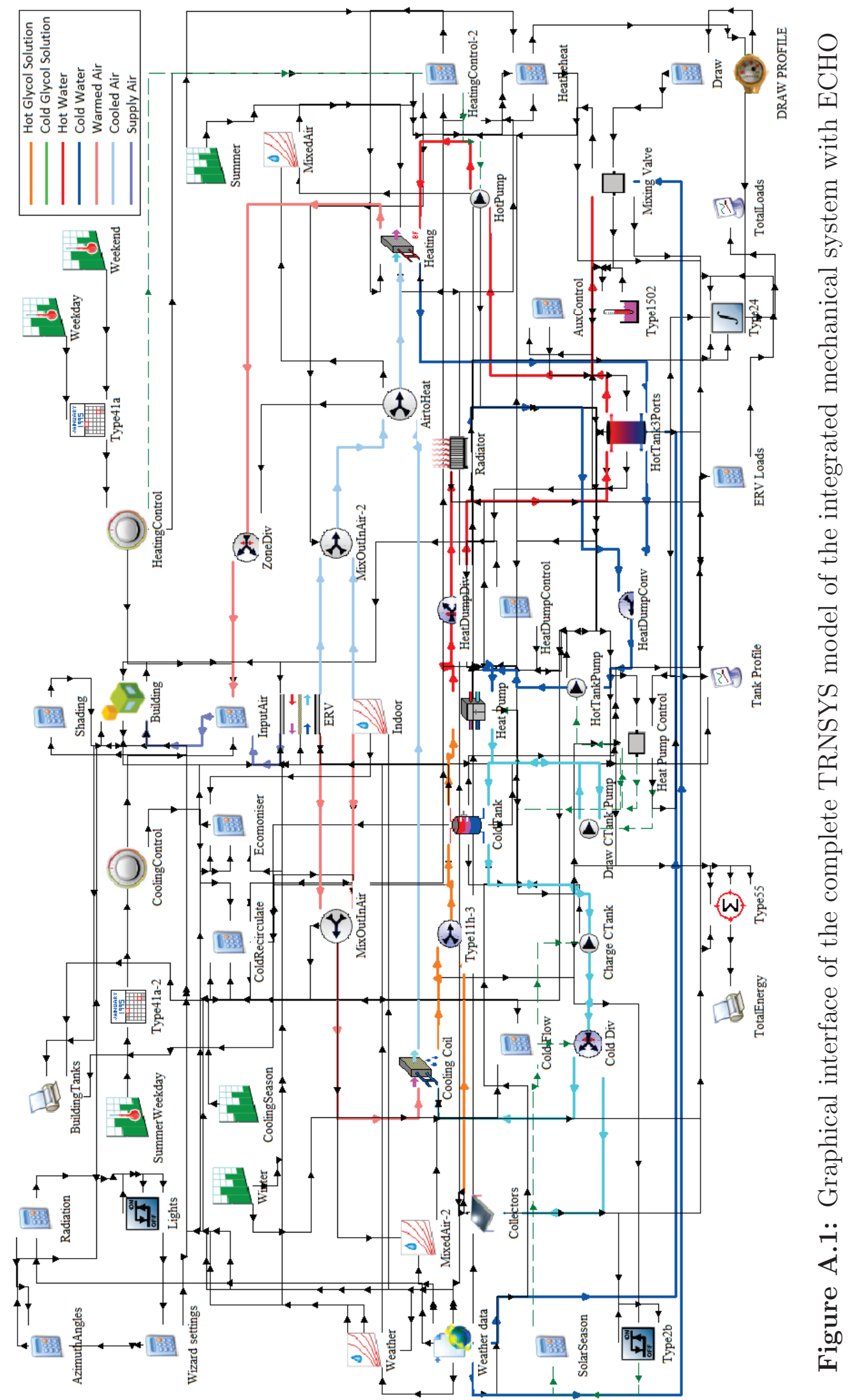


Table A.1: Key Types used in the TRNSYS model

\begin{tabular}{|c|c|}
\hline Type Number & Description \\
\hline 1 & $\begin{array}{l}\text { Solar thermal collectors (Quadratic efficiency collector with } \\
\text { 2nd-order incident angle modifiers) }\end{array}$ \\
\hline $2 \mathrm{~b}$ & Differential controller with hysteresis (for temperatures) \\
\hline 3 & Pumps \\
\hline 4 & Thermal energy storage tank (hot tank) \\
\hline 11 & Tee-piece \\
\hline 14 & Time dependent forcing function \\
\hline 15 & Weather data reading and processing (TMY2) \\
\hline 33 & Thermodynamic properties (psychrometrics) \\
\hline 41 & Forcing function sequencer (for weekdays and weekends) \\
\hline 56 & Loads and structures (multi-zone building) \\
\hline 60 & $\begin{array}{l}\text { Detailed fluid storage tank (vertical cylinder with uniform } \\
\text { losses and node heights) }\end{array}$ \\
\hline 71 & Evacuated tube collectors \\
\hline 178 & Flow mixer \\
\hline 296 & Custom heat pump controller developed by Elliot [6] \\
\hline 508 & Cooling coil (liquid source and bypass factor approach) \\
\hline 534 & Cylindrical storage tank (vertical storage tank) \\
\hline 667 & Air-to-air heat exchanger (sensible and latent transfer) \\
\hline 753 & Heating coils (liquid source and bypass factor approach) \\
\hline 927 & Liquid-to-liquid heat pump (single stage) \\
\hline 1231 & Radiator \\
\hline 1502 & Simple heating thermostat \\
\hline 1503 & Simple cooling thermostat \\
\hline
\end{tabular}




\section{Appendix B}

\section{Sensitivity Study of Simulation Parameters}

\section{B.1 Simulation Time-step}

TRNSYS computes the data at a user-defined simulation time-step. If the time-step is too long, any large fluctuations in the system within the time-step may not be captured or have little effect on the system. Additionally, the simulation may not be able to converge to a solution. On the other hand, if the time-step is too small, the simulation time will increase [3]. A sensitivity study of the time-step length was conducted using the base model. Figure B.1 shows the results of this study. The simulations were performed with $15,10,5,3$ and 1 minute time-steps. It was found that the annual FEF improved slightly as the simulation time-step decreased. However, the 15-minute time-step simulation had an annual $F E F$ that was only 0.00658 less than the annual FEF found with the 1-minute time-step simulation. The 1-minute time-step simulation took just over 3 hours to complete while the 3 -minute time-step simulation required about an hour to complete. Since the annual FEF only 
differed by 0.000107 between the 1 minute time-step simulation and the 3 minute timestep simulation, the 3 minute time-step was chosen for the other sensitivity studies to reduce simulation time.

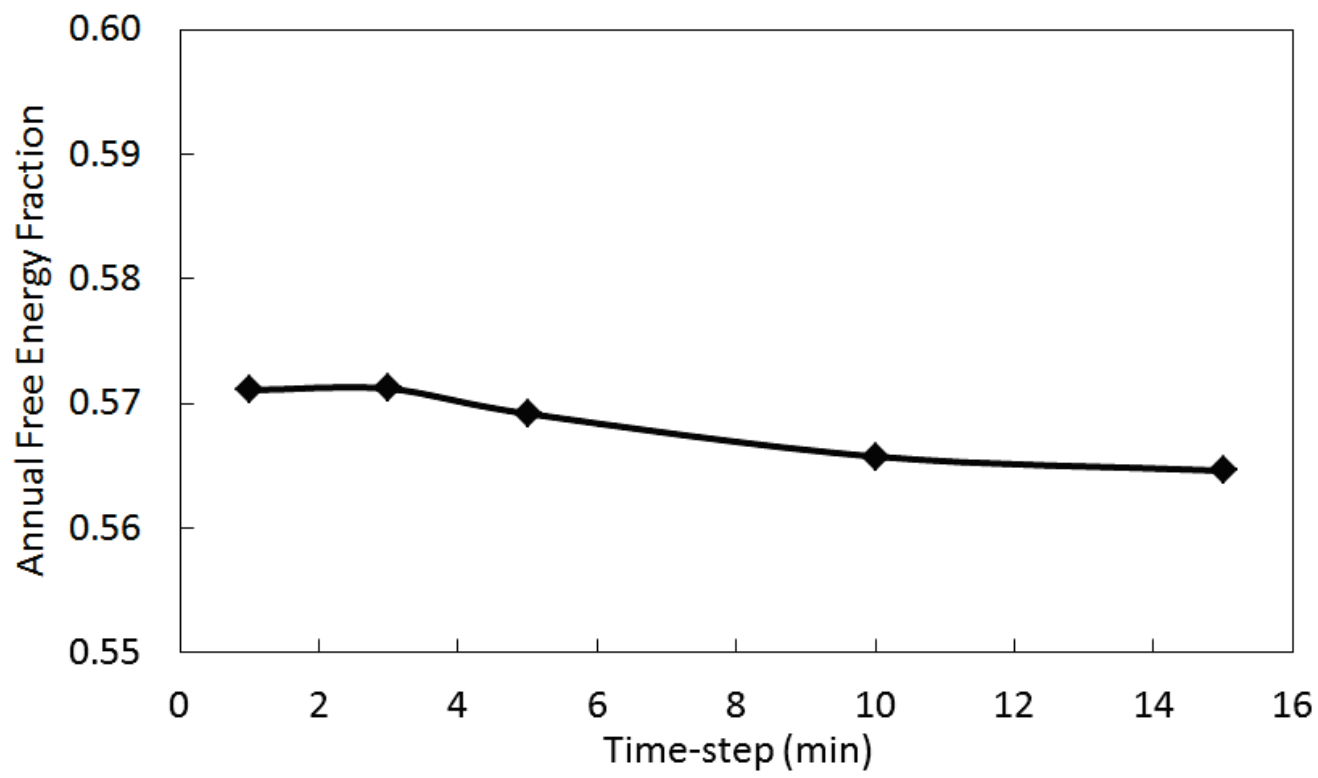

Figure B.1: Sensitivity study of simulation time-step

\section{B.2 Tank Nodes}

The sensitivity of the number of nodes in the hot tank was investigated. The model shown in Figure 4.6 was used for this study and Type 534 was used for the hot tank. The heat pump source side inlet temperature was maintained at $20^{\circ} \mathrm{C}$ and the hot tank was initially $20^{\circ} \mathrm{C}$ from the top to the bottom of the tank. The heat pump load side flow rate was set to $3 \mathrm{~L} / \mathrm{min}$. Simulations were conducted with 5, 10, 20, 30, 40 and 50 nodes in the hot tank. In the annual simulations of the IMS, the maximum number of nodes allowed was 50. If the number of nodes was set to greater than 50 in the simulations of the IMS, then the total number of derivative equations in the entire simulation would exceed the total number of derivative equations allowed. Figure B.2 


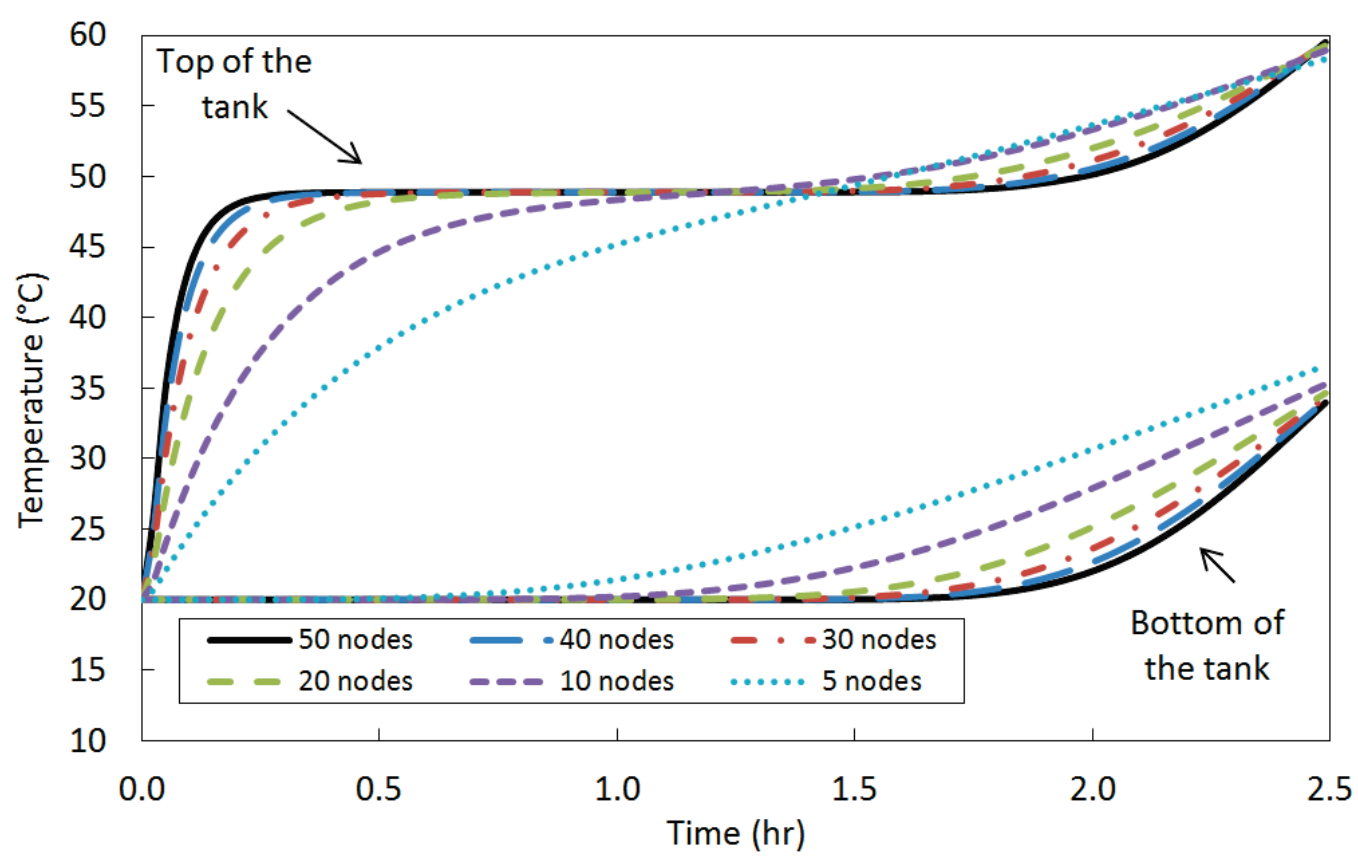

Figure B.2: Sensitivity study of the number of nodes in the hot tank

shows the temperatures at the top and bottom of the tank for each simulation. It was found that with more nodes, the rate of temperature of change of each node increases, which better resembles the temperature profiles of the $3 \mathrm{~L} / \mathrm{min}$ experimental data. With fewer nodes, the temperature changed more gradually in each node and the level of stratification achieved was reduced. These results are consistent with findings from Cruickshank [3] which examined node sensitivity for the case of a $270 \mathrm{~L}$ tank charged with a constant temperature of $50^{\circ} \mathrm{C}$ at $1.5 \mathrm{~L} / \mathrm{min}$. Type 60 was used for the tank and the number of nodes were varied from 1 to 75 . It was found that the temperature estimates improved with increasing number of nodes. The study concluded that a large number of nodes is required to accurately simulate high stratification in a $\operatorname{tank}[3]$. 


\section{Appendix $\mathrm{C}$}

\section{Deck File for the Integrated Mechanical System Model}

The following content was extracted from the deck file for the TRNSYS model of the integrated mechanical system. The deck file contains all the components used in the model and the parameters set for each component.

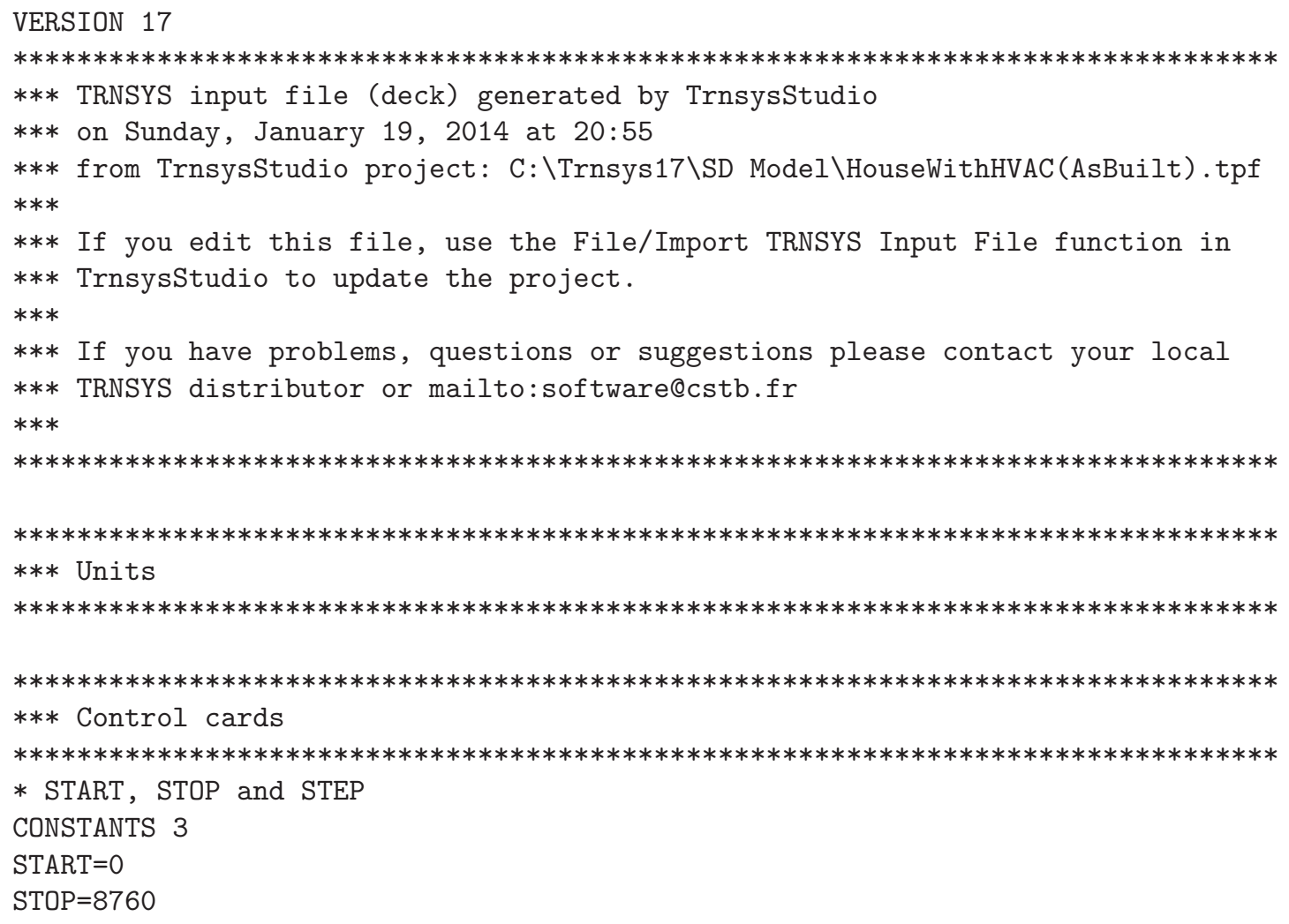




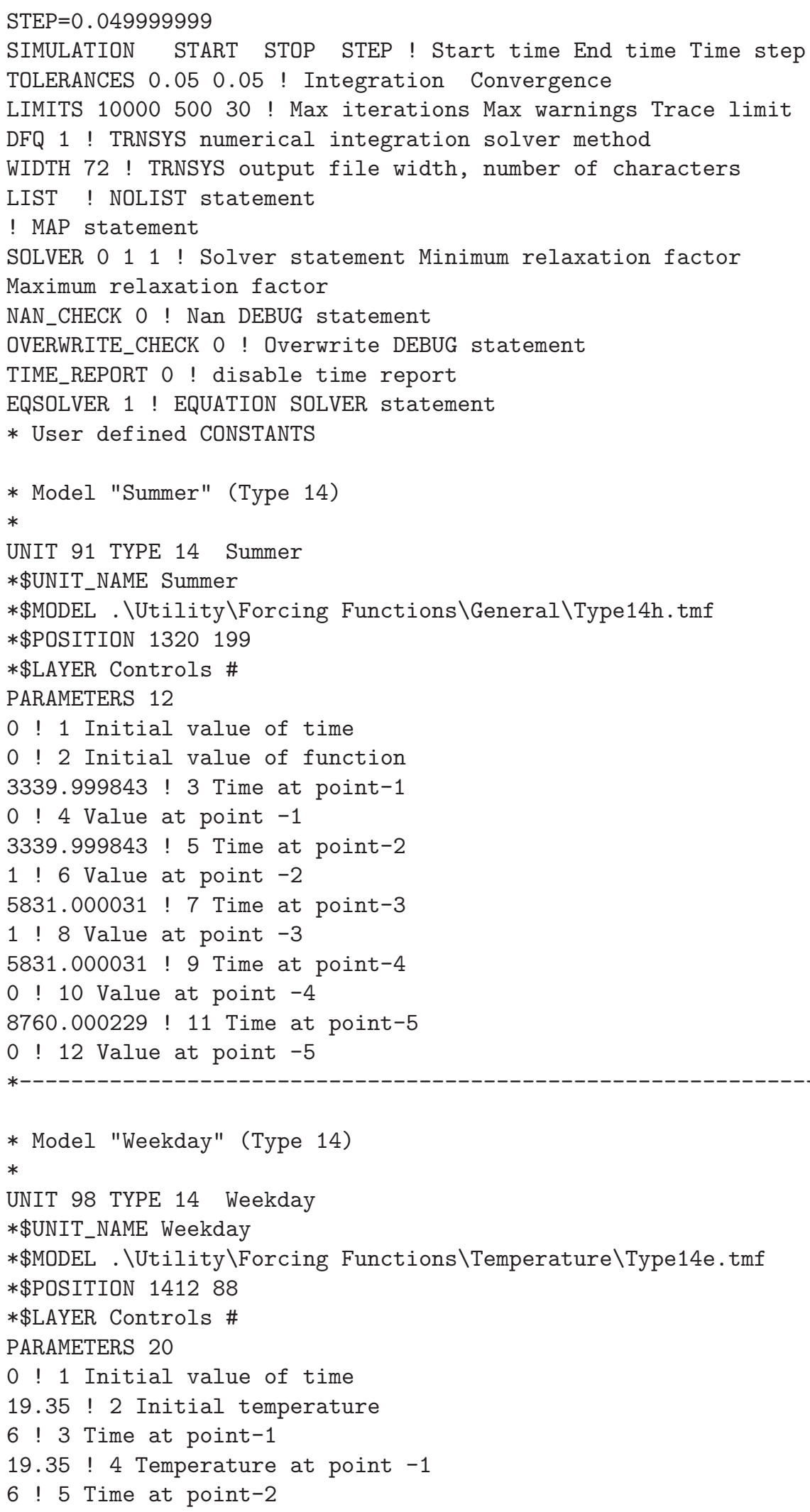




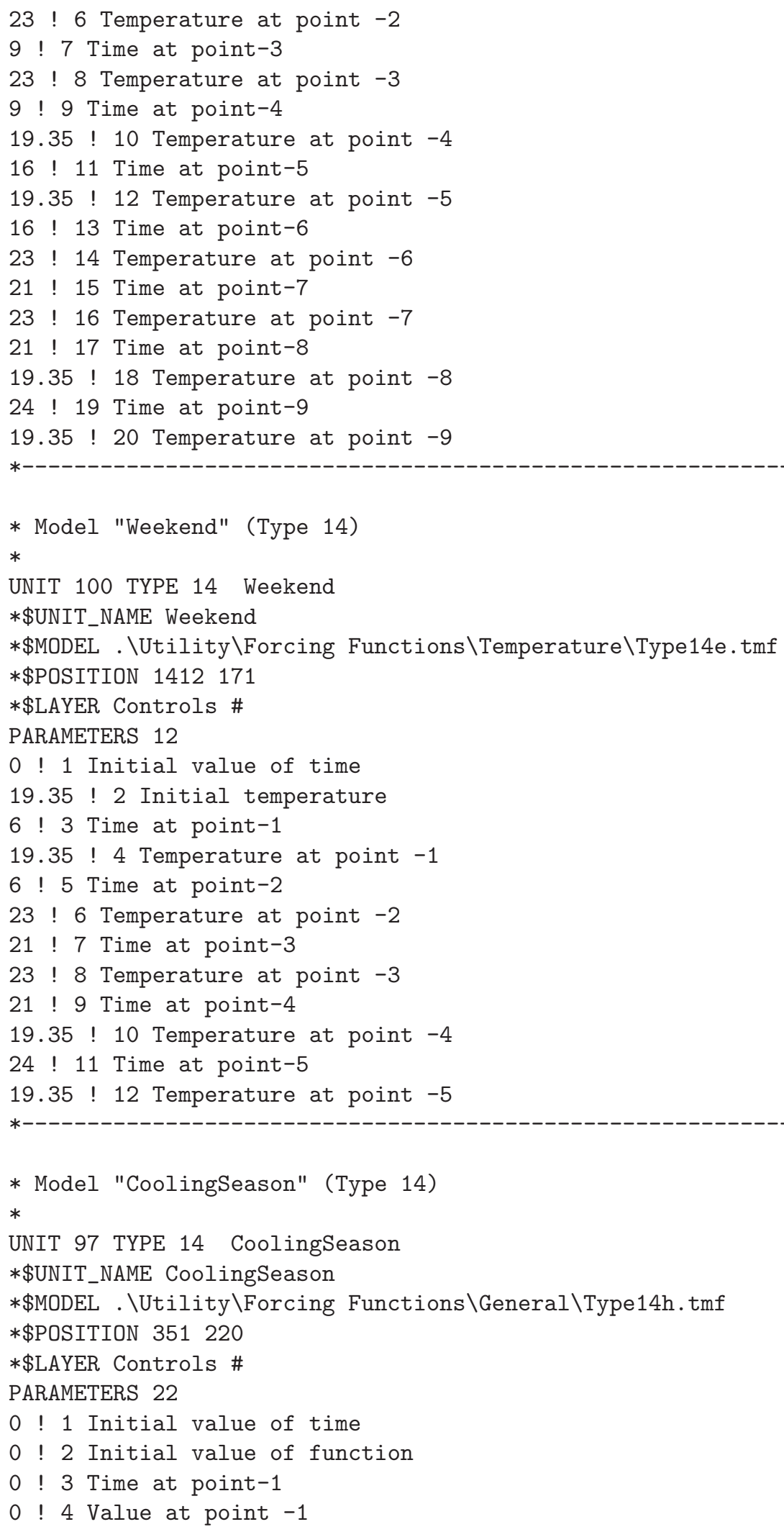




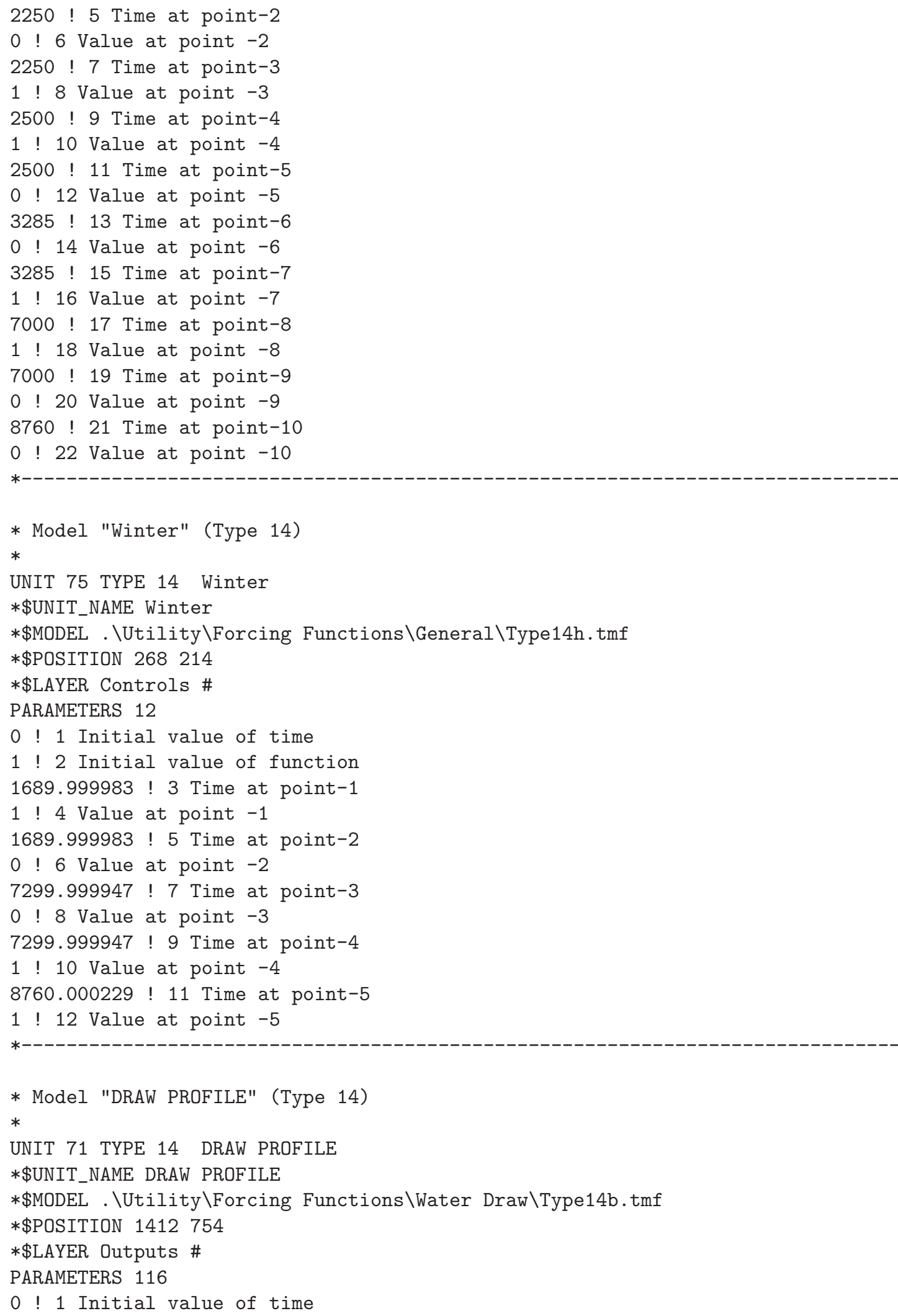




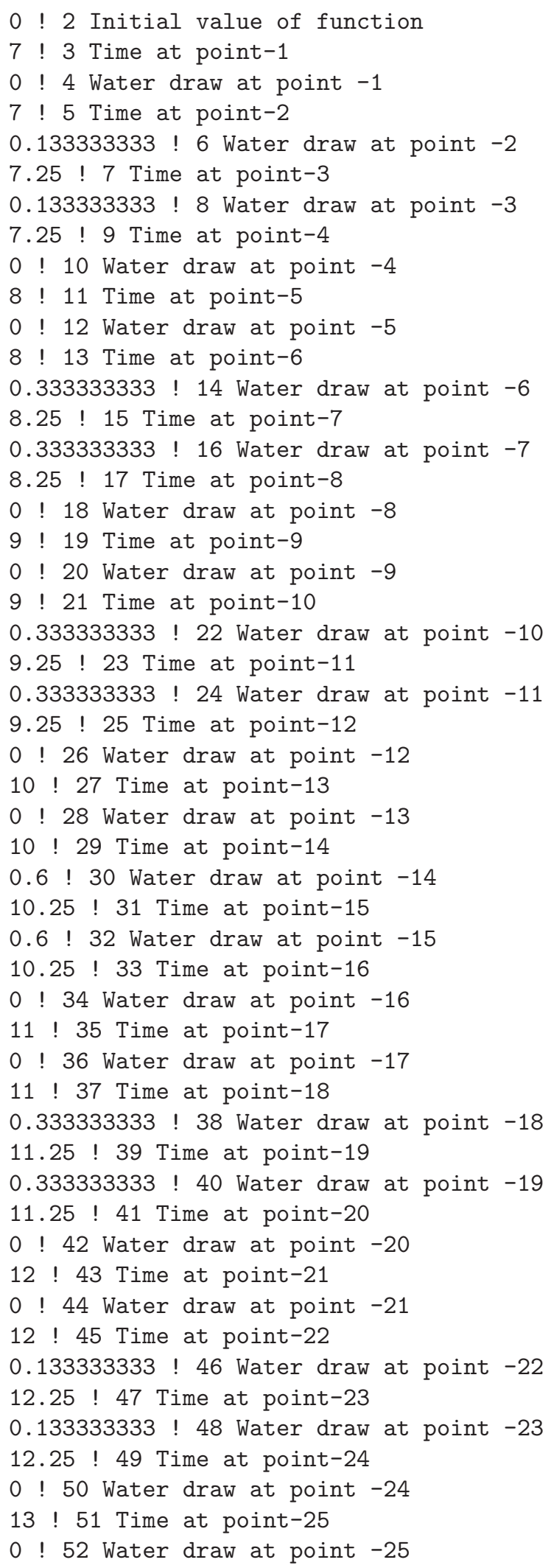




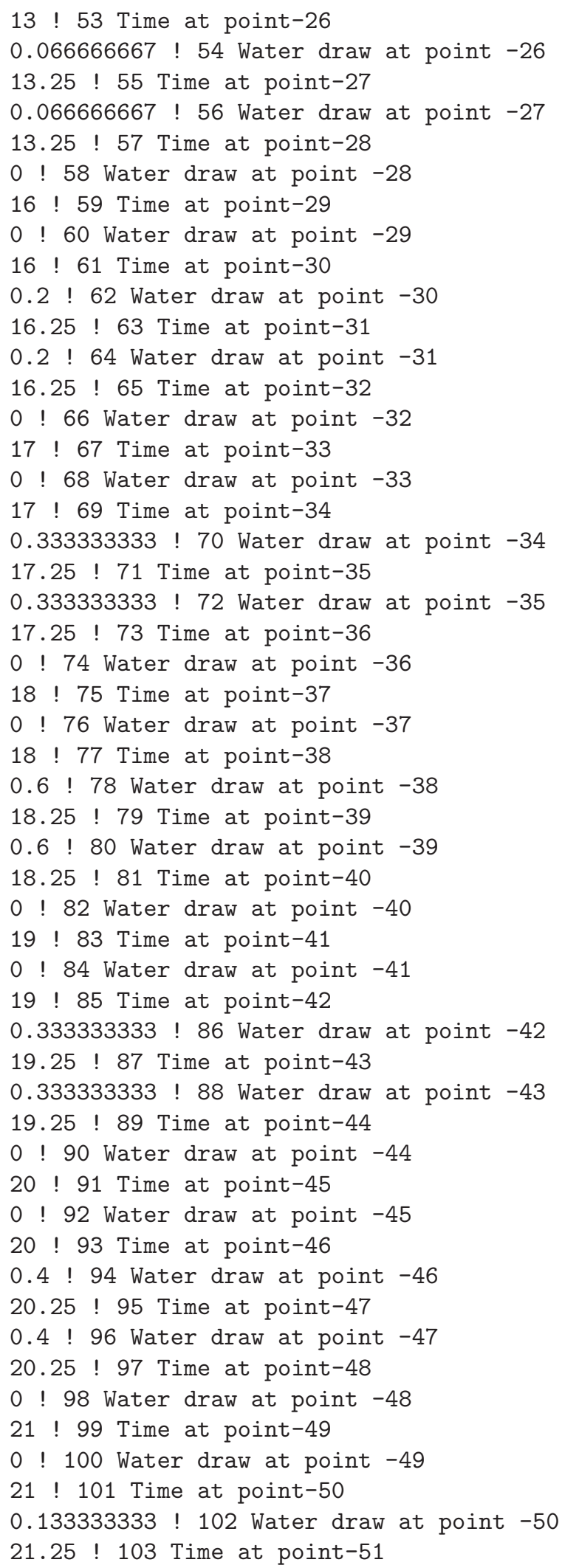




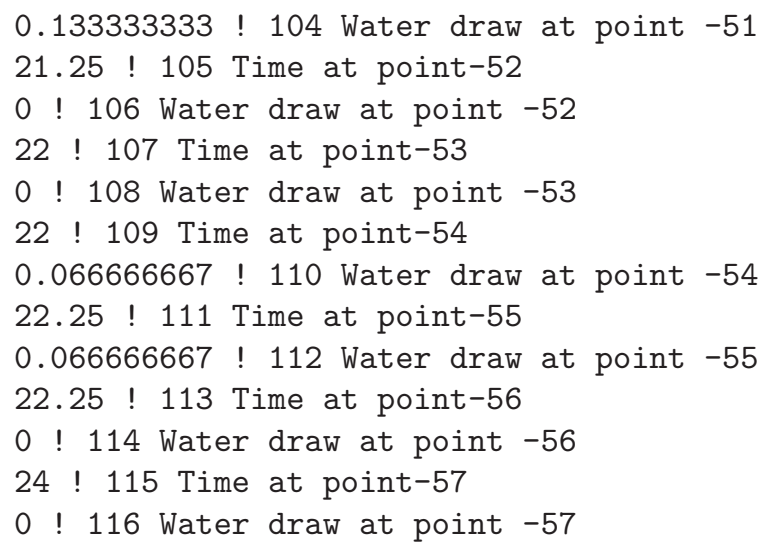




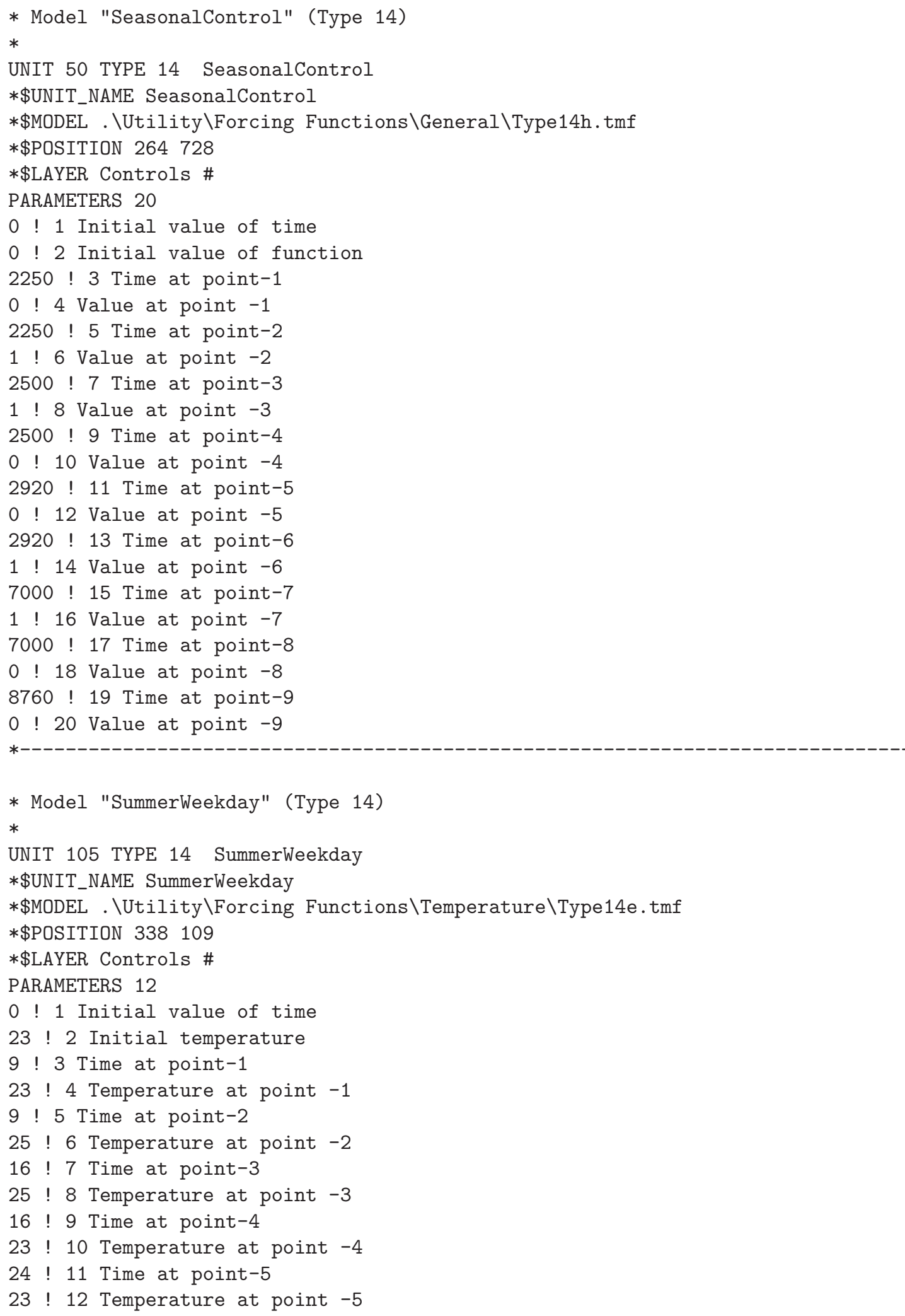




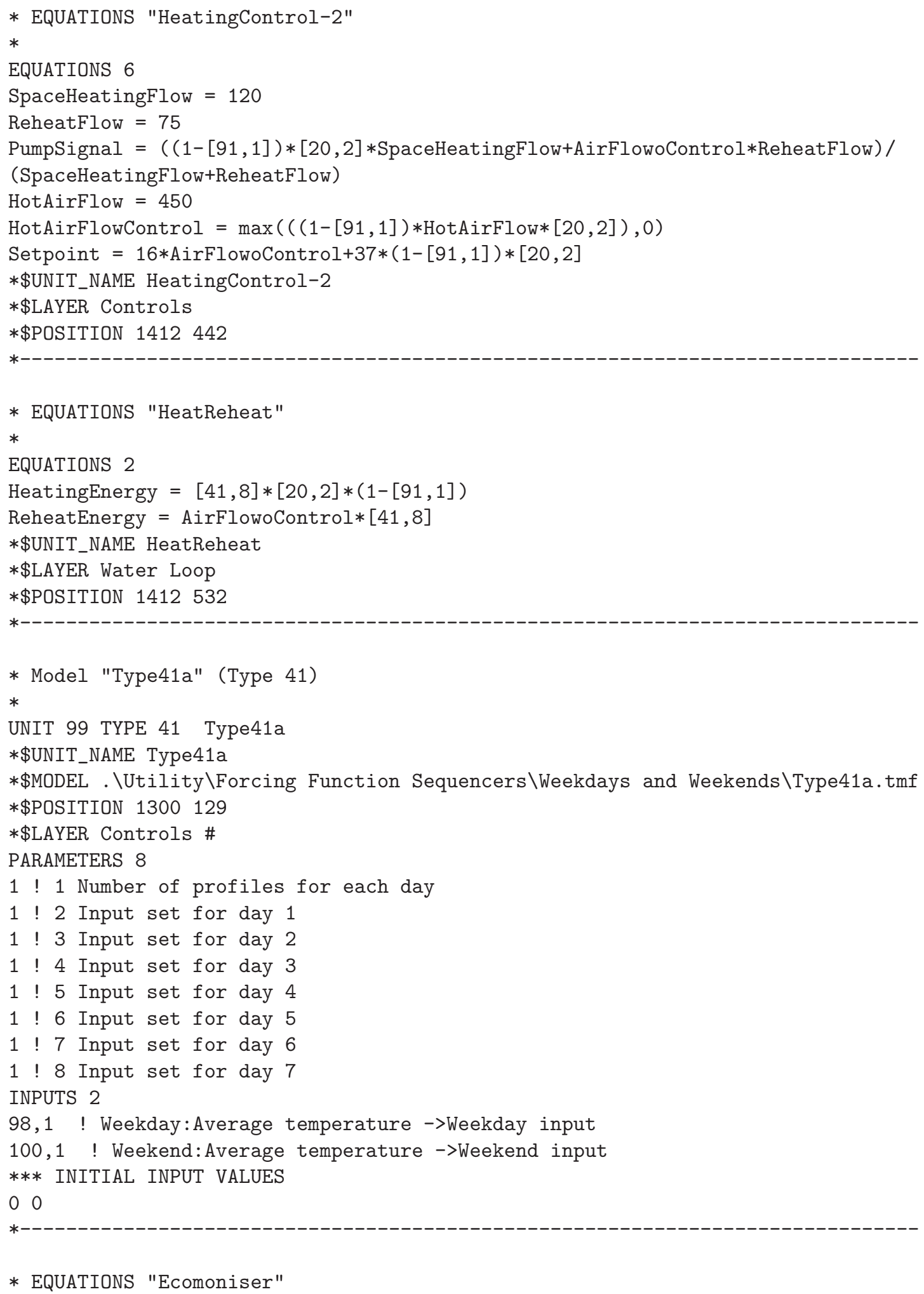




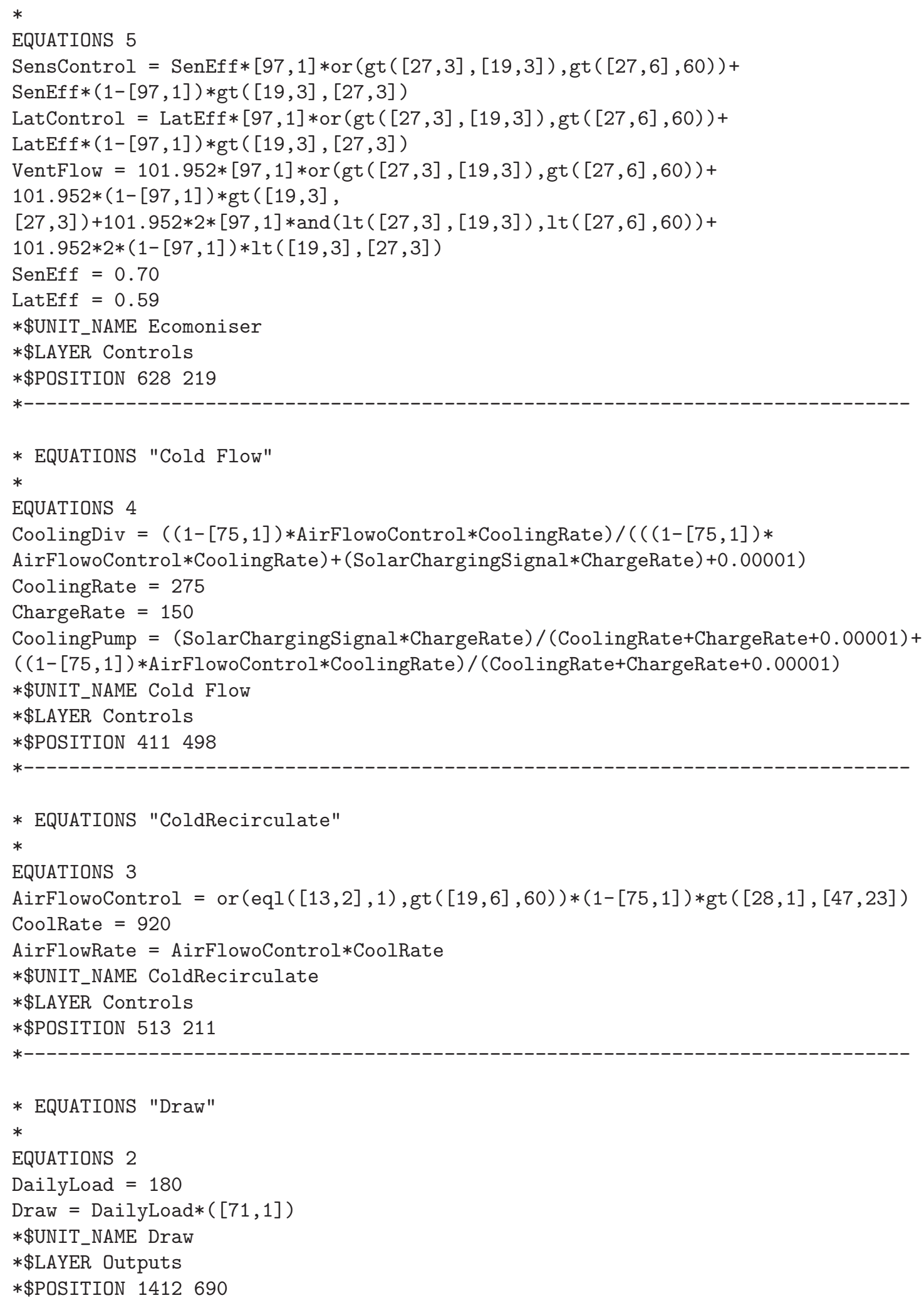




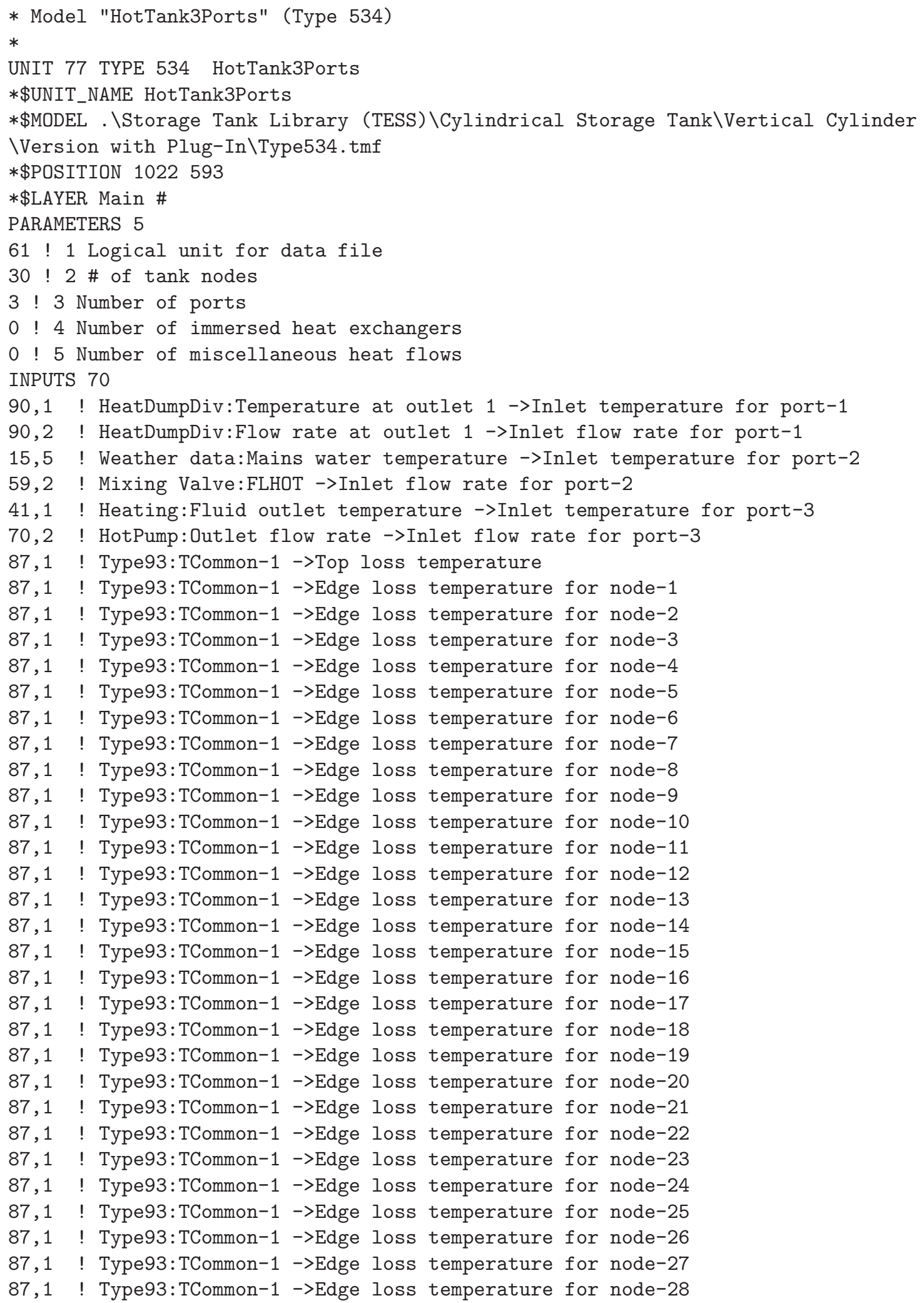


87,1 ! Type93:TCommon-1 ->Edge loss temperature for node-29

87,1 ! Type93:TCommon-1 ->Edge loss temperature for node-30

87,1 ! Type93:TCommon-1 ->Bottom loss temperature

0,0 ! [unconnected] Gas flue temperature

0,0 ! [unconnected] Inversion mixing flow rate

0,0 ! [unconnected] Auxiliary heat input for node-1

0,0 ! [unconnected] Auxiliary heat input for node-2

0,0 ! [unconnected] Auxiliary heat input for node-3

0,0 ! [unconnected] Auxiliary heat input for node-4

0,0 ! [unconnected] Auxiliary heat input for node-5

0,0 ! [unconnected] Auxiliary heat input for node-6

0,0 ! [unconnected] Auxiliary heat input for node-7

0,0 ! [unconnected] Auxiliary heat input for node-8

TankAuxSignal ! AuxControl:TankAuxSignal ->Auxiliary heat input for node-9

0,0 ! [unconnected] Auxiliary heat input for node-10

0,0 ! [unconnected] Auxiliary heat input for node-11

0,0 ! [unconnected] Auxiliary heat input for node-12

0,0 ! [unconnected] Auxiliary heat input for node-13

0,0 ! [unconnected] Auxiliary heat input for node-14

0,0 ! [unconnected] Auxiliary heat input for node-15

0,0 ! [unconnected] Auxiliary heat input for node-16

0,0 ! [unconnected] Auxiliary heat input for node-17

0,0 ! [unconnected] Auxiliary heat input for node-18

0,0 ! [unconnected] Auxiliary heat input for node-19

0,0 ! [unconnected] Auxiliary heat input for node-20

0,0 ! [unconnected] Auxiliary heat input for node-21

0,0 ! [unconnected] Auxiliary heat input for node-22

0,0 ! [unconnected] Auxiliary heat input for node-23

0,0 ! [unconnected] Auxiliary heat input for node-24

0,0 ! [unconnected] Auxiliary heat input for node-25

0,0 ! [unconnected] Auxiliary heat input for node-26

0,0 ! [unconnected] Auxiliary heat input for node-27

0,0 ! [unconnected] Auxiliary heat input for node-28

0,0 ! [unconnected] Auxiliary heat input for node-29

0,0 ! [unconnected] Auxiliary heat input for node-30

*** INITIAL INPUT VALUES

$0 \begin{array}{lllllllllllllllllllllllllllllllllllll}0 & 0 & 0 & 0 & 0 & 20 & 0 & 0 & 0 & 0 & 0 & 0 & 0 & 0 & 0 & 0 & 0 & 0 & 0 & 0 & 0 & 0 & 0 & 0 & 0 & 0 & 0 & 0 & 0 & 0 & 0 & 0 & 0 & 0 & 0 & 0 & 20\end{array}$

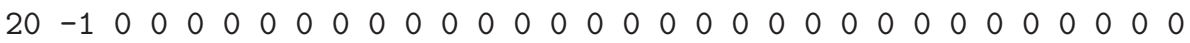

DERIVATIVES 30

56 ! 1 Initial Tank Temperature-1

56 ! 2 Initial Tank Temperature-2

56 ! 3 Initial Tank Temperature-3

56 ! 4 Initial Tank Temperature-4

56 ! 5 Initial Tank Temperature-5

56 ! 6 Initial Tank Temperature-6

56 ! 7 Initial Tank Temperature-7

56 ! 8 Initial Tank Temperature-8

56 ! 9 Initial Tank Temperature-9

56 ! 10 Initial Tank Temperature-10

56 ! 11 Initial Tank Temperature-11

56 ! 12 Initial Tank Temperature-12 


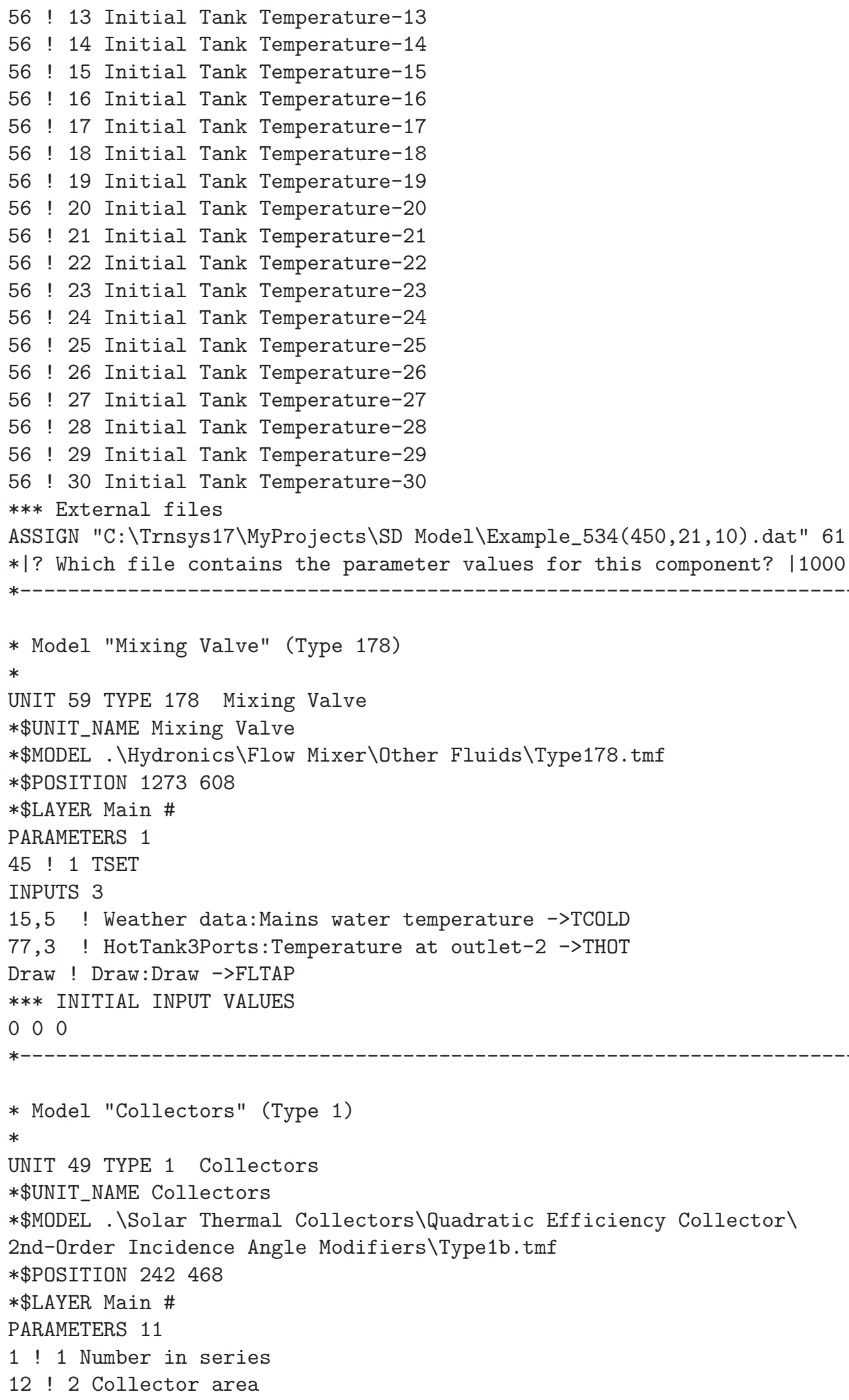




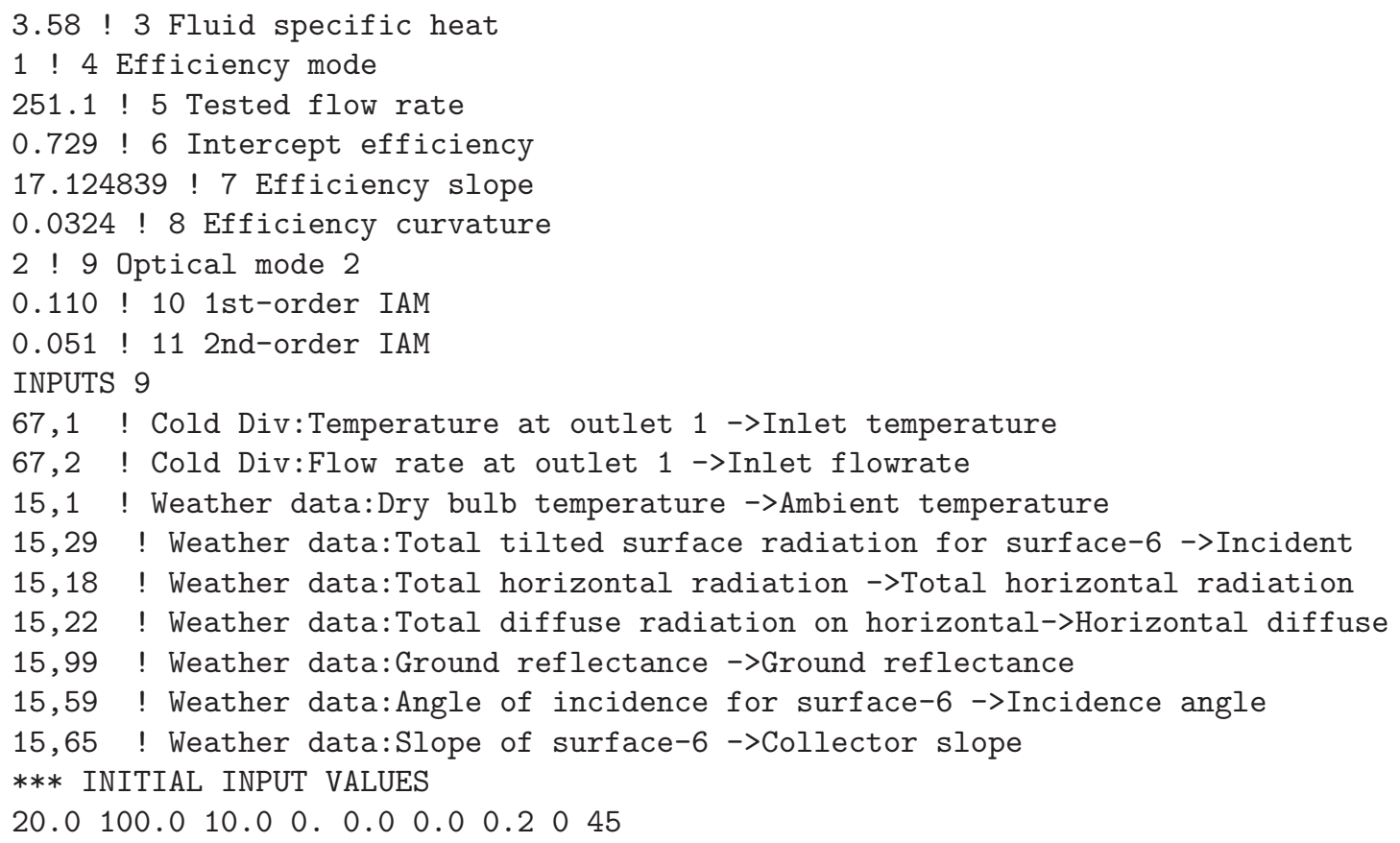




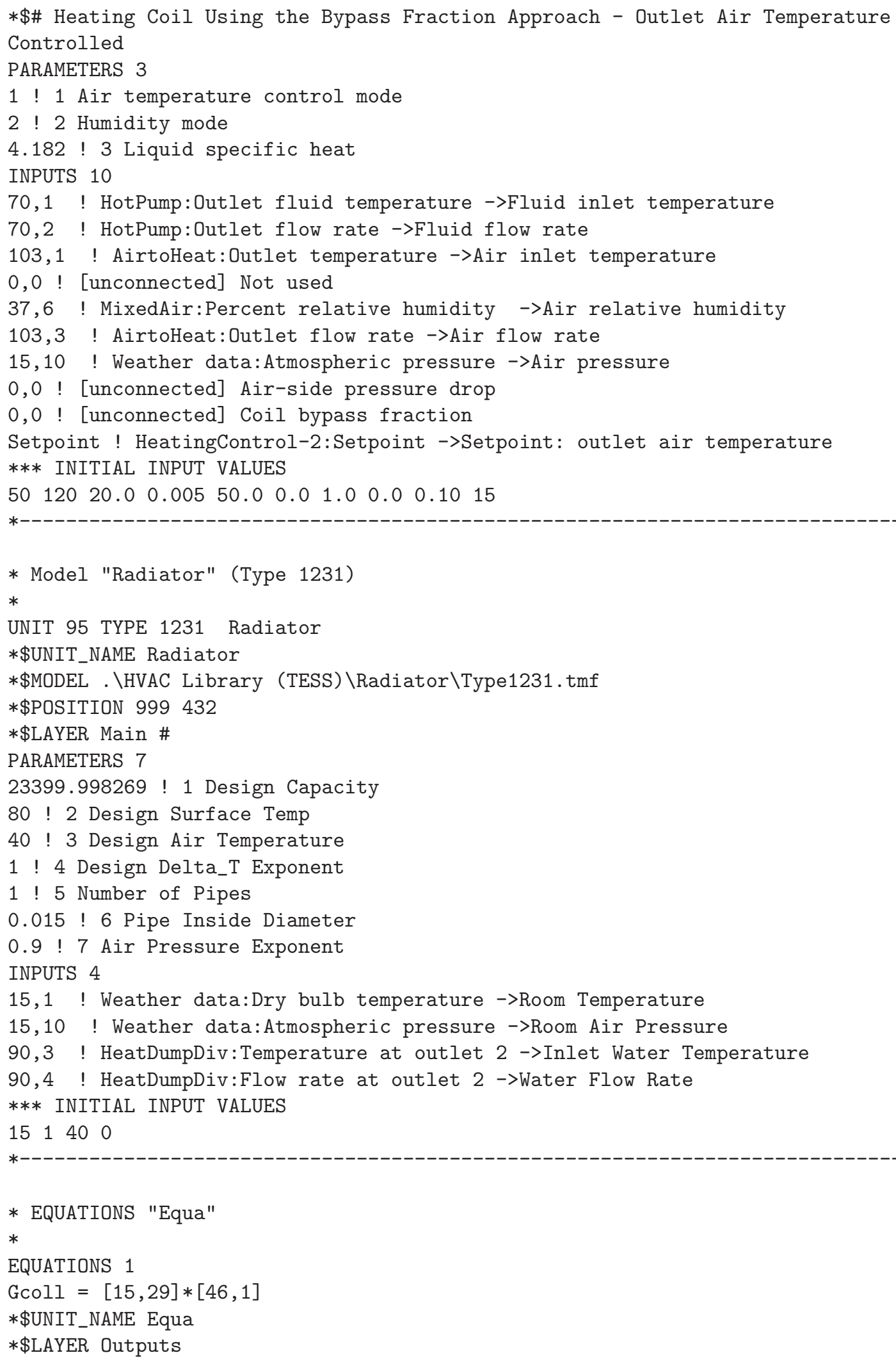


*\$POSITION 64728

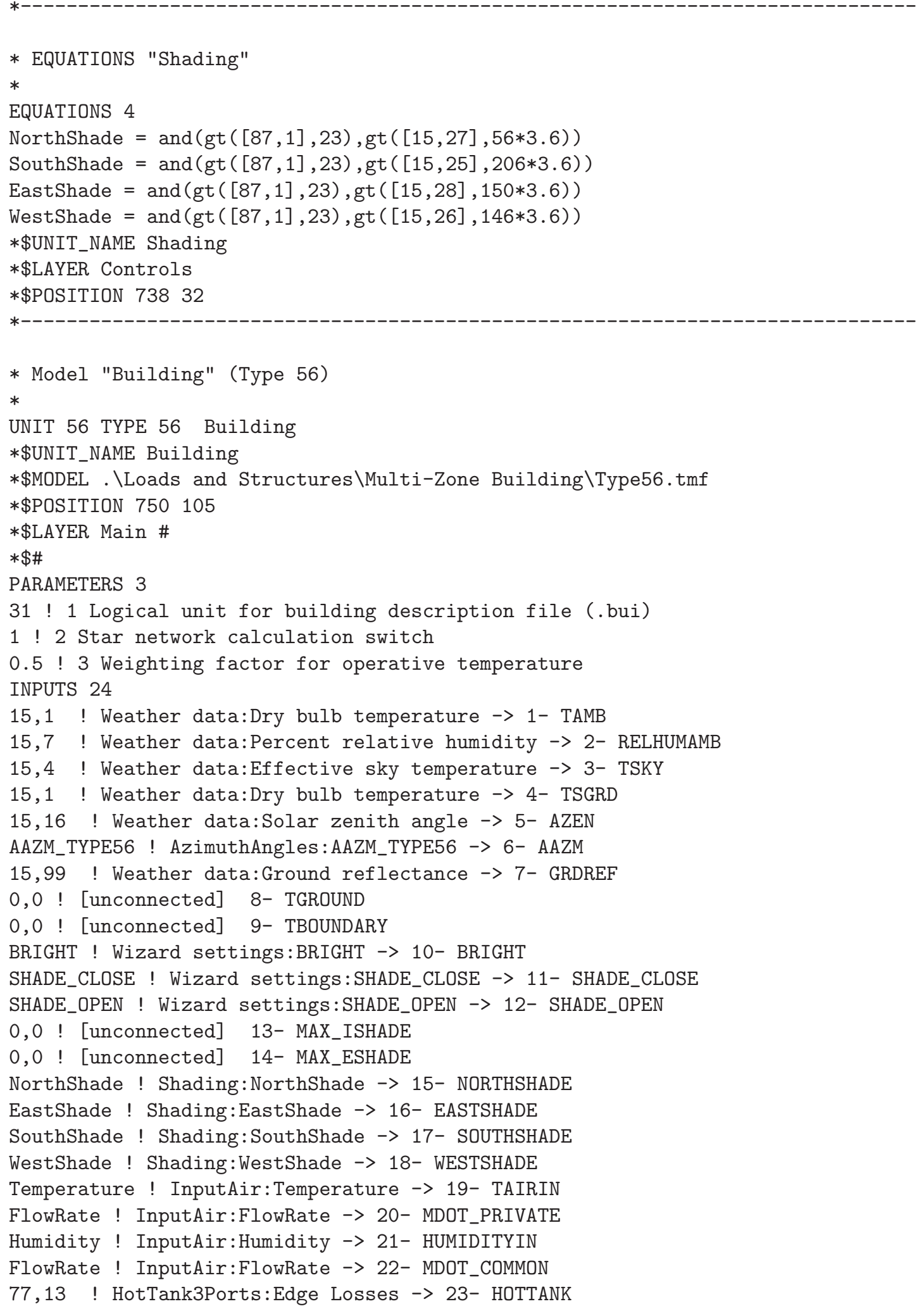




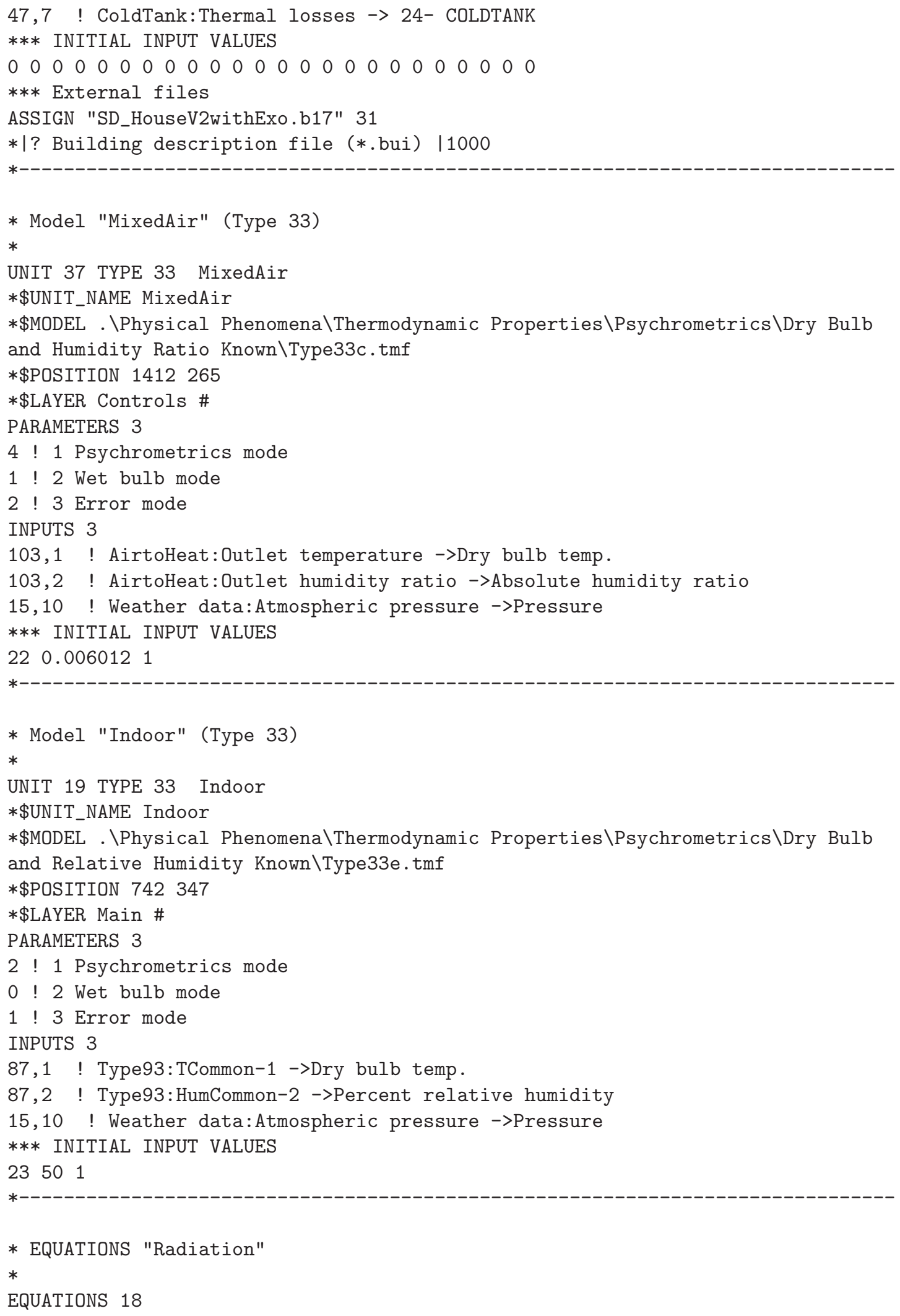




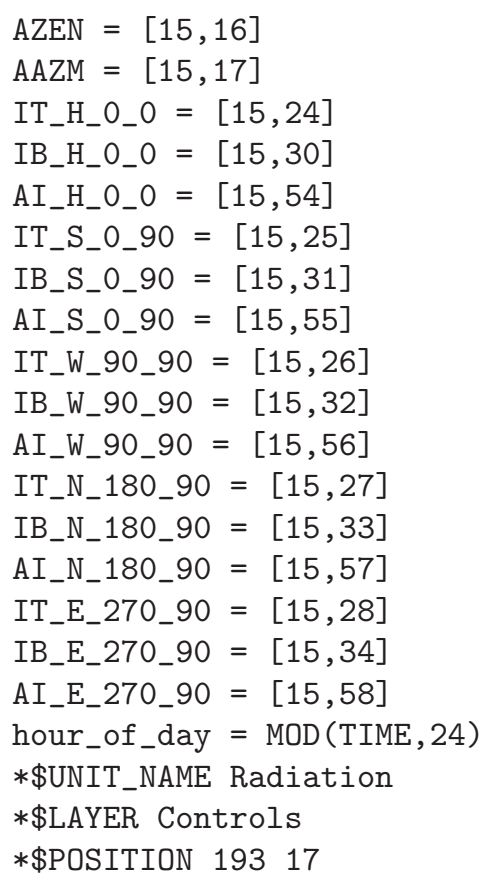




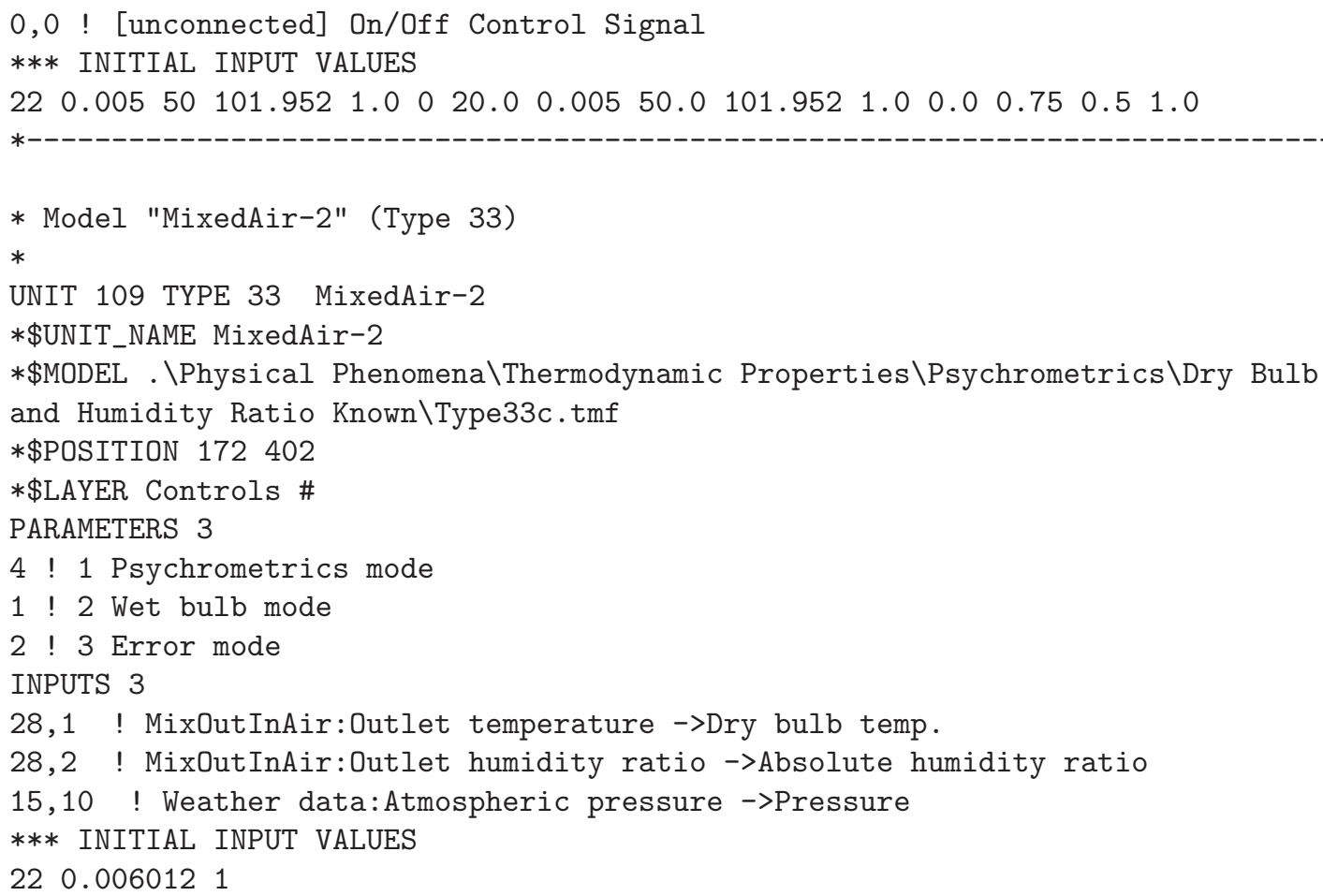




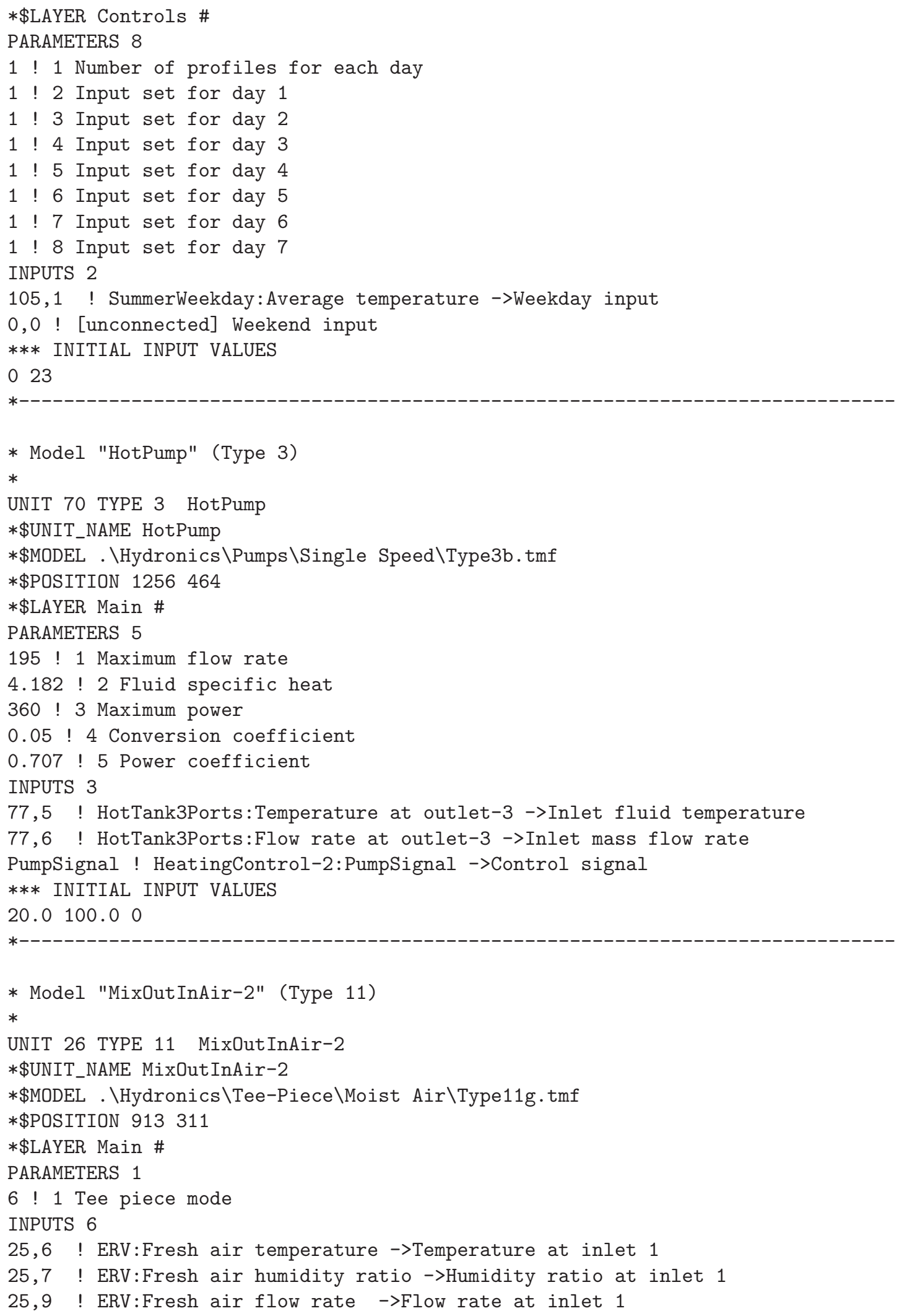




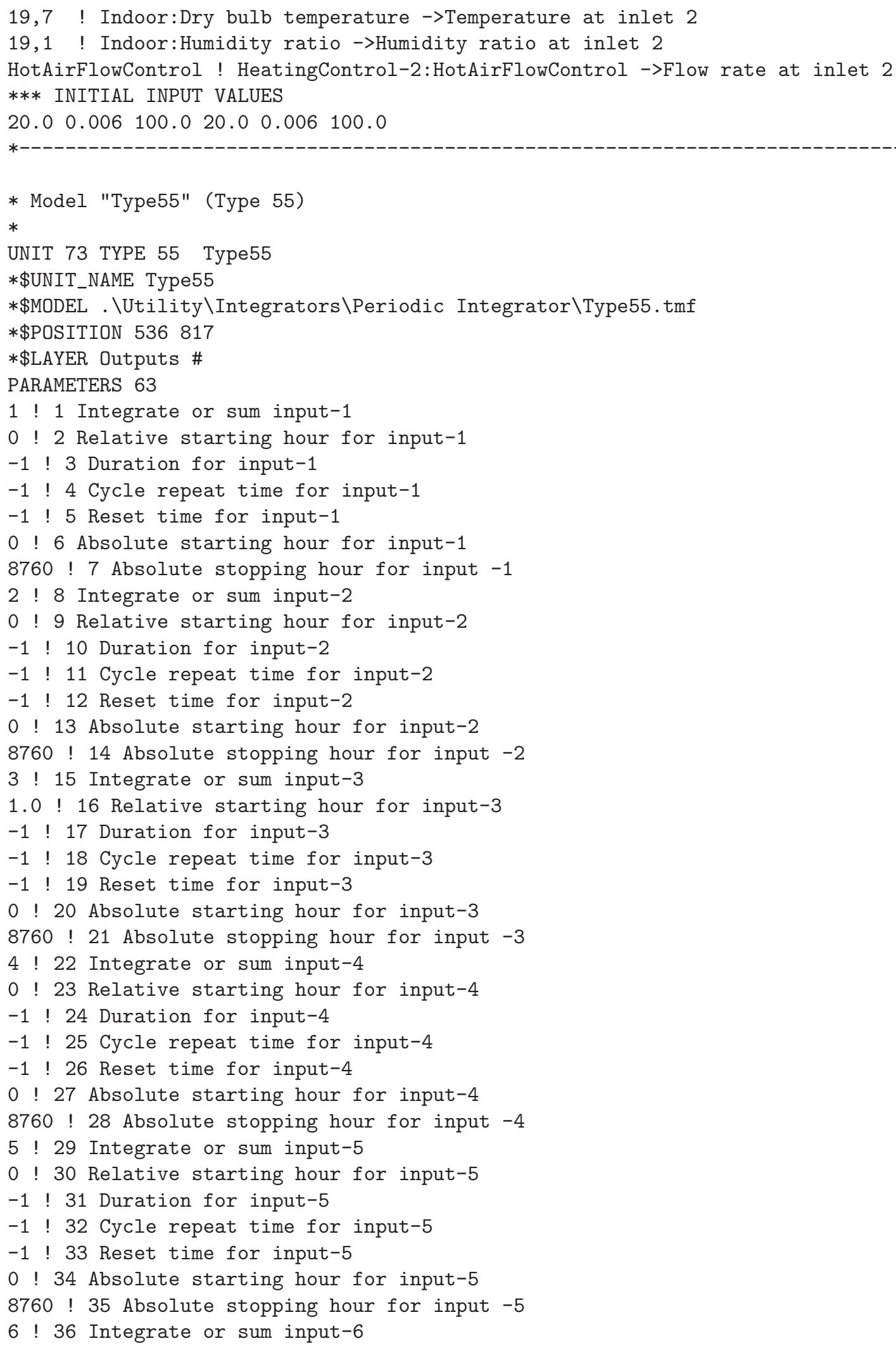


0 ! 37 Relative starting hour for input-6

-1 ! 38 Duration for input-6

-1 ! 39 Cycle repeat time for input-6

-1 ! 40 Reset time for input-6

0 ! 41 Absolute starting hour for input-6

8760 ! 42 Absolute stopping hour for input -6

7 ! 43 Integrate or sum input-7

0 ! 44 Relative starting hour for input-7

-1 ! 45 Duration for input-7

-1 ! 46 Cycle repeat time for input-7

-1 ! 47 Reset time for input-7

0 ! 48 Absolute starting hour for input-7

8760 ! 49 Absolute stopping hour for input -7

8 ! 50 Integrate or sum input-8

0 ! 51 Relative starting hour for input-8

-1 ! 52 Duration for input-8

-1 ! 53 Cycle repeat time for input-8

-1 ! 54 Reset time for input-8

0 ! 55 Absolute starting hour for input-8

8760 ! 56 Absolute stopping hour for input -8

9 ! 57 Integrate or sum input-9

0 ! 58 Relative starting hour for input-9

-1 ! 59 Duration for input-9

-1 ! 60 Cycle repeat time for input-9

-1 ! 61 Reset time for input-9

0 ! 62 Absolute starting hour for input-9

8760 ! 63 Absolute stopping hour for input -9

INPUTS 9

49,3 ! Collectors:Useful energy gain ->SolarGain-1

59,4 ! Mixing Valve:QTANK ->DHW-2

HeatingEnergy ! HeatReheat:HeatingEnergy ->Heating-3

108,8 ! Cooling Coil:Air-side heat transfer ->CoolingCoil-4

ReheatEnergy ! HeatReheat:ReheatEnergy ->ReheatCoil-5

86,7 ! Heat Pump:Heat pump power ->HeatPump-6

77,16 ! HotTank3Ports:Auxiliary heating rate $->$ Auxilary -7

95,1 ! Radiator:Heat Transfer Rate ->HeatDump-8

86,5 ! Heat Pump:Heat transfer to load ->HPLoad-9

*** INITIAL INPUT VALUES

0. 0. 0.0.0.0.0.0.0.

* Model "Type24" (Type 24)

UNIT 29 TYPE 24 Type24

*\$UNIT_NAME Type24

*\$MODEL . \Utility \Integrators \Quantity Integrator $\backslash$ Type24.tmf

*\$POSITION 1137728

*\$LAYER Outputs \#

PARAMETERS 2

STOP ! 1 Integration period

0 ! 2 Relative or absolute start time 


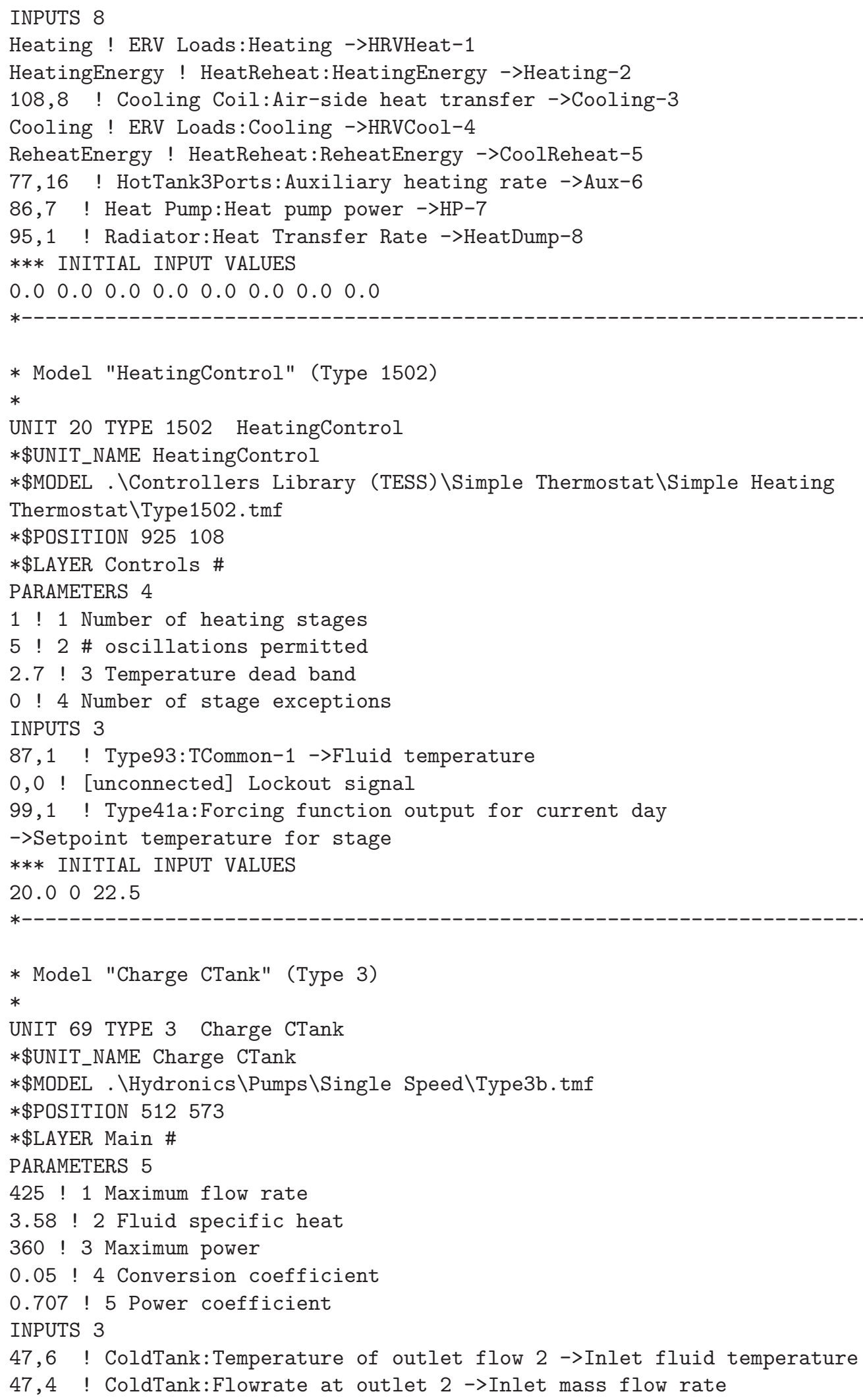




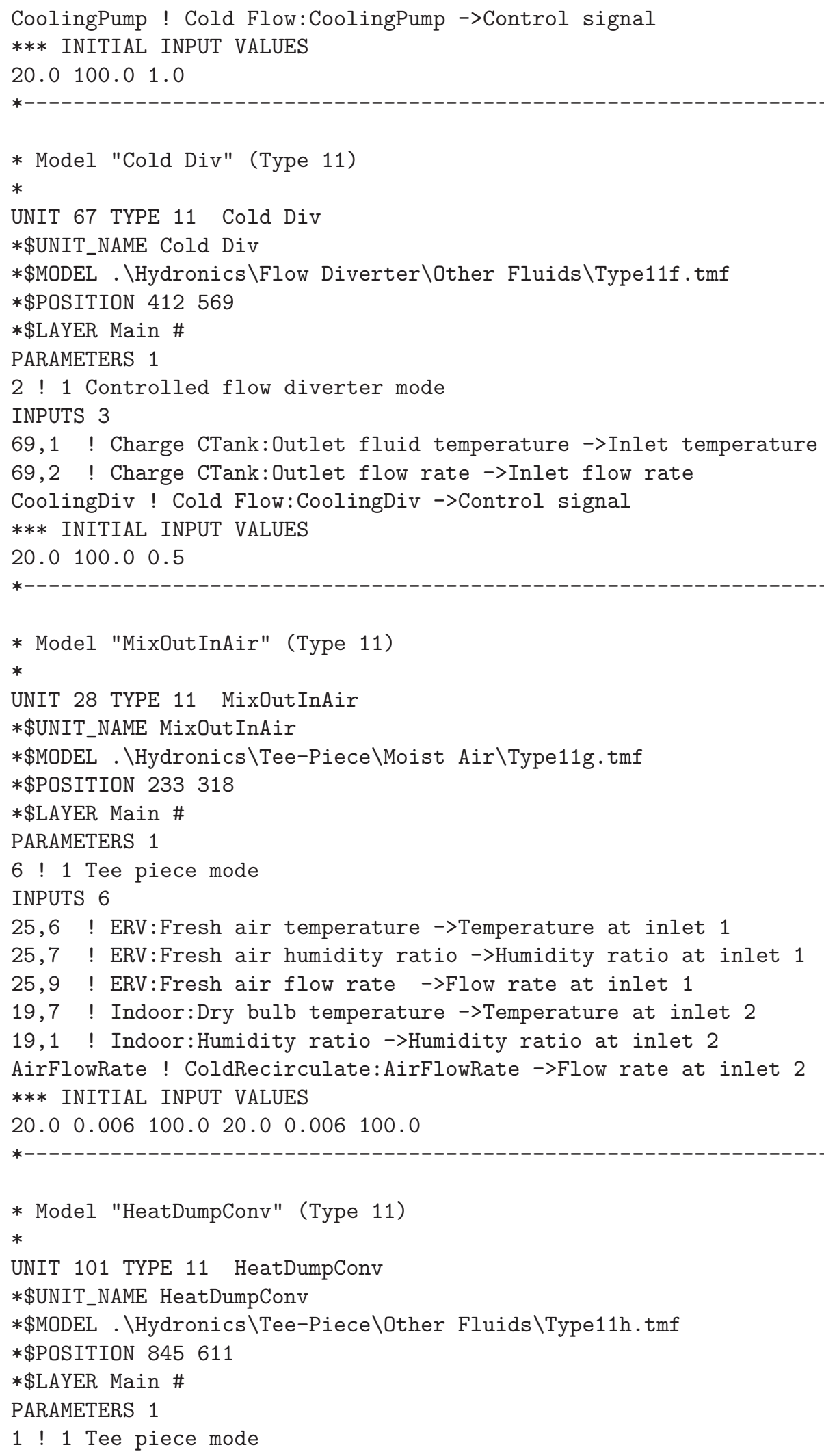




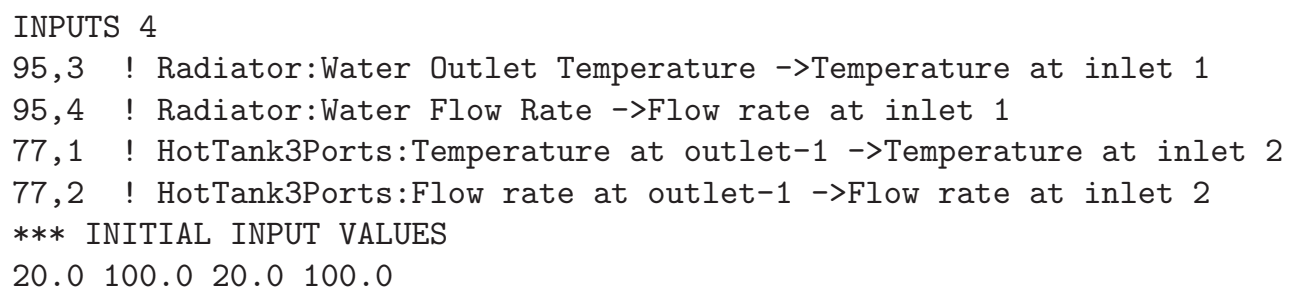




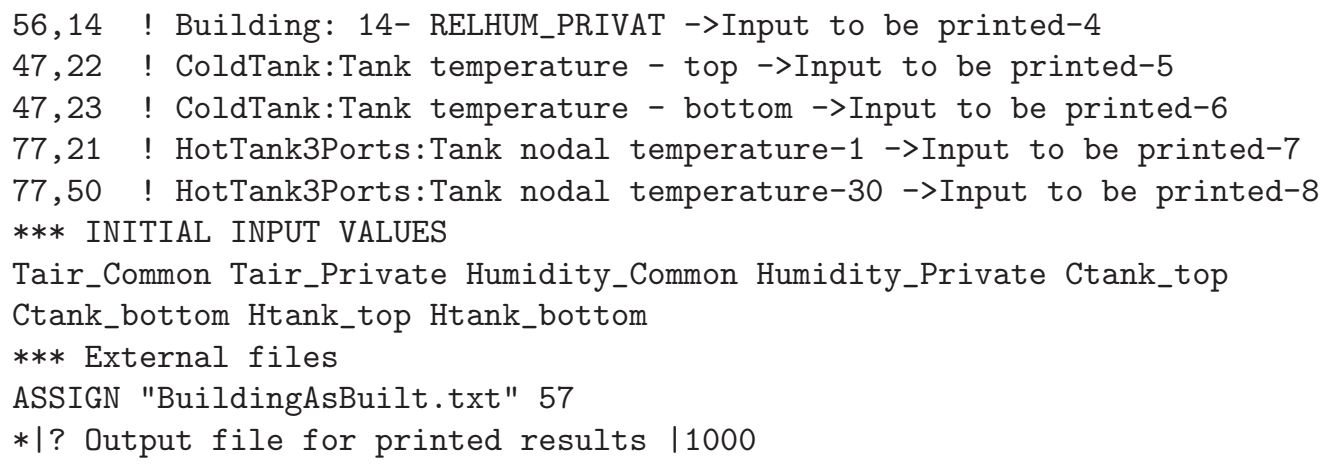




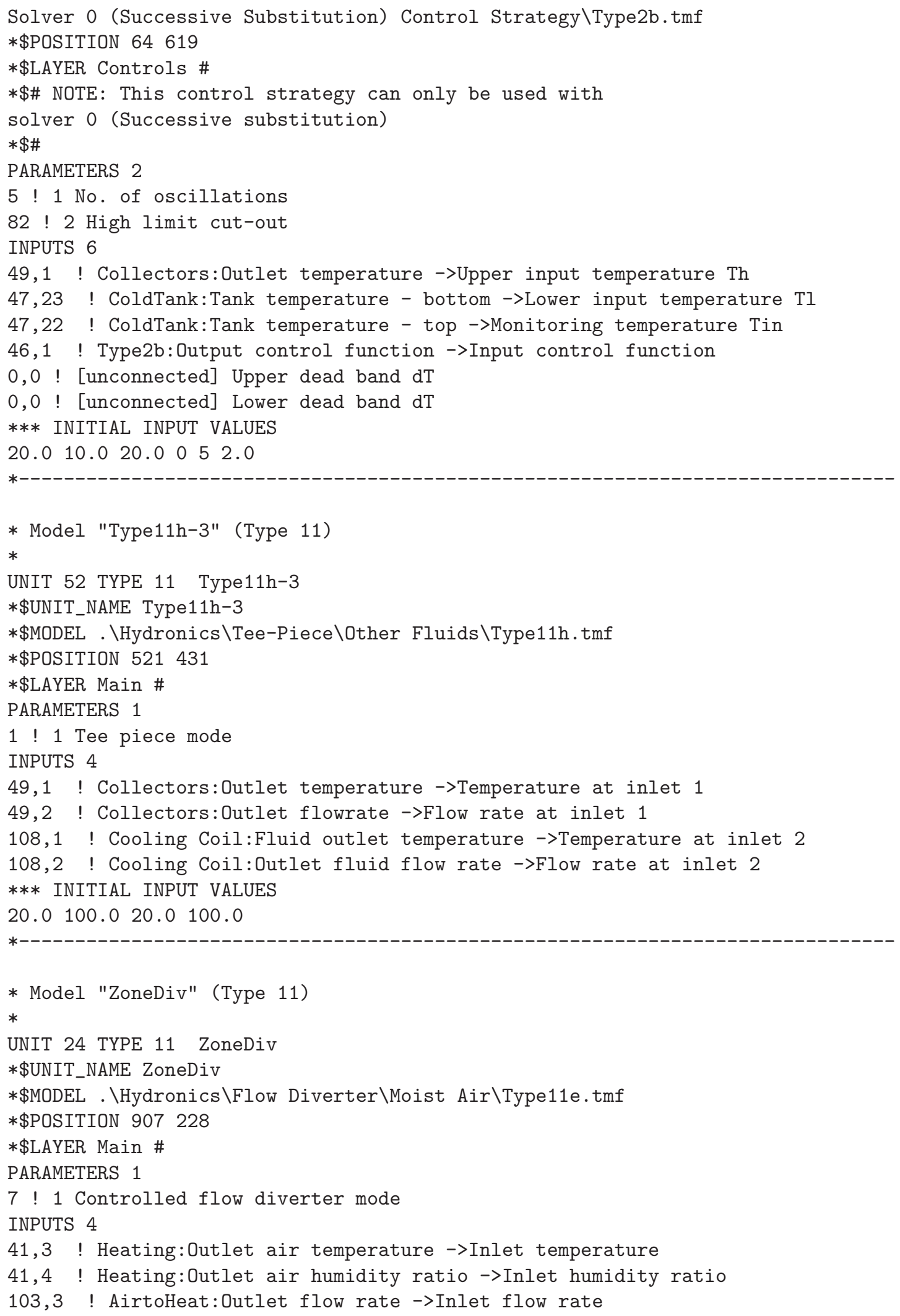




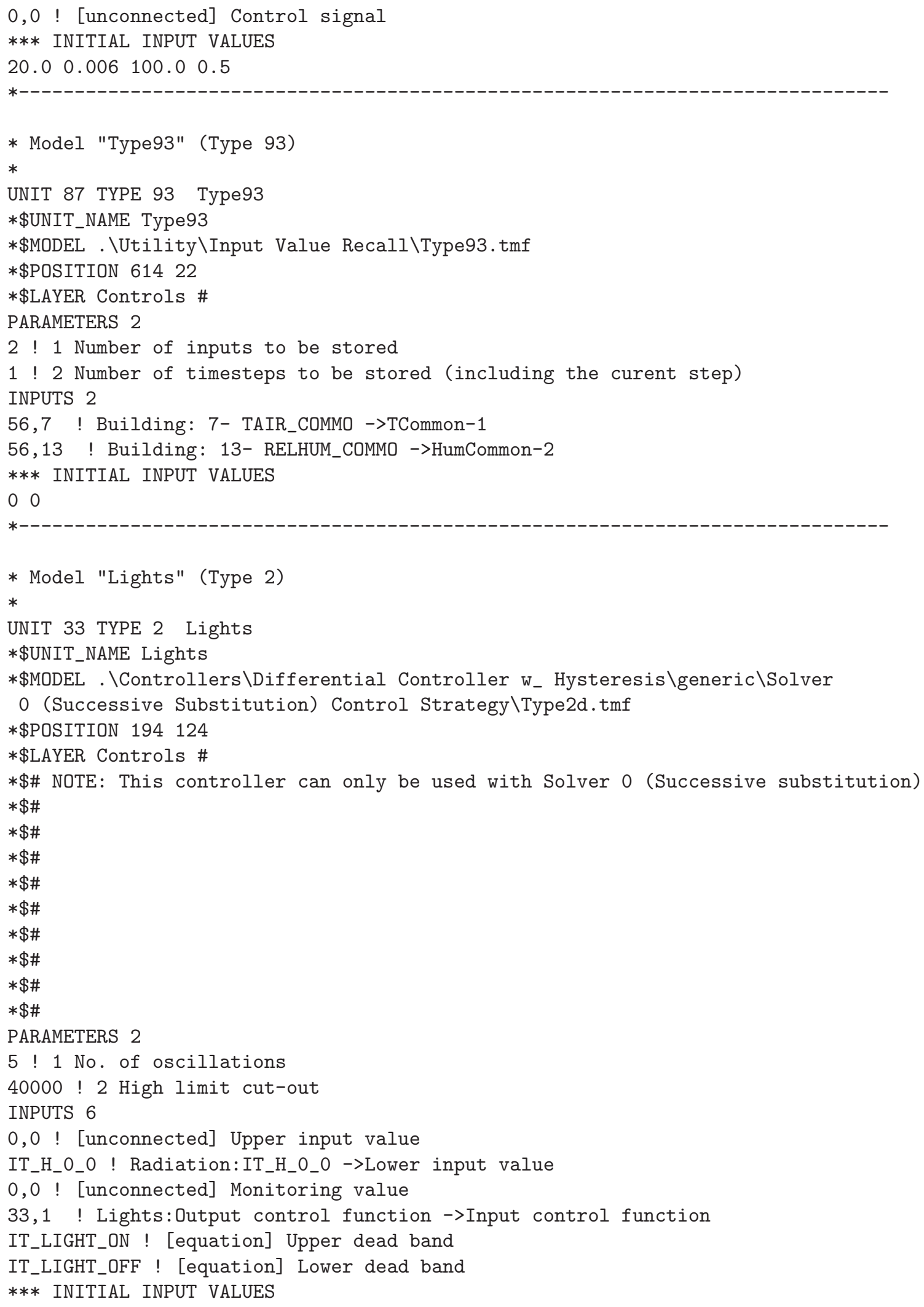


00000 IT_LIGHT_ON IT_LIGHT_OFF

* EQUATIONS "AzimuthAngles"

$*$

EQUATIONS 6

AA_H_O_O $=0+$ TURN ! azimuth angle of orientation

AA_S_0_90 $=0+$ TURN ! azimuth angle of orientation

AA_W_90_90 $=90+$ TURN ! azimuth angle of orientation

AA_N_180_90 = $180+$ TURN ! azimuth angle of orientation

AA_E_270_90 $=270+$ TURN ! azimuth angle of orientation

AAZM_TYPE56 = AAZM - (TURN) ! solar azimuth corrected by building rotation -

Input for Type 56 sun position for SHM and ISM

*\$UNIT_NAME AzimuthAngles

*\$LAYER Controls

*\$POSITION 6529

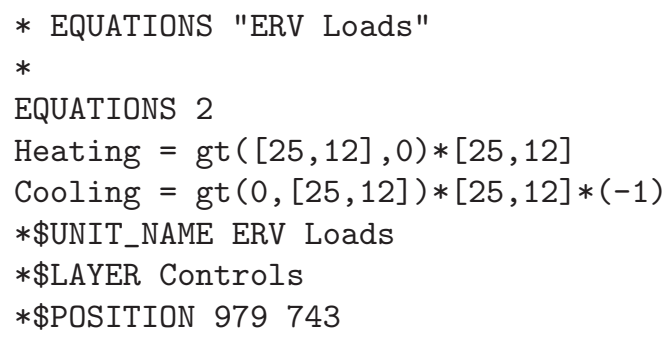




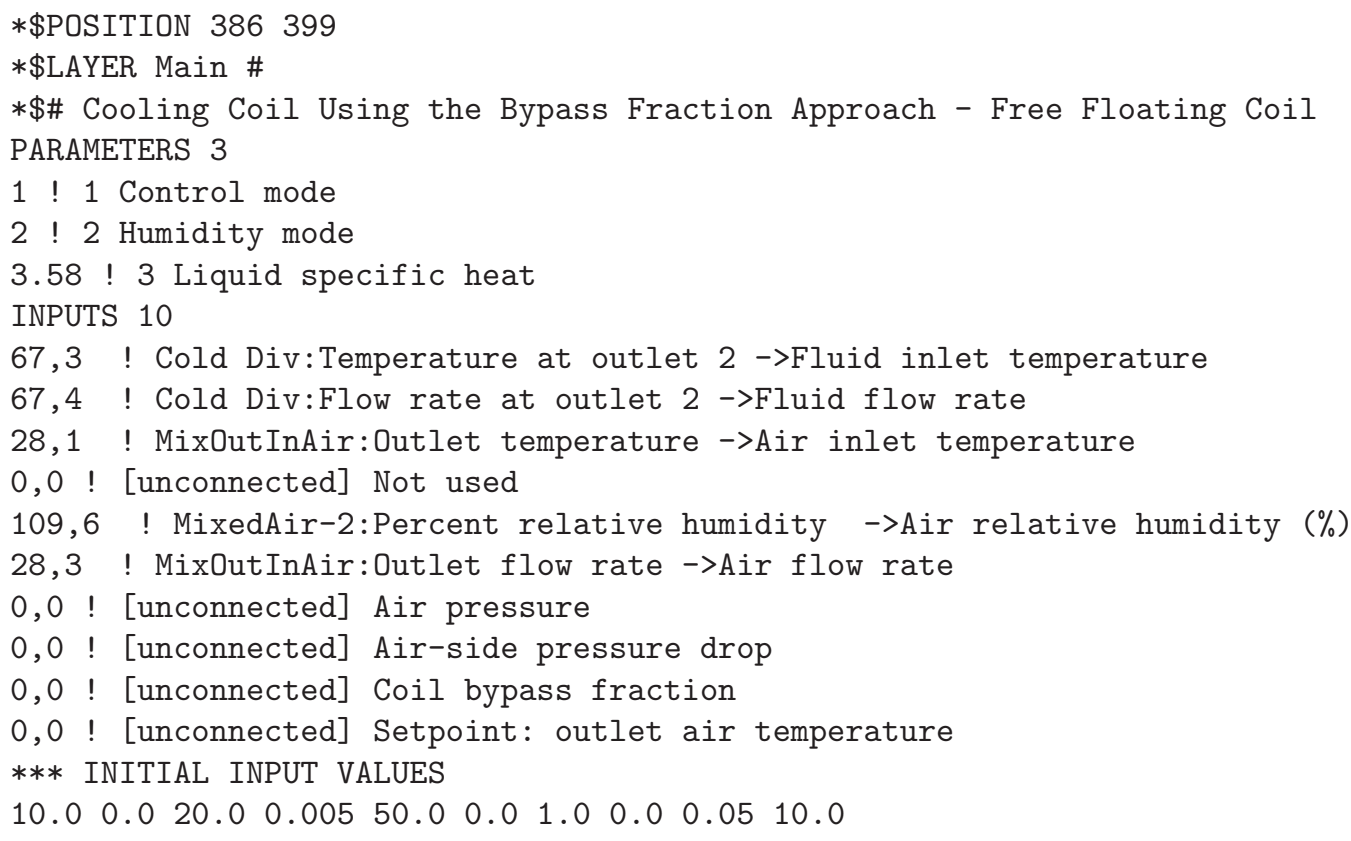




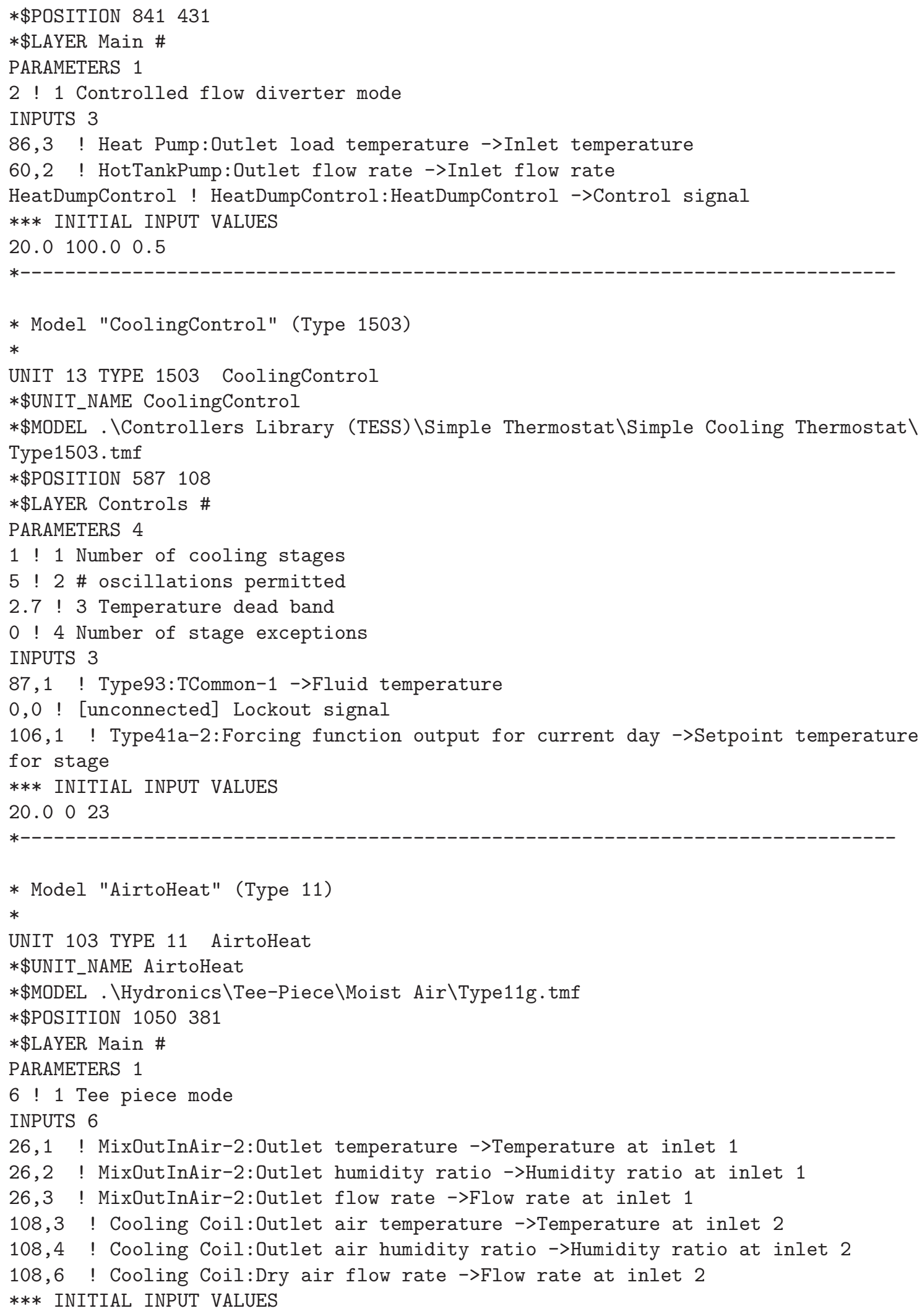


$20.0 \quad 0.006100 .020 .0 \quad 0.006 \quad 100.0$

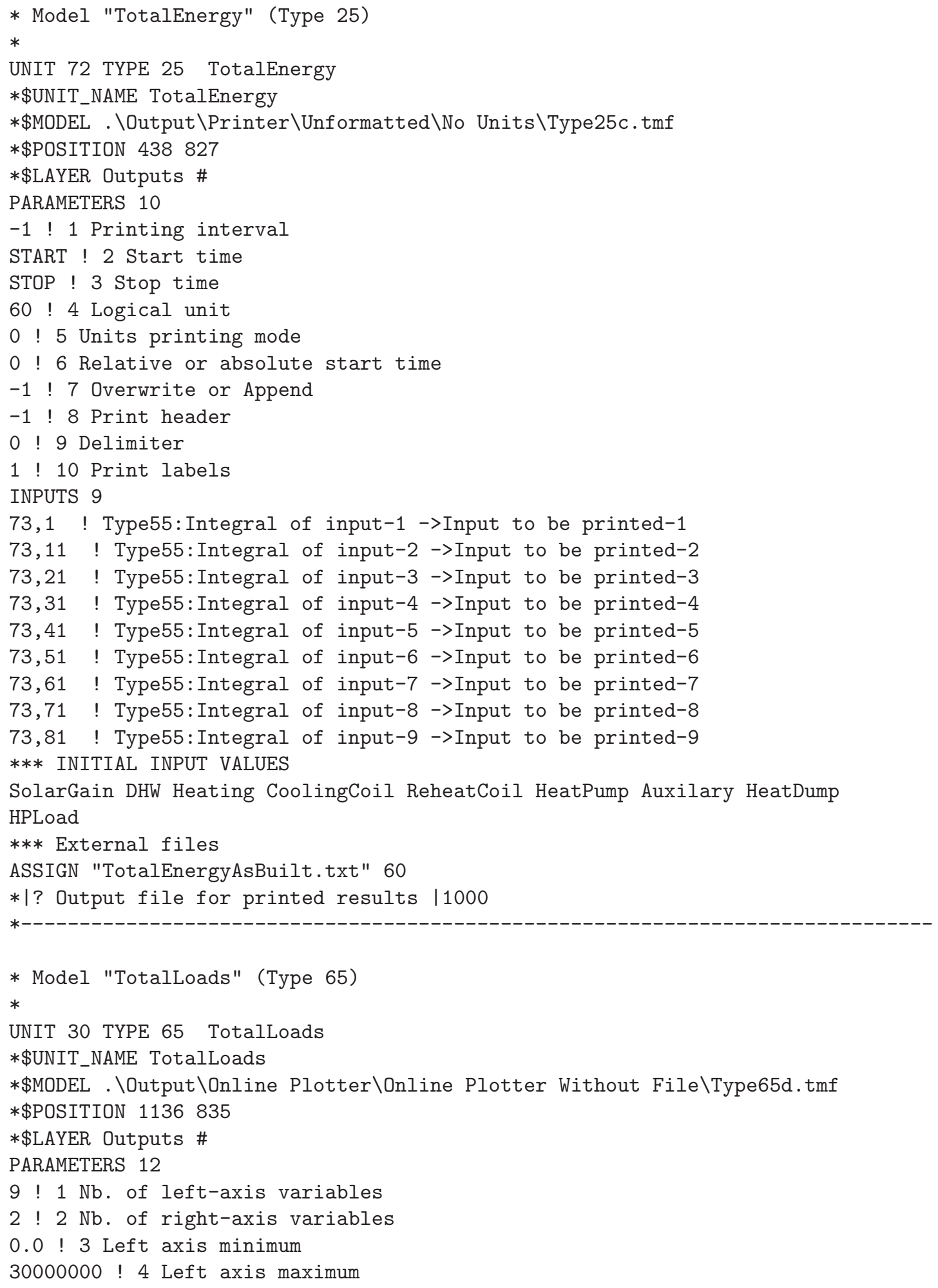




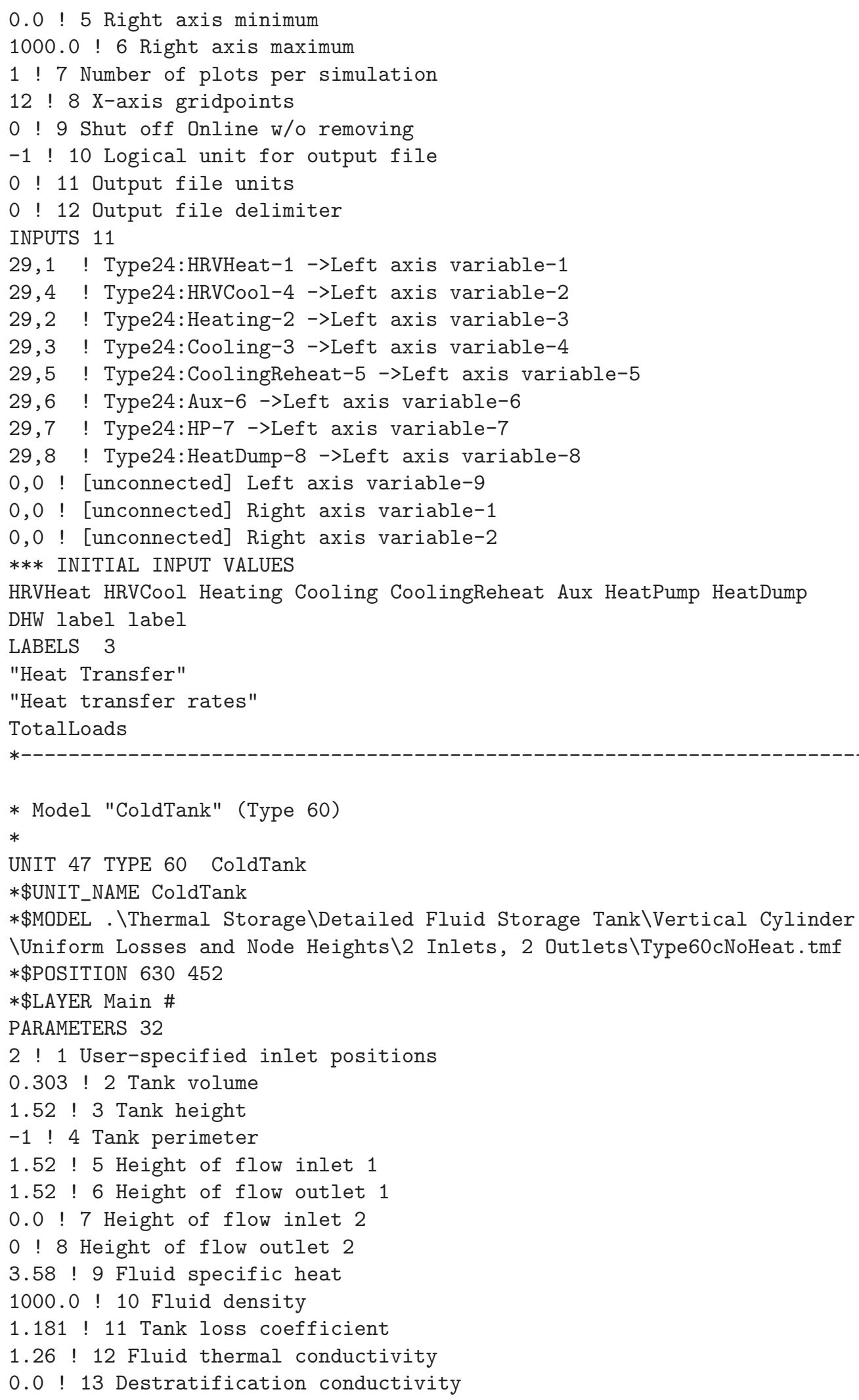




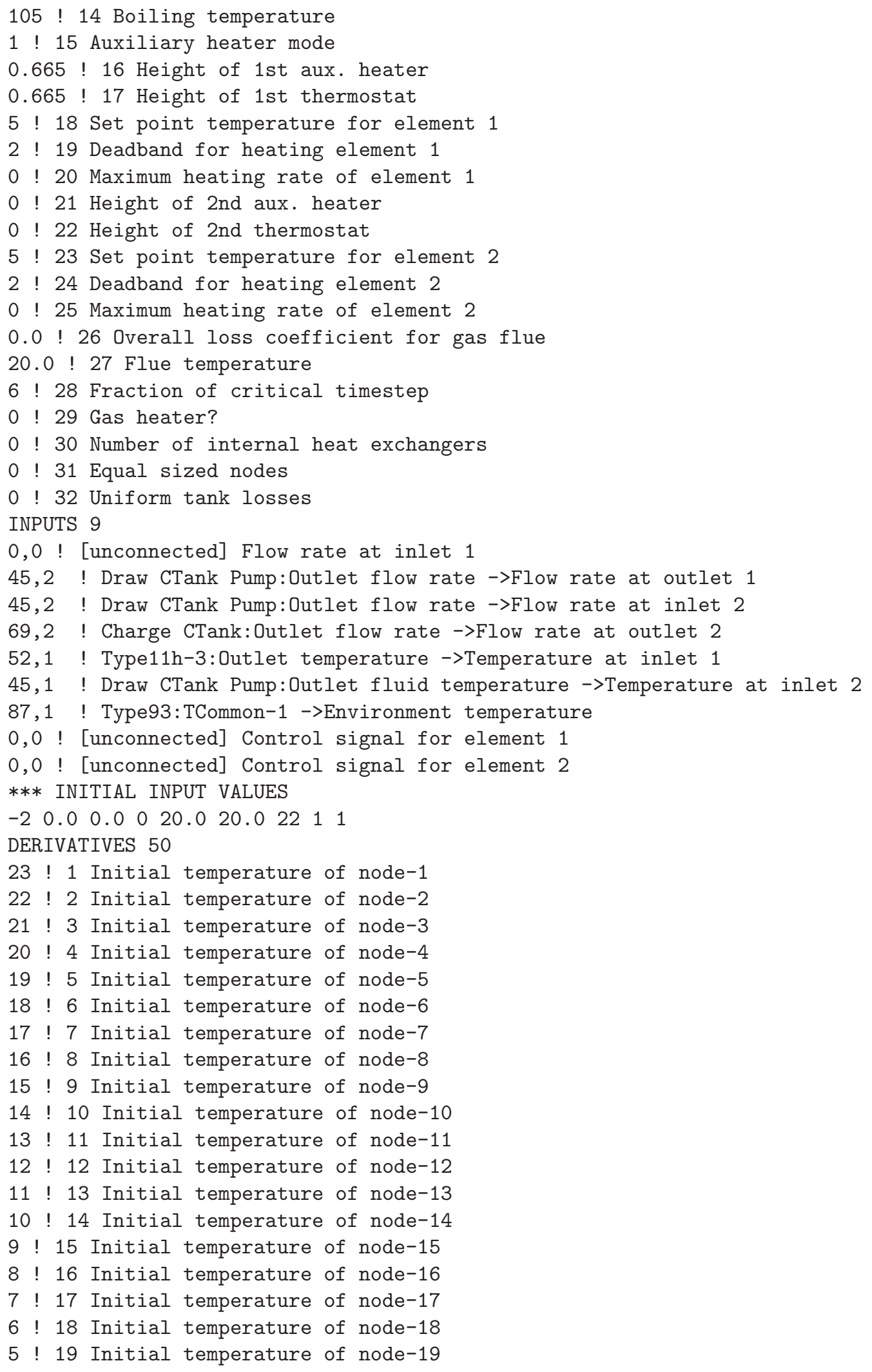




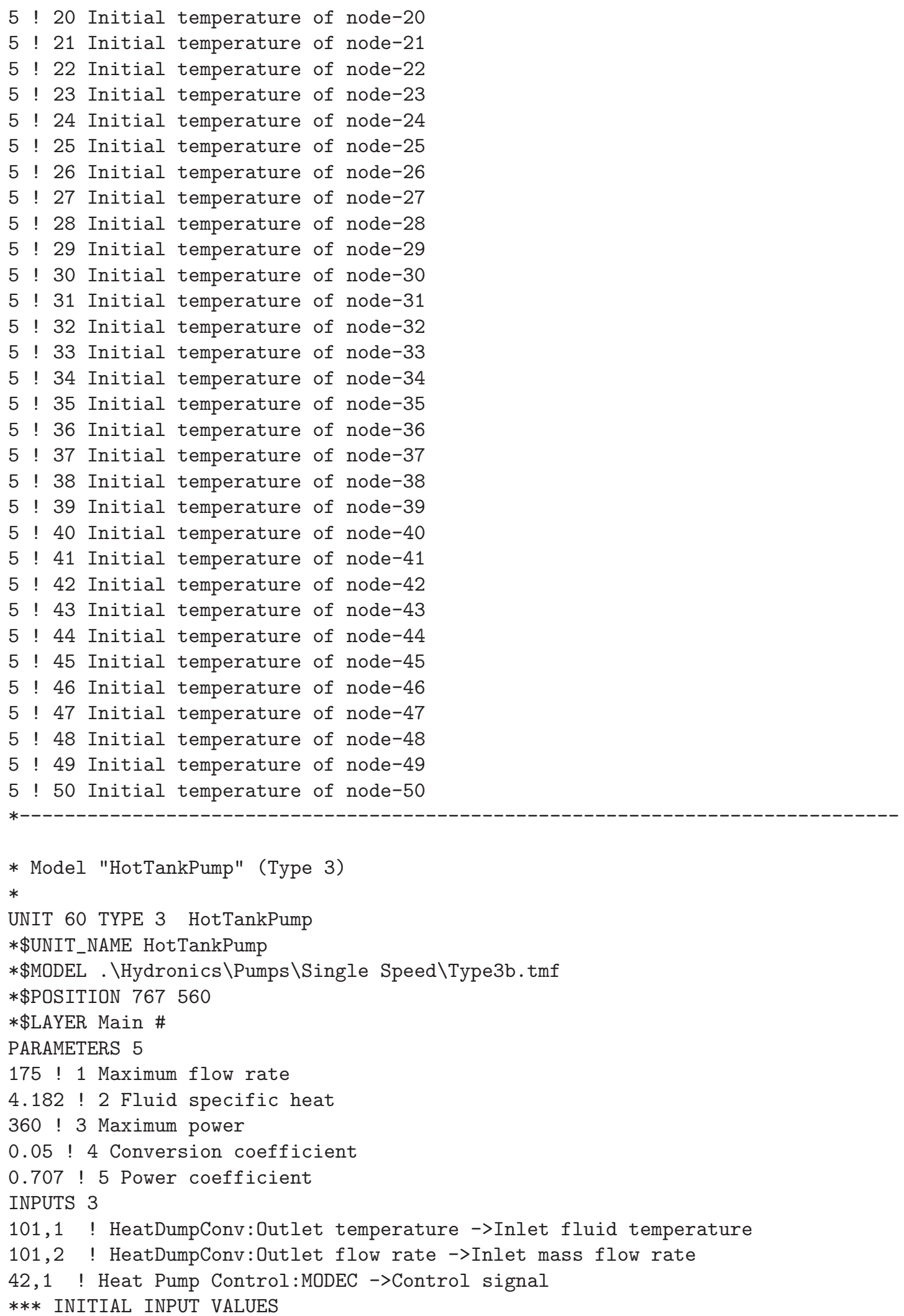


20.0100 .01 .0

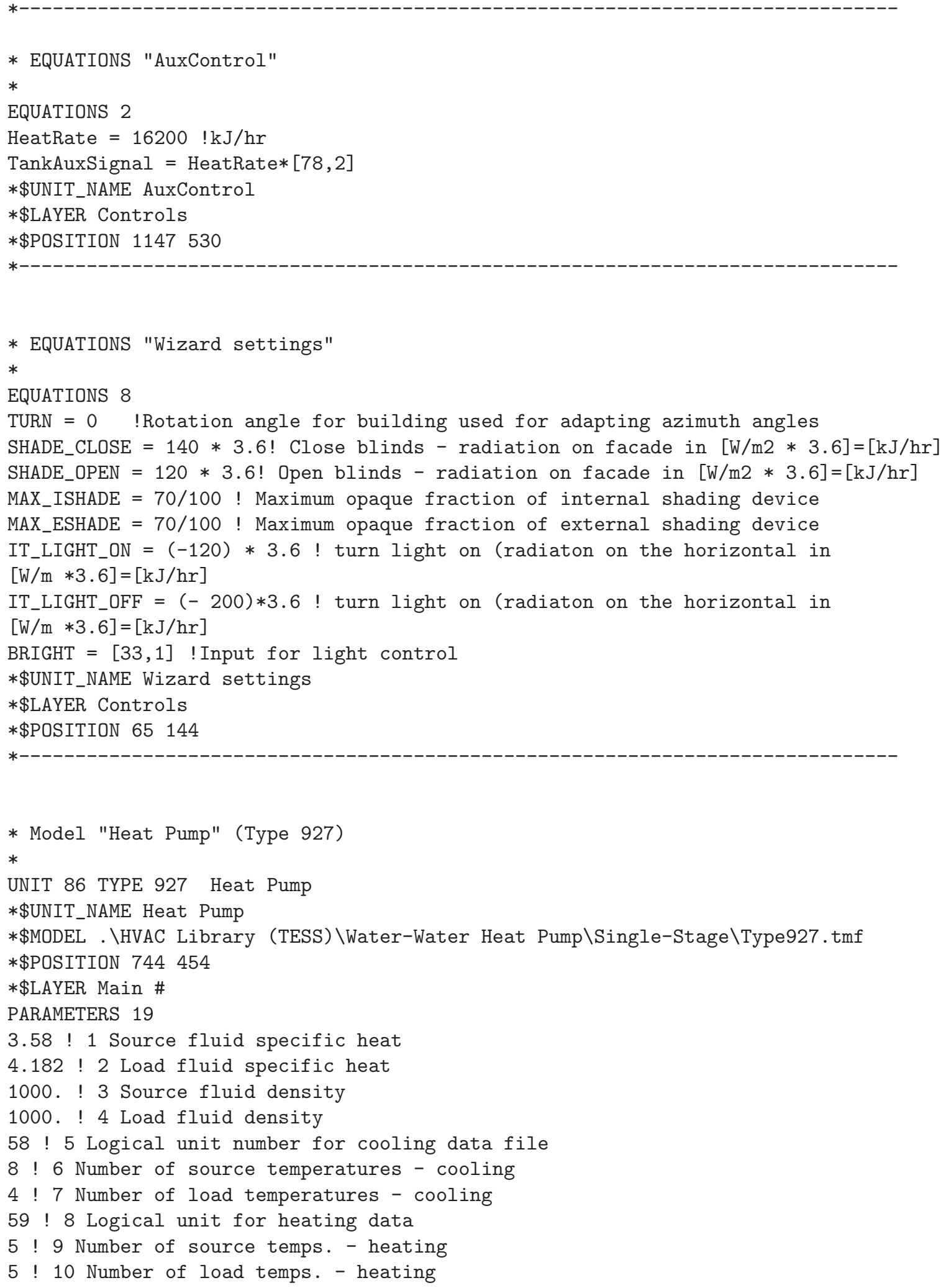




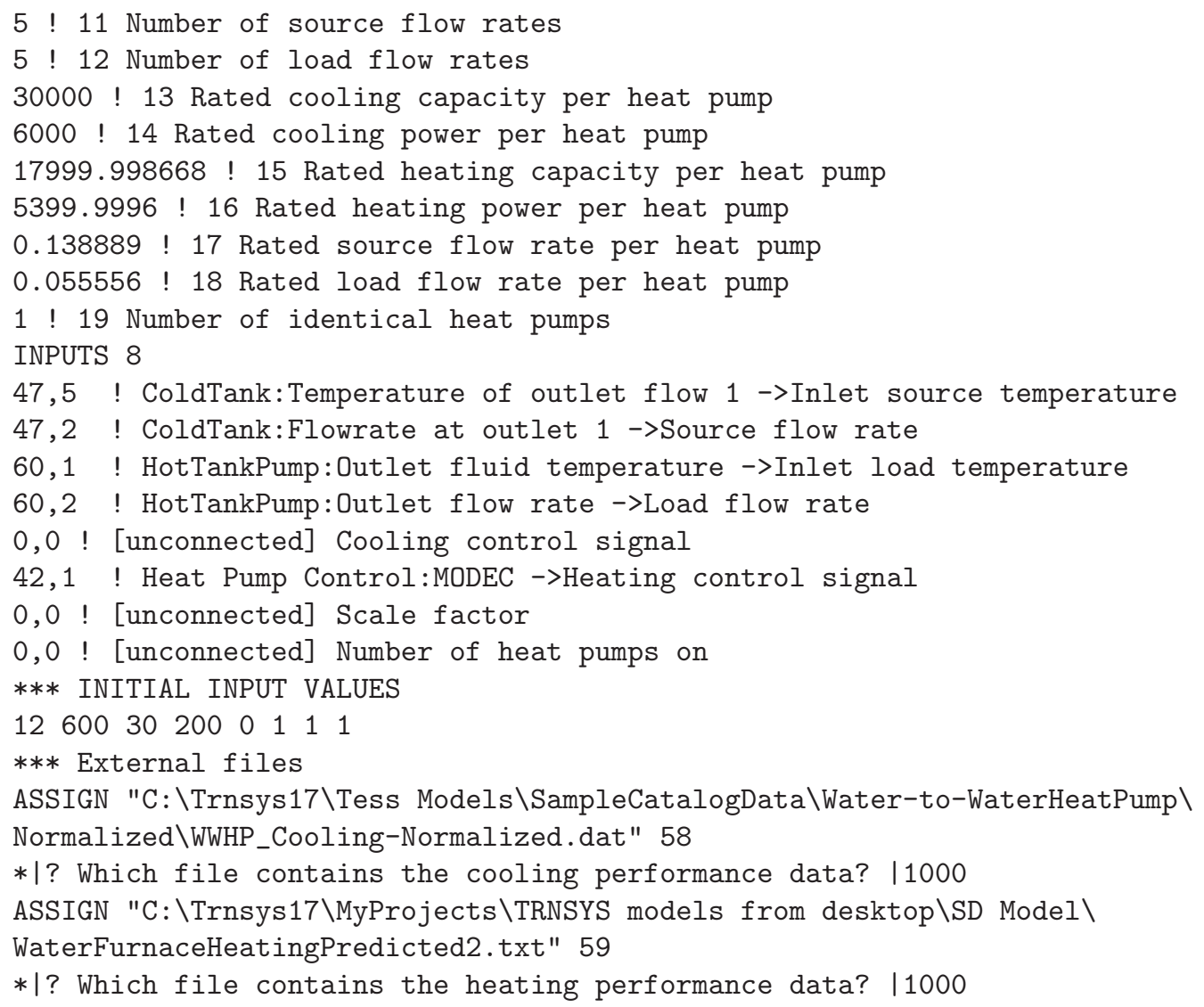




\section{Appendix D}

\section{Type 56 Multizone Building Setup File}

Members of Team Ontario created the Type 56 building model in TRNSYS to simulate the performance of their 2013 Solar Decathlon Competition entry. This model was incorporated into the model of the integrated mechanical system in order to appropriately size components for Team Ontario's high performance house. The following code was extracted from the building set-up file for the building model Type 56.

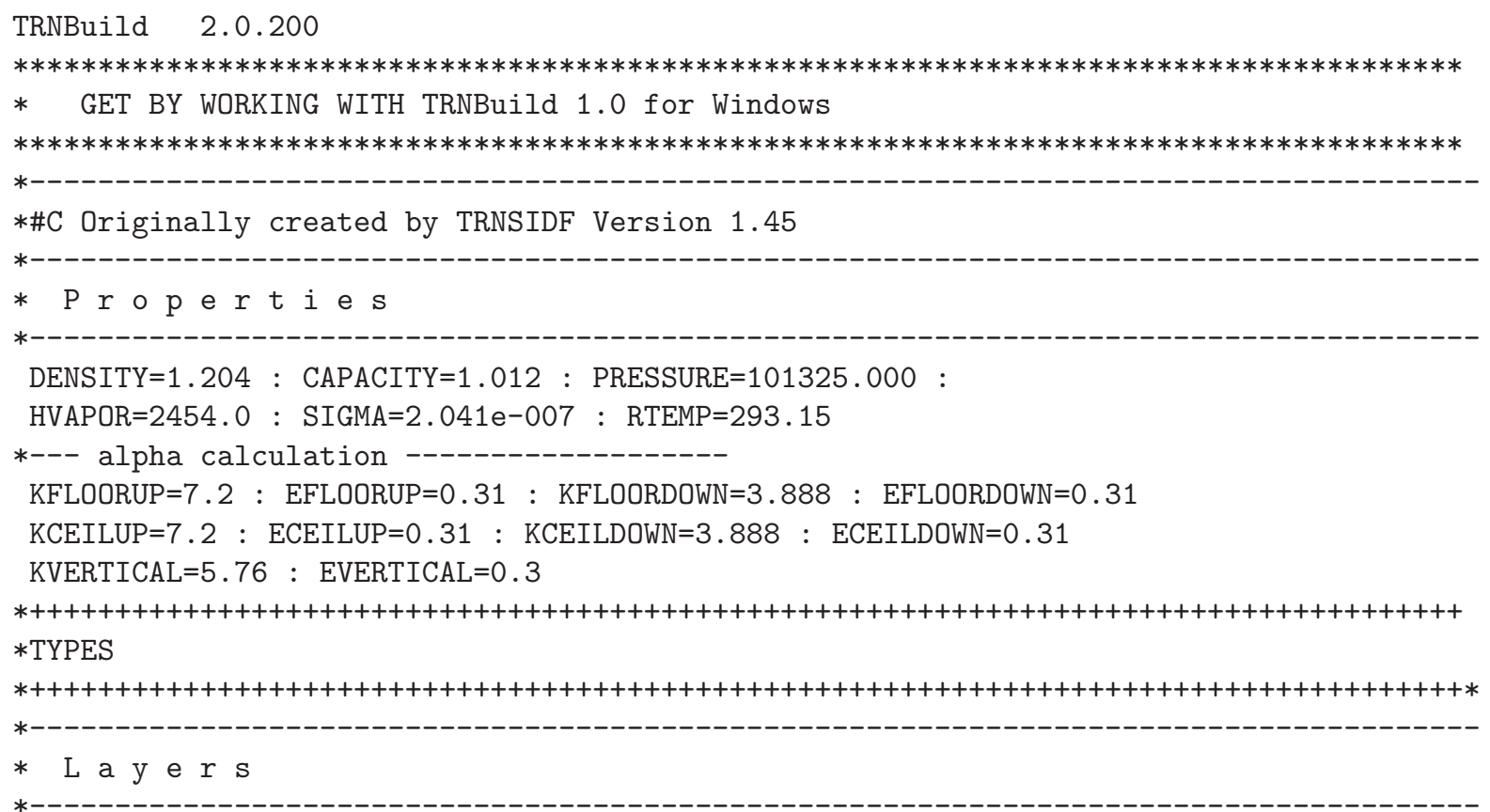




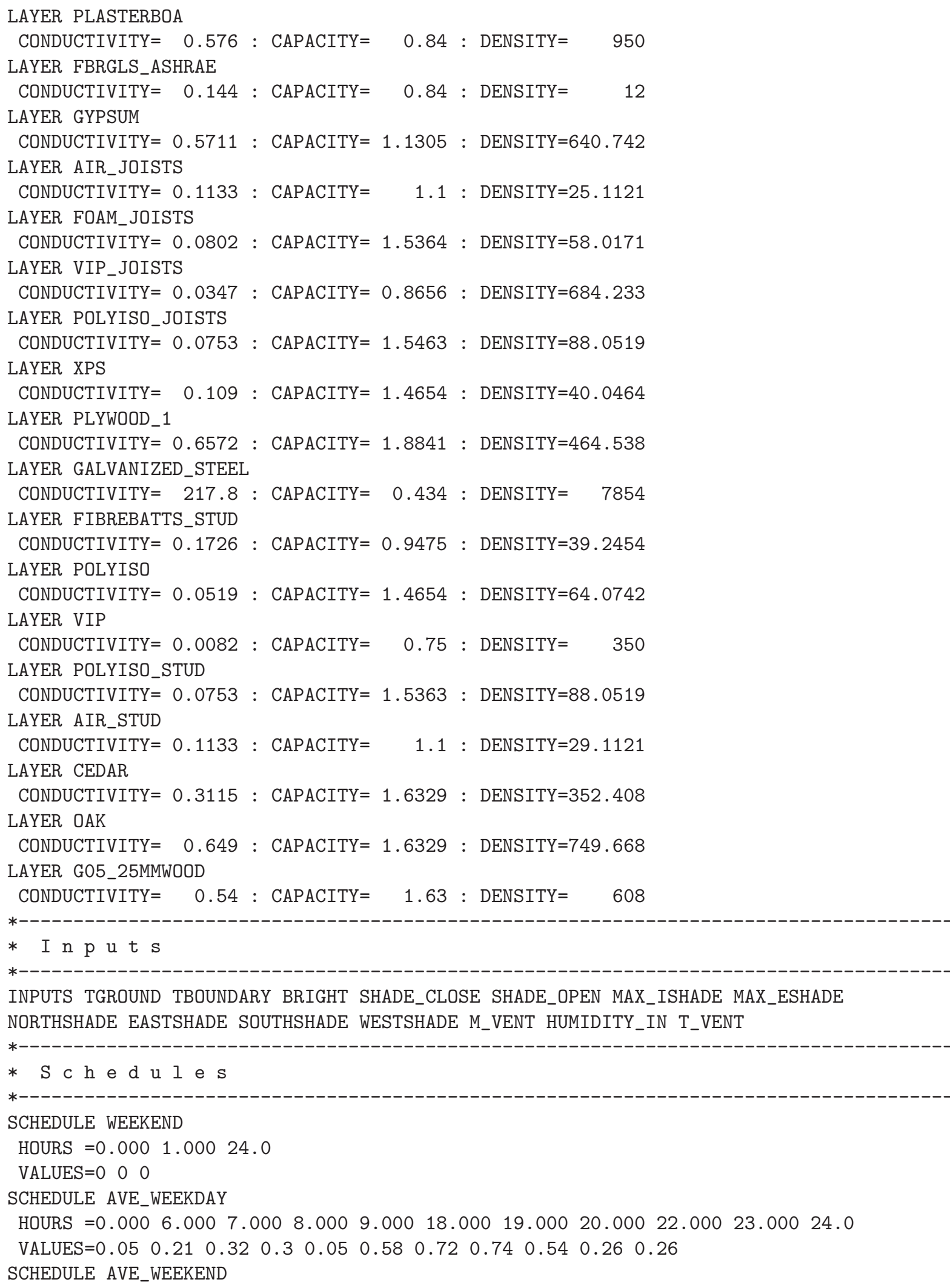




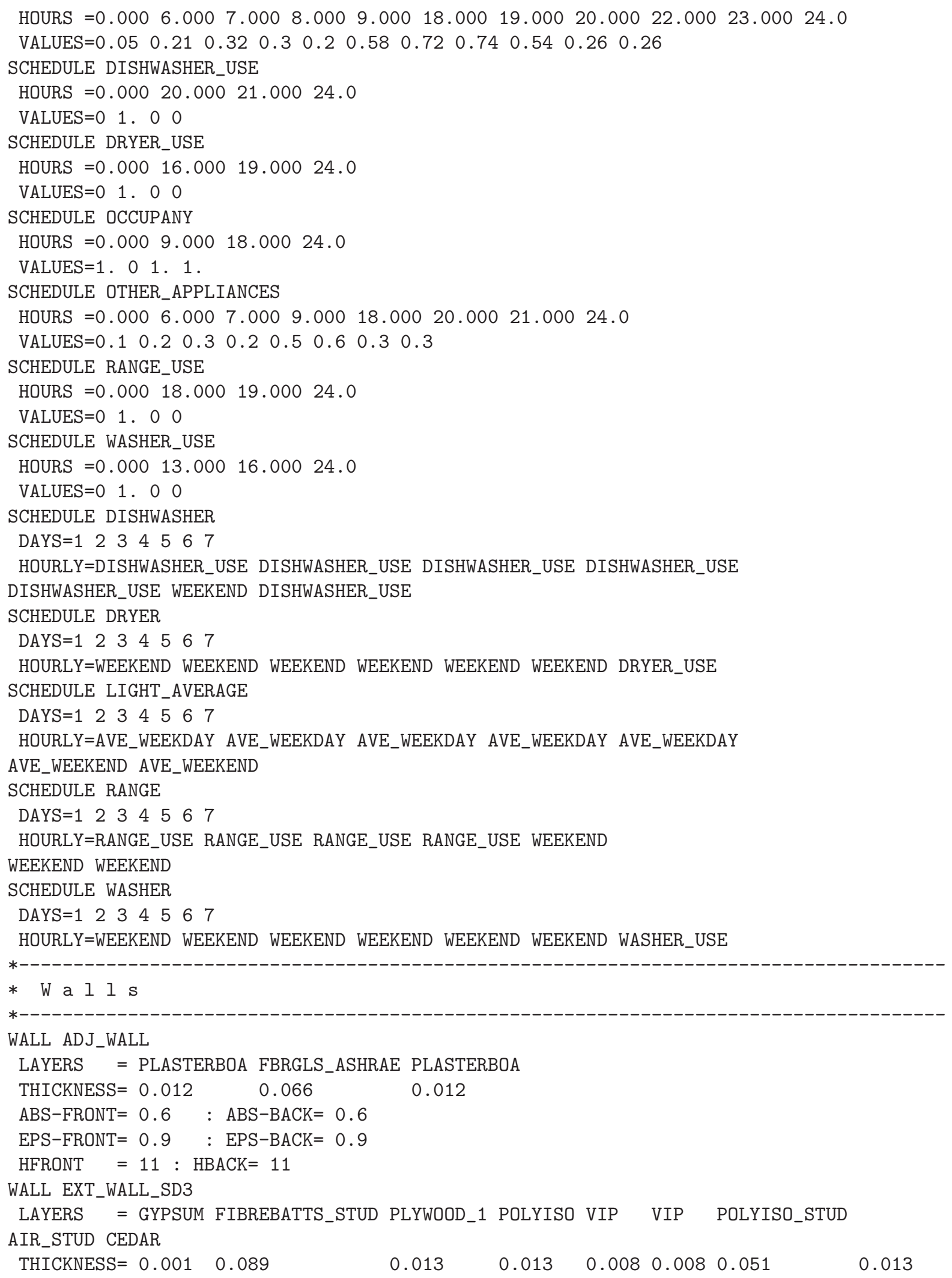




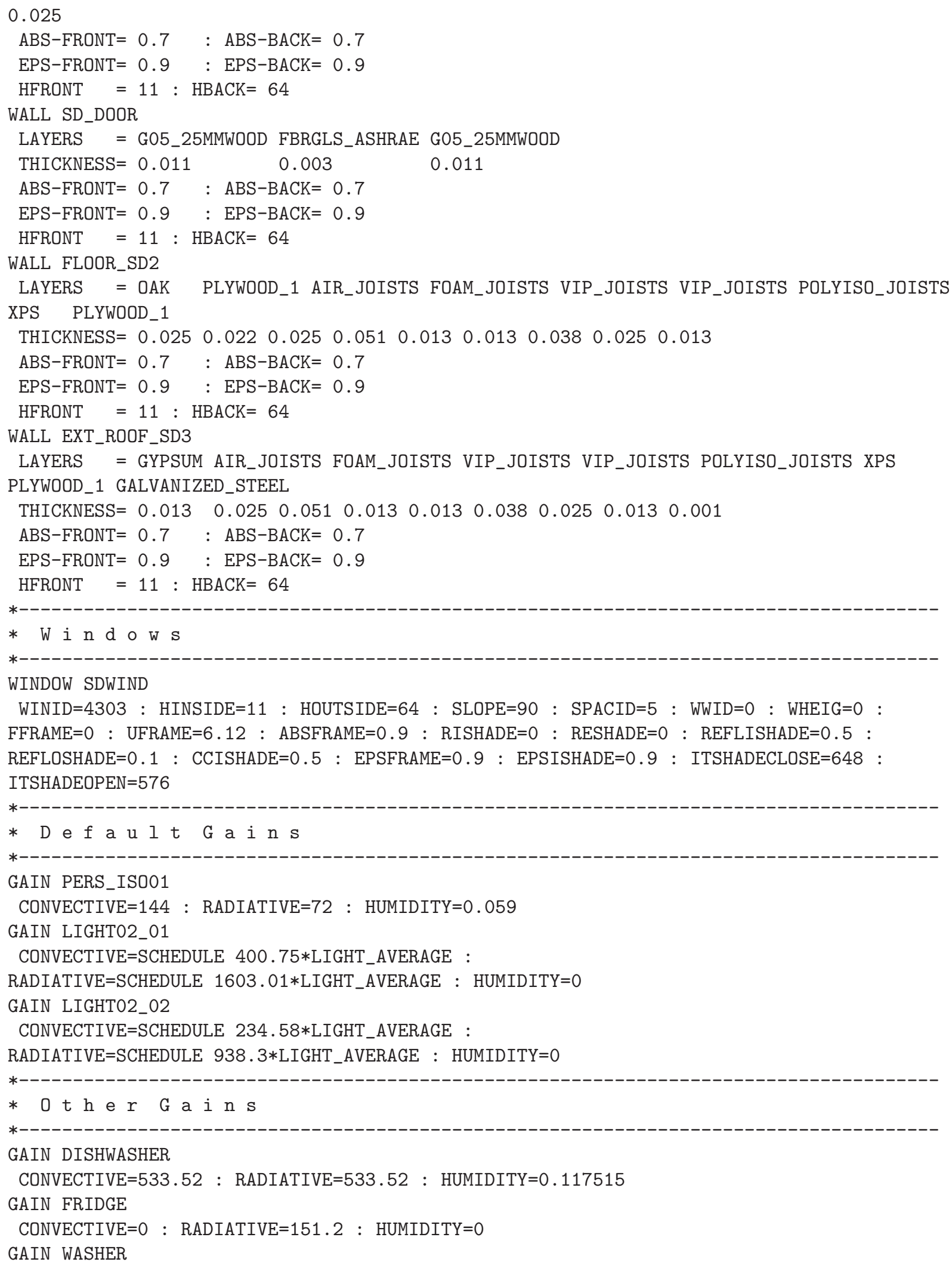




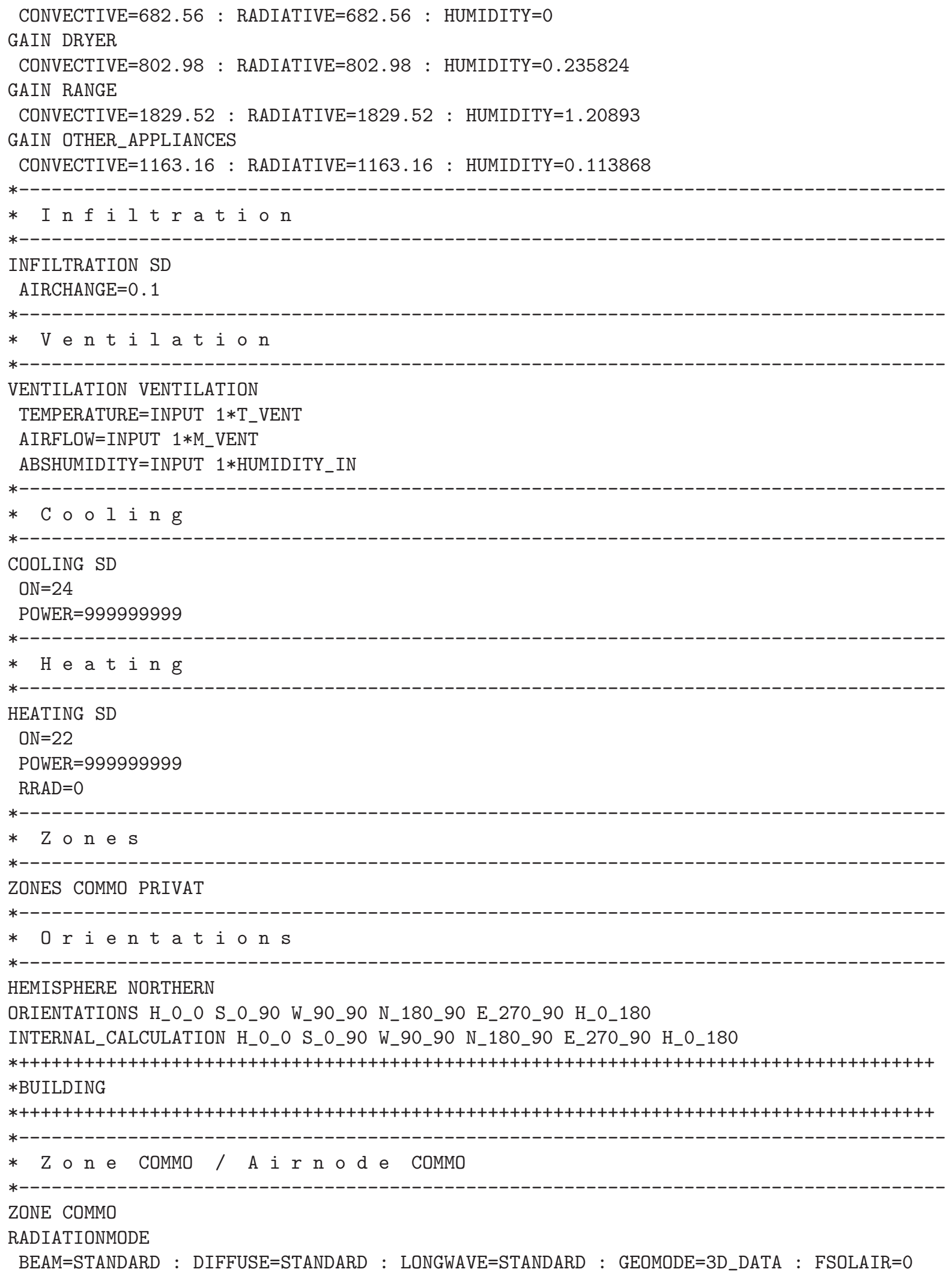




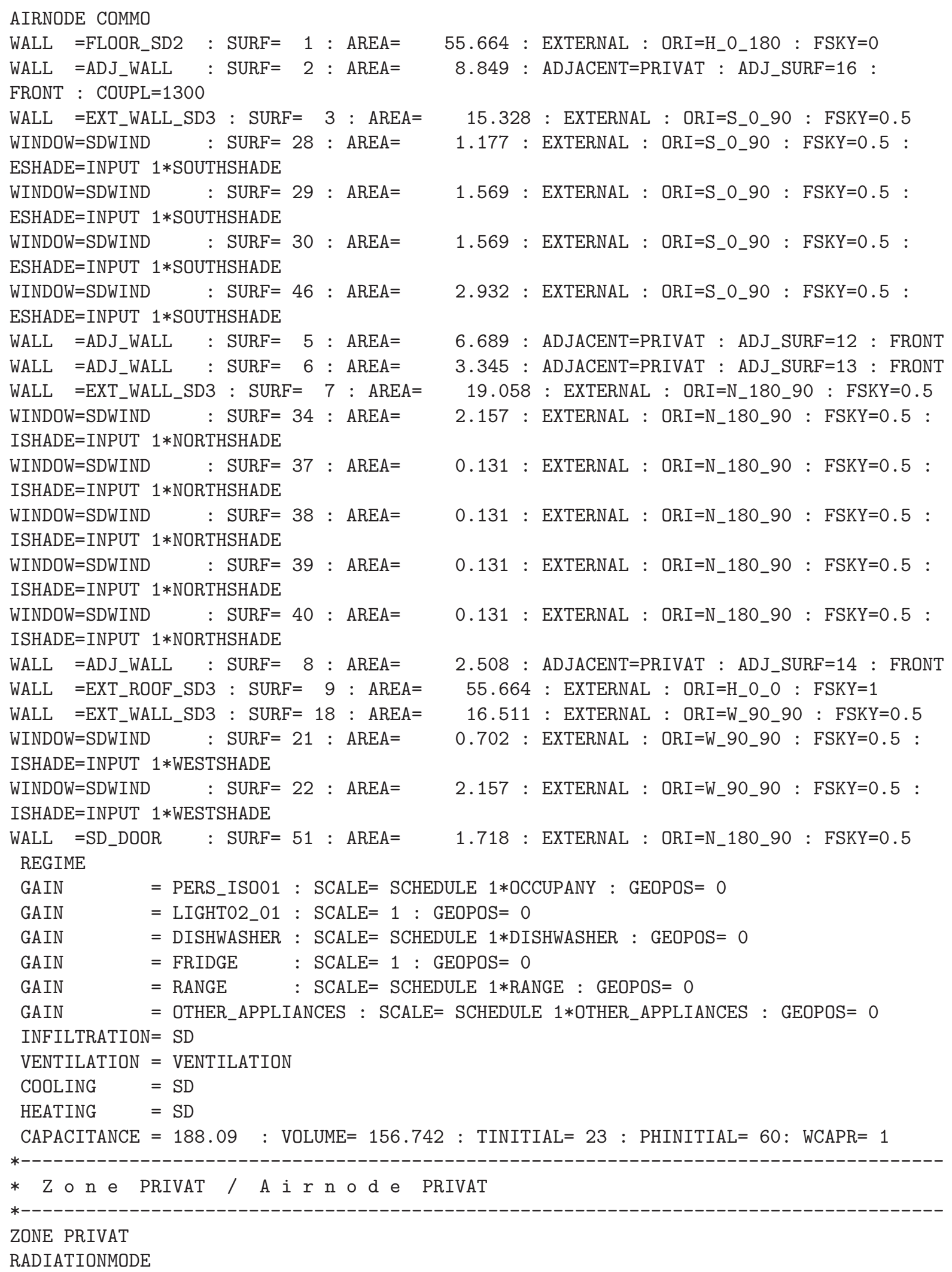




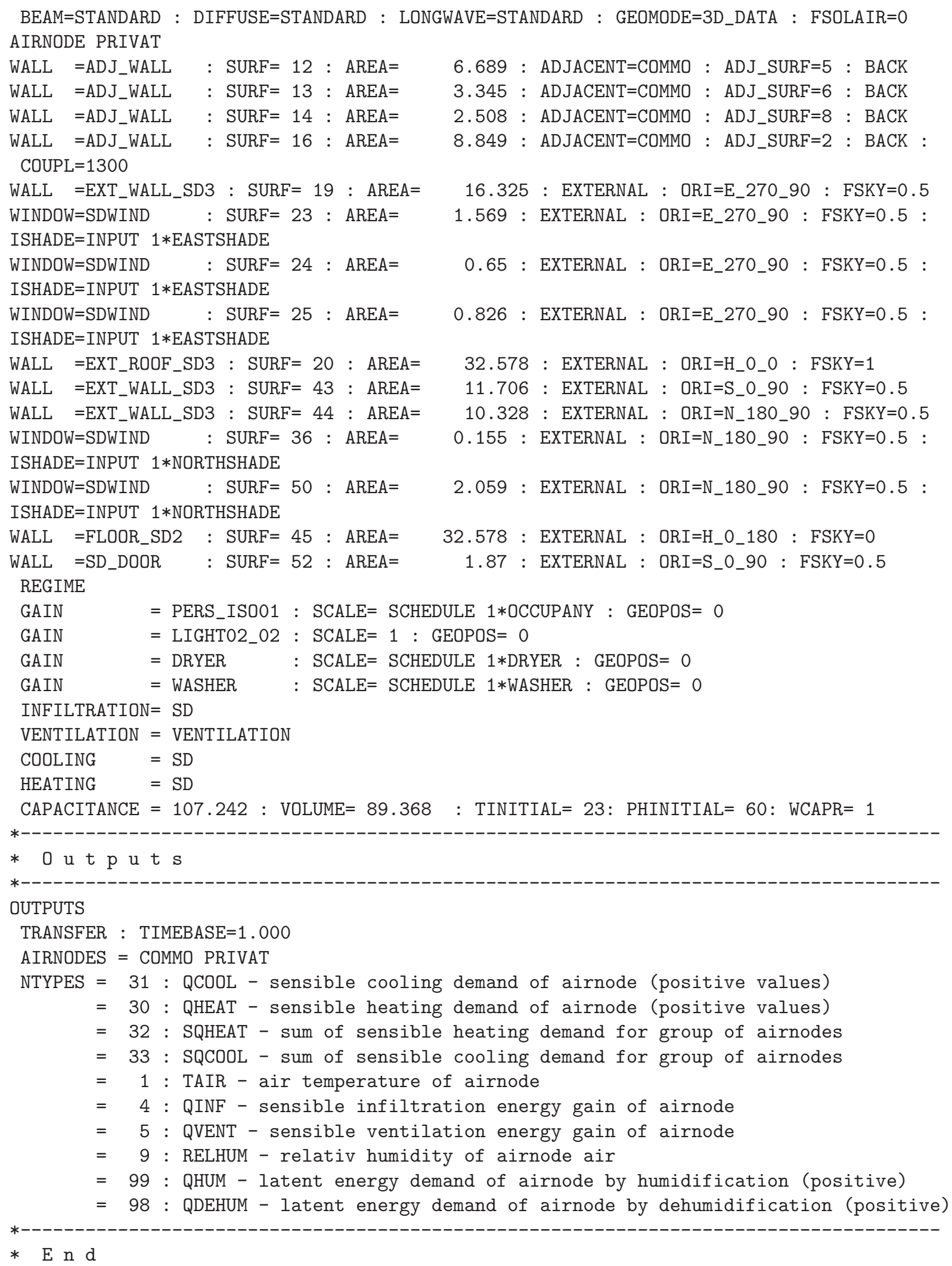




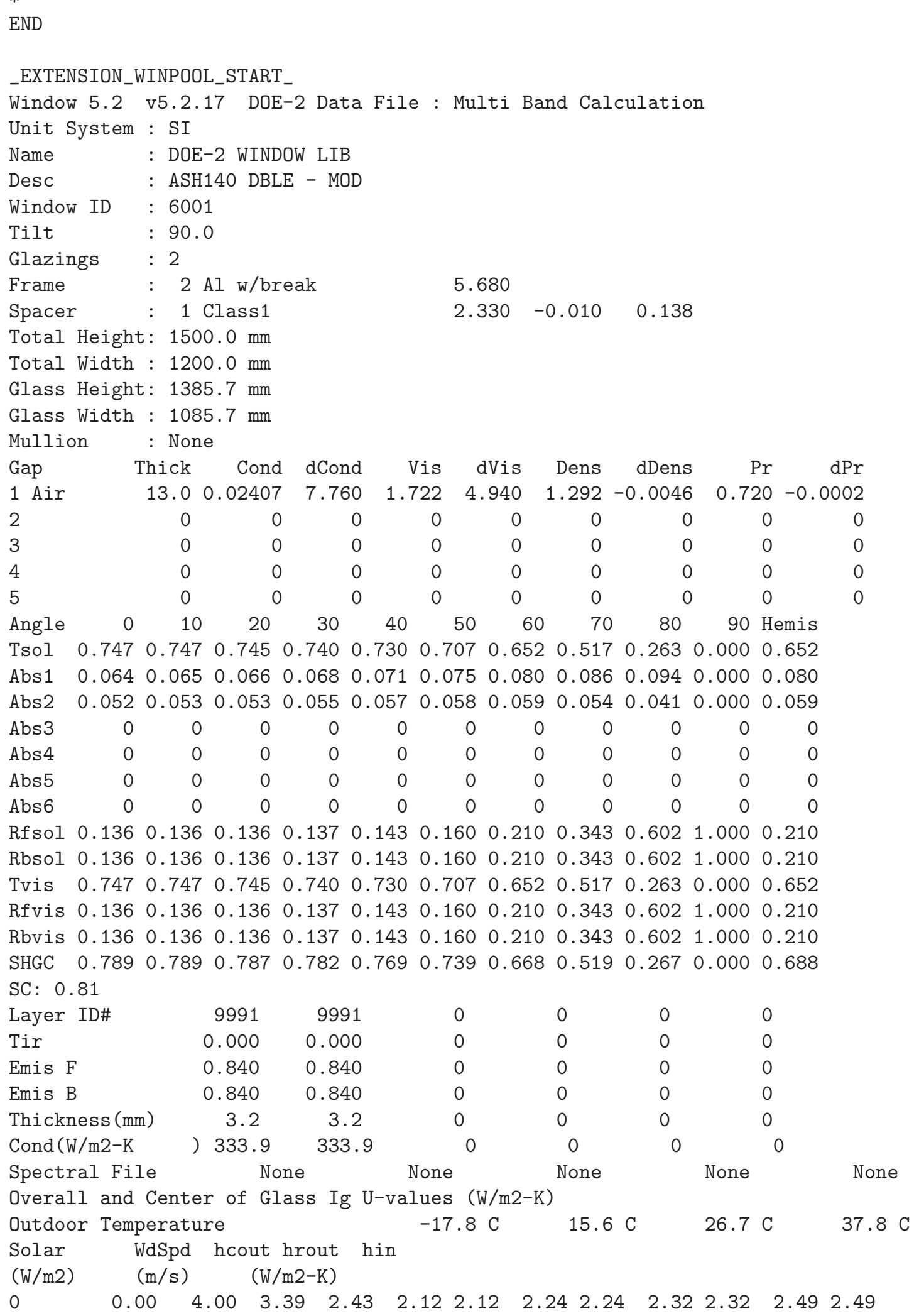




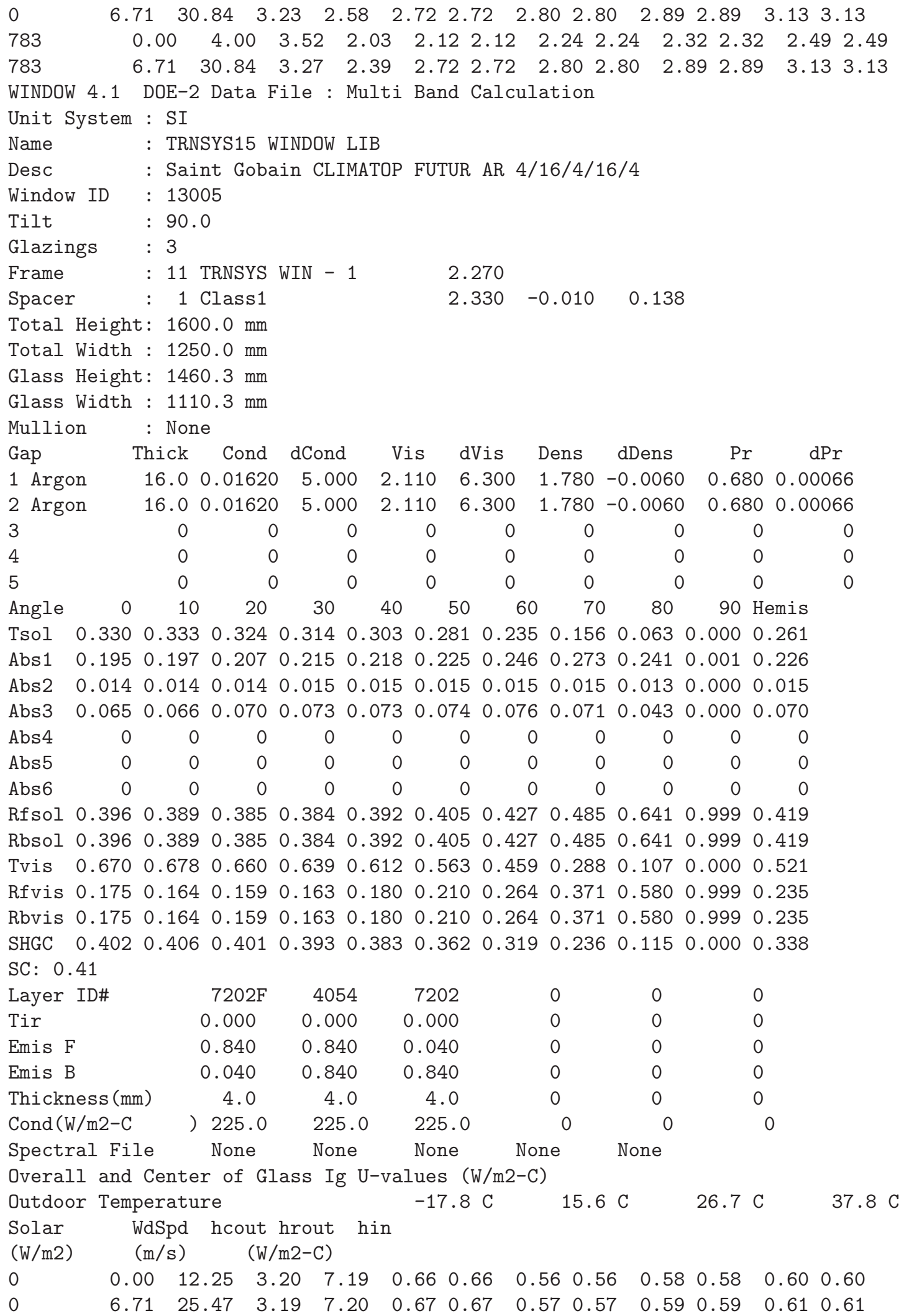




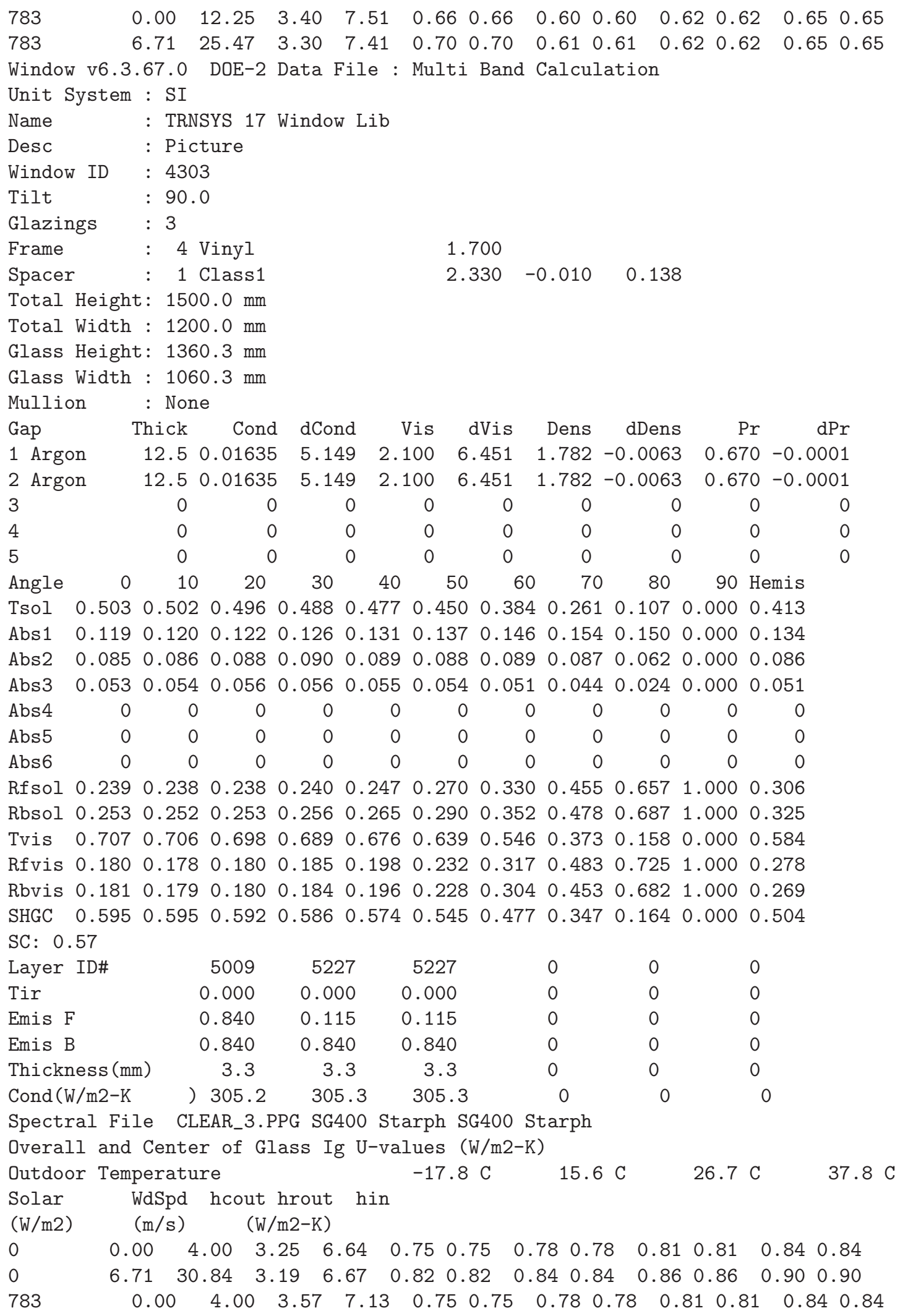




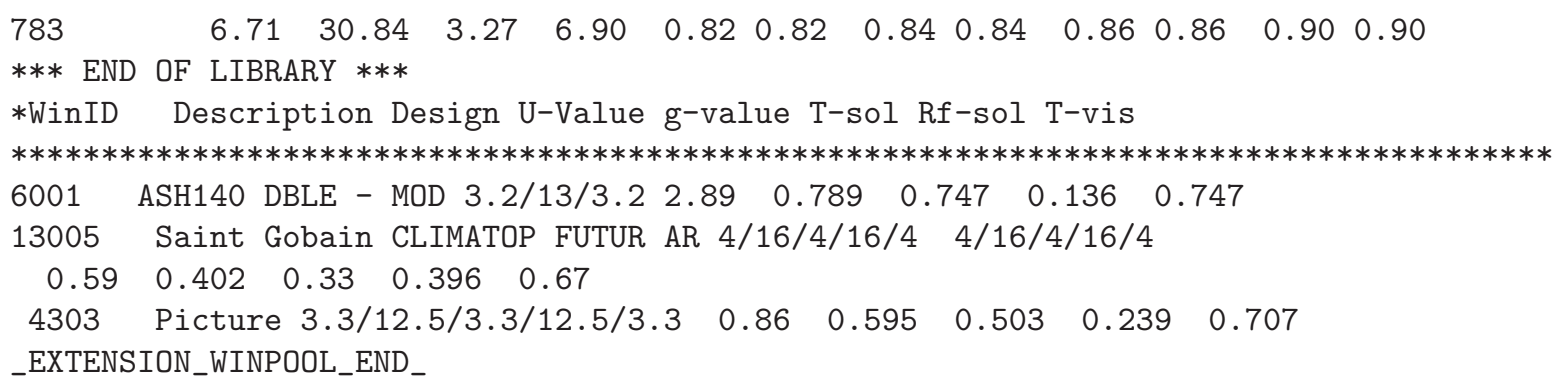


vertex $415.5689500000007 .061200000000 \quad 0.965200000000$ vertex $425.5689500000007 .061200000000 \quad 0.596900000000$ vertex $435.2133500000007 .061200000000 \quad 0.596900000000$ vertex $445.2133500000007 .061200000000 \quad 0.965200000000$ vertex 455.5689500000007 .0612000000001 .435100000000 vertex 465.5689500000007 .0612000000001 .066800000000 vertex 475.2133500000007 .0612000000001 .066800000000 vertex 485.2133500000007 .0612000000001 .435100000000 vertex 495.5689500000007 .0612000000001 .905000000000 vertex 505.5689500000007 .0612000000001 .536700000000 vertex 515.2133500000007 .0612000000001 .536700000000 vertex 525.2133500000007 .0612000000001 .905000000000 vertex 530.0000000000001 .5240000000001 .981200000000 vertex $54 \quad 0.0000000000001 .5240000000001 .117600000000$ vertex $550.000000000000 \quad 0.7112000000001 .117600000000$ vertex $56 \quad 0.000000000000 \quad 0.7112000000001 .981200000000$ vertex $57 \quad 0.0000000000007 .0104000000001 .981200000000$ vertex $580.0000000000007 .010400000000 \quad 0.050800000000$ vertex $590.0000000000005 .892800000000 \quad 0.050800000000$ vertex $60 \quad 0.0000000000005 .8928000000001 .981200000000$ vertex 616.5087500000007 .0612000000001 .989137500000 vertex $626.5087500000007 .061200000000 \quad 0.000000000000$ vertex 635.6451500000007 .0612000000000 .000000000000 vertex 645.6451500000007 .0612000000001 .989137500000

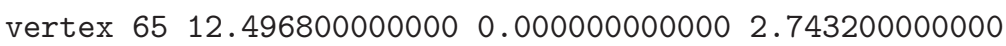
vertex $6612.4968000000000 .000000000000 \quad 0.000000000000$ vertex $67 \quad 12.496800000000 \quad 7.061200000000 \quad 0.000000000000$ vertex 6812.4968000000007 .0612000000002 .743200000000 vertex $6912.496800000000 \quad 0.3556000000001 .981200000000$ vertex $7012.496800000000 \quad 0.355600000000 \quad 0.050800000000$ vertex $71 \quad 12.4968000000001 .168400000000 \quad 0.050800000000$ vertex $72 \quad 12.4968000000001 .1684000000001 .981200000000$ vertex 7312.4968000000001 .2700000000001 .981200000000 vertex $74 \quad 12.4968000000001 .2700000000001 .574800000000$

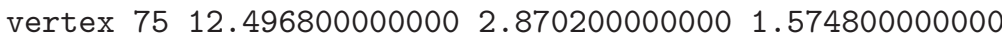

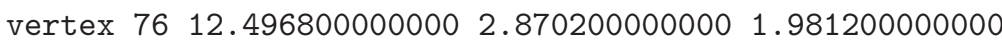
vertex 7712.4968000000004 .6736000000001 .981200000000 vertex $78 \quad 12.4968000000004 .6736000000001 .574800000000$ vertex 7912.4968000000006 .7056000000001 .574800000000 vertex 8012.4968000000006 .7056000000001 .981200000000 vertex 819.4599125000007 .0612000000001 .981200000000 vertex 829.4599125000007 .0612000000001 .473200000000 vertex 839.1551125000007 .0612000000001 .473200000000 vertex 849.1551125000007 .0612000000001 .981200000000 vertex 8512.1412000000007 .0612000000001 .981200000000 vertex 8612.1412000000007 .0612000000000 .050800000000 vertex 8711.0744000000007 .0612000000000 .050800000000 vertex 8811.0744000000007 .0612000000001 .981200000000 vertex 899.3757750000000 .0000000000002 .044700000000 vertex $909.375775000000 \quad 0.000000000000 \quad 0.000000000000$ vertex $9110.290175000000 \quad 0.000000000000 \quad 0.000000000000$ 
vertex $9210.290175000000 \quad 0.0000000000002 .044700000000$

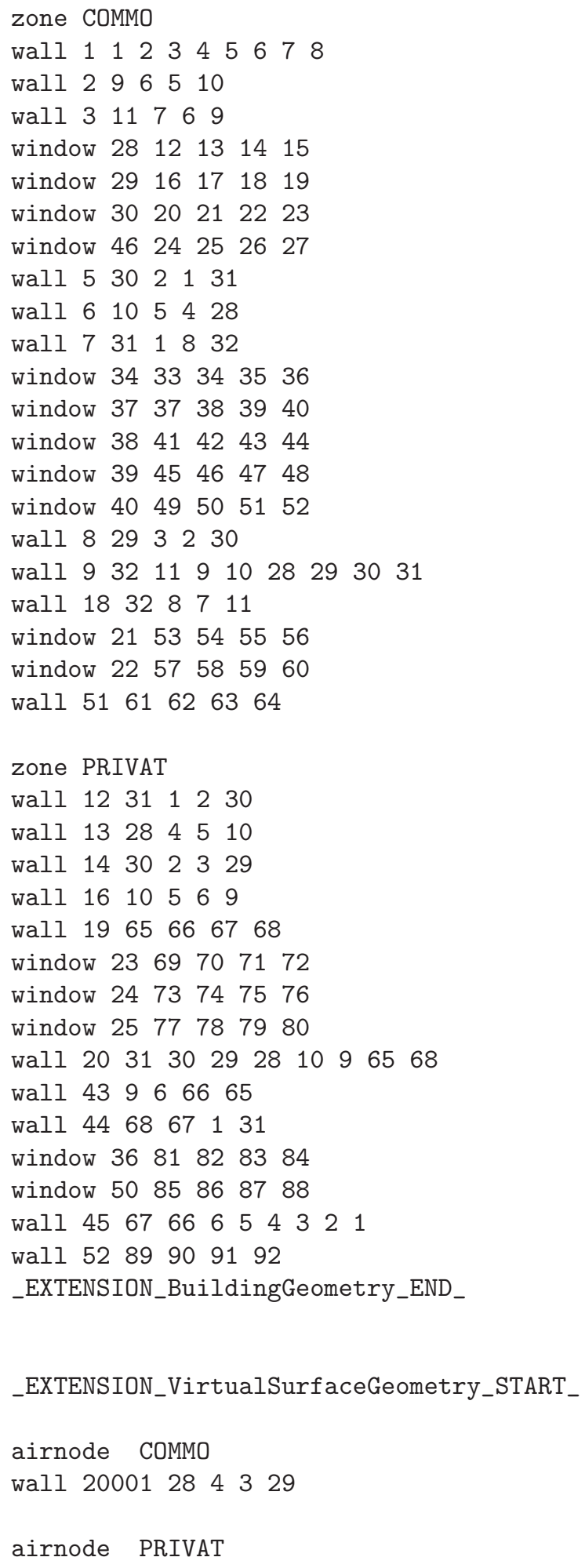


wall 20002293428

_EXTENSION_VirtualSurfaceGeometry_END_

_EXTENSION_ExternalShadingGeometry_START_

vertex $938.839200000000-2.7162125000003 .148119369250$

vertex $948.839200000000-2.716212500000 \quad 0.000000000000$

vertex $959.169761630945-2.716212500000 \quad 0.000000000000$

vertex $969.169761630945-2.716212500000 \quad 2.919001121890$

vertex $97 \quad 13.719536630945-2.716212500000 \quad 2.919001121890$

vertex $9813.719536630945-2.716212500000 \quad 0.000000000000$

vertex $9913.919200000000-2.716212500000 \quad 0.000000000000$

vertex $10013.919200000000-2.716212500000 \quad 3.148119369250$

vertex $101 \quad 13.919200000000 \quad 2.233499818178 \quad 4.435892706159$

vertex $10213.919200000000-2.5130125000012 .893657365579$

vertex $1038.839200000000-2.513012500000 \quad 2.893657365577$

vertex $1048.839200000000-1.172613989280 \quad 3.329179242511$

vertex $1052.946400000000-1.172613989281 \quad 3.329179242512$

vertex $1062.946400000000-2.5130125000002 .893657365578$

vertex $1070.000000000000-2.5130125000002 .893657365578$

vertex $108 \quad 0.000000000000 \quad 2.233499818178 \quad 4.435892706159$

vertex $10913.919200000000-2.513012500000 \quad 0.000000000000$

vertex $11013.719536630945-2.513012500000 \quad 0.000000000000$

vertex $111 \quad 13.719536630945-2.513012500001 \quad 2.893657365579$

vertex $1122.946400000000-2.513012500000 \quad 0.000000000000$

vertex $1132.946400000000-2.716212500000 \quad 0.000000000000$

vertex $1142.641600000000-2.716212500000 \quad 0.000000000000$

vertex $1152.641600000000-2.513012500000 \quad 0.000000000000$

vertex $1162.641600000000-2.5130125000002 .820491425536$

vertex $1172.641600000000-2.7162125000002 .820491425536$

vertex $1180.508000000000-2.716212500000 \quad 2.820491425536$

vertex $1190.508000000000-2.5130125000002 .820491425536$

vertex $120 \quad 0.508000000000-2.716212500000 \quad 0.000000000000$

vertex $1210.508000000000-2.513012500000 \quad 0.000000000000$

vertex $1220.000000000000-2.716212500000 \quad 0.000000000000$

vertex $1230.000000000000-2.513012500000 \quad 0.000000000000$

vertex $1240.000000000000-2.716212500000 \quad 3.148119369250$

vertex $1252.946400000000-2.716212500000 \quad 3.148119369250$

vertex $12613.719536630945-2.716212500000 \quad 2.893657365579$

vertex $1279.169761630945-2.7162125000002 .893657365577$

vertex $1289.169761630945-2.513012500000 \quad 2.893657365577$

vertex $1299.169761630945-2.513012500000 \quad 0.000000000000$

vertex $1308.839200000000-2.513012500000 \quad 0.000000000000$

vertex $131 \quad 13.919200000000 \quad 2.139311438293 \quad 4.725774732326$

vertex $1320.0000000000002 .139311438293 \quad 4.725774732326$

vertex $1332.946400000000-1.266802369166 \quad 3.619061268678$

vertex $1348.839200000000-1.266802369165 \quad 3.619061268678$

shader 1000193949596979899100

shader 10002101102103104105106107108

shader 10003102109110111 


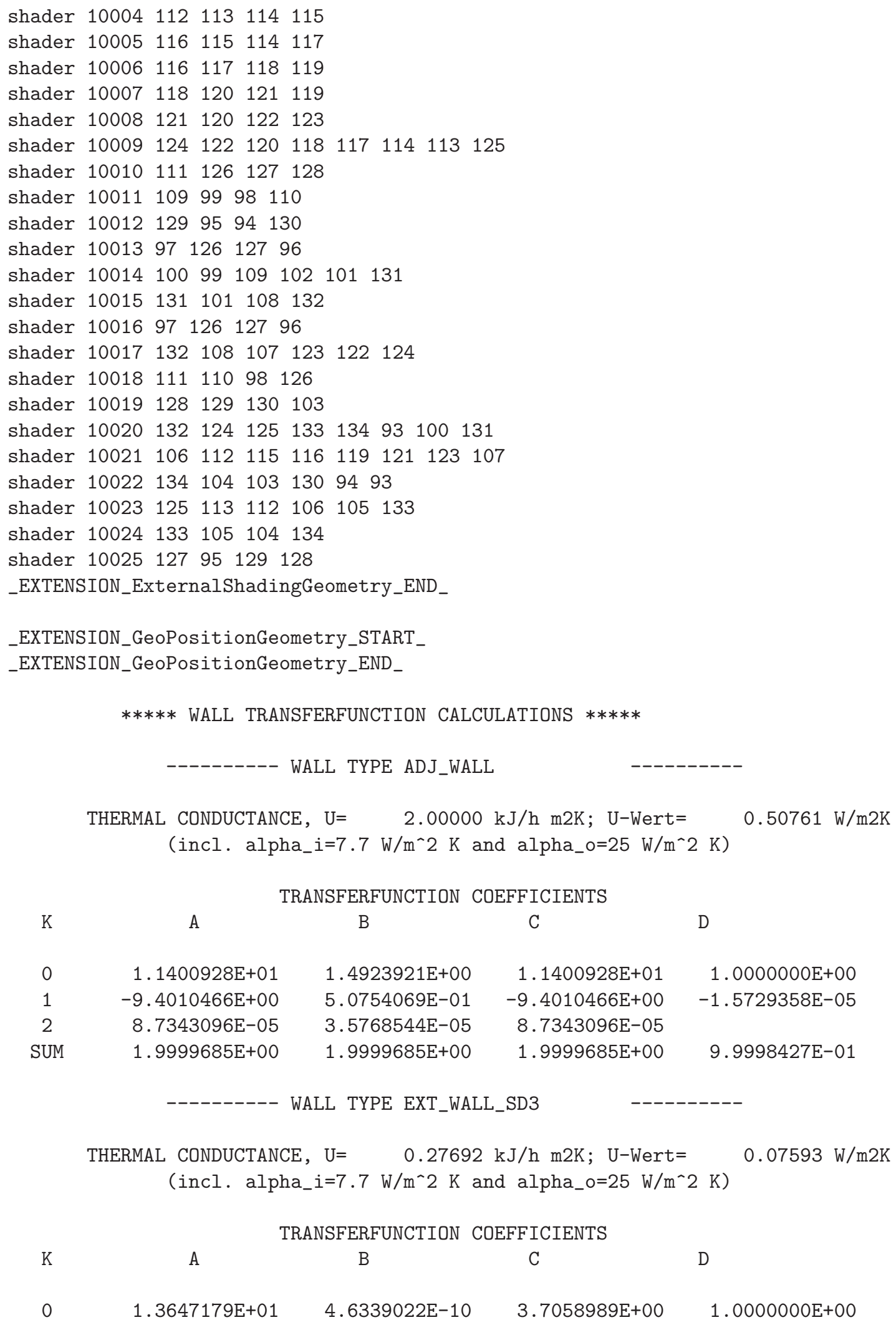

$\begin{array}{crrrr}0 & 1.1400928 \mathrm{E}+01 & 1.4923921 \mathrm{E}+00 & 1.1400928 \mathrm{E}+01 & 1.0000000 \mathrm{E}+00 \\ 1 & -9.4010466 \mathrm{E}+00 & 5.0754069 \mathrm{E}-01 & -9.4010466 \mathrm{E}+00 & -1.5729358 \mathrm{E}-05 \\ 2 & 8.7343096 \mathrm{E}-05 & 3.5768544 \mathrm{E}-05 & 8.7343096 \mathrm{E}-05 & \\ \text { SUM } & 1.9999685 \mathrm{E}+00 & 1.9999685 \mathrm{E}+00 & 1.9999685 \mathrm{E}+00 & 9.9998427 \mathrm{E}-01\end{array}$

WALL TYPE EXT_WALL_SD3

THERMAL CONDUCTANCE, $\mathrm{U}=0.27692 \mathrm{~kJ} / \mathrm{h} \mathrm{m} 2 \mathrm{~K}$; U-Wert= $0.07593 \mathrm{~W} / \mathrm{m} 2 \mathrm{~K}$ (incl. alpha_i=7.7 W/m^2 $\mathrm{K}$ and alpha_o=25 W/m^2 K)

K

0

TRANSFERFUNCTION COEFFICIENTS

A

B

$\mathrm{C}$

$3.7058989 \mathrm{E}+00$

$1.0000000 \mathrm{E}+00$ 


$\begin{array}{crrrr}1 & -3.9785190 \mathrm{E}+01 & 1.5832620 \mathrm{E}-05 & -9.8807644 \mathrm{E}+00 & -2.1210955 \mathrm{E}+00 \\ 2 & 4.2701798 \mathrm{E}+01 & 6.1313533 \mathrm{E}-04 & 9.7862971 \mathrm{E}+00 & 1.5387938 \mathrm{E}+00 \\ 3 & -2.0443303 \mathrm{E}+01 & 2.3711202 \mathrm{E}-03 & -4.4978471 \mathrm{E}+00 & -4.4523827 \mathrm{E}-01 \\ 4 & 4.1689377 \mathrm{E}+00 & 1.8697530 \mathrm{E}-03 & 9.8010162 \mathrm{E}-01 & 4.8173278 \mathrm{E}-02 \\ 5 & -2.9093560 \mathrm{E}-01 & 3.6028973 \mathrm{E}-04 & -9.1404812 \mathrm{E}-02 & -1.7015816 \mathrm{E}-03 \\ 6 & 6.8129978 \mathrm{E}-03 & 1.6887585 \mathrm{E}-05 & 2.9927767 \mathrm{E}-03 & 1.6714193 \mathrm{E}-05 \\ 7 & -5.2241014 \mathrm{E}-05 & 1.7359000 \mathrm{E}-07 & -2.6926414 \mathrm{E}-05 & -4.1227100 \mathrm{E}-08 \\ 8 & 1.1746916 \mathrm{E}-07 & 3.2801908 \mathrm{E}-10 & 5.1930389 \mathrm{E}-08 & \\ \text { SUM } & 5.2471929 \mathrm{E}-03 & 5.2471929 \mathrm{E}-03 & 5.2471929 \mathrm{E}-03 & 1.8948471 \mathrm{E}-02\end{array}$

WALL TYPE SD_DOOR

THERMAL CONDUCTANCE, $\mathrm{U}=16.24060 \mathrm{~kJ} / \mathrm{h} \mathrm{m} 2 \mathrm{~K}$; U-Wert=

$2.55319 \mathrm{~W} / \mathrm{m} 2 \mathrm{~K}$ (incl. alpha_i=7.7 W/m^2 $\mathrm{K}$ and alpha_o=25 W/m^2 K)

TRANSFERFUNCTION COEFFICIENTS

K

$0 \quad 2.4338747 \mathrm{E}+01$

$1-8.0984525 \mathrm{E}+00$

$2 \quad 5.6624998 \mathrm{E}-05$

SUM

K

$0 \quad 1.3882147 \mathrm{E}+01$

$1-4.3267557 \mathrm{E}+01$

2

3

4

5

6

7

8

SUM

$1.6240351 \mathrm{E}+01$
B

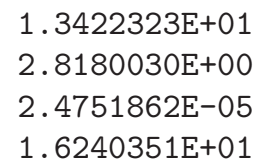

$\mathrm{C}$

$2.4338747 \mathrm{E}+01$

$-8.0984525 \mathrm{E}+00$

$5.6624998 \mathrm{E}-05$

1. $6240351 \mathrm{E}+01$
D

$1.0000000 \mathrm{E}+00$

$-1.5412716 \mathrm{E}-05$

$9.9998459 \mathrm{E}-01$

WALL TYPE FLOOR_SD2

THERMAL CONDUCTANCE, $\mathrm{U}=$

$0.41125 \mathrm{~kJ} / \mathrm{h} \mathrm{m} 2 \mathrm{~K}$; U-Wert=

$0.11206 \mathrm{~W} / \mathrm{m} 2 \mathrm{~K}$ (incl. alpha_i=7.7 W/m^2 K and alpha_o $=25 \mathrm{~W} / \mathrm{m}^{\wedge} 2 \mathrm{~K}$ )

TRANSFERFUNCTION COEFFICIENTS

$\begin{array}{llll}\text { A } & \text { B } & \text { C } & \text { D }\end{array}$
3.2178704E-12
$2.6054000 \mathrm{E}-06$
$2.8218907 \mathrm{E}-04$
2.1819764E-03
$3.3181450 \mathrm{E}-03$
$1.3193112 \mathrm{E}-03$
$1.4648803 \mathrm{E}-04$
$4.3621737 \mathrm{E}-06$
$3.1768665 \mathrm{E}-08$
7.2551091E-03

$3.1300403 \mathrm{E}+01$

$-9.0726079 \mathrm{E}+01$

$9.8182541 \mathrm{E}+01$

$-4.9605108 \mathrm{E}+01$

1. $2231382 \mathrm{E}+01$

$-1.4491397 \mathrm{E}+00$

$7.4478167 \mathrm{E}-02$

$-1.2261016 \mathrm{E}-03$

4.2775095E-06

$7.2551136 \mathrm{E}-03$

D

WALL TYPE EXT_ROOF_SD3

THERMAL CONDUCTANCE, U= $0.41975 \mathrm{~kJ} / \mathrm{h} \mathrm{m} 2 \mathrm{~K}$; U-Wert=

$0.11433 \mathrm{~W} / \mathrm{m} 2 \mathrm{~K}$ (incl. alpha_i=7.7 W/m^2 $\mathrm{K}$ and alpha_o=25 W/m^2 $\mathrm{K}$ )

TRANSFERFUNCTION COEFFICIENTS

$-2.2270449 \mathrm{E}+00$

1. $7985877 \mathrm{E}+00$

$-6.5386970 \mathrm{E}-01$

$1.0670442 \mathrm{E}-01$

$-6.8637061 \mathrm{E}-03$

1. 2844637E-04

$-5.4986040 \mathrm{E}-07$

1.7641711E-02 


$\begin{array}{crrrr}1 & -4.6407066 \mathrm{E}+01 & 7.9195257 \mathrm{E}-05 & -3.0307759 \mathrm{E}+01 & -1.7724961 \mathrm{E}+00 \\ 2 & 4.4900241 \mathrm{E}+01 & 2.3857831 \mathrm{E}-03 & 2.9072598 \mathrm{E}+01 & 1.0009684 \mathrm{E}+00 \\ 3 & -1.8951143 \mathrm{E}+01 & 7.0968717 \mathrm{E}-03 & -1.2167834 \mathrm{E}+01 & -2.0951230 \mathrm{E}-01 \\ 4 & 3.4049336 \mathrm{E}+00 & 4.1038595 \mathrm{E}-03 & 2.1670489 \mathrm{E}+00 & 1.5181708 \mathrm{E}-02 \\ 5 & -2.2721208 \mathrm{E}-01 & 5.3455286 \mathrm{E}-04 & -1.4343474 \mathrm{E}-01 & -2.7602625 \mathrm{E}-04 \\ 6 & 3.9556250 \mathrm{E}-03 & 1.4951670 \mathrm{E}-05 & 2.4930699 \mathrm{E}-03 & 7.5045155 \mathrm{E}-07 \\ 7 & -1.0271977 \mathrm{E}-05 & 7.7954670 \mathrm{E}-08 & -6.5228738 \mathrm{E}-06 & \\ \text { SUM } & 1.4215291 \mathrm{E}-02 & 1.4215295 \mathrm{E}-02 & 1.4215293 \mathrm{E}-02 & 3.3866482 \mathrm{E}-02\end{array}$

REQUIRED INPUTS

*:InpNR | Label

* I 1 | TAMB

* | 2 | RELHUMAMB

* $|3|$ TSKY

* | 4 | TSGRD

* | 5 | AZEN

* | 6 | AAZM

* | 7 | GRDREF

* $\quad 8$ TGROUND

* | 9 | TBOUNDARY

* | 10 | BRIGHT

* | 11 | SHADE_CLOSE

* | 12 | SHADE_OPEN

* | 13 | MAX_ISHADE

* | 14 | MAX_ESHADE

* | 15 | NORTHSHADE

* | 16 | EASTSHADE

* | 17 | SOUTHSHADE

* | 18 | WESTSHADE

* | 19 | M_VENT

* $\mid 20$ | HUMIDITY_IN

* | 21 | T_VENT
| UNIT

I C

I \%

I C

I C

| degrees

I degrees

I any

I any

I any

I any

I any

I any

I any

I any

I any

I any

I any

I any

I any

I any

I any

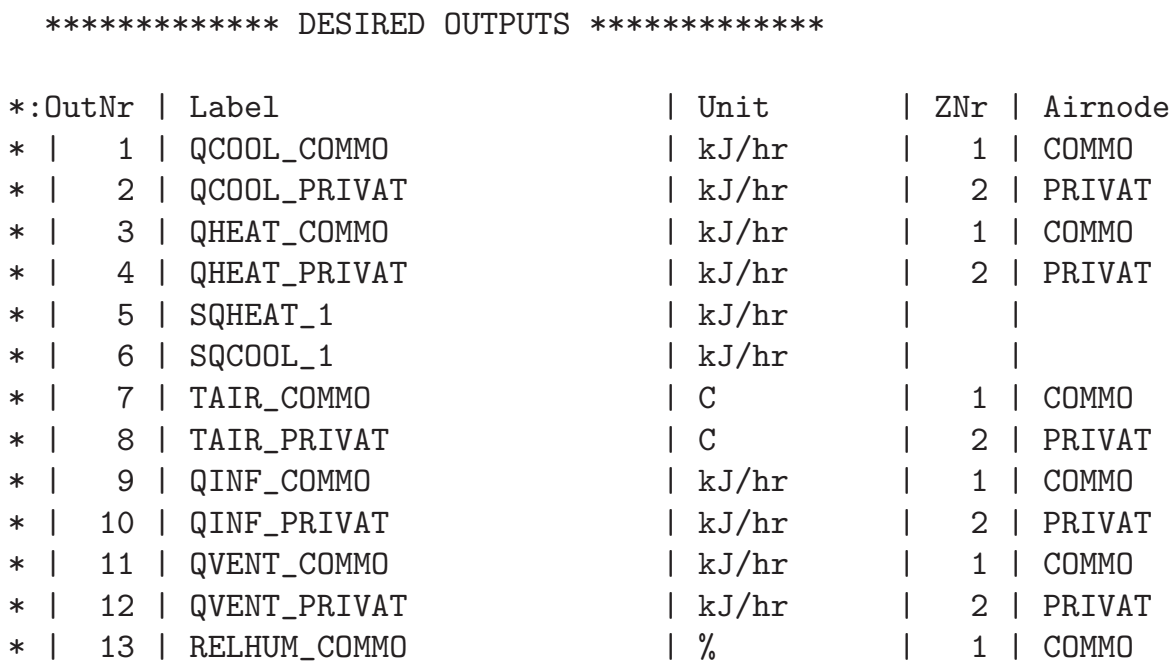




\begin{tabular}{|c|c|c|c|c|}
\hline$* 1$ & 14 | RELHUM_PRIVAT & $\%$ & | & $2 \mid$ PRIVAT \\
\hline$* 1$ & 15 | QHUM_COMMO & $\mathrm{kJ} / \mathrm{hr}$ & I & 1 | СОММО \\
\hline$* 1$ & 16 | QHUM_PRIVAT & $\mathrm{kJ} / \mathrm{hr}$ & I & 2 I PRIVAT \\
\hline$*$ & 17 | QDEHUM_COMMO & $\mathrm{kJ} / \mathrm{hr}$ & I & 1 | СОММО \\
\hline$*$ & 18 | QDEHUM_PRIVAT & $\mathrm{kJ} / \mathrm{hr}$ & 1 & 2 I PRIVAT \\
\hline
\end{tabular}

*** THERMAL CONDUCTANCE OF USED WALL TYPES $* * *$

(incl. alpha_i=7.7 W/m^2 $\mathrm{K}$ and alpha_o=25 W/m^2 K)

$\begin{array}{lll}\text { WALL ADJ_WALL } & \mathrm{U}= & 0.508 \mathrm{~W} / \mathrm{m} 2 \mathrm{~K} \\ \text { WALL EXT_WALL_SD3 } & \mathrm{U}= & 0.076 \mathrm{~W} / \mathrm{m} 2 \mathrm{~K} \\ \text { WALL SD_DOOR } & \mathrm{U}= & 2.553 \mathrm{~W} / \mathrm{m} 2 \mathrm{~K} \\ \text { WALL FLOOR_SD2 } & \mathrm{U}= & 0.112 \mathrm{~W} / \mathrm{m} 2 \mathrm{~K} \\ \text { WALL EXT_ROOF_SD3 } & \mathrm{U}= & 0.114 \mathrm{~W} / \mathrm{m} 2 \mathrm{~K}\end{array}$

$* * * * *$ WALL TRANSFERFUNCTION CALCULATIONS

WALL TYPE ADJ_WALL

THERMAL CONDUCTANCE, $\mathrm{U}=\quad 2.00000 \mathrm{~kJ} / \mathrm{h} \mathrm{m} 2 \mathrm{~K}$; U-Wert $=0.50761 \mathrm{~W} / \mathrm{m} 2 \mathrm{~K}$ (incl. alpha_i=7.7 W/m^2 $\mathrm{K}$ and alpha_o=25 W/m^2 K)

K

$0 \quad 1.1400928 \mathrm{E}+01$

$1-9.4010466 \mathrm{E}+00$

$2 \quad 8.7343096 \mathrm{E}-05$

SUM $\quad 1.9999685 \mathrm{E}+00$

TRANSFERFUNCTION COEFFICIENTS

B C D

$\begin{array}{rrr}1.4923921 \mathrm{E}+00 & 1.1400928 \mathrm{E}+01 & 1.0000000 \mathrm{E}+00 \\ 5.0754069 \mathrm{E}-01 & -9.4010466 \mathrm{E}+00 & -1.5729358 \mathrm{E}-05 \\ 3.5768544 \mathrm{E}-05 & 8.7343096 \mathrm{E}-05 & \\ 1.9999685 \mathrm{E}+00 & 1.9999685 \mathrm{E}+00 & 9.9998427 \mathrm{E}-01\end{array}$

WALL TYPE EXT_WALL_SD3

THERMAL CONDUCTANCE, $\mathrm{U}=0.27692 \mathrm{~kJ} / \mathrm{h} \mathrm{m} 2 \mathrm{~K}$; U-Wert=

$0.07593 \mathrm{~W} / \mathrm{m} 2 \mathrm{~K}$ (incl. alpha_i=7.7 W/m^2 $\mathrm{K}$ and alpha_o=25 W/m^2 $\mathrm{K}$ )

K

$\begin{array}{cr}0 & 1.3647179 \mathrm{E}+01 \\ 1 & -3.9785190 \mathrm{E}+01 \\ 2 & 4.2701798 \mathrm{E}+01 \\ 3 & -2.0443303 \mathrm{E}+01 \\ 4 & 4.1689377 \mathrm{E}+00 \\ 5 & -2.9093560 \mathrm{E}-01 \\ 6 & 6.8129978 \mathrm{E}-03 \\ 7 & -5.2241014 \mathrm{E}-05 \\ 8 & 1.1746916 \mathrm{E}-07 \\ \text { SUM } & 5.2471929 \mathrm{E}-03\end{array}$

TRANSFERFUNCTION COEFFICIENTS
A
B
C

$3.7058989 \mathrm{E}+00$
$-9.8807644 \mathrm{E}+00$
$9.7862971 \mathrm{E}+00$
$-4.4978471 \mathrm{E}+00$
$9.8010162 \mathrm{E}-01$
$-9.1404812 \mathrm{E}-02$
$2.9927767 \mathrm{E}-03$
$-2.6926414 \mathrm{E}-05$
$5.1930389 \mathrm{E}-08$
$5.2471929 \mathrm{E}-03$

1. $0000000 \mathrm{E}+00$

$-2.1210955 \mathrm{E}+00$

$1.5387938 \mathrm{E}+00$

$-4.4523827 \mathrm{E}-01$

$4.8173278 \mathrm{E}-02$

$-1.7015816 \mathrm{E}-03$

1.6714193E-05

$-4.1227100 \mathrm{E}-08$

$1.8948471 \mathrm{E}-02$

WALL TYPE SD_DOOR 
THERMAL CONDUCTANCE, U $\quad 16.24060 \mathrm{~kJ} / \mathrm{h} \mathrm{m} 2 \mathrm{~K}$; U-Wert= $2.55319 \mathrm{~W} / \mathrm{m} 2 \mathrm{~K}$ (incl. alpha_i=7.7 W/m^2 $\mathrm{K}$ and alpha_o=25 W/m^2 K)

\begin{tabular}{crccr}
\multicolumn{5}{c}{ TRANSFERFUNCTION } \\
K & A COEFFICIENTS & C & \multicolumn{1}{l}{ D } \\
& & B & & \\
0 & $2.4338747 \mathrm{E}+01$ & $1.3422323 \mathrm{E}+01$ & $2.4338747 \mathrm{E}+01$ & $1.0000000 \mathrm{E}+00$ \\
1 & $-8.0984525 \mathrm{E}+00$ & $2.8180030 \mathrm{E}+00$ & $-8.0984525 \mathrm{E}+00$ & $-1.5412716 \mathrm{E}-05$ \\
2 & $5.6624998 \mathrm{E}-05$ & $2.4751862 \mathrm{E}-05$ & $5.6624998 \mathrm{E}-05$ & \\
SUM & $1.6240351 \mathrm{E}+01$ & $1.6240351 \mathrm{E}+01$ & $1.6240351 \mathrm{E}+01$ & $9.9998459 \mathrm{E}-01$
\end{tabular}

WALL TYPE FLOOR_SD2

THERMAL CONDUCTANCE, $\mathrm{U}=0.41125 \mathrm{~kJ} / \mathrm{h} \mathrm{m} 2 \mathrm{~K}$; U-Wert $=$ $0.11206 \mathrm{~W} / \mathrm{m} 2 \mathrm{~K}$ (incl. alpha_i=7.7 W/m^2 $\mathrm{K}$ and alpha_o=25 W/m^2 K)

K

$\begin{array}{cr}0 & 1.3882147 \mathrm{E}+01 \\ 1 & -4.3267557 \mathrm{E}+01 \\ 2 & 5.2134397 \mathrm{E}+01 \\ 3 & -3.0690876 \mathrm{E}+01 \\ 4 & 9.1979823 \mathrm{E}+00 \\ 5 & -1.3263187 \mathrm{E}+00 \\ 6 & 7.8883662 \mathrm{E}-02 \\ 7 & -1.4087492 \mathrm{E}-03 \\ 8 & 5.8012959 \mathrm{E}-06 \\ \text { SUM } & 7.2551165 \mathrm{E}-03\end{array}$

TRANSFERFUNCTION COEFFICIENTS

$\begin{array}{llll}\text { A } & \text { B } & \text { C } & \text { D }\end{array}$

D

$$
\begin{array}{r}
3.1300403 \mathrm{E}+01 \\
-9.0726079 \mathrm{E}+01 \\
9.8182541 \mathrm{E}+01 \\
-4.9605108 \mathrm{E}+01 \\
1.2231382 \mathrm{E}+01 \\
-1.4491397 \mathrm{E}+00 \\
7.4478167 \mathrm{E}-02 \\
-1.2261016 \mathrm{E}-03 \\
4.2775095 \mathrm{E}-06 \\
7.2551136 \mathrm{E}-03
\end{array}
$$

$$
\begin{array}{r}
1.0000000 \mathrm{E}+00 \\
-2.2270449 \mathrm{E}+00 \\
1.7985877 \mathrm{E}+00 \\
-6.5386970 \mathrm{E}-01 \\
1.0670442 \mathrm{E}-01 \\
-6.8637061 \mathrm{E}-03 \\
1.2844637 \mathrm{E}-04 \\
-5.4986040 \mathrm{E}-07 \\
1.7641711 \mathrm{E}-02
\end{array}
$$

WALL TYPE EXT_ROOF_SD3

THERMAL CONDUCTANCE, $\mathrm{U}=0.41975 \mathrm{~kJ} / \mathrm{h} \mathrm{m} 2 \mathrm{~K}$; U-Wert=

$0.11433 \mathrm{~W} / \mathrm{m} 2 \mathrm{~K}$ (incl. alpha_i=7.7 W/m^2 $\mathrm{K}$ and alpha_o=25 W/m^2 $\mathrm{K}$ )

K

$\begin{array}{cr}0 & 1.7290517 \mathrm{E}+01 \\ 1 & -4.6407066 \mathrm{E}+01 \\ 2 & 4.4900241 \mathrm{E}+01 \\ 3 & -1.8951143 \mathrm{E}+01 \\ 4 & 3.4049336 \mathrm{E}+00 \\ 5 & -2.2721208 \mathrm{E}-01 \\ 6 & 3.9556250 \mathrm{E}-03 \\ 7 & -1.0271977 \mathrm{E}-05 \\ \text { SUM } & 1.4215291 \mathrm{E}-02\end{array}$

TRANSFERFUNCTION COEFFICIENTS
A
B
C
D

$$
\begin{array}{r}
1.1391110 \mathrm{E}+01 \\
-3.0307759 \mathrm{E}+01 \\
2.9072598 \mathrm{E}+01 \\
-1.2167834 \mathrm{E}+01 \\
2.1670489 \mathrm{E}+00 \\
-1.4343474 \mathrm{E}-01 \\
2.4930699 \mathrm{E}-03 \\
-6.5228738 \mathrm{E}-06 \\
1.4215293 \mathrm{E}-02
\end{array}
$$

(1)

\begin{abstract}
REQUIRED INPUTS $* * * * * * * * * * * * *$
\end{abstract}




\begin{tabular}{l|r|l|l|l}
$*:$ InpNR & Label & UNIT \\
$*$ & 1 & TAMB & C \\
$*$ & 2 & RELHUMAMB & ( & C \\
$*$ & 3 & TSKY & C \\
$*$ & 4 & TSGRD & degrees \\
$*$ & 5 & AZEN & degrees \\
$*$ & 6 & AAZM & any \\
$*$ & 7 & GRDREF & any \\
$*$ & 8 & TGROUND & any \\
$*$ & 9 & TBOUNDARY & any \\
$*$ & 10 & BRIGHT & any \\
$*$ & 11 & SHADE_CLOSE & any \\
$*$ & 12 & SHADE_OPEN & any \\
$*$ & 13 & MAX_ISHADE & any \\
$*$ & 14 & MAX_ESHADE & any \\
$*$ & 15 & NORTHSHADE & any \\
$*$ & 17 & SOUTHSHADE & any \\
$*$ & 18 & WESTSHADE & any \\
$*$ & 19 & M_VENT & any \\
$*$ & 20 & HUMIDITY_IN & any \\
$*$ & 21 & T_VENT &
\end{tabular}

*** THERMAL CONDUCTANCE OF USED WALL TYPES $* * *$ (incl. alpha_i=7.7 W/m^2 $\mathrm{K}$ and alpha_o=25 W/m^2 $\mathrm{K}$ )

WALL ADJ_WALL U $\quad 0.508 \mathrm{~W} / \mathrm{m} 2 \mathrm{~K}$

WALL EXT_WALL_SD3 U $\quad 0.076 \mathrm{~W} / \mathrm{m} 2 \mathrm{~K}$

WALL SD_DOOR U= $2.553 \mathrm{~W} / \mathrm{m} 2 \mathrm{~K}$

WALL FLOOR_SD2 U= $0.112 \mathrm{~W} / \mathrm{m} 2 \mathrm{~K}$

WALL EXT_ROOF_SD3 U= $0.114 \mathrm{~W} / \mathrm{m} 2 \mathrm{~K}$

$* * * * *$ WALL TRANSFERFUNCTION CALCULATIONS $* * * * *$

-------- WALL TYPE ADJ_WALL

THERMAL CONDUCTANCE, $\mathrm{U}=2.00000 \mathrm{~kJ} / \mathrm{h} \mathrm{m} 2 \mathrm{~K}$; U-Wert $=0.50761 \mathrm{~W} / \mathrm{m} 2 \mathrm{~K}$ (incl. alpha_i=7.7 W/m^2 $\mathrm{K}$ and alpha_o=25 W/m^2 K)

TRANSFERFUNCTION COEFFICIENTS

\begin{tabular}{crcrr} 
K & A & B & C & \multicolumn{1}{l}{ D } \\
& & & & \\
0 & $1.1400928 \mathrm{E}+01$ & $1.4923921 \mathrm{E}+00$ & $1.1400928 \mathrm{E}+01$ & $1.0000000 \mathrm{E}+00$ \\
1 & $-9.4010466 \mathrm{E}+00$ & $5.0754069 \mathrm{E}-01$ & $-9.4010466 \mathrm{E}+00$ & $-1.5729358 \mathrm{E}-05$ \\
2 & $8.7343096 \mathrm{E}-05$ & $3.5768544 \mathrm{E}-05$ & $8.7343096 \mathrm{E}-05$ & \\
SUM & $1.9999685 \mathrm{E}+00$ & $1.9999685 \mathrm{E}+00$ & $1.9999685 \mathrm{E}+00$ & $9.9998427 \mathrm{E}-01$
\end{tabular}

WALL TYPE EXT_WALL_SD3

THERMAL CONDUCTANCE, $\mathrm{U}=\quad 0.27692 \mathrm{~kJ} / \mathrm{h} \mathrm{m} 2 \mathrm{~K}$; U-Wert=

$0.07593 \mathrm{~W} / \mathrm{m} 2 \mathrm{~K}$

(incl. alpha_i=7.7 W/m^2 $\mathrm{K}$ and alpha_o=25 W/m^2 $\mathrm{K}$ ) 
TRANSFERFUNCTION COEFFICIENTS

K

$0 \quad 1.3647179 \mathrm{E}+01$

$1-3.9785190 \mathrm{E}+01$

$24.2701798 \mathrm{E}+01$

$3-2.0443303 \mathrm{E}+01$

$4 \quad 4.1689377 \mathrm{E}+00$

$5-2.9093560 \mathrm{E}-01$

$6 \quad 6.8129978 \mathrm{E}-03$

$7-5.2241014 \mathrm{E}-05$

$8 \quad 1.1746916 \mathrm{E}-07$

SUM $\quad 5.2471929 \mathrm{E}-03$
B
4. $6339022 \mathrm{E}-10$
1. 5832620E-05
6.1313533E-04
$2.3711202 \mathrm{E}-03$
$1.8697530 \mathrm{E}-03$
3. 6028973E-04
1. 6887585E-05
$1.7359000 \mathrm{E}-07$
3. $2801908 \mathrm{E}-10$
5. 2471929E-03

$\mathrm{C}$

$3.7058989 \mathrm{E}+00$
$-9.8807644 \mathrm{E}+00$
$9.7862971 \mathrm{E}+00$
$-4.4978471 \mathrm{E}+00$
$9.8010162 \mathrm{E}-01$
$-9.1404812 \mathrm{E}-02$
$2.9927767 \mathrm{E}-03$
$-2.6926414 \mathrm{E}-05$
$5.1930389 \mathrm{E}-08$
$5.2471929 \mathrm{E}-03$

D
$1.0000000 \mathrm{E}+00$
$-2.1210955 \mathrm{E}+00$
1. $5387938 \mathrm{E}+00$
$-4.4523827 \mathrm{E}-01$
4.8173278E-02
$-1.7015816 \mathrm{E}-03$
1.6714193E-05
$-4.1227100 \mathrm{E}-08$
1. 8948471E-02

WALL TYPE SD_DOOR

THERMAL CONDUCTANCE, $\mathrm{U}=16.24060 \mathrm{~kJ} / \mathrm{h} \mathrm{m} 2 \mathrm{~K}$; U-Wert= $2.55319 \mathrm{~W} / \mathrm{m} 2 \mathrm{~K}$ (incl. alpha_i=7.7 W/m^2 K and alpha_o=25 W/m^2 K)

K

0

1

2

SUM

TRANSFERFUNCTION COEFFICIENTS

A

$$
\begin{array}{r}
2.4338747 \mathrm{E}+01 \\
-8.0984525 \mathrm{E}+00 \\
5.6624998 \mathrm{E}-05 \\
1.6240351 \mathrm{E}+01
\end{array}
$$

B

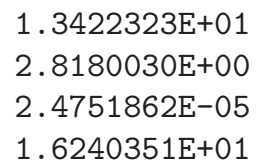

C

$$
\begin{array}{r}
2.4338747 \mathrm{E}+01 \\
-8.0984525 \mathrm{E}+00 \\
5.6624998 \mathrm{E}-05 \\
1.6240351 \mathrm{E}+01
\end{array}
$$

D

$$
\begin{array}{r}
1.0000000 \mathrm{E}+00 \\
-1.5412716 \mathrm{E}-05 \\
9.9998459 \mathrm{E}-01
\end{array}
$$

WALL TYPE FLOOR_SD2

THERMAL CONDUCTANCE, U $=0.41125 \mathrm{~kJ} / \mathrm{h} \mathrm{m} 2 \mathrm{~K}$; U-Wert= $0.11206 \mathrm{~W} / \mathrm{m} 2 \mathrm{~K}$ (incl. alpha_i=7.7 W/m^2 $\mathrm{K}$ and alpha_o=25 W/m^2 K)

K

$\begin{array}{cr}0 & 1.3882147 \mathrm{E}+01 \\ 1 & -4.3267557 \mathrm{E}+01 \\ 2 & 5.2134397 \mathrm{E}+01 \\ 3 & -3.0690876 \mathrm{E}+01 \\ 4 & 9.1979823 \mathrm{E}+00 \\ 5 & -1.3263187 \mathrm{E}+00 \\ 6 & 7.8883662 \mathrm{E}-02 \\ 7 & -1.4087492 \mathrm{E}-03 \\ 8 & 5.8012959 \mathrm{E}-06 \\ \text { SUM } & 7.2551165 \mathrm{E}-03\end{array}$

TRANSFERFUNCTION COEFFICIENTS

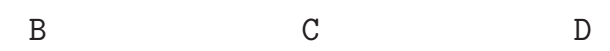

$B$

$\mathrm{C}$

D

3. $2178704 \mathrm{E}-12$

$2.6054000 \mathrm{E}-06$

$2.8218907 \mathrm{E}-04$

$2.1819764 \mathrm{E}-03$

3.3181450E-03

1.3193112E-03

$1.4648803 \mathrm{E}-04$

4.3621737E-06

3.1768665E-08

7. 2551091E-03

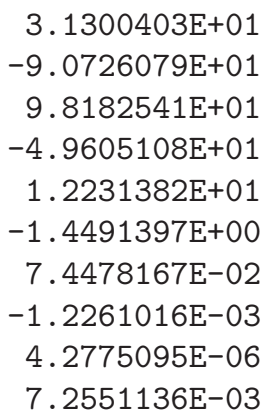
$1.0000000 \mathrm{E}+00$
$-2.2270449 \mathrm{E}+00$
$1.7985877 \mathrm{E}+00$
$-6.5386970 \mathrm{E}-01$
$1.0670442 \mathrm{E}-01$
$-6.8637061 \mathrm{E}-03$
$1.2844637 \mathrm{E}-04$
$-5.4986040 \mathrm{E}-07$
1. 7641711E-02

WALL TYPE EXT_ROOF_SD3

THERMAL CONDUCTANCE, $U=$ 
TRANSFERFUNCTION COEFFICIENTS

\begin{tabular}{crcrr} 
K & \multicolumn{1}{c}{$\mathrm{A}$} & $\mathrm{B}$ & \multicolumn{1}{c}{$\mathrm{C}$} & \multicolumn{1}{l}{$\mathrm{l}$} \\
& & & & \\
0 & $1.7290517 \mathrm{E}+01$ & $3.0881377 \mathrm{E}-09$ & $1.1391110 \mathrm{E}+01$ & $1.0000000 \mathrm{E}+00$ \\
1 & $-4.6407066 \mathrm{E}+01$ & $7.9195257 \mathrm{E}-05$ & $-3.0307759 \mathrm{E}+01$ & $-1.7724961 \mathrm{E}+00$ \\
2 & $4.4900241 \mathrm{E}+01$ & $2.3857831 \mathrm{E}-03$ & $2.9072598 \mathrm{E}+01$ & $1.0009684 \mathrm{E}+00$ \\
3 & $-1.8951143 \mathrm{E}+01$ & $7.0968717 \mathrm{E}-03$ & $-1.2167834 \mathrm{E}+01$ & $-2.0951230 \mathrm{E}-01$ \\
4 & $3.4049336 \mathrm{E}+00$ & $4.1038595 \mathrm{E}-03$ & $2.1670489 \mathrm{E}+00$ & $1.5181708 \mathrm{E}-02$ \\
5 & $-2.2721208 \mathrm{E}-01$ & $5.3455286 \mathrm{E}-04$ & $-1.4343474 \mathrm{E}-01$ & $-2.7602625 \mathrm{E}-04$ \\
6 & $3.9556250 \mathrm{E}-03$ & $1.4951670 \mathrm{E}-05$ & $2.4930699 \mathrm{E}-03$ & $7.5045155 \mathrm{E}-07$ \\
7 & $-1.0271977 \mathrm{E}-05$ & $7.7954670 \mathrm{E}-08$ & $-6.5228738 \mathrm{E}-06$ & \\
SUM & $1.4215291 \mathrm{E}-02$ & $1.4215295 \mathrm{E}-02$ & $1.4215293 \mathrm{E}-02$ & $3.3866482 \mathrm{E}-02$
\end{tabular}

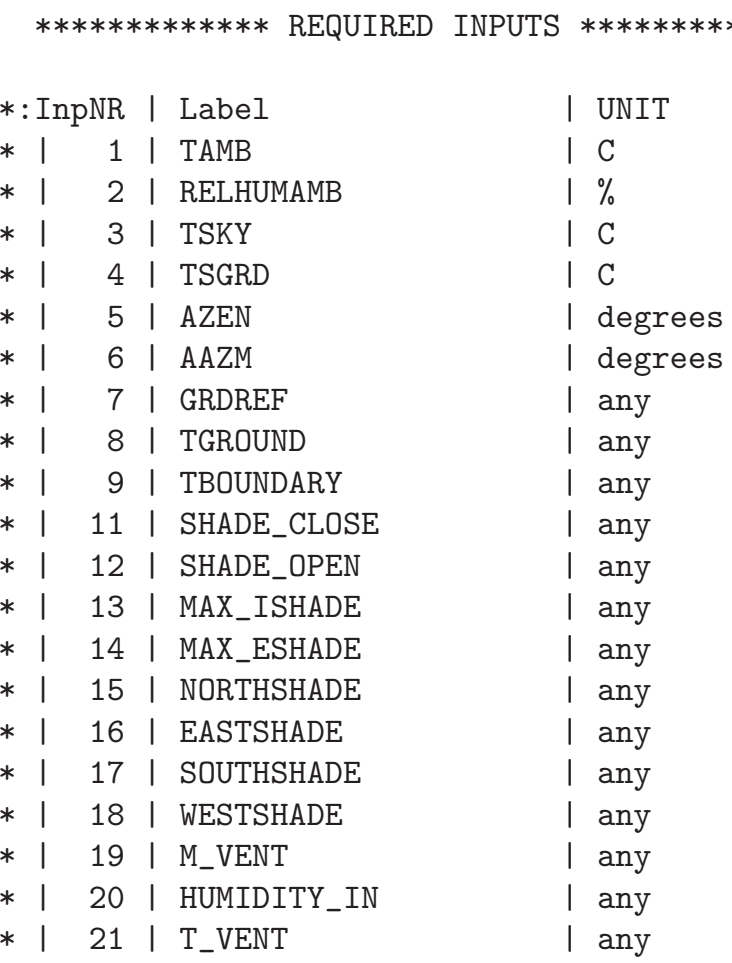

\begin{tabular}{|c|c|c|}
\hline WALL ADJ_WALL & $\mathrm{U}=$ & $0.508 \mathrm{~W} / \mathrm{m} 2 \mathrm{~K}$ \\
\hline WALL EXT_WALL_SD3 & $\mathrm{U}=$ & $0.076 \mathrm{~W} / \mathrm{m} 2 \mathrm{~K}$ \\
\hline WALL SD_DOOR & $\mathrm{U}=$ & $2.553 \mathrm{~W} / \mathrm{m} 2 \mathrm{~K}$ \\
\hline WALL FLOOR_SD2 & $\mathrm{U}=$ & $0.112 \mathrm{~W} / \mathrm{m} 2 \mathrm{~K}$ \\
\hline WALL EXT_ROOF_SD3 & $\mathrm{U}=$ & $0.114 \mathrm{~W} / \mathrm{m} 2 \mathrm{~K}$ \\
\hline
\end{tabular}


THERMAL CONDUCTANCE, $\mathrm{U}=2.00000 \mathrm{~kJ} / \mathrm{h} \mathrm{m} 2 \mathrm{~K}$; U-Wert=

$0.50761 \mathrm{~W} / \mathrm{m} 2 \mathrm{~K}$ (incl. alpha_i=7.7 W/m^2 K and alpha_o=25 W/m^2 K)

TRANSFERFUNCTION COEFFICIENTS

$\mathrm{K}$

$\begin{array}{cr}0 & 1.1400928 \mathrm{E}+01 \\ 1 & -9.4010466 \mathrm{E}+00 \\ 2 & 8.7343096 \mathrm{E}-05 \\ \text { SUM } & 1.9999685 \mathrm{E}+00\end{array}$

B

$1.4923921 \mathrm{E}+00$
$5.0754069 \mathrm{E}-01$
$3.5768544 \mathrm{E}-05$
$1.9999685 \mathrm{E}+00$

$\mathrm{C}$

$1.1400928 \mathrm{E}+01$
$-9.4010466 \mathrm{E}+00$
$8.7343096 \mathrm{E}-05$
$1.9999685 \mathrm{E}+00$

D

$1.0000000 \mathrm{E}+00$

$-1.5729358 \mathrm{E}-05$

$9.9998427 \mathrm{E}-01$

WALL TYPE EXT_WALL_SD3

THERMAL CONDUCTANCE, $\mathrm{U}=0.27692 \mathrm{~kJ} / \mathrm{h} \mathrm{m} 2 \mathrm{~K}$; U-Wert= (incl. alpha_i $=7.7 \mathrm{~W} / \mathrm{m}^{\wedge} 2 \mathrm{~K}$ and alpha_o $=25 \mathrm{~W} / \mathrm{m}^{\wedge} 2 \mathrm{~K}$ )

$0.07593 \mathrm{~W} / \mathrm{m} 2 \mathrm{~K}$

TRANSFERFUNCTION COEFFICIENTS

K

$0 \quad 1.3647179 \mathrm{E}+01$

$1-3.9785190 \mathrm{E}+01$

$2 \quad 4.2701798 \mathrm{E}+01$

$3-2.0443303 E+01$

$4 \quad 4.1689377 \mathrm{E}+00$

$5 \quad-2.9093560 \mathrm{E}-01$

$6 \quad 6.8129978 \mathrm{E}-03$

$7 \quad-5.2241014 \mathrm{E}-05$

$8 \quad 1.1746916 \mathrm{E}-07$

SUM $\quad 5.2471929 E-03$

B
4. $6339022 \mathrm{E}-10$
1. 5832620E-05
$6.1313533 \mathrm{E}-04$
2.3711202E-03
$1.8697530 \mathrm{E}-03$
3. $6028973 \mathrm{E}-04$
$1.6887585 \mathrm{E}-05$
1.7359000E-07
3. 2801908E-10
5. 2471929E-03

$\mathrm{C}$

$3.7058989 \mathrm{E}+00$
$-9.8807644 \mathrm{E}+00$
$9.7862971 \mathrm{E}+00$
$-4.4978471 \mathrm{E}+00$
$9.8010162 \mathrm{E}-01$
$-9.1404812 \mathrm{E}-02$
$2.9927767 \mathrm{E}-03$
$-2.6926414 \mathrm{E}-05$
$5.1930389 \mathrm{E}-08$
$5.2471929 \mathrm{E}-03$

D
$1.0000000 \mathrm{E}+00$
$-2.1210955 \mathrm{E}+00$
1. $5387938 \mathrm{E}+00$
$-4.4523827 \mathrm{E}-01$
$4.8173278 \mathrm{E}-02$
$-1.7015816 \mathrm{E}-03$
1.6714193E-05
$-4.1227100 \mathrm{E}-08$
$1.8948471 \mathrm{E}-02$

WALL TYPE SD_DOOR

THERMAL CONDUCTANCE, $\mathrm{U}=16.24060 \mathrm{~kJ} / \mathrm{h} \mathrm{m} 2 \mathrm{~K}$; U-Wert= $2.55319 \mathrm{~W} / \mathrm{m} 2 \mathrm{~K}$ (incl. alpha_i=7.7 W/m^2 $\mathrm{K}$ and alpha_o=25 W/m^2 $\mathrm{K}$ )

$\begin{array}{cr}\text { K } & \text { A } \\ & \\ 0 & 2.4338747 \mathrm{E}+01 \\ 1 & -8.0984525 \mathrm{E}+00 \\ 2 & 5.6624998 \mathrm{E}-05 \\ \text { SUM } & 1.6240351 \mathrm{E}+01\end{array}$

TRANSFERFUNCTION COEFFICIENTS

$\begin{array}{crr}\text { B } & \text { C } & \text { D } \\ & & \\ .3422323 \mathrm{E}+01 & 2.4338747 \mathrm{E}+01 & 1.0000000 \mathrm{E}+00 \\ .8180030 \mathrm{E}+00 & -8.0984525 \mathrm{E}+00 & -1.5412716 \mathrm{E}-05 \\ .4751862 \mathrm{E}-05 & 5.6624998 \mathrm{E}-05 & \\ .6240351 \mathrm{E}+01 & 1.6240351 \mathrm{E}+01 & 9.9998459 \mathrm{E}-01\end{array}$


TRANSFERFUNCTION COEFFICIENTS

$\begin{array}{cr}\mathrm{K} & \mathrm{A} \\ 0 & 1.3882147 \mathrm{E}+01 \\ 1 & -4.3267557 \mathrm{E}+01 \\ 2 & 5.2134397 \mathrm{E}+01 \\ 3 & -3.0690876 \mathrm{E}+01 \\ 4 & 9.1979823 \mathrm{E}+00 \\ 5 & -1.3263187 \mathrm{E}+00 \\ 6 & 7.8883662 \mathrm{E}-02 \\ 7 & -1.4087492 \mathrm{E}-03 \\ 8 & 5.8012959 \mathrm{E}-06 \\ \text { SUM } & 7.2551165 \mathrm{E}-03\end{array}$

$B$

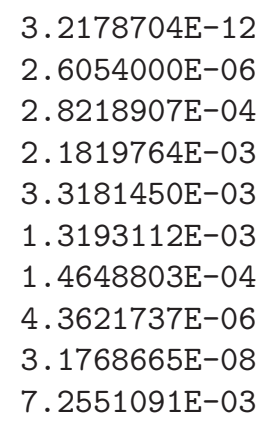

3. 1300403E+01 $-9.0726079 \mathrm{E}+01$

$9.8182541 \mathrm{E}+01$

$-4.9605108 \mathrm{E}+01$

1. $2231382 \mathrm{E}+01$

$-1.4491397 \mathrm{E}+00$

$7.4478167 \mathrm{E}-02$

$-1.2261016 \mathrm{E}-03$

4.2775095E-06

7. 2551136E-03
3. 2178704E-12
D

$1.0000000 \mathrm{E}+00$

$-2.2270449 \mathrm{E}+00$

$1.7985877 \mathrm{E}+00$

$-6.5386970 \mathrm{E}-01$

$1.0670442 \mathrm{E}-01$

$-6.8637061 \mathrm{E}-03$

1. $2844637 \mathrm{E}-04$

$-5.4986040 \mathrm{E}-07$

$1.7641711 \mathrm{E}-02$

WALL TYPE EXT_ROOF_SD3

THERMAL CONDUCTANCE, $\mathrm{U}=0.41975 \mathrm{~kJ} / \mathrm{h} \mathrm{m} 2 \mathrm{~K}$; U-Wert= (incl. alpha_i=7.7 W/m^2 $\mathrm{K}$ and alpha_o $=25 \mathrm{~W} / \mathrm{m}^{\wedge} 2 \mathrm{~K}$ )

$0.11433 \mathrm{~W} / \mathrm{m} 2 \mathrm{~K}$

TRANSFERFUNCTION COEFFICIENTS

\begin{tabular}{crcrr} 
K & A & B & \multicolumn{1}{c}{ C } & \multicolumn{1}{l}{ D } \\
& & & & \\
0 & $1.7290517 \mathrm{E}+01$ & $3.0881377 \mathrm{E}-09$ & $1.1391110 \mathrm{E}+01$ & $1.0000000 \mathrm{E}+00$ \\
1 & $-4.6407066 \mathrm{E}+01$ & $7.9195257 \mathrm{E}-05$ & $-3.0307759 \mathrm{E}+01$ & $-1.7724961 \mathrm{E}+00$ \\
2 & $4.4900241 \mathrm{E}+01$ & $2.3857831 \mathrm{E}-03$ & $2.9072598 \mathrm{E}+01$ & $1.0009684 \mathrm{E}+00$ \\
3 & $-1.8951143 \mathrm{E}+01$ & $7.0968717 \mathrm{E}-03$ & $-1.2167834 \mathrm{E}+01$ & $-2.0951230 \mathrm{E}-01$ \\
4 & $3.4049336 \mathrm{E}+00$ & $4.1038595 \mathrm{E}-03$ & $2.1670489 \mathrm{E}+00$ & $1.5181708 \mathrm{E}-02$ \\
5 & $-2.2721208 \mathrm{E}-01$ & $5.3455286 \mathrm{E}-04$ & $-1.4343474 \mathrm{E}-01$ & $-2.7602625 \mathrm{E}-04$ \\
6 & $3.9556250 \mathrm{E}-03$ & $1.4951670 \mathrm{E}-05$ & $2.4930699 \mathrm{E}-03$ & $7.5045155 \mathrm{E}-07$ \\
7 & $-1.0271977 \mathrm{E}-05$ & $7.7954670 \mathrm{E}-08$ & $-6.5228738 \mathrm{E}-06$ & \\
SUM & $1.4215291 \mathrm{E}-02$ & $1.4215295 \mathrm{E}-02$ & $1.4215293 \mathrm{E}-02$ & $3.3866482 \mathrm{E}-02$
\end{tabular}

\begin{tabular}{|c|c|c|}
\hline : InpNR & | Label & | UNIT \\
\hline 1 & I TAMB & I C \\
\hline 2 & I RELHUMAMB & $1 \%$ \\
\hline & I TSKY & I C \\
\hline & I TSGRD & I C \\
\hline 5 & I AZEN & | degrees \\
\hline 6 & I AAZM & | degrees \\
\hline 7 & I GRDREF & I any \\
\hline & I TGROUND & I any \\
\hline 9 & I TBOUNDARY & I any \\
\hline 11 & I SHADE_CLOSE & I any \\
\hline 12 & I SHADE_OPEN & I any \\
\hline 13 & I MAX_ISHADE & I any \\
\hline 14 & I MAX_ESHADE & I any \\
\hline 15 & I NORTHSHADE & I any \\
\hline 16 & I EASTSHADE & I any \\
\hline 17 & I SOUTHSHADE & I any \\
\hline 18 & I WESTSHADE & any \\
\hline
\end{tabular}


\begin{tabular}{l|l|l|l}
$*$ & 19 & M_VENT & any \\
$*$ & 20 & HUMIDITY_IN & any \\
$*$ & 21 & T_VENT & any
\end{tabular}

*** THERMAL CONDUCTANCE OF USED WALL TYPES $* * *$

(incl. alpha_i=7.7 W/m^2 $\mathrm{K}$ and alpha_o=25 W/m^2 K)

WALL ADJ_WALL U $\quad 0.508 \mathrm{~W} / \mathrm{m} 2 \mathrm{~K}$

WALL EXT_WALL_SD3 U $=0.076 \mathrm{~W} / \mathrm{m} 2 \mathrm{~K}$

WALL SD_DOOR U= $2.553 \mathrm{~W} / \mathrm{m} 2 \mathrm{~K}$

WALL FLOOR_SD2 U= $0.112 \mathrm{~W} / \mathrm{m} 2 \mathrm{~K}$

WALL EXT_ROOF_SD3 U $=0.114 \mathrm{~W} / \mathrm{m} 2 \mathrm{~K}$

$* * * * *$ WALL TRANSFERFUNCTION CALCULATIONS $* * * * *$

WALL TYPE ADJ_WALL

THERMAL CONDUCTANCE, $\mathrm{U}=2.00000 \mathrm{~kJ} / \mathrm{h} \mathrm{m} 2 \mathrm{~K}$; U-Wert $=0.50761 \mathrm{~W} / \mathrm{m} 2 \mathrm{~K}$

(incl. alpha_i=7.7 W/m^2 $\mathrm{K}$ and alpha_o=25 W/m^2 $\mathrm{K}$ )

$\mathrm{K}$

$\begin{array}{cr}0 & 1.1400928 \mathrm{E}+01 \\ 1 & -9.4010466 \mathrm{E}+00 \\ 2 & 8.7343096 \mathrm{E}-05 \\ \text { SUM } & 1.9999685 \mathrm{E}+00\end{array}$

TRANSFERFUNCTION COEFFICIENTS

$\begin{array}{llll}\text { A } & \text { B } & \text { C }\end{array}$
$1.4923921 \mathrm{E}+00$
$1.1400928 \mathrm{E}+01$
$1.0000000 \mathrm{E}+00$
$5.0754069 \mathrm{E}-01$
$-9.4010466 \mathrm{E}+00$
$-1.5729358 \mathrm{E}-05$
$3.5768544 \mathrm{E}-05$
$8.7343096 \mathrm{E}-05$
1.9999685E+00
$1.9999685 \mathrm{E}+00$
9.9998427E-01

WALL TYPE EXT_WALL_SD3

THERMAL CONDUCTANCE, $\mathrm{U}=0.27692 \mathrm{~kJ} / \mathrm{h} \mathrm{m} 2 \mathrm{~K} ; \mathrm{U}-$ Wert $=0.07593 \mathrm{~W} / \mathrm{m} 2 \mathrm{~K}$ (incl. alpha_i=7.7 W/m^2 $\mathrm{K}$ and alpha_o=25 W/m^2 K)

K

$0 \quad 1.3647179 \mathrm{E}+01$

$1-3.9785190 \mathrm{E}+01$

$24.2701798 \mathrm{E}+01$

$3-2.0443303 E+01$

$4 \quad 4.1689377 \mathrm{E}+00$

$5-2.9093560 \mathrm{E}-01$

$6 \quad 6.8129978 \mathrm{E}-03$

$7 \quad-5.2241014 \mathrm{E}-05$

$8 \quad 1.1746916 \mathrm{E}-07$

SUM $\quad 5.2471929 \mathrm{E}-03$

\section{TRANSFERFUNCTION COEFFICIENTS}

$\begin{array}{lll}B & C & D\end{array}$
4. $6339022 \mathrm{E}-10$
$1.5832620 \mathrm{E}-05$
$6.1313533 \mathrm{E}-04$
$2.3711202 \mathrm{E}-03$
3. $6028973 \mathrm{E}-04$
$1.6887585 \mathrm{E}-05$
$1.7359000 \mathrm{E}-07$
3. $2801908 \mathrm{E}-10$
$5.2471929 \mathrm{E}-03$

$3.7058989 \mathrm{E}+00$

$-9.8807644 \mathrm{E}+00$

$9.7862971 \mathrm{E}+00$

$-4.4978471 \mathrm{E}+00$

$9.8010162 \mathrm{E}-01$

$-9.1404812 \mathrm{E}-02$

$2.9927767 \mathrm{E}-03$

$-2.6926414 \mathrm{E}-05$

$5.1930389 \mathrm{E}-08$
D
$1.0000000 \mathrm{E}+00$
$-2.1210955 \mathrm{E}+00$
1. $5387938 \mathrm{E}+00$
$-4.4523827 \mathrm{E}-01$
4.8173278E-02
$-1.7015816 \mathrm{E}-03$
1. $6714193 \mathrm{E}-05$
$-4.1227100 \mathrm{E}-08$
1. $8948471 \mathrm{E}-02$

WALL TYPE SD_DOOR

THERMAL CONDUCTANCE, U $=16.24060 \mathrm{~kJ} / \mathrm{h} \mathrm{m} 2 \mathrm{~K}$; U-Wert= $2.55319 \mathrm{~W} / \mathrm{m} 2 \mathrm{~K}$ (incl. alpha_i=7.7 W/m^2 $\mathrm{K}$ and alpha_o $=25 \mathrm{~W} / \mathrm{m}^{\wedge} 2 \mathrm{~K}$ ) 


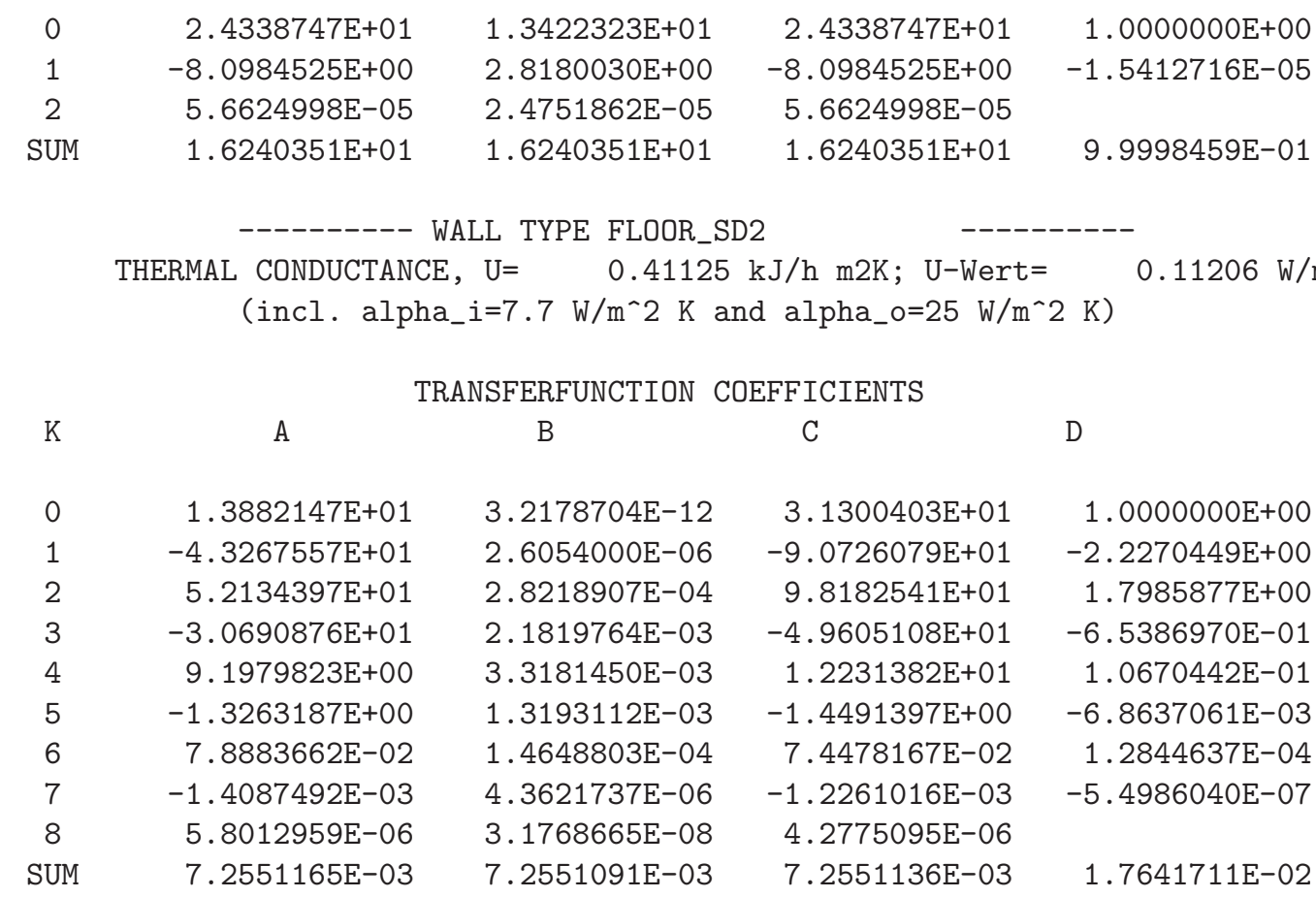

WALL TYPE EXT_ROOF_SD3

THERMAL CONDUCTANCE, $\mathrm{U}=0.41975 \mathrm{~kJ} / \mathrm{h} \mathrm{m} 2 \mathrm{~K}$; U-Wert $=0.11433 \mathrm{~W} / \mathrm{m} 2 \mathrm{~K}$ (incl. alpha_i=7.7 W/m^2 $\mathrm{K}$ and alpha_o=25 W/m^2 $\mathrm{K}$ )

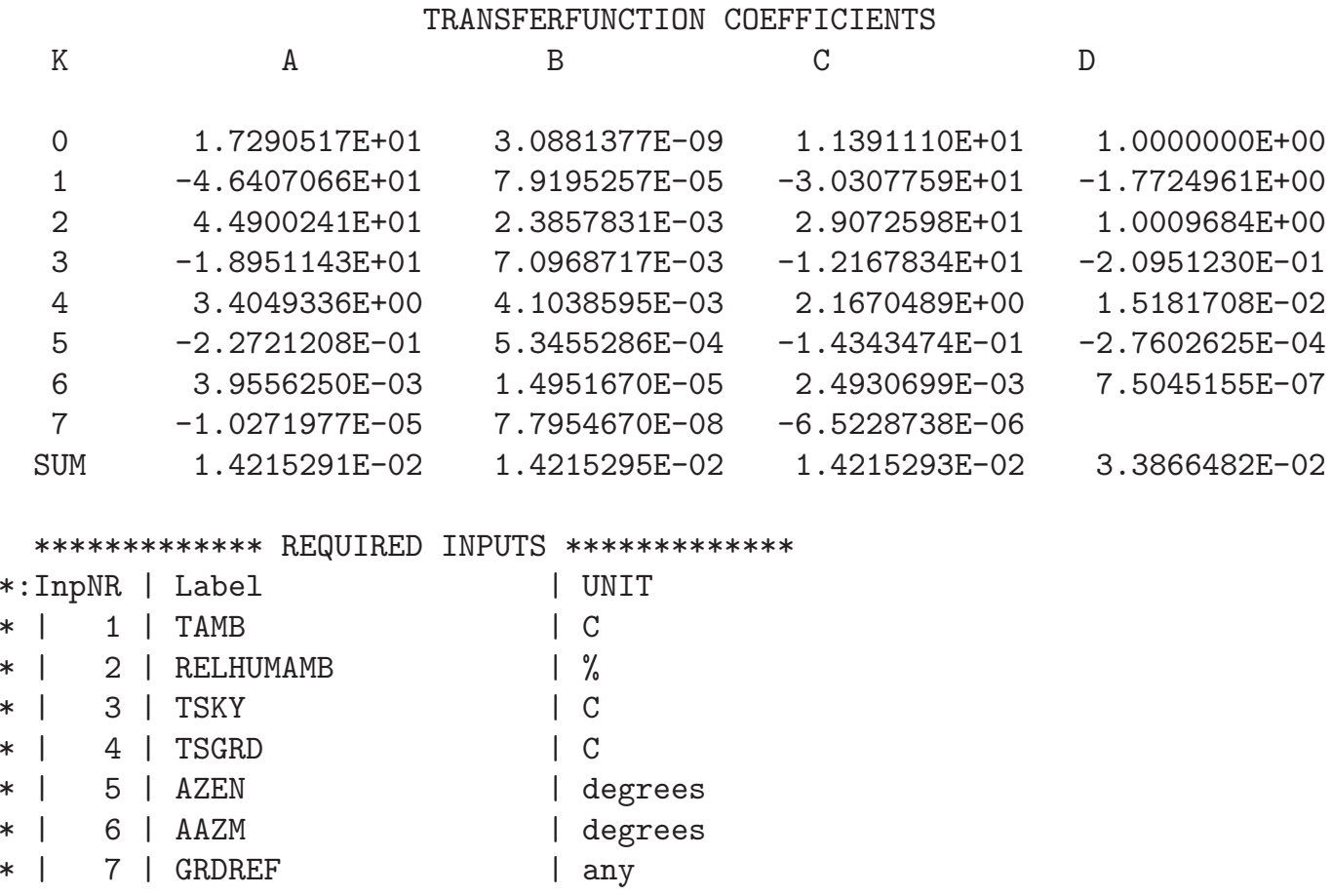




\begin{tabular}{l|r|l|l|l}
$*$ & 8 & TGROUND & any \\
$*$ & 9 & TBOUNDARY & any \\
$*$ & 11 & SHADE_CLOSE & any \\
$*$ & 12 & SHADE_OPEN & any \\
$*$ & 13 & MAX_ISHADE & any \\
$*$ & 14 & MAX_ESHADE & any \\
$*$ & 15 & NORTHSHADE & any \\
$*$ & 16 & EASTSHADE & any \\
$*$ & 17 & SOUTHSHADE & any \\
$*$ & 18 & WESTSHADE & any \\
$*$ & 19 & M_VENT & any \\
$*$ & 20 & HUMIDITY_IN & any \\
$*$ & 21 & T_VENT & any
\end{tabular}

*** THERMAL CONDUCTANCE OF USED WALL TYPES $* * *$ (incl. alpha_i=7.7 W/m^2 K and alpha_o=25 W/m^2 K)

WALL ADJ_WALL

WALL EXT_WALL_SD3

WALL SD_DOOR

WALL FLOOR_SD2

WALL EXT_ROOF_SD3

$\begin{array}{ll}\mathrm{U}= & 0.508 \mathrm{~W} / \mathrm{m} 2 \mathrm{~K} \\ \mathrm{U}= & 0.076 \mathrm{~W} / \mathrm{m} 2 \mathrm{~K} \\ \mathrm{U}= & 2.553 \mathrm{~W} / \mathrm{m} 2 \mathrm{~K} \\ \mathrm{U}= & 0.112 \mathrm{~W} / \mathrm{m} 2 \mathrm{~K} \\ \mathrm{U}= & 0.114 \mathrm{~W} / \mathrm{m} 2 \mathrm{~K}\end{array}$




\section{Appendix E}

\section{Additional Mathemathical References for TRNSYS Types Used}

Chapter 3 describes the mathematical equations used in the key SAHP components in the model such as the solar collectors, the tanks, and the heat pump. This appendix contains the mathematical relationships used in other key components that were used to model the IMS such as the energy recovery ventilator (ERV), the heating coil, the cooling coil, and the DHW mixing valve. These mathematical relations for the ERV and the heating and cooling coils are based from the TRNSYS documentations provided with the software.

\section{E.1 Energy Recovery Ventilator}

The energy recovery ventilator was modelled with Type 667 which uses a "constant effectiveness - minimum capacitance" approach [42]. Equations E.1 and E.2 are used to determine the sensible energy transferred, $\dot{Q}_{\text {sens }}$ in $\mathrm{kJ} / \mathrm{h}$, and moisture transferred, $\dot{m}_{\text {transfer }}$ in $\mathrm{kg} / \mathrm{h}$, between the air streams.

$$
\dot{Q}_{\text {sens }}=\epsilon_{\text {sens }} C_{\text {min }}\left(T_{\text {exhaust,in }}-T_{\text {fresh,in }}\right)
$$


where $\epsilon_{\text {sens }}$ is the sensible effectiveness, $C_{\text {min }}$ is the minimum capacitance $\left(\dot{m} c_{\mathrm{p}}\right)$ of the two air streams, in $\mathrm{kJ} / \mathrm{h} \cdot \mathrm{K}, T_{\text {exhaust,in }}$ is the temperature of the air entering the exhaust air side, in ${ }^{\circ} \mathrm{C}$, and $T_{\text {fresh,in }}$ is the temperature of the air entering the fresh air side, in ${ }^{\circ} \mathrm{C}$.

$$
\dot{m}_{\text {transfer }}=\epsilon_{\text {lat }} \dot{m}_{\text {min }}\left(\omega_{\text {exhaust,in }}-\omega_{\text {fresh,in }}\right)
$$

where $\epsilon_{\text {lat }}$ is the latent effectiveness, $\dot{m}_{\text {min }}$ is the minimum of the two air stream flow rates, in $\mathrm{kg} / \mathrm{h}, \omega_{\text {exhaust,in }}$ is the absolute humidity ratio of air entering the exhaust air side, in $\mathrm{kg}_{\text {water }} / \mathrm{kg}_{\text {air }}$, and $\omega_{\text {fresh,in }}$ is the absolute humidity ratio of air entering the fresh air side, in $\mathrm{kg}_{\text {water }} / \mathrm{kg}_{\text {air }}$.

Equations E.3 and E.4 are used to determine the enthalpies of the exhaust and fresh air outlet streams, $h_{\text {exhaust,out }}$ and $h_{\text {fresh,out }}$, respectively, in $\mathrm{kJ} / \mathrm{kg}$.

$$
\begin{aligned}
& h_{\text {exhaust,out }}=h_{\text {exhaust,in }}-\frac{\dot{Q}_{\text {sens }}}{\dot{m}_{\text {exhaust }}}+\dot{m}_{\text {FreshToExhaust }} \frac{h_{\mathrm{v}, \text { fresh,in }}}{\dot{m}_{\text {exhaust }}} \\
& -\dot{m}_{\text {ExhaustToFresh }} \frac{h_{\mathrm{v}, \text { exhaust,in }}}{\dot{m}_{\text {exhaust }}}
\end{aligned}
$$

where $h_{\text {exhaust,in }}$ is the enthalpy of air entering the exhaust air side, in $\mathrm{kJ} / \mathrm{kg}, \dot{m}_{\text {exhaust }}$ is the mass flow rate of the exhaust air, in $\mathrm{kg} / \mathrm{h}, \dot{m}_{\text {FreshToExhaust }}$ is the mass flow rate of moisture from the fresh air stream to the exhaust air stream, in $\mathrm{kg} / \mathrm{h}, h_{\mathrm{v}}$,fresh,in is the enthalpy of water vapour of the fresh air entering the ERV, in $\mathrm{kJ} / \mathrm{kg}, \dot{m}_{\text {ExhaustToFresh }}$ is the mass flow rate of moisture from the exhaust air stream to the fresh air stream,

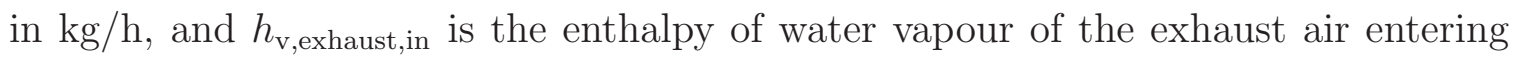
the ERV, in $\mathrm{kJ} / \mathrm{kg}$.

$$
\begin{aligned}
h_{\text {fresh,out }}=h_{\text {fresh,in }}+\frac{\dot{Q}_{\text {sens }}}{\dot{m}_{\text {fresh }}}-\dot{m}_{\text {FreshtoExhaust }} \frac{h_{\mathrm{v}, \text { fresh,in }}}{\dot{m}_{\text {fresh }}} \\
+\dot{m}_{\text {ExhausttoFresh }} \frac{h_{\mathrm{v}, \text { exhaust,in }}}{\dot{m}_{\text {fresh }}}
\end{aligned}
$$


where $h_{\text {fresh,in }}$ is the enthalpy of air entering the exhaust air side of the ERV, in $\mathrm{kJ} / \mathrm{kg}$ and $\dot{m}_{\text {fresh }}$ is the mass flow rate of the fresh air, in $\mathrm{kg} / \mathrm{h}$.

The outlet humidity ratios are determined with Equations E.5 and E.6.

$$
\begin{aligned}
\omega_{\text {exhaust,out }} & =\omega_{\text {exhaust,in }}+\frac{\dot{m}_{\text {FreshToExhaust }}}{\dot{m}_{\text {exhaust }}}-\frac{\dot{m}_{\text {ExhaustToFresh }}}{\dot{m}_{\text {exhaust }}} \\
\omega_{\text {fresh,out }} & =\omega_{\text {fresh,in }}-\frac{\dot{m}_{\text {FreshToExhaust }}}{\dot{m}_{\text {fresh }}}+\frac{\dot{m}_{\text {ExhaustToFresh }}}{\dot{m}_{\text {fresh }}}
\end{aligned}
$$

where $\omega_{\text {exhaust,out }}$ is the humidity ratio of the exiting exhaust air, and $\omega_{\text {fresh,out }}$ is the humidity ratio of the air exiting the fresh air side, in $\mathrm{kg}_{\text {water }} / \mathrm{kg}_{\text {air }}$.

Equations E.7 and E.8 are used to calculate the total energy transferred between the streams, $\dot{Q}_{\text {tot }}$, and the latent energy transferred, $\dot{Q}_{\text {latent }}$ in kJ/h [42].

$$
\begin{gathered}
\dot{Q}_{\text {tot }}=\dot{m}_{\text {exhaust }}\left(h_{\text {exhaust,in }}-h_{\text {exhaust,out }}\right)=\dot{m}_{\text {fresh }}\left(h_{\text {fresh,out }}-h_{\text {fresh,in }}\right) \\
\dot{Q}_{\text {latent }}=\dot{Q}_{\text {tot }}-\dot{Q}_{\text {sens }}
\end{gathered}
$$

\section{E.2 Heating and Cooling Coils}

The heating coil was modelled with Type 753 which uses a bypass model in which the user specifies the fraction of air that bypasses the coils. For this model, a portion of the fluid flow can also bypass the coils in order to maintain a desired set-point temperature of the air. Equation E.9 is used to calculate the energy transfer from the fluid to the air stream, $\dot{Q}_{\text {fluid }}$ in kJ/h [42].

$$
\dot{Q}_{\text {fluid }}=\dot{m}_{\text {air }}\left(1-f_{\text {AirBypass }}\right)\left(h_{\text {air,CoilOut }}-h_{\text {air,in }}\right)
$$


where $\dot{m}_{\text {air }}$ is the mass flow rate of air entering the coils, in $\mathrm{kg} / \mathrm{h}, f_{\text {AirBypass }}$ is the fraction of the air stream that bypasses the coils, $h_{\text {air,CoilOut }}$ is the enthalpy of the air exiting the coils, in $\mathrm{kJ} / \mathrm{kg}$, and $h_{\text {air,in }}$ is the enthalpy of the air entering the coils , in $\mathrm{kJ} / \mathrm{kg}$.

The fluid temperature exiting the coils, $T_{\text {fluid,CoilOut }}$ in ${ }^{\circ} \mathrm{C}$, is then determined with Equation E.10.

$$
T_{\text {fluid,CoilOut }}=T_{\text {fluid,in }}-\frac{\dot{Q}_{\text {fluid }}}{\dot{m}_{\text {fluid }}\left(1-f_{\text {FluidBypass }}\right) c_{\mathrm{p}, \text { fluid }}}
$$

where $T_{\text {fluid,in }}$ is the fluid inlet temperature, in ${ }^{\circ} \mathrm{C}$, and $c_{\mathrm{p}, \text { fluid }}$ is the specific heat of the fluid, in $\mathrm{kJ} / \mathrm{kg} \cdot \mathrm{K}$.

If fluid outlet temperature is less than the air inlet temperature, $T_{\text {air,in }}$ in ${ }^{\circ} \mathrm{C}$, then the air inlet temperature would be set to the fluid outlet temperature and Equation E.11 would be used to calculate the energy transferred from the fluid to the air stream.

$$
\dot{Q}_{\text {fluid }}=\dot{m}_{\text {fluid }}\left(1-f_{\text {FluidBypass }}\right) c_{\mathrm{p}, \text { fluid }}\left(T_{\text {fluid,in }}-T_{\text {air,in }}\right)
$$

Then the enthalpy of air exiting the coils can be determined with Equation E.12.

$$
h_{\text {air }, \text { CoilOut }}=h_{\text {air,in }}+\frac{\dot{Q}_{\text {fluid }}}{\dot{m}_{\text {air }}\left(1-f_{\text {AirBypass }}\right)}
$$

The overall exiting air enthalpy, $h_{\text {air,out }}$ in $\mathrm{kJ} / \mathrm{h}$, is determined with Equation E.12 which accounts for the fraction of air that bypassed the coils.

$$
h_{\text {air }, \text { out }}=\left(1-f_{\text {AirBypass }}\right) h_{\text {air,CoilOut }}+f_{\text {AirBypass }} h_{\text {air,in }}
$$

The fluid temperature accounting for the portion that bypassed the coil, $T_{\text {fluid,out }}$ 
in ${ }^{\circ} \mathrm{C}$, is determined with Equation E.14.

$$
T_{\text {fluid,out }}=\left(1-f_{\text {FluidBypass }}\right) T_{\text {fluid,CoilOut }}+f_{\text {FluidBypass }} T_{\text {fluid,in }}
$$

Finally, the energy transferred to the air stream is calculated by Equation E.15.

$$
\dot{Q}_{\text {air }}=\dot{m}_{\text {air }}\left(h_{\text {air,out }}-h_{\text {air,in }}\right)
$$

If the user specifies an outlet temperature set-point, then the calculated outlet temperature of the air needs to be compared to the set-point. When the bypass fraction of the fluid is set to zero and the calculated outlet temperature is less than the set-point then the calculated temperature will be the final outlet temperature of the air. If the calculated outlet air temperature is greater than the set-point then a new lower fluid bypass fraction is guessed and if the new calculated outlet air temperature is less than the set-point then a new higher fluid bypass fraction is guessed. This process iterates until the calculated temperature matches the set-point within the set tolerance [42].

The cooling coils, modelled with Type 508, also use an iterative process, however, in cases where saturation occurs, the formation of condensate must be accounted for as well. The mass flow rate of the condensate, $\dot{m}_{\text {cond }}$ in $\mathrm{kg} / \mathrm{h}$, can be found with Equation E.16 [42].

$$
\dot{m}_{\text {cond }}=\dot{m}_{\text {air }}\left(1-f_{\text {AirBypass }}\right)\left(\omega_{\text {air,CoilOut }}-\omega_{\text {air,in }}\right)
$$

where $\omega_{\text {air,in }}$ and $\omega_{\text {air,CoilOut }}$ are the inlet and outlet air humidity ratios, in $\mathrm{kg}_{\text {water }} / \mathrm{kg}_{\text {air }}$. The heat transferred from the fluid to air would then be calculated with Equation 
E.17.

$$
\dot{Q}_{\text {fluid }}=\dot{m}_{\text {air }}\left(1-f_{\text {AirBypass }}\right)\left(h_{\text {air,in }}-h_{\text {air,out }}\right)-\dot{m}_{\text {cond }} h_{\text {cond }}
$$

where $h_{\text {cond }}$ is the enthalpy of the condensate, $\mathrm{kJ} / \mathrm{kg}$.

The humidity ratio of the exiting air, accounting for the bypassed fraction, $\omega_{\text {air,out }}$ in $\mathrm{kg}_{\text {water }} / \mathrm{kg}_{\text {air }}$, is calculated with Equation E.18 [42]

$$
\omega_{\text {air }, \text { out }}=\left(1-f_{\text {AirBypass }}\right) \omega_{\text {air,CoilOut }}+f_{\text {AirBypass }} \omega_{\text {air,in }}
$$

\section{E.3 Mixing Valve}

The mixing valve ensures that DHW is delivered at the occupant specified temperature, $T_{\mathrm{DHW}}$ in ${ }^{\circ} \mathrm{C}$. For the IMS this temperature was set to $45^{\circ} \mathrm{C}$ as required for the Solar Decathlon Competition [13]. The temperatures from the hot tank are usually greater than the desired delivery temperature. As a result, water from the hot tank was mixed with mains water. The portion of the flow from the hot tank and from the mains is determined using the energy and mass balances indicated in Equations E.19 and E.20, respectively.

$$
\begin{gathered}
\dot{m}_{\mathrm{DHW}} c_{\mathrm{p}} T_{\mathrm{DHW}}=\dot{m}_{\text {tank,DHW}} c_{\mathrm{p}} T_{\mathrm{tank}}+\dot{m}_{\mathrm{div}} c_{\mathrm{p}} T_{\text {mains }} \\
\dot{m}_{\mathrm{DHW}}=\dot{m}_{\mathrm{tank}, \mathrm{DHW}}+\dot{m}_{\mathrm{div}}
\end{gathered}
$$

where $\dot{m}_{\text {DHW }}$ is the DHW delivery flow rate, in $\mathrm{kg} / \mathrm{h}, \dot{m}_{\text {tank }}$ is the mass flow rate of water coming from the hot tank, in $\mathrm{kg} / \mathrm{h}, c_{\mathrm{p}}$ is the specific heat of water, in $\mathrm{kJ} / \mathrm{kg} \cdot \mathrm{K}$, $T_{\text {tank }}$ is the temperature of the water coming from the hot tank, in ${ }^{\circ} \mathrm{C}, \dot{m}_{\mathrm{div}}$ is the mass flow rate of mains water to the valve, in $\mathrm{kg} / \mathrm{h}$, and $T_{\text {mains }}$ is the temperature of the mains water. 


\section{Appendix F}

\section{Creating the Heat Pump Performance Map with MATLAB}

The following MATLAB code was used to create a performance map using manufacturer's and/or experimental data. The performance map indicates the heat capacity and power draw at set load and source side flow rates and inlet temperatures. The code was originally developed by Wilkie Choi, member of Team Ontario.

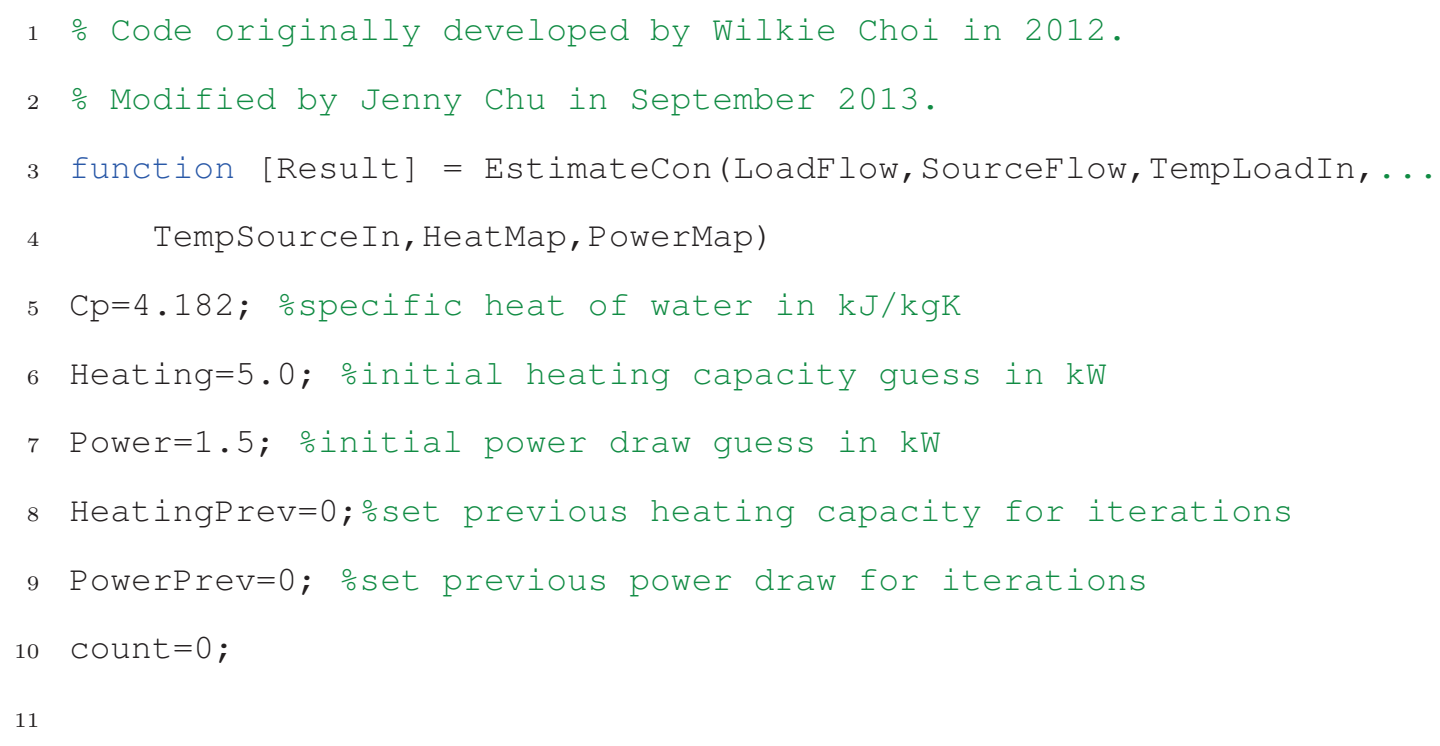


12 oiterate until guessed heating capacity and power draw is less ...

that 0.01 different than the interpolated heating capacity and ... power draw and when counter is less than 50000

13 while((abs (Heating-HeatingPrev) $>0.01|| \ldots$

abs (Power-PowerPrev) $>0.01) \& \&$ count $<50000)$

$14 \quad$ count $=$ count $+1 ; \%$ add 1 to counter

Cooling=Heating-Power; calculate cooling capacity with ... guessed values

24 end

25 Result=[Heating Power TempLoadOut TempSourceOut]; \%output results

26 end 
28

onterpolate plots of heating capacity and power as a function of ... average load and source side temperature. The experimental ... and/or manufacturer's data are used for the plots.

29

37 


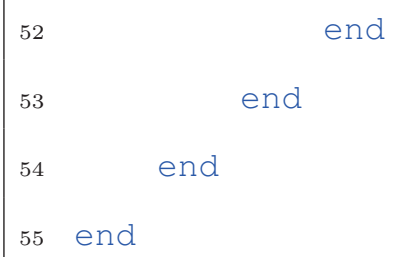

Figures F.1, F.2, F.3, and F.4 show the scatter plots used for interpolation to create the performance maps. These figures show the heat pump heating capacity and power draw (on the $z$ axis) as a function of the average source and load side temperatures (on the $x$ and $y$ axes). As mentioned in Chapter 3, it was assumed that the performance at each operating point can be characterized by the average source and load side temperatures which are related to the condensing and evaporating temperatures of the refrigerant, respectively. Therefore, Figures F.1, F.2, F.3, and F.4 containing manufacturer's data and/or experimental data were used to create the performance map required for Type 927 in the TRNSYS model. Subsection 3.2.6 also summarizes the method that the MATLAB code was written to perform to create the performance map. Figures F.5 and F.6 show the data from the performance map created through the MATLAB code. 


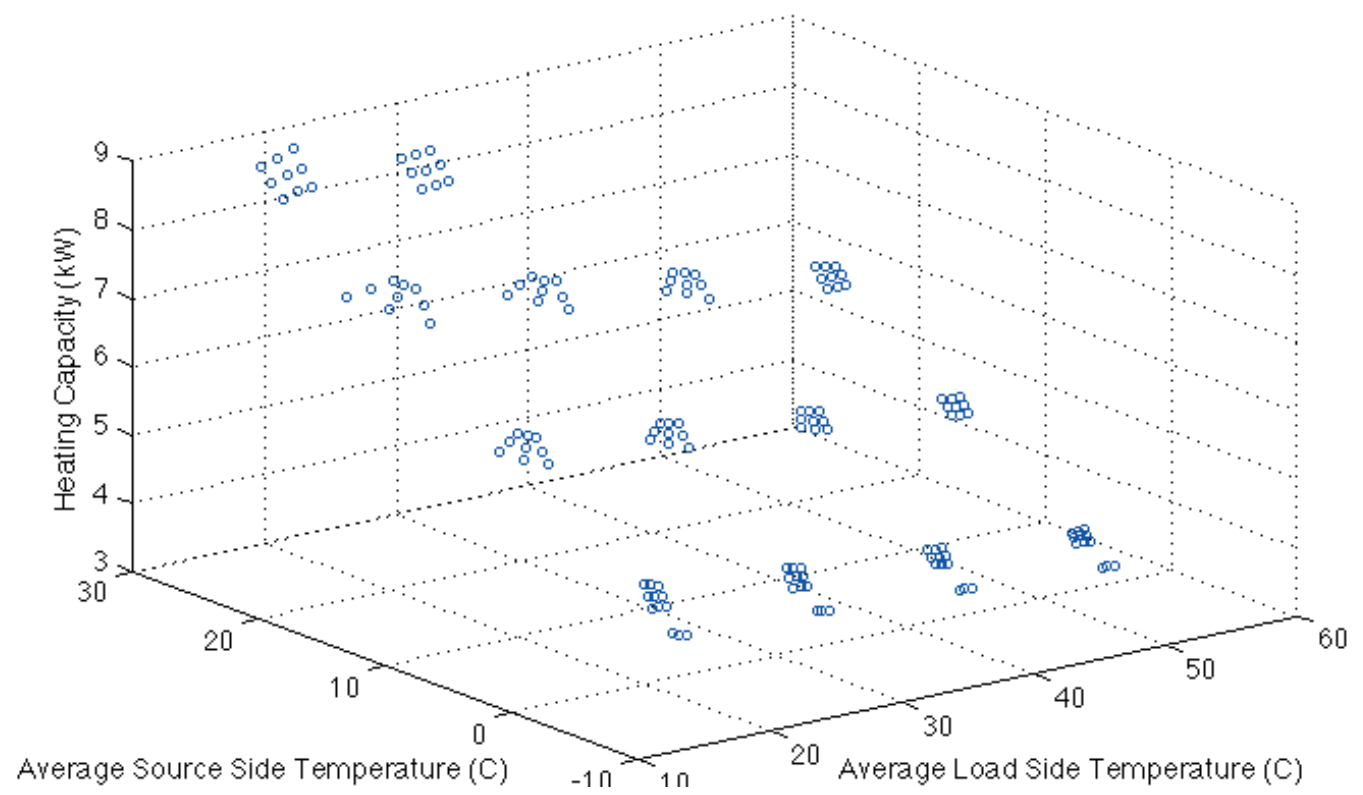

Figure F.1: Heating capacity versus average load and source side temperatures from manufacturer's data

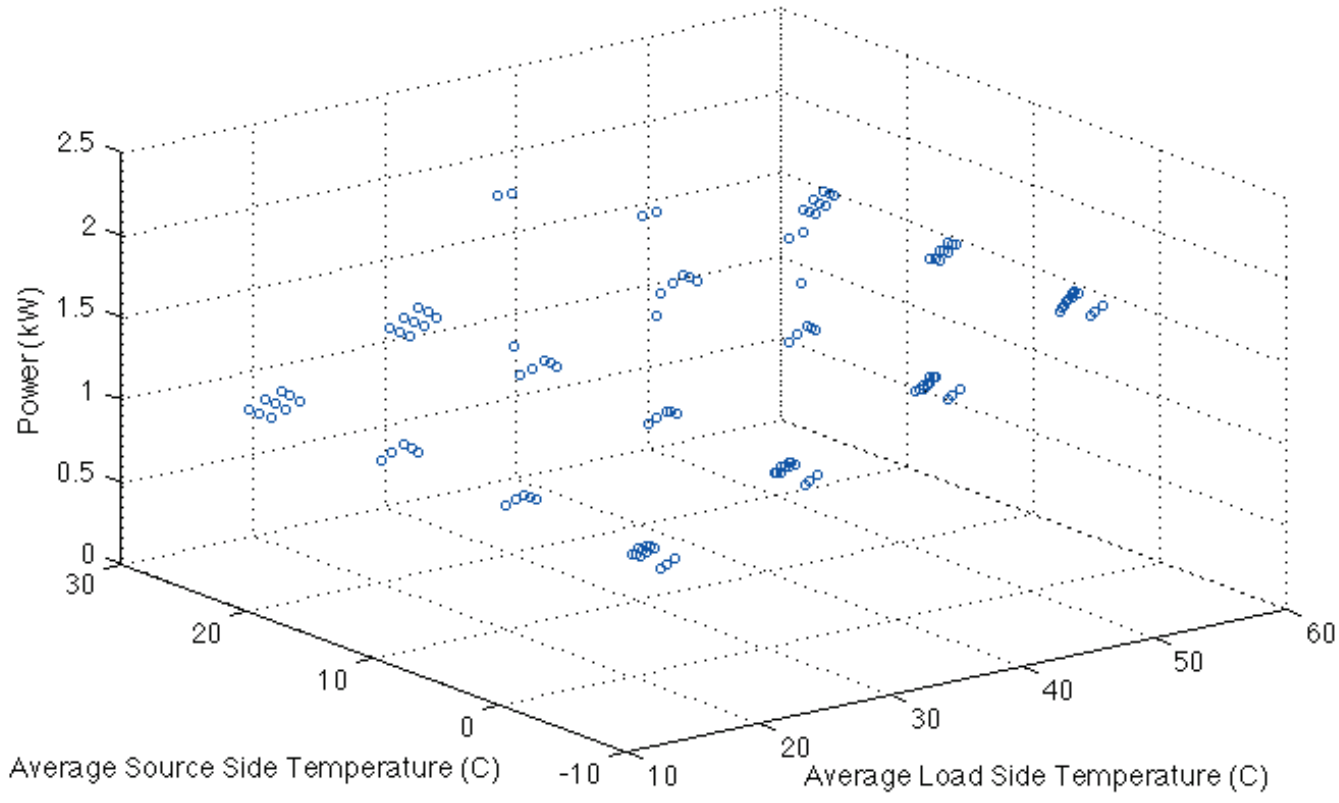

Figure F.2: Power draw versus average load and source side temperatures from manufacturer's data 


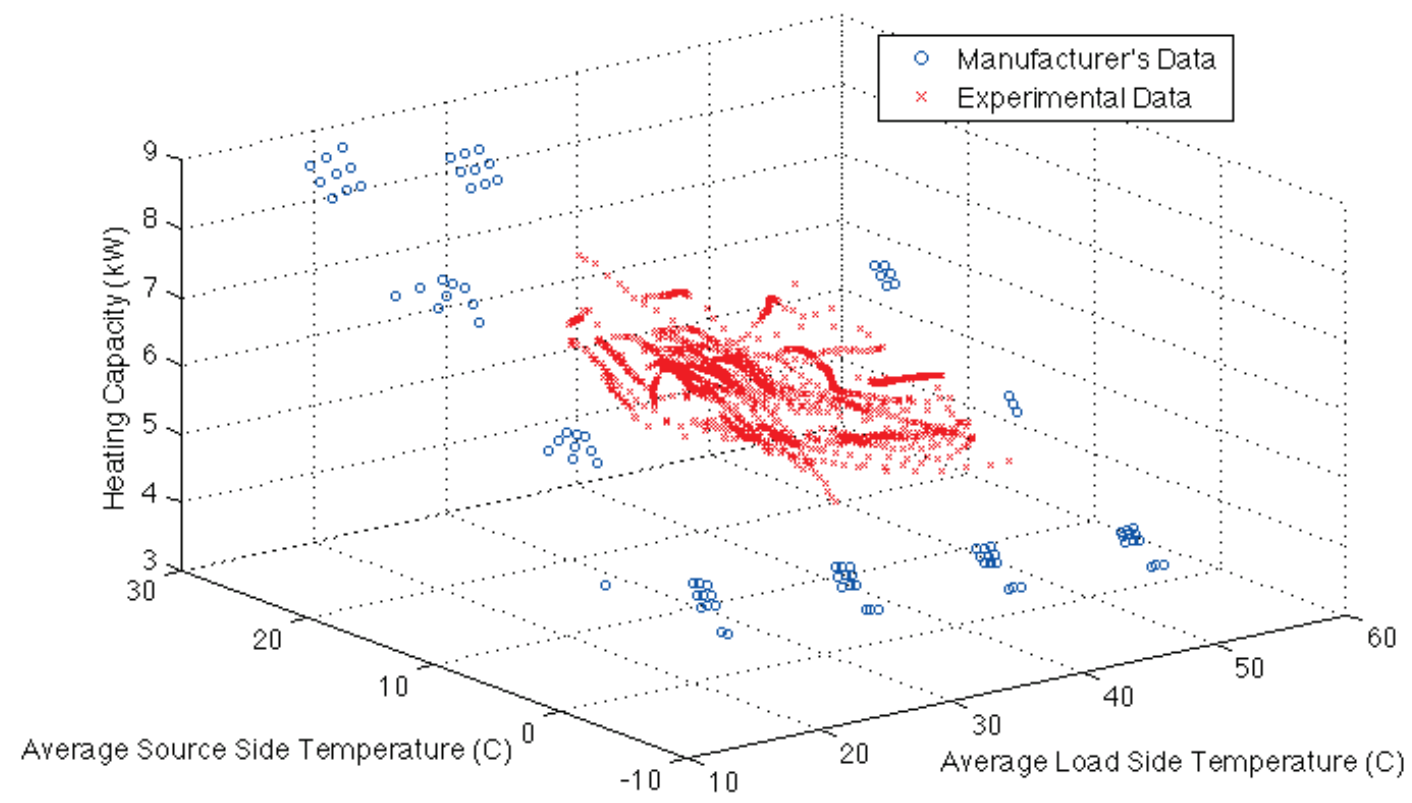

Figure F.3: Heating capacity versus average load and source side temperatures from experimental and manufacturer's data

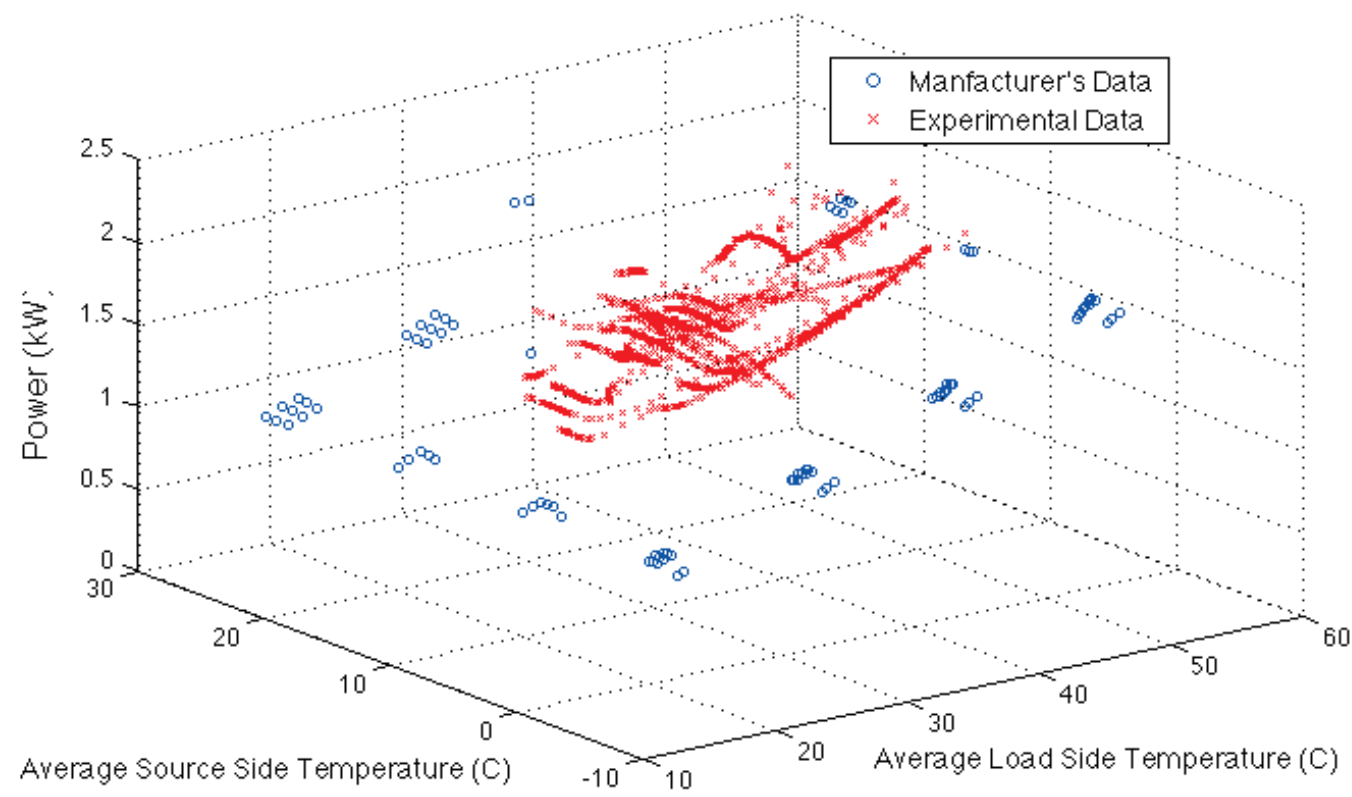

Figure F.4: Power draw versus average load and source side temperatures from experimental and manufacturer's data 


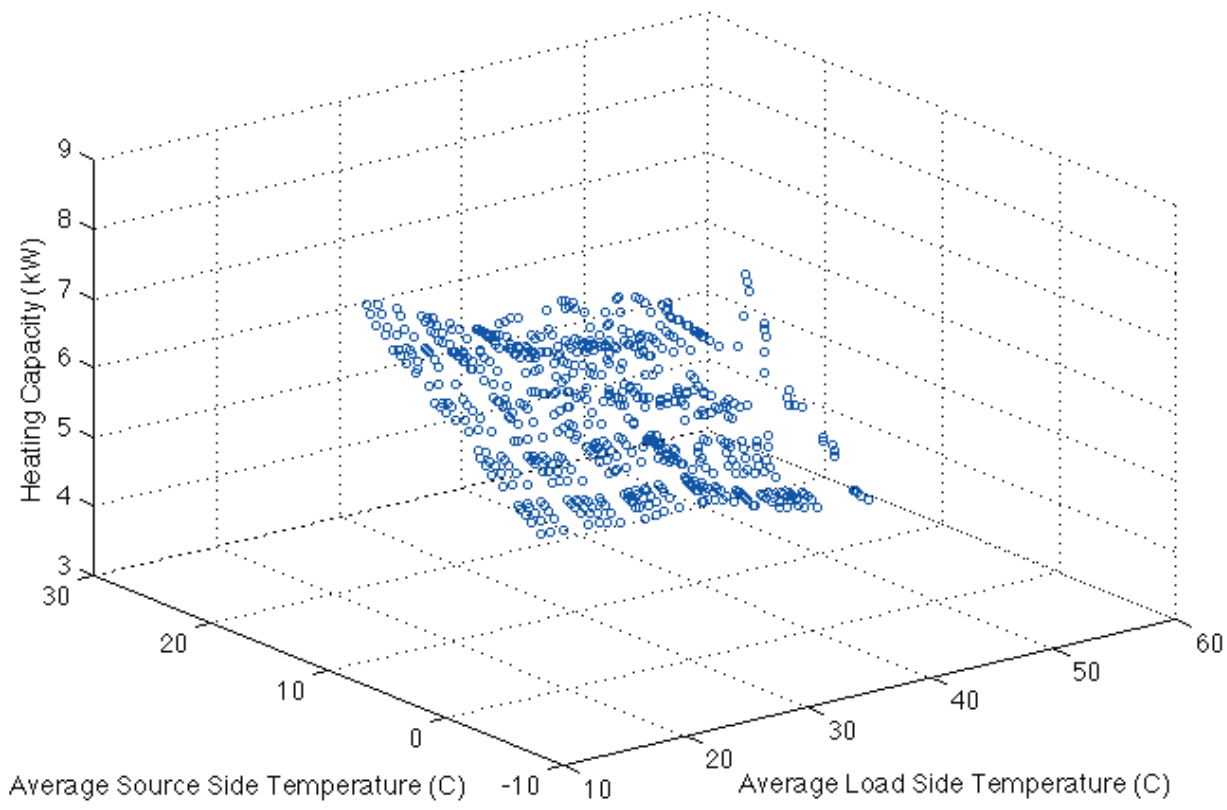

Figure F.5: Heating capacity versus average load and source side temperatures from performance map created from MATLAB

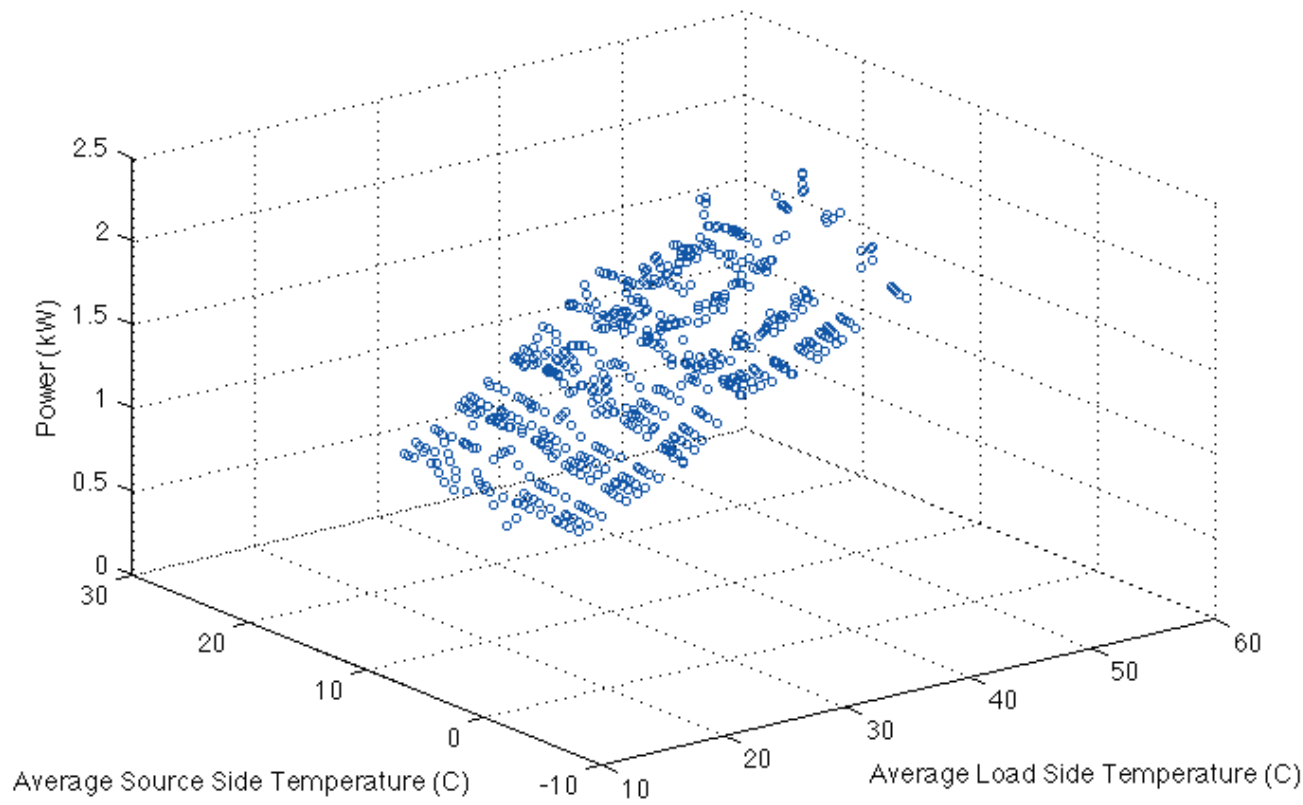

Figure F.6: Power draw versus average load and source side temperatures from performance map created from MATLAB 


\section{Appendix G}

\section{Heat Pump Performance Data for Type}

\section{7}

Table G.1 provides sample of the performance map data required for Type 927. This data was created from the combination of experimental and manufacturer's data.

Table G.1: Heat performance map created from MATLAB with experimental data and manufacturer's data

\begin{tabular}{|c|c|c|c|c|c|}
\hline $\begin{array}{c}\text { Load Flow } \\
(\mathrm{kg} / \mathbf{h r})\end{array}$ & $\begin{array}{c}\text { Source } \\
\text { Flow } \\
(\mathbf{k g} / \mathbf{h r})\end{array}$ & $\begin{array}{c}\text { Entering } \\
\text { Source } \\
\text { Temp. }\left({ }^{\circ} \mathbf{C}\right)\end{array}$ & $\begin{array}{c}\text { Entering } \\
\text { Load Temp. } \\
\left({ }^{\circ} \mathbf{C}\right)\end{array}$ & $\begin{array}{c}\text { Heating } \\
\text { Capacity } \\
(\mathbf{k W})\end{array}$ & $\begin{array}{c}\text { Power } \\
\text { Draw (kW) }\end{array}$ \\
\hline 175 & 400 & 16 & 6 & 4.980 & 1.163 \\
\hline 175 & 400 & 16 & 10 & 5.365 & 1.231 \\
\hline 175 & 400 & 16 & 14 & 5.593 & 1.217 \\
\hline 175 & 400 & 16 & 18 & 5.908 & 1.258 \\
\hline 175 & 400 & 16 & 21 & 6.361 & 1.363 \\
\hline 175 & 400 & 21 & 6 & 4.985 & 1.467 \\
\hline 175 & 400 & 21 & 10 & 5.278 & 1.387 \\
\hline 175 & 400 & 21 & 14 & 5.529 & 1.410 \\
\hline 175 & 400 & 21 & 18 & 5.938 & 1.577 \\
\hline 175 & 400 & 21 & 21 & 6.228 & 1.533 \\
\hline 175 & 400 & 26 & 6 & 4.734 & 1.504 \\
\hline
\end{tabular}




\begin{tabular}{|c|c|c|c|c|c|}
\hline $\begin{array}{l}\text { Load Flow } \\
\quad(\mathrm{kg} / \mathrm{hr})\end{array}$ & $\begin{array}{c}\text { Source } \\
\text { Flow } \\
(\mathrm{kg} / \mathrm{hr})\end{array}$ & $\begin{array}{c}\text { Entering } \\
\text { Source } \\
\text { Temp. }\left({ }^{\circ} \mathrm{C}\right)\end{array}$ & $\begin{array}{c}\text { Entering } \\
\text { Load Temp. } \\
\left({ }^{\circ} \mathrm{C}\right)\end{array}$ & $\begin{array}{c}\text { Heating } \\
\text { Capacity } \\
(\mathrm{kW})\end{array}$ & $\begin{array}{c}\text { Power } \\
\text { Draw }(\mathrm{kW})\end{array}$ \\
\hline 175 & 400 & 26 & 10 & 4.917 & 1.549 \\
\hline 175 & 400 & 26 & 14 & 5.364 & 1.648 \\
\hline 175 & 400 & 26 & 18 & 5.748 & 1.680 \\
\hline 175 & 400 & 26 & 21 & 5.970 & 1.643 \\
\hline 175 & 400 & 31 & 6 & 4.493 & 1.626 \\
\hline 175 & 400 & 31 & 10 & 4.707 & 1.681 \\
\hline 175 & 400 & 31 & 14 & 5.324 & 1.970 \\
\hline 175 & 400 & 31 & 18 & 5.910 & 1.838 \\
\hline 175 & 400 & 31 & 21 & 6.019 & 1.839 \\
\hline 175 & 400 & 37 & 6 & 4.329 & 1.761 \\
\hline 175 & 400 & 37 & 10 & 4.677 & 1.871 \\
\hline 175 & 400 & 37 & 14 & 5.074 & 2.035 \\
\hline 175 & 400 & 37 & 18 & 5.283 & 2.085 \\
\hline 175 & 400 & 37 & 21 & 5.460 & 1.931 \\
\hline 175 & 540 & 16 & 6 & 5.064 & 1.179 \\
\hline 175 & 540 & 16 & 10 & 5.456 & 1.248 \\
\hline 175 & 540 & 16 & 14 & 5.685 & 1.226 \\
\hline 175 & 540 & 16 & 18 & 6.165 & 1.322 \\
\hline 175 & 540 & 16 & 21 & 6.321 & 1.332 \\
\hline 175 & 540 & 21 & 6 & 5.087 & 1.486 \\
\hline 175 & 540 & 21 & 10 & 5.262 & 1.399 \\
\hline 175 & 540 & 21 & 14 & 5.963 & 1.612 \\
\hline 175 & 540 & 21 & 18 & 5.923 & 1.538 \\
\hline 175 & 540 & 21 & 21 & 6.171 & 1.470 \\
\hline 175 & 540 & 26 & 6 & 4.767 & 1.513 \\
\hline 175 & 540 & 26 & 10 & 4.940 & 1.551 \\
\hline 175 & 540 & 26 & 14 & 5.672 & 1.689 \\
\hline 175 & 540 & 26 & 18 & 5.924 & 1.817 \\
\hline 175 & 540 & 26 & 21 & 5.772 & 1.570 \\
\hline 175 & 540 & 31 & 6 & 4.532 & 1.636 \\
\hline 175 & 540 & 31 & 10 & 4.752 & 1.706 \\
\hline 175 & 540 & 31 & 14 & 5.341 & 1.825 \\
\hline
\end{tabular}




\begin{tabular}{|c|c|c|c|c|c|}
\hline $\begin{array}{l}\text { Load Flow } \\
\qquad(\mathrm{kg} / \mathrm{hr})\end{array}$ & $\begin{array}{c}\text { Source } \\
\text { Flow } \\
(\mathrm{kg} / \mathrm{hr})\end{array}$ & $\begin{array}{c}\text { Entering } \\
\text { Source } \\
\text { Temp. }\left({ }^{\circ} \mathrm{C}\right)\end{array}$ & $\begin{array}{c}\text { Entering } \\
\text { Load Temp. } \\
\left({ }^{\circ} \mathrm{C}\right)\end{array}$ & $\begin{array}{c}\text { Heating } \\
\text { Capacity } \\
(\mathrm{kW})\end{array}$ & $\begin{array}{c}\text { Power } \\
\text { Draw }(\mathrm{kW})\end{array}$ \\
\hline 175 & 540 & 31 & 18 & 5.943 & 1.840 \\
\hline 175 & 540 & 31 & 21 & 6.026 & 1.819 \\
\hline 175 & 540 & 37 & 6 & 4.350 & 1.772 \\
\hline 175 & 540 & 37 & 10 & 4.709 & 1.924 \\
\hline 175 & 540 & 37 & 14 & 5.057 & 1.981 \\
\hline 175 & 540 & 37 & 18 & 5.516 & 2.125 \\
\hline 175 & 540 & 37 & 21 & 5.850 & 1.849 \\
\hline 175 & 660 & 16 & 6 & 5.120 & 1.189 \\
\hline 175 & 660 & 16 & 10 & 5.517 & 1.258 \\
\hline 175 & 660 & 16 & 14 & 5.870 & 1.289 \\
\hline 175 & 660 & 16 & 18 & 6.285 & 1.349 \\
\hline 175 & 660 & 16 & 21 & 6.217 & 1.295 \\
\hline 175 & 660 & 21 & 6 & 5.112 & 1.492 \\
\hline 175 & 660 & 21 & 10 & 5.519 & 1.493 \\
\hline 175 & 660 & 21 & 14 & 5.938 & 1.590 \\
\hline 175 & 660 & 21 & 18 & 6.380 & 1.625 \\
\hline 175 & 660 & 21 & 21 & 6.617 & 1.675 \\
\hline 175 & 660 & 26 & 6 & 4.789 & 1.518 \\
\hline 175 & 660 & 26 & 10 & 5.021 & 1.590 \\
\hline 175 & 660 & 26 & 14 & 5.536 & 1.610 \\
\hline 175 & 660 & 26 & 18 & 5.960 & 1.806 \\
\hline 175 & 660 & 26 & 21 & 5.856 & 1.572 \\
\hline 175 & 660 & 31 & 6 & 4.558 & 1.643 \\
\hline 175 & 660 & 31 & 10 & 4.831 & 1.671 \\
\hline 175 & 660 & 31 & 14 & 5.371 & 1.751 \\
\hline 175 & 660 & 31 & 18 & 5.963 & 1.843 \\
\hline 175 & 660 & 31 & 21 & 6.026 & 1.805 \\
\hline 175 & 660 & 37 & 6 & 4.364 & 1.781 \\
\hline 175 & 660 & 37 & 10 & 4.734 & 1.901 \\
\hline 175 & 660 & 37 & 14 & 5.046 & 1.947 \\
\hline 175 & 660 & 37 & 18 & 5.697 & 2.004 \\
\hline 175 & 660 & 37 & 21 & 6.149 & 1.795 \\
\hline
\end{tabular}




\begin{tabular}{|c|c|c|c|c|c|}
\hline $\begin{array}{l}\text { Load Flow } \\
\quad(\mathrm{kg} / \mathrm{hr})\end{array}$ & $\begin{array}{l}\text { Source } \\
\text { Flow } \\
(\mathrm{kg} / \mathrm{hr})\end{array}$ & $\begin{array}{c}\text { Entering } \\
\text { Source } \\
\text { Temp. }\left({ }^{\circ} \mathrm{C}\right)\end{array}$ & $\begin{array}{c}\text { Entering } \\
\text { Load Temp. } \\
\left({ }^{\circ} \mathbf{C}\right)\end{array}$ & $\begin{array}{c}\text { Heating } \\
\text { Capacity } \\
(\mathrm{kW})\end{array}$ & $\begin{array}{c}\text { Power } \\
\text { Draw }(\mathrm{kW})\end{array}$ \\
\hline 175 & 780 & 16 & 6 & 5.160 & 1.196 \\
\hline 175 & 780 & 16 & 10 & 5.560 & 1.266 \\
\hline 175 & 780 & 16 & 14 & 6.052 & 1.339 \\
\hline 175 & 780 & 16 & 18 & 6.324 & 1.352 \\
\hline 175 & 780 & 16 & 21 & 6.299 & 1.327 \\
\hline 175 & 780 & 21 & 6 & 5.142 & 1.492 \\
\hline 175 & 780 & 21 & 10 & 5.509 & 1.398 \\
\hline 175 & 780 & 21 & 14 & 5.940 & 1.583 \\
\hline 175 & 780 & 21 & 18 & 6.223 & 1.543 \\
\hline 175 & 780 & 21 & 21 & 6.629 & 1.674 \\
\hline 175 & 780 & 26 & 6 & 4.804 & 1.522 \\
\hline 175 & 780 & 26 & 10 & 5.230 & 1.550 \\
\hline 175 & 780 & 26 & 14 & 5.695 & 1.640 \\
\hline 175 & 780 & 26 & 18 & 6.035 & 1.748 \\
\hline 175 & 780 & 26 & 21 & 6.118 & 1.617 \\
\hline 175 & 780 & 31 & 6 & 4.579 & 1.647 \\
\hline 175 & 780 & 31 & 10 & 4.957 & 1.704 \\
\hline 175 & 780 & 31 & 14 & 5.207 & 1.758 \\
\hline 175 & 780 & 31 & 18 & 5.978 & 1.845 \\
\hline 175 & 780 & 31 & 21 & 6.104 & 1.921 \\
\hline 175 & 780 & 37 & 6 & 4.373 & 1.787 \\
\hline 175 & 780 & 37 & 10 & 4.792 & 1.887 \\
\hline 175 & 780 & 37 & 14 & 5.121 & 1.953 \\
\hline 175 & 780 & 37 & 18 & 5.788 & 2.078 \\
\hline 175 & 780 & 37 & 21 & 6.251 & 1.792 \\
\hline 175 & 900 & 16 & 6 & 5.189 & 1.201 \\
\hline 175 & 900 & 16 & 10 & 5.592 & 1.271 \\
\hline
\end{tabular}




\section{Appendix $\mathbf{H}$}

\section{Instrumentation Calibration and Uncertainty Analysis}

The accuracy of the experimental data depends on the uncertainty of the experimental analysis. Errors from each measurement would propagate through all the calculations to yield a final overall uncertainty of the calculated values. The two general types of errors are systematic errors, also known as the bias error, which remains constant for repeated measurements with the same operating conditions, and random errors which appear as a scatter of measured data that were repeatedly taken at fixed operating conditions. These are normally distributed about the sample mean [58]. The flow rate and temperature measurements were calibrated to reduce the systematic errors of the measured data. The random errors were determined through statistical analysis of the calibrated measured data.

From [58], a result, $R$, which is a function of $L$ variables can be expressed as:

$$
R=f_{1}\left(x_{1}, x_{2}, \ldots, x_{\mathrm{L}}\right)
$$

where $x_{1}, x_{2}, \ldots, x_{\mathrm{L}}$ are variables with their own associated uncertainty. The true mean 
value, $R^{\prime}$, is the mean value, $\bar{R}$, plus an uncertainty, $u_{\mathrm{R}}$.

$$
R^{\prime}=\bar{R} \pm u_{\mathrm{R}}
$$

The uncertainty, $u_{\mathrm{R}}$, can be estimated by the root-sum-square (RSS) method.

$$
u_{\mathrm{R}}=\left[\sum_{\mathrm{i}=1}^{L}\left(\theta_{\mathrm{i}} u_{x_{\mathrm{i}}}\right)^{2}\right]^{1 / 2}
$$

where the sensitivity factor, $\theta$, for a specific variable is derived with the Taylor series expansion [58].

$$
\theta_{\mathrm{i}}=\frac{\partial R}{\partial x_{\mathrm{i}}} \quad i=1,2, \ldots, L
$$

\section{H.1 Flow Rate Uncertainty}

The load side flow rate of the heat pump was measured using a Yokogawa AXF Megnetic Flow Meter. The flow rates were captured with a Hewlett-Packard 3497A data acquisition system. The system was connected to a computer and LabVIEW VI program was used to record and display the data. The recorded values were calibrated by comparison with gravimetric flow rate measurements made over a range of flow rates used for the experimental analysis. For the gravimetric flow rate measurements, the water was pumped through the flow meter and was diverted into a container which sat on top of a scale. The scale was calibrated with reference weights obtain from Natural Resources Canada and the resulting uncertainty of the weight measurement was estimated at $\pm 0.000414 \mathrm{~kg}$. Before the tests, the container weight was taken in order to determine the weight of the water added to the container. For each test the final weight of the container plus water and the time required to fill the container were

recorded. The gravimetric volume metric flow rate, $\dot{V}_{\mathrm{GR}}$, in $\mathrm{L} / \mathrm{min}$, was determine 
with the following equation.

$$
\dot{V}_{\mathrm{GR}}=\frac{m_{\text {final }}-m_{\text {containter }}}{t \rho}
$$

where $m_{\text {final }}$ is the final measured mass, in $\mathrm{kg}, m_{\text {containter }}$ is the mass of the container before the test, in $\mathrm{kg}, t$ is time, in minutes and $\rho$ is the density of water, in $\mathrm{kg} / \mathrm{m}^{3}$.

At room temperature, the density of the water was assumed to be $1000 \mathrm{~kg} / \mathrm{m}^{3}$ with an uncertainty of $3 \mathrm{~kg} / \mathrm{m}^{3}$ and the uncertainty of the time was assumed to be \pm 0.15 s. Equation H.3 was used to estimate the error for each gravimetric flow rate measurement. These errors are shown by the error bars in Figure H.1(a).

Figure H.1(a) shows the comparison of the gravimetric flow rates and the recorded flow rates from LabVIEW. The difference between the recorded flow rates and the gravimetric flow rates can be found in Figure H.1(b). To calibrate the recorded flow rates to the gravimetric flow rates, the recorded flow rates were multiplied by a factor of 1.005 then reduced by 0.053 . This helped reduce the systematic errors of the measurement. Figures H.1(c) and H.1(d) shows the comparison of the calibrated values to the gravimetric measurements. After calibration, the remaining random error between the calibrated values and the gravimetric values was determined using a statistical analysis. The standard deviation of the sample of errors, $S_{x}$, and the t-value of the sample at a $95 \%$ confidence interval, $t_{\mathrm{L}-1,95}$, was used to determine the uncertainty of the calibrated flow rates as compared to the gravimetric flow rates.

$$
\begin{gathered}
x_{\mathrm{i}}=\bar{x} \pm t_{\mathrm{L}-1,95} S_{x} \\
S_{x}=\left[\frac{1}{L-1} \sum_{\mathrm{i}=1}^{L}\left(x_{\mathrm{i}}-\bar{x}\right)\right]^{1 / 2}
\end{gathered}
$$

For Equations H.6 and H.7, the $x_{i}$ and $\bar{x}$ represent the error value at each point 


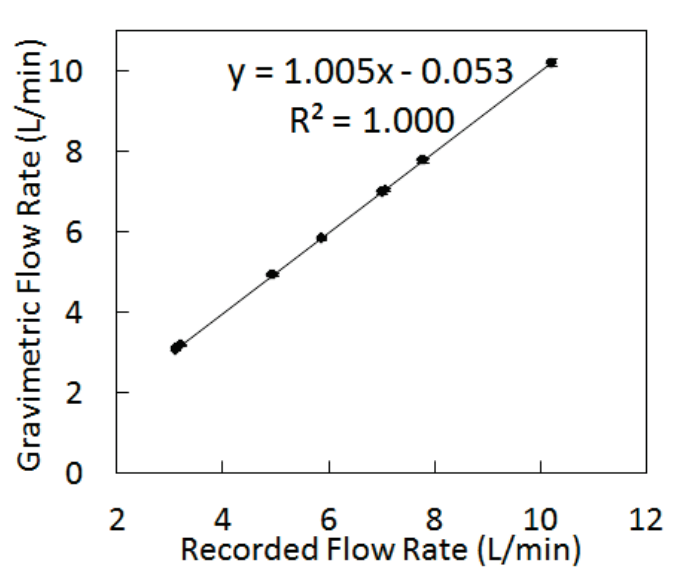

(a) Comparison of uncalibrated flow rates with gravimetric flow rates

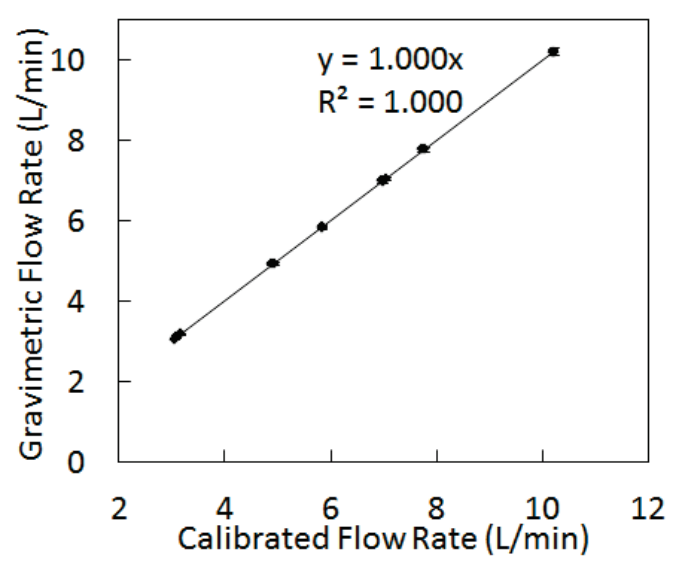

(c) Comparison of calibrated flow rates with gravimetric flow rates

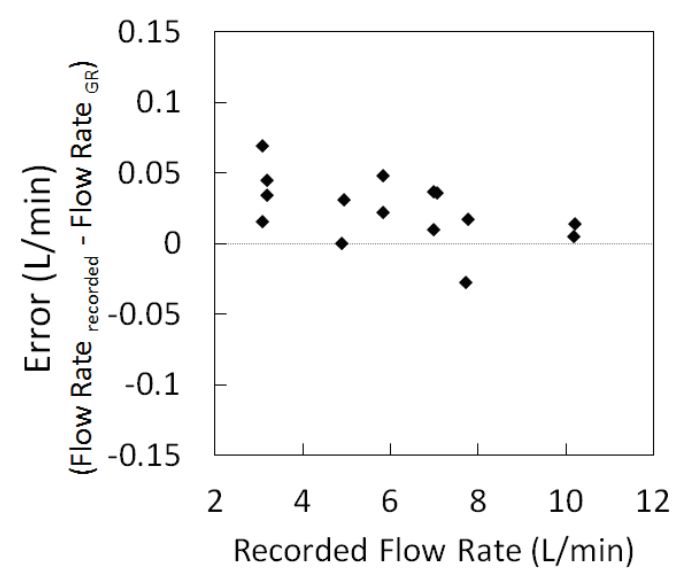

(b) Residual plot of uncalibrated errors

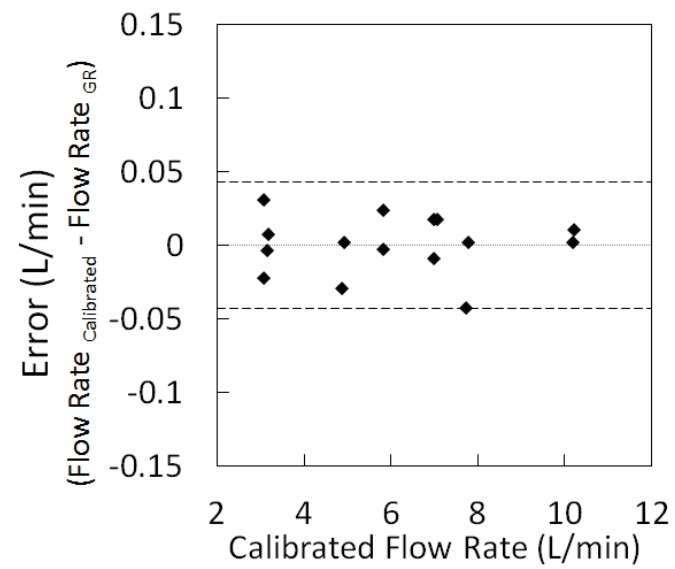

(d) Residual plot of calibrated errors

Figure H.1: Recorded and gravimetric flow rates before and after calibration

and the sample mean of the errors, respectively. For this analysis, the error on the flow rate calibrated to the gravimetric flow rate was determine to be $\pm 0.043 \mathrm{~L} / \mathrm{min}$. To determine the overall uncertainty accounting for the errors of the gravimetric flow rate and the calibrated flow rate, the RSS method was used with the two errors. Approximating the gravimetric flow rate error to be about $\pm 0.014 \mathrm{~L} / \mathrm{min}$ from the error bars shown in Figure H.1(a), the overall error of the flow rate was assumed to be $\pm 0.045 \mathrm{~L} / \mathrm{min}$. 


\section{H.2 Thermocouple Uncertainty}

The temperature measurements were made using Type $\mathrm{T}$ thermocouples and were also captured using a Hewlett-Packard model 3497A data acquisition system. The four thermocouples on the inlets and the outlets of the source and load side of the heat pump were calibrated with an EXTECH temperature bath and a Guildline platinum resistant thermometer (PRT). The PRT was independently calibrated to an accuracy of $\pm 0.012^{\circ} \mathrm{C}$ by the manufacturer [59]. Both the thermocouples and the PRT were placed in the temperature bath, and calibration was conducted for a temperatures ranging from $10^{\circ} \mathrm{C}$ to $60^{\circ} \mathrm{C}$. Figure H.2(a) shows the direct comparison of the recorded temperatures and the PRT temperatures. Figure H.2(b) shows the difference between the two temperatures. A linear regression was applied to obtain a line of best fit for the measured data. To calibrate the recorded data to the PRT data, the recorded data was multiplied by 0.9535 and then increased by $1.7395^{\circ} \mathrm{C}$. Figure H.2(c) shows the comparison after calibration. Similar to the flow rate calibration, the error of the calibrated data was determined with a statistical analysis of the errors between the calibrated data and the PRT data. Equations H.6 and H.7 were used again to determine the $95 \%$ confidence interval of the data. It was determined that the uncertainty of the recorded temperature calibrated to the PRT temperature was be approximately $\pm 0.10^{\circ} \mathrm{C}$.

The thermocouples inside the tank were fixed to a temperature probe. Therefore, these sensors were not calibrated with a temperature bath. Dickinson [57] used the same temperature probe for his experimental set-up to investigate draw strategies for a multi-tank thermal storage system for solar heating applications. Dickinson conducted a repeatability test where the temperature probe measured the temperatures 


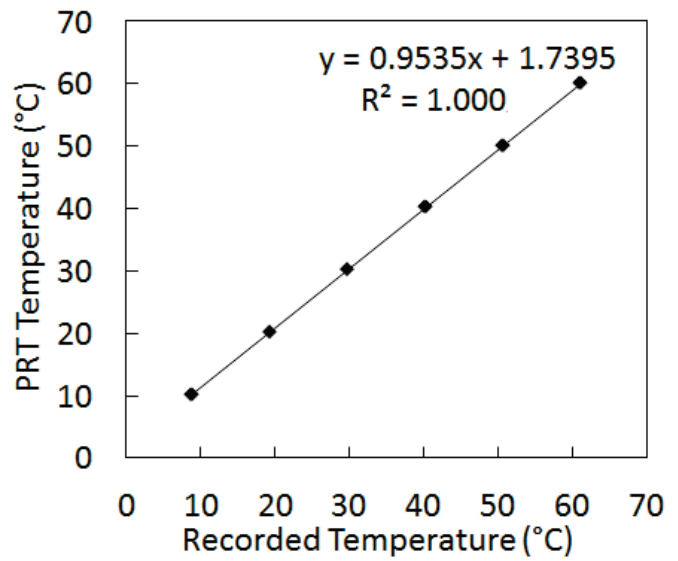

(a) Comparison of recorded temperatures with PRT temperatures

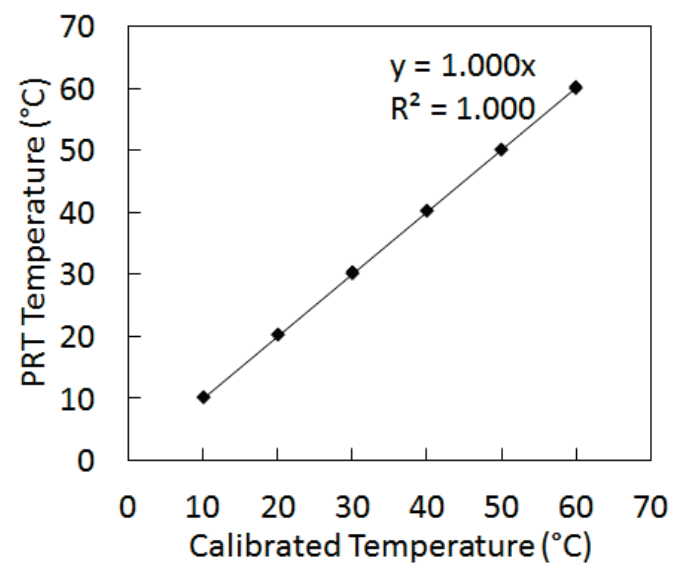

(c) Comparison of calibrated temperatures with PRT temperatures

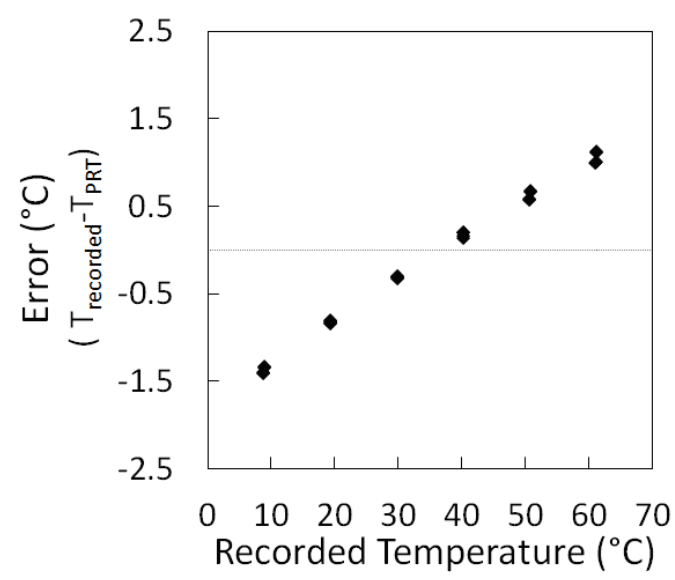

(b) Residual plot of uncalibrated errors

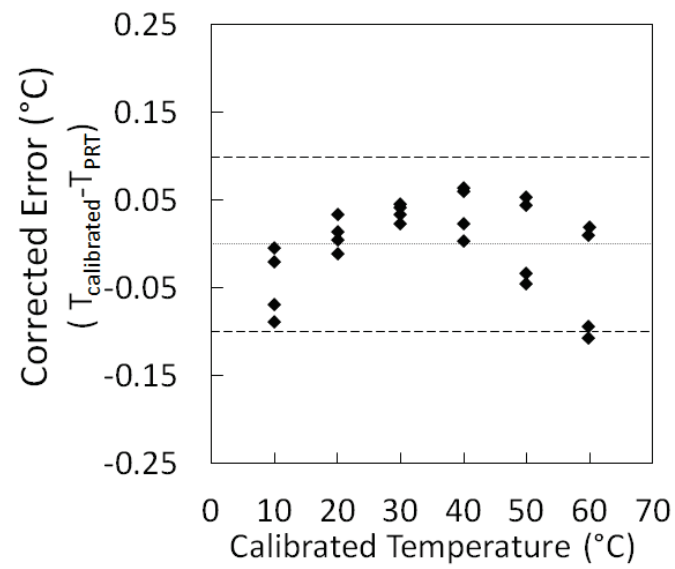

(d) Residual plot of calibrated errors

Figure H.2: Recorded temperatures and platinum resistant thermometer temperatures before and after calibration

within a fully mixed tank for an hour. A standard deviation of $\pm 0.13^{\circ} \mathrm{C}$ was determined from the 510 data points gathered. Like the study conducted by Dickinson, the error on the temperature readings of the probe was approximated as $\pm 1.0^{\circ} \mathrm{C}$ as indicated in the ASME PTC 19.3-1974 Standard for Type T thermocouples [60]. 


\section{H.3 Error Propagation of Heat Pump Energy Transfer Rate}

For the calculated values, an analysis was conducted to determine the overall uncertainty from propagated measurement errors. The experimental heat transfer rate of

the heat pump, $\dot{Q}_{\text {load }}$ in kW, was calculated with Equation 4.1. Equation H.3 was used with Equation 4.1 to yield the following equations for the overall uncertainty of the heat pump heat transfer rate, $u_{\dot{Q}_{\text {load }}}$ in $\mathrm{kW}$.

$$
\begin{aligned}
u_{\dot{Q}_{\text {load }}}= \pm & {\left[\left(\frac{\partial \dot{Q}_{\text {load }}}{\partial \dot{V}_{\text {load }}} u_{\dot{V}_{\text {load }}}\right)^{2}+\left(\frac{\partial \dot{Q}_{\text {load }}}{\partial \rho_{\text {water }}} u_{\rho_{\text {water }}}\right)^{2}+\left(\frac{\partial \dot{Q}_{\text {load }}}{\partial c_{\mathrm{p}, \text { water }}} u_{c_{\mathrm{p}, \text { water }}}\right)^{2}\right.} \\
& \left.+\left(\frac{\partial \dot{Q}_{\text {load }}}{\partial T_{\text {load }, \text { in }}} u_{\mathrm{T}}\right)^{2}+\left(\frac{\partial \dot{Q}_{\text {load }}}{\partial T_{\text {load } \text { out }}} u_{\mathrm{T}}\right)^{2}\right]^{1 / 2} \\
u_{\dot{Q}_{\text {load }}}= & \pm\left[\left(\rho_{\text {water }} c_{\mathrm{p}, \text { water }} \Delta T u_{\dot{V}_{\text {load }}}\right)^{2}+\left(\dot{V}_{\text {load }} c_{\mathrm{p}, \text { water }} \Delta T u_{\rho_{\text {water }}}\right)^{2}\right. \\
& \left.+\left(\dot{V}_{\text {load }} \rho_{\text {water }} \Delta T u_{c_{\mathrm{p}, \text { water }}}\right)^{2}+2\left(\dot{V}_{\text {load }} \rho_{\text {water }} c_{\mathrm{p}, \text { water }} u_{\mathrm{T}}\right)^{2}\right]^{1 / 2}
\end{aligned}
$$

where

$$
\Delta T=T_{\text {load }, \text { in }}-T_{\text {load,out }}
$$

Dividing Equation H.9 by the heat transfer rate, $\dot{Q}_{\text {load }}$, the ratio of the uncertainty to the calculated heat transfer rate, $\frac{u_{\dot{Q}_{\text {load }}}}{\dot{Q}_{\text {load }}}$, can be found with Equation H.11.

$$
\frac{u_{\dot{Q}_{\text {load }}}}{\dot{Q}_{\text {load }}}= \pm\left[\left(\frac{u_{\dot{V}_{\text {load }}}}{\dot{V}_{\text {load }}}\right)^{2}+\left(\frac{u_{\rho_{\text {water }}}}{\rho_{\text {water }}}\right)^{2}+\left(\frac{u_{c_{\mathrm{p}, \text { water }}}}{c_{\text {p,water }}}\right)^{2}+2\left(\frac{u_{\mathrm{T}}}{\Delta T}\right)^{2}\right]^{1 / 2}
$$

The uncertainty values for the load side volume flow rate and temperatures were 
determined after the calibration process of the flow meter and thermocouples, respectively. The density and heat capacity of water was approximated with the average load side temperature which ranged from about $25^{\circ} \mathrm{C}$ to $40^{\circ} \mathrm{C}$. As a result, the density and heat capacity at $32.5^{\circ} \mathrm{C}$ was used in the calculations and a conservative range of $\pm 10^{\circ} \mathrm{C}$ was used to determine the corresponding uncertainty values. The uncertainty of the density was set to $\pm 0.32 \%$ and the uncertainty of the heat capacity was set to $\pm 0.15 \%$. For each test, the load side flow rate, density and specific heat capacity were assumed to be constant. Based on Equation H.11, the uncertainty would vary over time as the temperature differences vary. The uncertainty for each data point of each test was then determined using Equation H.11. Figure H.3 shows the energy transfer rate for the $3 \mathrm{~L} / \mathrm{min}$ case with dotted lines indicating the error range. The maximum heat transfer rate uncertainties for each test are summarized in Table H.1.

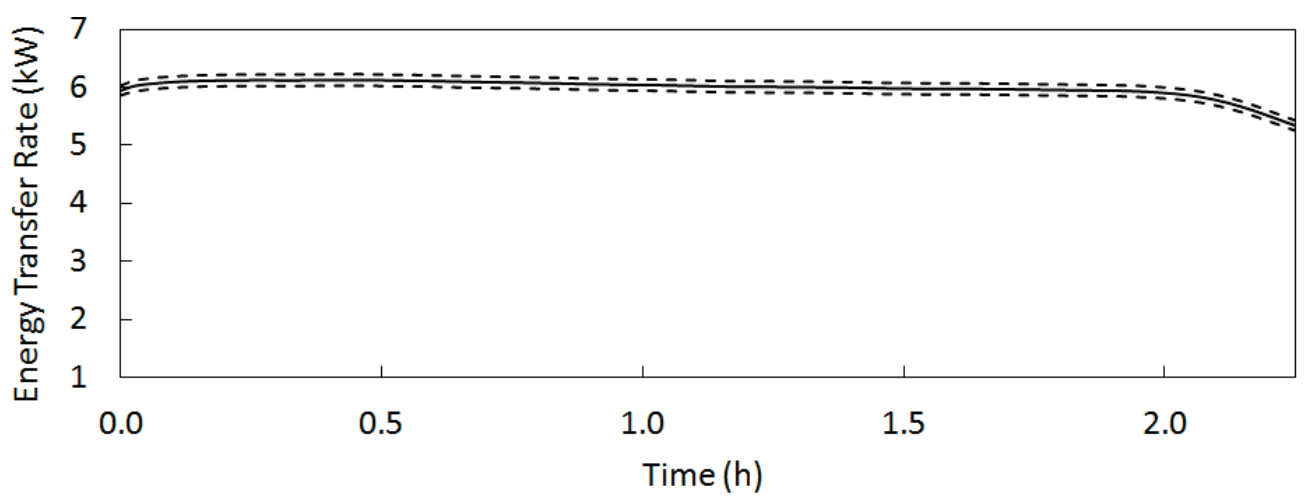

Figure H.3: Energy transfer rate for the $3 \mathrm{~L} / \mathrm{min}$ test 
Table H.1: Propagated errors of the heat transfer rates and coefficient of performances

\begin{tabular}{|c|c|c|c|}
\hline Test Case & Max. $\frac{u_{\dot{Q}_{\text {load }}}}{\dot{Q}_{\text {load }}}(\%)$ & Max. $\frac{u_{\dot{P}_{\text {comp }}}}{\dot{P}_{\text {comp }}}(\%)$ & Max. $\frac{u_{C O P}}{C O P}(\%)$ \\
\hline $2 \mathrm{~L} / \mathrm{min}$ & \pm 2.18 & \pm 0.424 & \pm 2.20 \\
$3 \mathrm{~L} / \mathrm{min}$ & \pm 1.56 & \pm 0.449 & \pm 1.71 \\
$4 \mathrm{~L} / \mathrm{min}$ & \pm 1.45 & \pm 0.472 & \pm 1.49 \\
$6 \mathrm{~L} / \mathrm{min}$ & \pm 1.55 & \pm 0.519 & \pm 1.59 \\
$8 \mathrm{~L} / \mathrm{min}$ & \pm 1.77 & \pm 0.556 & \pm 1.80 \\
$10 \mathrm{~L} / \min$ & \pm 2.13 & \pm 0.557 & \pm 2.15 \\
\hline
\end{tabular}

\section{H.4 Error Propagation of Coefficient of Performance}

The $C O P$ was determined using Equation 2.1 and the overall propagated error of the $C O P$ was determined using Equation H.3. The error of the power consumption of the heat pump had to be determined. A Yokogawa Digital AC Power Meter, Type 2503, was used to record the sum of the power draw from the heat pump and the two circulations pumps. Based on the pump curve shown in Figure 4.5 on page 71 , the power draw of the circulation pumps, $\dot{P}_{\text {circ }}$ in $\mathrm{kW}$, was estimated and subtracted from the measured power, $\dot{P}_{\text {measured }}$ in $\mathrm{kW}$, to determined the power consumption of the heat pump alone, $\dot{P}_{\text {comp }}$ in $\mathrm{kW}$. A conservative uncertainty of $\pm 5 \mathrm{~W}$ was applied to the estimated power draws of the circulation pumps due to the reading error of Figure 4.5 and the approximation of the source side flow rate with Equation 4.3. The uncertainty of the power meter was indicated as $\pm(0.2 \%$ of reading $+0.07 \%$ of range $)[54]$ while the range, Range $_{\dot{P}_{\text {measured }}}$, was set to 1800 W. Applying Equation H.3 gives the following 
relationship for the uncertainty of the heat pump power consumption, $u_{\dot{P}_{\text {comp }}}$ in $\mathrm{kW}$.

$$
u_{\dot{P}_{\text {comp }}}=\left[\left(0.002 \dot{P}_{\text {measured }}+0.0007 \text { Range }_{\dot{P}_{\text {measured }}}\right)^{2}+2\left(u_{\dot{P}_{\text {circ }}}\right)^{2}\right]^{1 / 2}
$$

Equation 2.1 was used to determine the instantaneous $C O P$ of the heat pump. The uncertainty of the $C O P, u_{\mathrm{COP}}$, is a function of the heat transfer rate, $\dot{Q}_{\text {load }}$ in $\mathrm{kW}$, the power consumption of the heat pump, $\dot{P}_{\text {comp }}$ in $\mathrm{kW}$, and the uncertainties associated with these variables.

$$
u_{\mathrm{COP}}=\left[\left(\frac{u_{\dot{Q}_{\text {load }}}}{\dot{P}_{\text {comp }}}\right)^{2}+\left(\frac{\dot{Q}_{\text {load }} u_{\dot{P}_{\text {comp }}}}{\dot{P}_{\text {comp }}^{2}}\right)^{2}\right]^{1 / 2}
$$

The uncertainty of the $C O P$ changes for each reading and Figure H.4 depicts the uncertainty range over the $3 \mathrm{~L} / \mathrm{min}$ test. Also summarized in Table H.1 are the uncertainties of the heat pump compressor power draws and the COP for each test.

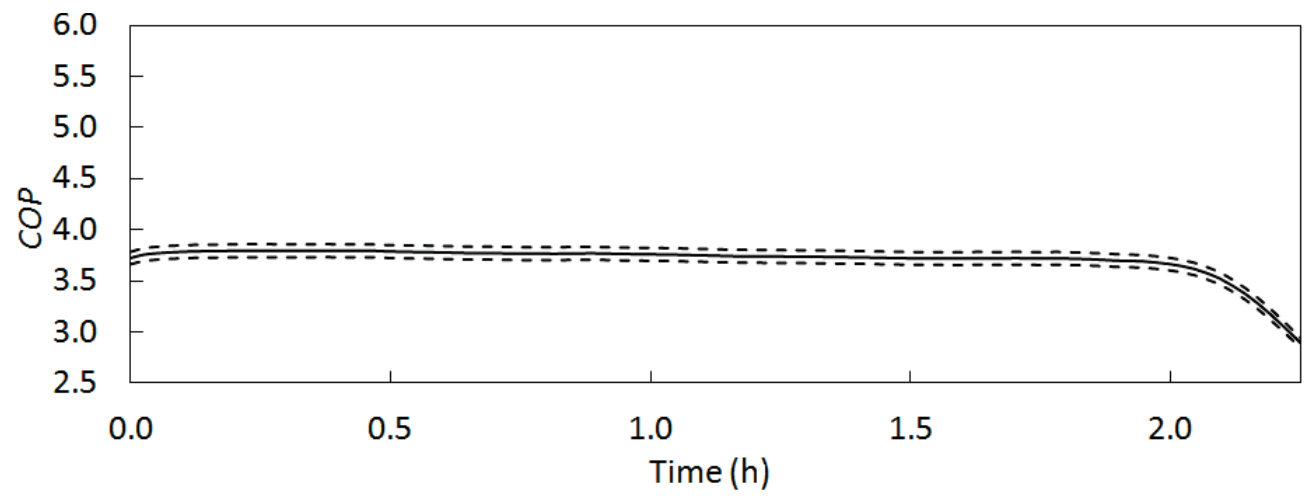

Figure H.4: Coefficient of performance for the $3 \mathrm{~L} /$ min test 


\section{H.5 Error Propagation of Accumulated Energy Transferred and Average Coefficient of Performance}

Equation 4.4 on page 72 was used to calculate the total energy transferred to the load from the heat pump. Equation H.14 was used to solve for the uncertainty of the accumulated energy transferred, $u_{Q_{\text {load }}}$ in $\mathrm{kJ}$, assuming the uncertainty on the time was negligible since it was recorded with high accuracy in LabVIEW.

$$
u_{Q_{\text {load }}}=\left[\sum_{i=1}^{n}\left(u_{\dot{Q}_{\text {load }, \mathrm{i}}}\right)^{2}\right]^{1 / 2}
$$

where $n$ is the number of data points measured and $u_{\dot{Q}_{\text {load,i }}}$ is the uncertainty of energy transfer rate at each point, in $\mathrm{kW}$, as found through Equation H.9. Figure H.5 shows uncertainty for the accumulated energy transferred calculated for the $3 \mathrm{~L} / \mathrm{min}$ test.

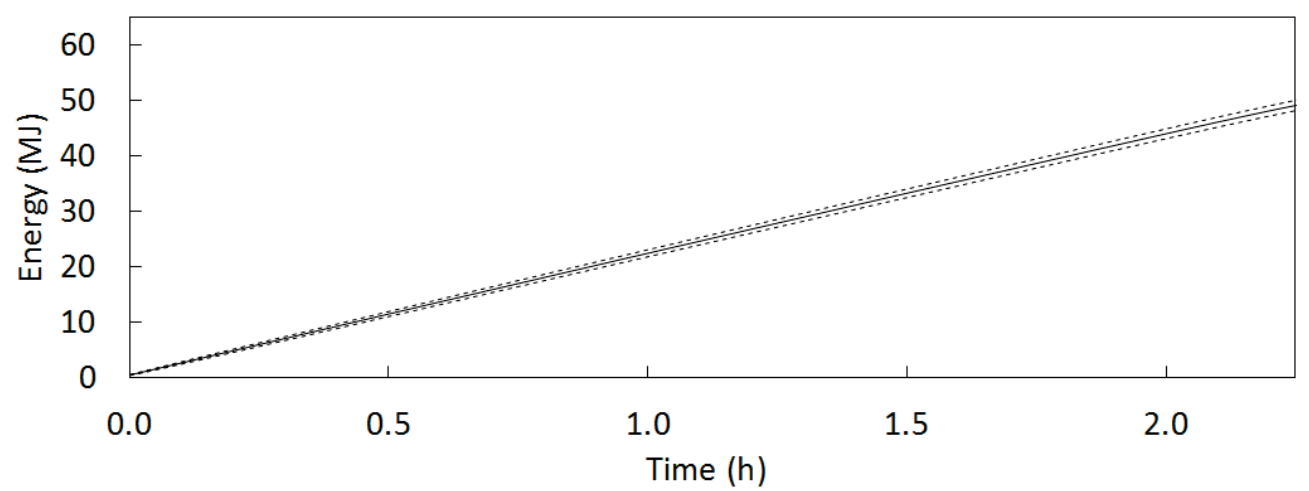

Figure H.5: Accumulated energy transferred by the heat pump for the $3 \mathrm{~L} / \mathrm{min}$ test

Similarly, the uncertainty of the accumulated heat pump energy consumption, $u_{P_{\text {comp }}}$ in $\mathrm{kJ}$, was found with Equation H.15 where $u_{\dot{P}_{\text {comp }, \mathrm{i}}}$, in $\mathrm{kW}$, was calculated with Equation H.12 at each measurement point. 


$$
u_{P_{\mathrm{comp}}}=\left[\sum_{\mathrm{i}=1}^{n}\left(u_{\dot{P}_{\mathrm{comp}, \mathrm{i}}}\right)^{2}\right]^{1 / 2}
$$

The uncertainty of the average $C O P, u_{C O P_{\text {average }}}$, was found using Equation H.16.

$$
u_{C O P_{\text {average }}}=\left[\left(\frac{u_{Q_{\text {load }}}}{P_{\text {comp }}}\right)^{2}+\left(\frac{Q_{\text {load }} u_{P_{\text {comp }}}}{P_{\text {comp }}^{2}}\right)^{2}\right]^{1 / 2}
$$

The uncertainty range of the average $C O P$ for the $3 \mathrm{~L} /$ min test is shown Figure H.6. As the accumulated energy transferred and consumed by the heat pump increased, the uncertainty of the average $C O P$ decreased.

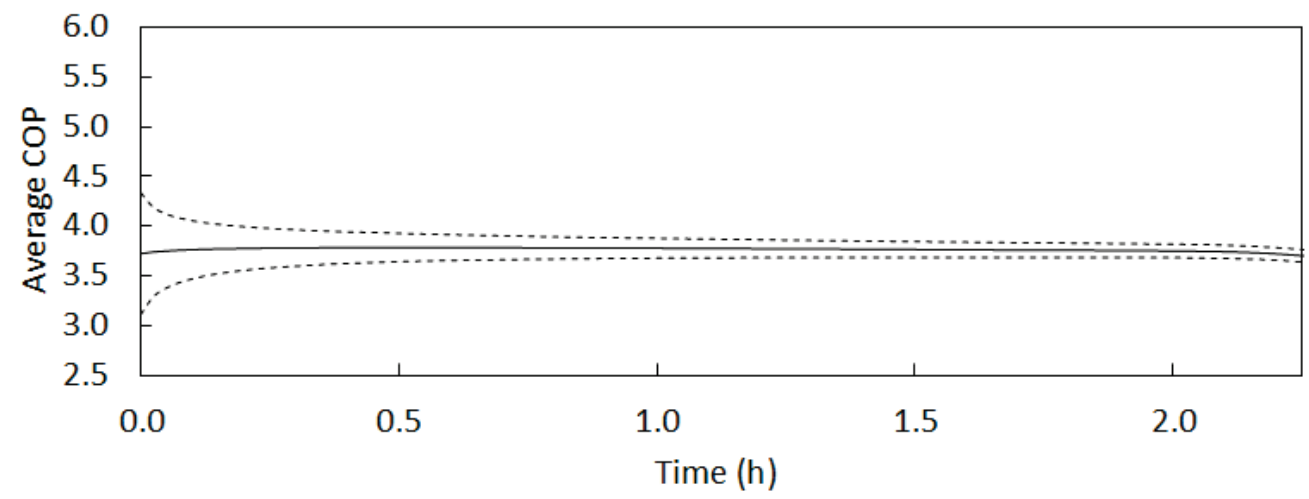

Figure H.6: Average coefficient of performance for the $3 \mathrm{~L} / \mathrm{min}$ test

Table H.2 summarizes the uncertainties of the final accumulated values for each test.

Table H.2: Propagated errors of the accumulated energy transferred and average coefficient of performances

\begin{tabular}{|c|c|c|c|}
\hline Test Case & $\frac{u_{Q_{\text {load }}}}{Q_{\text {load }}}(\%)$ & $\frac{u_{P_{\text {comp }}}}{P_{\text {comp }}}(\%)$ & $\frac{u_{C O P_{\text {average }}}}{C O P_{\text {average }}}(\%)$ \\
\hline $2 \mathrm{~L} / \mathrm{min}$ & \pm 2.30 & \pm 0.480 & \pm 2.35 \\
$3 \mathrm{~L} / \mathrm{min}$ & \pm 1.86 & \pm 0.477 & \pm 1.92 \\
$4 \mathrm{~L} / \mathrm{min}$ & \pm 1.74 & \pm 0.576 & \pm 1.84 \\
$6 \mathrm{~L} / \mathrm{min}$ & \pm 1.63 & \pm 0.560 & \pm 1.72 \\
$8 \mathrm{~L} / \mathrm{min}$ & \pm 1.80 & \pm 0.522 & \pm 1.88 \\
$10 \mathrm{~L} / \mathrm{min}$ & \pm 2.16 & \pm 0.513 & \pm 2.22 \\
\hline
\end{tabular}

